\title{
Gastrointestinal function during physical exercise : Basic and applied research
}

Citation for published version (APA):

van Nieuwenhoven, M. A. (1999). Gastrointestinal function during physical exercise : Basic and applied research. [Doctoral Thesis, Maastricht University]. Universitaire Pers Maastricht. https://doi.org/10.26481/dis.19991112mn

Document status and date:

Published: 01/01/1999

DOI:

10.26481/dis.19991112mn

Document Version:

Publisher's PDF, also known as Version of record

\section{Please check the document version of this publication:}

- A submitted manuscript is the version of the article upon submission and before peer-review. There can be important differences between the submitted version and the official published version of record.

People interested in the research are advised to contact the author for the final version of the publication, or visit the DOI to the publisher's website.

- The final author version and the galley proof are versions of the publication after peer review.

- The final published version features the final layout of the paper including the volume, issue and page numbers.

Link to publication

\footnotetext{
General rights rights.

- You may freely distribute the URL identifying the publication in the public portal. please follow below link for the End User Agreement:

www.umlib.nl/taverne-license

Take down policy

If you believe that this document breaches copyright please contact us at:

repository@maastrichtuniversity.nl

providing details and we will investigate your claim.
}

Copyright and moral rights for the publications made accessible in the public portal are retained by the authors and/or other copyright owners and it is a condition of accessing publications that users recognise and abide by the legal requirements associated with these

- Users may download and print one copy of any publication from the public portal for the purpose of private study or research.

- You may not further distribute the material or use it for any profit-making activity or commercial gain

If the publication is distributed under the terms of Article $25 \mathrm{fa}$ of the Dutch Copyright Act, indicated by the "Taverne" license above, 


\section{Gastrointestinal function during physical exercise}

Basic and applied research 


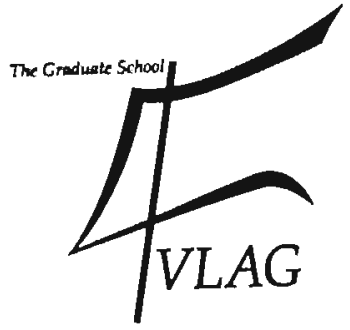

Ruting
The study presented in this thesis was performed at the Nutrition and Toxicology Research Institute Maastricht (NUTRIM) which participates in the Graduate School VLAG (Food Technology. Agrobiotechnology. Nutrition and Health Sciences), accredited by the Royal Netherlands Academy of Arts and Sciences.

- Michiel van Nieuwenhoven, Maastricht 1999

ISBN 90-9013199-x

Cover design: Michiel van Nieuwenhoven

Production: Datawyse | Universitaire Pers Maastricht.

The studies described in this thesis were supported with grants from Novartis Nutrition Ltd, Janssen-Cilag b.v. and NOC-NSF.

Printing of this thesis was financially supported by Novartis Nutrition Ltd, NOCNSF, Janssen-Cilag b.v., AstraZeneca, MMS and Tramedico. 


\title{
Gastrointestinal function during physical exercise
}

\author{
Basic and applied research
}

\author{
PROEFSCHRIFT
}

ter verkrijging van de graad van doctor aan de Universiteit Maastricht, op gezag van de Rector Magnificus, Prof Dr AC Nieuwenhuijzen Kruseman, volgens het besluit van het College van Decanen, in het openbaar te verdedigen op vrijdag 12 november 1999 om 12.00 uur

door

Michiel Adrianus van Nieuwenhoven

geboren op 25-09-1965 te Amsterdam 


\title{
Promotor
}

Prof. dr. ir. WHM Saris

\section{Co-promotores}

\author{
Dr. R-JM Brummer \\ Dr. F Brouns
}

\section{Beoordelingscommissie}

Prof. dr. H Kuipers (voorzitter)

Mw. dr. MA van Baak

Prof. dr. P Hespel (Katholieke Universiteit Leuven, België)

Prof. dr. AJPM Smout (Universiteit Utrecht)

Prof. dr. RW Stockbrügger 
Quam dilectatum ex studio capimus!

Cicero 


\section{Contents}

Chapter 1 Introduction

Chapter 2 Exercise and gastrointestinal function: a review

Chapter 3 Performance of the $\left[{ }^{13} \mathrm{C}\right]$-acetate gastric emptying breath test during physical exercise

Chapter 4 The sensitivity of the lactulose/rhamnose gut permeability test

Chapter 5 The effect of pre- and postabsorptive factors on the lactulose/rhamnose gut permeability test

Chapter 6 The effect of physical exercise on parameters of gastrointestinal function

Chapter 7 Gastrointestinal function during exercise: a comparison between water, a sports drink and a sports drink with caffeine

Chapter 8 Effects of the degree of dehydration and hyperthermia on gastrointestinal function at rest and during exercise

Chapter 9 The effect of physical exercise on gastrointestinal function in symptomatic subjects

Chapter 10 General discussion

Summary

Samenvatting

Nawoord

Publications

Curriculum Vitae 
ajnstrios 


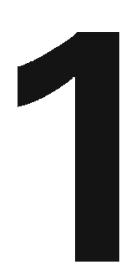

Introduction 


\section{Introduction}

Gastrointestinal (GI) symptoms are commonly experienced by people who exercise, both in association with training and during competition. These disturbances may impair athletic performance. Runners especially suffer from these symptoms, probably due to the up-and down bouncing movements. In this respect, "Runners Trots" is a well-known expression among the runner fraternity, and it refers to the watery diarrhea that can afflict athletes during or immediately after exercise. A variety of symptoms may occur during exercise, which may be attributed to disorders of the upper and the lower Gl tract.

The upper Gl tract is commonly defined as the esophagus and the stomach, and the lower Gl tract as the small bowel and the colon.

Upper Gl symptoms comprise heartburn, nausea, bloating and abdominal cramping. Athletes also frequently report symptoms such as loss of appetite and vomiting. Lower $\mathrm{Gl}$ symptoms comprise lower abdominal cramping, the urge to defecate, increased frequency of bowel movements, flatulence and diarrhea. All these symptoms suggest that exercise can influence Gl function, and most of them seem to be related to alterations in GI motility. Normally, GI motility is studied at rest, and in that respect, physical exercise may serve as a good "model" to gain more insight in the (patho)physiology of Gl motility.

Although some people experience symptoms in almost every endurance race, it seems very difficult to attribute these symptoms to a specific cause, because many factors may be involved in the etiology of exercise-induced Gl symptoms.

\section{Epidemiology}

A number of field studies in which participants of endurance events were surveyed on $\mathrm{Gl}$ symptoms have been reported in the last two decades ${ }^{1-5}$. It appeared that up to $42 \%$ of the participants suffer from one or more GI symptoms during, or immediately after exercise. In general, lower GI symptoms are more common than upper Gl symptoms, women experience more often symptoms than men, younger athletes experience more often symptoms than older athletes, exercising at a high intensity induces more symptoms than exercising at a lower intensity, and running induces more symptoms than "gliding" sports such as cycling, swimming, skating or rowing.

\section{Pathogenesis}

The etiology of Gl symptoms associated with exercise has been little studied and remains speculative. It appears that gastric emptying, intestinal transit and intestinal absorption and secretion are involved. These processes may be influenced by factors such as a change in splanchnic blood flow, hormonal 
changes and alterations in neural regulation, which all can be affected by exercise. Also the type of exercise seems to be an important factor, as "gliding" types of sports induce less GI symptoms. Finally, climatic conditions, environmental factors such as type of surface and altitude, nutritional habits, hyperthermia and dehydration may be involved in the etiology of GI symptoms. The question arises what causes upper Gl symptoms such as nausea and heartburn. The investigation of the relation between Gl symptoms and changes in gastric emptying is troubled by the complexity of changing variables during exercise, although it is well-established that the gastric emptying rate depends on several variables such as type, caloric contents and temperature of the ingested meal ${ }^{6}$. Other factors such as type and intensity of the exercise and the use of nasogastric tubes may also affect gastric emptying. Heartburn may be caused by gastroesophageal reflux. A number of studies have examined the relationship between exercise-induced heartburn, gastroesophageal reflux and gastric juice composition ${ }^{7-12}$. In general, it seems that exercise leads - in an intensity-dependent way - to an increased exposure of the esophagus to gastric contents, probably caused by an increased prevalence of transient relaxations of the lower esophageal sphincter (LES). Attempts to establish the causes of lower Gl symptoms during exercise have yielded equivocal results. In general, investigators have focused on changes in intestinal transit time. Small intestinal transit time has been studied using radiotelemetry capsules and radiopaque markers ${ }^{13.14}$ and also using the hydrogen breath test ${ }^{15-21}$. A disadvantage of the latter method, however, is the need to administer lactulose, which accelerates intestinal transit. In general, the results of these studies are conflicting, due to the lack of standardisation in both type, duration and intensity of the exercise, the diet, and the applied measurement techniques. The role of the colon in the etiology of exercised-induced Gl symptoms has been proven difficult to study because of the large inter- and intraindividual variability in both colonic transit time and consumed diet. The number of controlled studies is limited ${ }^{22.23}$ but they seem to suggest that exercise does not significantly influence colonic transit time.

A reduction in blood flow to the lower Gl tract is considered important in relation to lower Gl symptoms during exercise, and may result in relative ischemia. This may lead to alterations in mucosal integrity, absorption and secretion. Direct measurement of the splanchnic blood flow during exercise is a complicated procedure, but an ischemic condition of the small bowel may be indirectly reflected by an increased intestinal permeability ${ }^{24.25}$ and a decreased intestinal absorption ${ }^{26.27}$. In a later stage, this condition may lead to bleeding of the mucosa, followed by transfer of bacteria and endotoxins into the portal circulation. 


\section{Research on GI motility during exercise}

The studies concerning the effect of physical exercise on gastrointestinal function, which have been published so far, have been performed under different testing conditions, varying from field studies using questionnaires, to more or less standardized laboratory settings using techniques to study physiological parameters. This hampers the comparison and interpretation of the various results. Recently, several studies concerning $\mathrm{Gl}$ function during exercise have been performed, but refer to small segments of the Gl tract. Systematic research in which the whole Gl tract is studied in an integrated approach, has not been carried out yet. Preferably, the Gl tract should be studied as a whole under standardized and reproducible conditions and the used techniques should not interfere with the normal Gl physiology. Such a design allows the investigator to vary factors such as diet, type of exercise and hydration state, and to study its effect on Gl function.

In that respect, this thesis attempts to provide further insight in the effect of physical exercise on gastrointestinal function. Therefore, the following aims have been formulated.

\section{Specific aims}

1 The validation of a noninvasive technique to measure gastric emptying during exercise; the ${ }^{13} \mathrm{C}$-acetate breath test. This technique enables to investigate gastric emptying, avoiding nasogastric intubation.

2 To establish the quantity of lactulose sufficient to measure intestinal permeability.

3 Further validation of the lactulose/rhamnose permeabilty test in order to establish its usefulness as a technique to study intestinal permeability.

\section{General aims}

1 To investigate the effect of high-intensity exercise on esophageal motility, gastroesophageal reflux, gastric $\mathrm{pH}$, gastric emptying, orocecal transit time, intestinal permeability and intestinal glucose absorption simultaneously, using a rest-exercise-rest protocol which is as non-invasive as possible, in a controlled laboratory setting. 
2 To investigate the effect of:

i) A carbohydrate-electrolyte solution (CES) against a water placebo on GI function during exercise.

ii) Supplementation of a CES with caffeine, which is suspected to induce Gl disturbances, against a placebo on GI function during exercise.

iii) The effect of dehydration and hyperthermia on Gl function during exercise.

3 To evaluate the difference in Gl function between people who never suffer from exercise-induced Gl symptoms, and people who frequently suffer from exercise-induced GI symptoms.

\section{Outline of the thesis}

Chapter 2 reviews the current knowledge on the relationship between $\mathrm{Gl}$ function, Gl complaints and exercise. Chapter 3 describes the validation of the

${ }^{13} \mathrm{C}$-acetate breath test during physical exercise. The processes of intestinal absorption and subsequent oxidation of the tracers are specifically considered as well. Chapter 4 describes the sensitivity of the lactulose/rhamnose gut permeability test under conditions of both a normal and an increased permeability. Chapter 5 discusses the role of both intestinal transit and renal clearance of lactulose and rhamnose on the outcome of the lactulose/rhamnose permeability test. The evaluation of these techniques enabled us to carry out the study described in Chapter 6 . In this study a number of Gl parameters are measured simultaneously in healthy well-trained male subjects using a standardized rest-exercise-rest protocol. The same protocol was used in Chapter 7. which describes the effect of a water placebo drink, a carbohydrateelectrolyte solution and a carbohydrate-electrolyte solution with added caffeine on $\mathrm{Gl}$ function. Chapter 8 describes the effect of controlled dehydration preceding exercise on $\mathrm{Gl}$ function using the same standardized rest-exercise-rest protocol and Chapter 9 describes the differences between the asymptomatic subjects studied in Chapter 6 and subjects who frequently suffer from general exercise-induced $\mathrm{Gl}$ symptoms, both during rest and exercise conditions. Moreover, the differences in Gl function between running and cycling were studied in these subjects. Finally, the results of the studies reported in this thesis and their consequences are discussed in Chapter 10. 


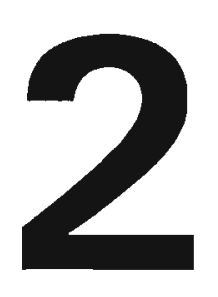

\section{Exercise and gastrointestinal function: a review}

MA van Nieuwenhoven, F Brouns, R-JM Brummer

Exercise: Basic and Applied Science. Lippincott Williams \& Wilkins, Philadelphia 205-216 (in press). 


\section{Introduction}

Participation in endurance events has become very popular. Many people participate in races, some of which last $>15 \mathrm{~h}$. Participants frequently suffer from abdominal pains, abnormal defecation, heartburn, nausea and vomiting. This suggests that exercise can influence gastrointestinal function. Although some people seem to have such problems in almost every endurance race, it seems very difficult to find a specific cause, because many factors may play a role in the etiology of a specific gastrointestinal disturbance. The chance that a person suffering from a gastrointestinal disease which is not related to exercise participates in a race increases with the number of participants. Such a person may experience gastrointestinal symptoms during exercise, although exercise itself is not the causative factor'.

\section{Epidemiology, types and frequencies of gastrointestinal (GI) symptoms}

Exercise-induced Gl symptoms have gained scientific attention only recently. A number of studies have been performed in which questionnaires have been applied to participants in endurance events. Keeffe et al. ${ }^{2}$ surveyed 1700 participants in a marathon race. Lower Gl symptoms, such as diarrhea, abdominal cramps, urge to defecate, flatulence and Gl bleeding were found to be more common than upper Gl symptoms, such as nausea, vomiting, heartburn, bloating and side ache. The most common symptom experienced was urge to defecate $(36-39 \%$ of the participants), both during and immediately after running. Bowel movements (35\%) and diarrhea (19\%) were reported relatively frequent immediately after running. During the race runners had to stop to move their bowels (16-18\%) and some runners had to stop because of diarrhea (8-10\%). Bloody bowel movements were reported by $1-2 \%$ of the participants. Lower Gl symptoms were more common in women than in men, and some symptoms were more frequently reported by younger than older participants. Comparable results were obtained by Riddoch ${ }^{3}$. He also reported lower Gl symptoms as the most common symptoms, he also observed more symptoms in women than in men, and more symptoms in younger than in older people. Worobetz et al. ${ }^{4}$ compared the effect of swimming, cycling and running on the prevalence of $\mathrm{Gl}$ symptoms. He demonstrated that the frequency of $\mathrm{Gl}$ symptoms was low during cycling and swimming. Running, however, was associated with a high frequency of gastroesophageal and colonic symptoms. This was probably caused by mechanical stress due to the up-and-down movements of the abdominal organs during running. The need to defecate was the most common reason for interrupting exercise. This indicates that the type of exercise can affect the etiology of Gl symptoms. It also appeared that both 
upper and lower Gl symptoms were affected by exercise intensity, frequency of meals and intake of specific foods during exercise, such as fiber-rich food, coffee and orange juice. Anxiety seemed to influence the occurrence of lower GI symptoms. Women were more likely to experience abdominal cramps during menstruation. Rehrer et al. $^{5}$ made an attempt to correlate dietary intake (including food and fluid intake) during triathlon competition and the occurrence of $\mathrm{Gl}$ symptoms. It was observed that, in general, triathletes who consumed hypertonic carbohydrate solutions during exercise and those who consumed food products high in dietary fiber, fat or protein before competition suffered more from Gl symptoms. The last 3 factors were especially related to vomiting and gastroesophageal reflux. In addition, the time of the last meal played a role; triathletes who consumed a solid meal shortly before exercise suffered more from vomiting. Peters ${ }^{6}$ investigated the relationship between Gl symptoms and the type of consumed meal during exercise. Three different types of meals were studied; a semi-solid carbohydrate meal, a liquid carbohydrate meal and a water placebo. He only observed a small difference in duration of nausea between the water placebo and the semi-solid carbohydrate meal; nausea lasted longer after ingestion of the water placebo.

There are other factors that can initiate exercise-induced Gl symptoms. Sandell et al.' reported that inadequate training, no carbohydrate-rich meal consumption beforehand, hypoglycemia, no breakfast on the race day, pre-race illness and hypothermia can play a role in exercise-induced Gl symptoms.

\section{Etiology}

The underlying etiology of Gl symptoms associated with exercise, especially running, has been little studied and remains speculative. Nevertheless it appears that gastric emptying, intestinal transit and intestinal absorption and secretion may be involved. These functions are largely regulated by nervous and hormonal processes which, in turn, are influenced by the immediate physiological activity level, i.e. metabolic demand and blood supply. The question then arises whether exercise alters these functions by influencing the regulating factors. At the onset of exercise, many physiological and biochemical processes adapt to the increased degree of physical activity. The most important alterations are immediate local changes in tissue biochemistry, such as changes in oxygen saturation, concentration of energy-rich phosphates and accumulation of metabolites, as well as changes in sympathic and parasympathic output and circulating hormones ${ }^{1.8}$. The muscular blood flow is increased and the Gl tract receives less blood during exercise $e^{9,10}$. Rowell and co-workers demonstrated a $60-70 \%$ reduction in splanchnic blood flow in subjects exercising at an intensity of $70 \% \mathrm{VO}_{2 \max }{ }^{11}$. Clausen ${ }^{12}$ reported that blood flow may be reduced to $20 \%$ of the resting level during maximal exercise, in both trained and untrained people. 
Sympathic output plays a major role in redistributing blood flow during exercise. Blood flow may be decreased to critical levels during maximal sympathic stimulation and maximal hormonal changes, which take place when hyperthermia, dehydration, hypoglycemia, hypoxia or a combination of these factors may cause fatigue and exhaustion. The plasma noradrenalin concentration has been shown to vary inversely with the oxygen saturation of mixed venous blood. Hyperthermia and hypoglycemia lead to highly increased sympathic stimulation and plasma catecholamine levels and may therefure influence blood flow significantly ${ }^{11}, 13$. Continuing dehydration $1>3 \%$ body weight) leads to tissue dehydration and decreased capillary blood supply in peripheral tissues such as muscle and skin and may reduce intestinal blood flow to practically zero. In addition, blood viscosity is known to be affected by exercise-induced hyperthermia. Plasma viscosity is temperature-dependent and shows a $10 \%$ increase at $40^{\circ} \mathrm{C}$. Whole blood viscosity, which may further affect intestinal capillary blood flow, is influenced by hydration status ${ }^{14}$. Dehydration, reduced splanchnic blood flow and tissue hypoxia strongly influence the occurrence of Gl symptoms associated with especially the lower Gl tract. A lack of oxygen may induce acute energy deficits, which may influence active, energy-dependent absorption of nutrients, such as glucose or amino acids, and may also interfere with $\mathrm{Na}^{+}-\mathrm{K}^{+}$- ATPase activity. As a result, gastrointestinal motility, intestinal absorption and mucosal integrity may be disturbed.

\section{Effect of exercise on esophageal motility and gastroesophageal reflux}

Athletes frequently suffer from exercise-induced gastrointestinal (GI) symptoms ${ }^{8.15}$. These symptoms can be divided into upper and lower $\mathrm{Gl}$ symptoms. Upper $\mathrm{Gl}$ symptoms which have been reported include nausea, vomiting, belching and heartburn ${ }^{16}$. Gl symptoms ascribed to the esophagus include heartburn and chest pain. These symptoms indicate disturbances in esophageal motility and an increased incidence of gastroesophageal reflux. Hence, the general believe that exercise-induced chest pain suggests a cardiac, rather than a Gl origin, is not true in case of exercise-induced esophageal complaints. The primary pathophysiologic event of non-cardiac chest pain is an abnormal exposure of the esophagus to gastric juice. Two main factors can play a role in the pathogenesis; an increased rate of reflux episodes, and/or a decreased rate of esophageal clearance via primary and secondary peristalsis. The composition of the refluxate, especially the acidity and the quantity of pepsin, and the sensitivity of the esophageal mucosa for the refluxate can play a role in the perception of heartburn as well.

Since the ambulatory measurement of reflux, LES and esophageal motility are relatively recent techniques, only a small number of studies on the effect of exercise on gastroesophageal reflux have been carried out.

In 1989 Clark et al. ${ }^{17}$ studied exercise-induced gastroesophageal reflux in 12 
healthy volunteers. The subjects were studied on 2 different occasions; fasted and after a meal. They underwent a rest-exercise protocol, and esophageal pH was measured. The exercise consisted of $15 \mathrm{~min}$ cycling, $15 \mathrm{~min}$ of a weight routine and $15 \mathrm{~min}$ running on a treadmill. 5 min rest followed each exercise bout, and the exercise was conducted at near-maximal effort. The results indicated that strenuous exercise could induce gastroesophageal reflux in normal volunteers. It was also observed that running caused the most reflux, and cycling produced less reflux. In the weight routine bout gastroesophageal reflux was induced in some subjects, but no particular exercise was associated with more reflux. Postprandial exercise showed a similar pattern of gastroesophageal reflux to reflux during exercise under fasted condition, but it was quantitatively larger. This finding is consistent with the known postprandial increase of gastroesophageal reflux in healthy sedentary subjects. The exercise-induced increase in gastroesophageal reflux was not associated with an increase in upper Gl symptoms. Kraus et al. ${ }^{18}$ studied gastroesophageal reflux in runners in a rest-exercise protocol comprising a $1 \mathrm{~h}$ baseline recording, and $1 \mathrm{~h}$ of nearmaximal running on a treadmill. The effect of ranitidine vs. a placebo was studied as well. They observed that gastroesophageal reflux was prevalent in many subjects and that symptoms, primarily belching, were more frequent during running than at rest. These symptoms were associated with reflux episodes. Ranitidine reduced the acidity of the refluxate and the duration of reflux episodes as well.

Soffer et al. ${ }^{19.20}$ carried out 2 studies, in which they investigated the effect of exercise intensity on esophageal motility and gastroesophageal reflux in both trained and untrained subjects. The untrained subjects underwent a restexercise protocol and the exercise comprised of 4 periods of cycling at 40,60 , 75 and $90 \%$ of their maximal oxygen uptake $\left(\mathrm{VO}_{2 \max }\right)$. They were encouraged to exercise for as long as they could in each session, with a resting period between each cycling session. At the highest intensity the load could not be maintained longer than 2-3 min. The trained subjects underwent a protocol comprising of $60 \mathrm{~min}$ at $60 \% \mathrm{VO}_{2 \max }, 45 \mathrm{~min}$ at $75 \% \mathrm{VO}_{2 \max }$ and $10 \mathrm{~min}$ at $90 \% \mathrm{VO}_{2 \max }$. Thirty min rest followed each cycling session. Similar results were obtained in both groups; the duration, amplitude, and frequency of esophageal contractions declined with increasing exercise intensity and the differences reached significance for all 3 parameters at $90 \% \mathrm{VO}_{2 \max }$.

The number and duration of reflux episodes were increased during the highest intensity, but not at lower intensities. The underlying mechanism for this increase in gastroesophageal reflux may be an exercise-induced decrease of the LES pressure. Peters et al. ${ }^{21}$ studied the LES pressure in healthy volunteers before and immediately after 30 min of cycling at an increasing intensity. They observed that the LES pressure decreased with severe exercise. Schoeman et al. ${ }^{22}$ studied reflux and LES pressure in ambulatory subjects. During the $24 \mathrm{~h}$ registration the subjects performed a standardized exercise program consisting of three $10 \mathrm{~min}$ periods of exercise with vigorous cycling on an exercise bike, 
walking at steady-state pace on a treadmill, and walking as fast as possible on a treadmill. The intensities were not standardized. They observed an increase in gastroesophageal reflux during exercise, and a decrease in basal LES pressure during exercise, which was, however, unrelated to the occurrence of reflux. The majority of the reflux episodes were associated with transient LES relaxations (TLESR). The number of TLESR's was not increased during exercise.

At present, it is still unclear how exercise affects the characteristics of LES motility. The relation between the rate of gastric emptying and reflux at high intensity exercise and the possible long-term effects of exercise-induced reflux are areas to be clarified in the future.

\section{Effect of exercise on gastric emptying}

Since the last two decades substantial interest has been given to the effects of dehydration and rehydration in the exercising athlete. This item has been reviewed in a number of papers ${ }^{23-28}$. Although low-intensity exercise increases solid meal gastric emptying rates ${ }^{29}$, during exercise predominantly liquids are consumed. Generally, after swallowing a liquid down to the stomach, gastric emptying is considered being the first limiting step in making fluid available to the circulation. The stomach functions as a reservoir from which no significant absorption takes place and from which fluid has to be emptied into the intestine, prior to absorption.

In relation to exercise, the gastric emptying rate (GER) depends on:

- Exercise intensity

- Volume of the drink

- Energy density of the drink

- Temperature of the drink

- Osmolality of the drink

- Body temperature/dehydration level

- Type of exercise

- Psychological stress level

These factors will be discussed hereafter.

\section{Exercise intensity}

From studies done at rest and during exercise it appears that up to an exercise intensity levels of $70-80 \% \mathrm{VO}_{2 \max }$, there is no difference in the regulation of the GER between both conditions. At higher intensities, the GER has been found to be reduced. However, the significance of this finding for the exercising athlete is low, since exercise at intensities of $>80 \% V^{2} O_{2 \max }$ generally cannot be 
performed long enough to cause a limitation in fluid availability. Even if this would happen, the exercise-induced hyperventilation would be so intense that drinking would cause a direct disturbance of breathing patterns and with it the ability to perform well (e.g. a $10.000 \mathrm{~m}$ run in the heat would not allow for drinking). It appears that factors which are related to the quantity of the fluid consumed and to its chemical composition are of prime importance in making fluid available for absorption.

\section{Volume of the drink}

When a meal or fluid bolus enters the stomach, it allows for volume adjustment, i.e. the gastric wall distends. The result of this adaptation is that the volume increases without an increase in pressure. The latter will only occur once the capacity to distend has been maximized. Once contractions of the corpus are initiated, the quantity which is emptied from the stomach is larger if the gastric content is large. This effect can be observed in most GER studies and is presented by a more or less exponential gastric emptying response after the ingestion of fluids. Firstly, there is a rapid emptying phase followed by a phase of reduced emptying once the volume of the stomach has been reduced to about $30 \%$ of its initial content.

\section{Energy density of the drink}

This volume effect can be overruled by the chemical composition of a drink. For example, drinks which have a high nutrient content (thus also a high caloric value/energy density) do not exert an exponential response, but empty almost linearly from the stomach. Two important conclusions can be drawn from these findings: 1) for substantial fluid replacement, drinks should have a relatively low nutrient content; 2) volume drinking may have advantages over frequent "small body drinking" 27 .

Since athletes deal with two major limiting factors to perform endurance exercise in the heat, i.e. fluid and carbohydrate (CHO) availability, it is important to determine how high the $\mathrm{CHO}$ content of a drink should be, without limiting fluid availability. Many studies have been done in this respect. Generally, these show that the addition of $\mathrm{CHO}$ in quantities up to $4 \%(40 \mathrm{~g} / \mathrm{L})$ does not inhibit the GER. Higher quantities progressively reduce $\mathrm{GER}^{30-32}$. Yet, there is some degree of freedom to use slightly higher $\mathrm{CHO}$ contents during exercise, i.e. $6-8 \%$. Observations on the quantity of fluid usually consumed during endurance exercise highlight the fact that runners seldom ingest $>500 \mathrm{ml} / \mathrm{h}^{33}$ while cyclists can ingest more, i.e. $500-800 \mathrm{ml} / \mathrm{h}$. Both quantities are substantially less than the maximal GER. Therefore, the fact that drinks containing 40-80 g CHO/L are more slowly emptied from the stomach may not necessarily be of physiological significance when relatively small to moderate fluid volumes are consumed. As a general rule, drinks for the endurance athlete exercising in the heat may contain 40-80 $\mathrm{g} \mathrm{CHO} / \mathrm{L}$, whereas drinks with a 
higher $\mathrm{CHO}$ content may be more beneficial to support $\mathrm{CHO}$ availability and oxidation in conditions where sweat loss is small. Maximal oral $\mathrm{CHO}$ oxidation has been observed to approximate $0.5-1.0 \mathrm{~g} / \mathrm{min}$, requiring $600-750 \mathrm{ml}$ of an $8 \%$ solution $^{34}$.

\section{Osmolality}

A high content of simple $\mathrm{CHO}$ causes a drink to have a high osmotic pressure. In the early seventies it was believed that osmolality is one of the most important factors in the control of the GER. However, osmolality and content of simple or short-chain $\mathrm{CHO}$ are related. Increasing the $\mathrm{CHO}$ content will increase osmolality. For that reason we have recently performed a study to compare the effect of six drinks with osmolalities ranging from $240-390 \mathrm{mOsm} / \mathrm{L}$, but all with a $\mathrm{CHO}$ content of $60 \mathrm{~g} / \mathrm{L}$. It was observed that all drinks emptied at the same rate ${ }^{30}$. Thus, although osmolalities may reduce $\mathrm{GER}^{32}$, this does not seem to be an important factor in relation to most sports drinks consumed (range of 200-400 $\mathrm{mOsm} / \mathrm{L}$ ).

\section{Temperature}

When considering the effect of temperature on the total time to empty liquids from the stomach, the effect can be considered as physiologically unimportant. Athletes are advised to adjust drink temperature to personal preference and tolerance during exercise and that cooled drinks may offer some benefit in taking up heat from the body. In contrast, when exercising in cold conditions, warm drinks may offer a psychological benefit.

\section{Stress level}

Psychological and severe physical stress is known to affect gastrointestinal motility and to reduce the GER. Changes in plasma stress hormones and GI hormones, related to stress and exercise will be discussed further down. The only remedy to reduce such effects is by adequate training and mental preparation. Stress due to dehydration in the heat, i.e. hyperthermia, is known to coincide with heat exhaustion and intestinal upset. Studies on the effect of exercise dehydration-induced hyperthermia have shown that the GER slows down ${ }^{28}$ and that Gl upset may occur ${ }^{35}$. This is most probably caused by stress-related hormonal changes and a significant drop in gastrointestinal blood flow'.

\section{Type of exercise}

Running exercise leads to a much higher incidence of Gl symptoms compared to gliding types of exercise such as cycling, cross-country skiing, rowing, swimming and skating ${ }^{1,23}$. Consequently, fluid intakes during running events are 
small and range from 150 to maximally $600 \mathrm{ml} / \mathrm{h}^{33}$ and the incidence of dehydration and related $\mathrm{Gl}$ upset is large ${ }^{35}$. This may have a direct effect on $\mathrm{Gl}$ motility and the GER. However, when different types of exercise are compared in controlled laboratory circumstances, Gl problems do generally not occur and differences in the GER are not observed ${ }^{35}$.

Women are observed to have a slower GER compared to men, but during ovulation this is reversed ${ }^{36}$. Women also have lower sweat production rates than men. If women and men drink equal volumes during endurance exercise, this causes more gastric complaints of distention in women compared to men ${ }^{37}$. Thus, both men and women should monitor their body weight loss as result of endurance exercise in order to calculate the required fluid replacement.

\section{Keys for practice}

- Drinks retaining in the stomach are not available to the body.

- Drinks with a high-energy content reduce the fluid delivery to the gut.

- Temperature, osmolality and training status are not considered to be of great importance to the GER.

- Optimally, rehydration drinks to be ingested during exercise in the heat should contain $<80 \mathrm{~g} \mathrm{CHO} / \mathrm{L}$.

- Drinks to be ingested in conditions where fluid loss is not performance limiting, i.e. during wintertime, may contain more $\mathrm{CHO}$ and may also be warm.

- Athletes should find out their personal preference and tolerance for both drink volume and drink temperature in training sessions.

\section{The effect of exercise on small bowel motility}

Intense exercise can cause Gl symptoms, reduced intestinal blood flow', and elevated plasma concentrations of catecholamines, endorphins ${ }^{38}$, and all types of GI hormones ${ }^{39}$, each of which can affect intestinal motility. However, the few reports concerning the effect of exercise on intestinal motor function are conflicting. Studies of intestinal motility during exercise are obstructed by the technical problems associated with recording during physical exercise. Cammack et al. ${ }^{40}$ carried out one of the first studies on small intestinal transit during a low-intensity $60 \mathrm{~km}$ cycle ride, using the breath hydrogen technique. No effect was observed. Keeling et al. ${ }^{41.42}$, however, reported an acceleration in orocecal transit time (OCTT) in both men and women during walking at 5.6 $\mathrm{km} / \mathrm{h}$. They also used the breath hydrogen technique. It must be noted that quite a large quantity of the non-digestible carbohydrate lactulose was used; 20 g. In contrast, Meshkinpour ${ }^{43}$ reported a delay in OCTT during walking. $10 \mathrm{~g}$ of lactulose was administered in this study. Soffer et al. ${ }^{44}$ measured the effect of 
cycling at different intensities on duodeno-jejunal motor activity and OCTT in 8 well-trained cyclists. It was observed that exercise at higher intensities can affect intestinal postprandial motor activity. In a number of subjects interruptions of the fed pattern by a burst of rhythmic activity resembling an activity front that propagated from the duodenum to the jejunum were observed. This effect was exercise intensity-dependent, but not related to gastrointestinal symptoms. The OCTT was measured as well, and appeared to be unchanged by short intense exercise. Peters et al. ${ }^{45}$ studied the effect of prolonged physical exercise and fluid supplementation (water versus carbohydrate solution) in triathletes on antroduodenal motility. They observed an early reappearance of phase III during exercise, especially with carbohydrate, which was unexpected because no phases III were present before exercise and energy intake in the morning prior to the exercise. Koffler et al. ${ }^{46}$ studied OCTT in untrained middle-aged and elderly men, after a 13 weeks total body strength training period. They were also unable to observe an effect of physical exercise on OCTT. These results were confirmed by Liu et al. ${ }^{47}$ in a study in which 9 physical active elderly men were studied after a period of 2 weeks of inactivity. Intestinal markers to study intestinal transit have also been used. Harrison et al. ${ }^{48}$ used oral radiopaque markers in recreational runners, and observed no differences in intestinal transit between active and inactive periods. Evans et al. ${ }^{49}$ used jejunal pressure-sensitive radiotelemetry capsules, attached to a wire, to study 20 fasted male subjects at rest and during exercise. They observed a decreased occurrence of MMC, which indicates a delayed intestinal transit. In another study the intestinal transit of capsules was reported to be delayed ${ }^{50}$. Ollerenshaw et al. ${ }^{51}$ used radioactive labeled raisin beans to study the effect of 3 different intensity levels on mean intestinal transit time. No differences in transit time could be observed.

Summarizing, it can be concluded that the effect of exercise, or exercise intensity on intestinal transit remains unclear. Studies which have been carried out so far, show conflicting results. Various methods to measure intestinal transit, different types of subjects and different quantities of lactulose to determine OCTT have been used which makes it difficult to compare the studies. More standardized research is needed to elucidate the role of exercise on intestinal motility. Its relation with gastric emptying, intestinal absorption and exercise-induced Gl symptoms are areas to be elucidated in the future as well.

\section{The effect of exercise on small bowel absorption}

Impaired intestinal fluid and electrolyte absorption causes an osmotic load, which may result in gastrointestinal distress and diarrhea. Most studies on small intestinal absorption in exercise have applied the triple lumen perfusion technique $^{61}$. In one of the first studies using this technique, no effect of $1 \mathrm{~h}$ 
treadmill running at an exercise intensity of $70 \% \mathrm{VO}_{2 \max }$ was found on water glucose and electrolyte absorption in 5 athletes ${ }^{52}$. Barclay and Turnberg ${ }^{53}$ however, observed that exercise of moderate intensity (45 to $50 \%$ of $\mathrm{VO}_{2 \text { max }}$ ) significantly reduced jejunal absorption of water, sodium, chloride and potassium. It has been suggested that a reduction of mesenteric blood flow by more than $50 \%$ causes a linear fall in the rate of glucose absorption ${ }^{54}$. Using deuteriumoxide as a tracer for water absorption, Maughan et al..$^{55}$ observed impaired water absorption when exercise was performed at $80 \% \quad \mathrm{VO}_{2 \max }$ compared with 42 or $61 \% \mathrm{VO}_{2 \max }$.

It has been suggested that the intraluminal concentration of carbohydrates and sodium affect fluid absorption, because of carbohydrate and sodium share a coupled active transport system in the intestinal wall ${ }^{56}$. However, sodium may not necessarily be of physiological significance for the rate of glucose absorption ${ }^{57}$. Rehrer et al ${ }^{58}$ observed, using deuteriumoxide-enriched beverages, that net jejunal water absorption occurred if a beverage was consumed containing either water, $4.5 \%$ glucose, or $17 \%$ maltodextrin, while net secretion took place if $17 \%$ glucose was consumed, during 80 minutes at $70 \%$ $\mathrm{VO}_{2 \max }$. Using the triple lumen technique it was shown that differences in osmolality of the beverages were eliminated within the proximal duodenum and that $6 \%$ carbohydrate solutions with osmolalities ranging from 186 to 403 $\mathrm{mosmol} / \mathrm{kg}$ did not produce significant differences in fluid homeostasis (plasma volume) at the end of 80 minutes test period ${ }^{59}$. Generally, fluid absorption in small intestinal segments after water perfusion is smaller (about $1 \mathrm{ml} / \mathrm{cm} / \mathrm{h}$ ) compared to well-composed carbohydrate solutions with an absorption rate of about $3.4 \mathrm{ml} / \mathrm{cm} / \mathrm{h}^{60}$. The rate of water absorption may even be enhanced by using a relatively low carbohydrate content (3-4\%) and a low osmolality 1240 $270 \mathrm{mOsm} / L^{61.62}$. However, such a low carbohydrate administration limits the effects on exercise performance. Drinks with a very high absorption rate have not been shown to result in better water retention, probably because a rapid increase in plasma volume stimulates urine production by pressure receptors.

\section{The effect of exercise on intestinal permeability}

The role of the physiological barrier function of the small bowel and its possible role in health and disease has attracted much attention over the last decade. The intact intestinal mucosa serves as a barrier between the non-sterile lumen and the sterile interior of the body. Micro-organisms or endotoxins such as toxic lipopolysaccharides may sometimes penetrate this barrier. This process is named translocation. In a normal healthy subject translocation causes only a limited bacteriaemic/endotoxaemic challenge, which can be cleared by the defense systems (mesenteric lymphe nodes and the hepatic reticuloendothelial system) of the body ${ }^{63}$. Under conditions of an ischemic intestinal mucosa the 
leakage of bacteria and/or endotoxins through the more permeable intestinal mucosa may be increased, resulting in a condition which may give rise to $\mathrm{Gl}$ symptoms. It has been shown in an animal study that reduction of the small intestinal blood supply of more than $50 \%$ induces detectable tissue injury ${ }^{64}$.

Exercise may lead to a substantial decrease in Gl blood flow of more than $50 \%{ }^{9,10}$. Rowell et al. ${ }^{11}$ demonstrated a $60-70 \%$ reduction in splanchnic blood flow in subjects exercising at an intensity of $70 \% V_{3 m . x}$, and Clausen ${ }^{12}$ reported a reduction in splanchnic blood flow of $80 \%$ of the resting level during maximal exercise. It may also lead to an alteration in intestinal motility. Mechanical trauma due to, for instance, running may occur as well. These factors may lead to an injury of the intestinal mucosa, and as a consequence, an increase in intestinal permeability. Recently, there has been increasing evidence that, in addition to the mucosal injury taking place under ischemic conditions, intestinal injury also takes place during reperfusion ${ }^{65}$. The underlying mechanism of reperfusion damage is generally believed to be an increased production of oxygen-derived free radicals. There is not much data available concerning the effect of exercise on intestinal permeability. Øktedalen et al. ${ }^{66}$ studied 2 groups of long-distance runners for the effect of marathon running on the gastrointestinal mucosa. They observed gastric erosions in 5 out of 9 subjects, and a substantial increase in the $24 \mathrm{~h}$ urinary excretion of ${ }^{51} \mathrm{Cr}$-labeled EDTA after oral intake of this probe. This indicates an increased intestinal permeability, caused by damage of the intercellular junctions of adjacent enterocytes. However, they did not use a control probe besides the ${ }^{51} \mathrm{Cr}$-EDTA, therefore it cannot be excluded that other factors than changes in intestinal permeability caused the increase in urinary excretion. Moreover, ${ }^{51} \mathrm{Cr}$-EDTA is non-decomposable for bacteria, and therefore reflects colonic permeation as well ${ }^{67}$. None of the subjects experienced Gl symptoms during the marathon. Moses et al ${ }^{68}$ reported an increased permeability within $6 \mathrm{~h}$ to oral polyethylene glycol (PEG-400) combined with $6 \%$ glucose solution in asymptomatic subjects who underwent a protocol of $90 \mathrm{~min}$ of alternating high-intensity $(15 \mathrm{~min}$ of $\left.60 / 85 \% V_{2 \max }\right)$ treadmill running with $30 \mathrm{~s}$ sprints to exhaustion. PEG-400 consists of polymers with molecular masses ranging from 190-500 Dalton. Therefore they may follow variable routes of intestinal permeation. PEG-400 also exhibits variable urinary excretion (26-69\%) after intravenous administration as well. For these reasons interpretation of the results is difficult. Ryan et al. ${ }^{69}$ evaluated the effect of exercise and aspirin intake on intestinal permeability, using a hyperosmotic lactulose/mannitol test solution. The exercise comprised of $60 \mathrm{~min}$ treadmill running at $65 \% \mathrm{VO}_{2 \max }$. An increase in intestinal permeability was observed, due to aspirin ingestion, but not to exercise. Running was not associated with Gl symptoms. To summarize, it can be concluded that the influence of physical exercise on intestinal permeability is not clear yet. It cannot be excluded that changes in intestinal permeability may occur during more severe or prolonged exercise, eventually in combination with hyperthermia and/or dehydration. The use of anti-inflammatory drugs, during 
exercise, to reduce pain may lead to adverse effects on Gl function and should thus not be recommended.

\section{Effect of exercise on colonic function}

There is a general believe that inactivity is a risk factor for constipation and that increasing the level of physical exercise is effective against chronic constipation $^{70,47}$. The substantial evidence that physical activity reduces the risk for colon cancer may be associated with the change in gastrointestinal transit ${ }^{71}$. Other circumstantial evidence for the effect of exercise on colonic motility is the fact that many long-distance runners often experience diarrhea and urge to defecate $e^{3.72}$. Furthermore, the amount of exercise was reported to correlate with the prevalence of diarrhea. Colonic transit normally lasts for about 20-60 hours with a wide inter-individual and intra-individual variation. Hence, gut transit is mainly a colonic event, and exercise-induced diarrhea may therefore be considered as the result of a colonic function disorder. Nowadays, the specific transit of a segment of the gut can be determined with sophisticated transit measurements. However, the different compartments of the Gl tract should not be regarded as independent organs. The gastro-colonic response is a typical illustration of the functional cohesion of the Gl system. According to this phenomenon, the acceleration of colonic transit due to mass movements originates from the level of the stomach.

Only a few studies investigated the effect of exercise on colonic motility, and the results are rather conflicting. Cordain ${ }^{73}$ found transit to be accelerated by an aerobic training program, while Bingham ${ }^{74}$ did not find an effect of exercise. Moderate aerobic exercise in healthy males with a sedentary life-style did not significantly change total and segmental colonic transit ${ }^{75.76}$, although a trend towards accelerated right colonic transit was observed. In contrast to these findings, a comparative study between soccer players and age-matched sedentary controls showed that right colonic transit was considerably slower in the soccer players, whereas left colonic and rectal transit was slightly accelerated $^{77}$. Using a sophisticated manometric device, the acute colonic response to moderate aerobic exercise was studied ${ }^{78}$. During exercise, a shift towards increased frequency and intensity of the contractions was observed.

It is well-known that several factors may influence the results of studies on the effect of exercise on colonic motility, such as duration and intensity of exercise, mode of exercise, training status, hydration state, diet and gender.

Periods of intensive long-lasting exercise induce changes in the dietary intake of several nutrients. Generally, dietary fiber increases fecal mass, which reduces colonic transit and the metabolism of minerals, nitrogen and bile acids is affected $^{79.80}$.

In athletes, both dietary fiber and secretion changes will affect intestinal transit 
in periods of intensive exercise. This is most pronounced in athletes who consume vegetarian diets ${ }^{81}$. Rehrer et al. ${ }^{82}$ observed that triathletes who ingested pre-exercise meals which were relatively rich in dietary fiber, experienced more Gl symptoms during exercise.

The etiology of the experience of urge to defecate during exercise, especially running, is still a matter of debate. Early work of DeYoung ${ }^{83}$ in dogs, using intracolonic balloons, showed a rapid increase in colonic pressure shortly after the start of exercise, followed by relative relaxation and decreased sphincter pressure. This combination of events was assumed to cause defecation. Cordain et al. ${ }^{73}$ hypothesized that sympathic stimulation causes a relaxation of the $\mathrm{Gl}$ tract. This relaxation could facilitate the passage of intraluminal contents from the colon into the rectum during the up-and-down bouncing motion associated with running. This would be followed by the urge to defecate.

Many other explanations of diarrhea and urge to defecate during exercise could be proposed. Direct exercise-induced irritation by a hypertrophied psoas muscle on the rectosigmoid colon has been shown ${ }^{84}$, but its significance has never been proved. Several Gl hormones may affect internal anal sphincter pressure ${ }^{85}$.

It should be emphasized that GI symptoms due to (often latent) pre-existing GI disorders, such as irritable bowel syndrome, lactose malabsorption, celiac disease and giardiasis infection, may aggravate during intense exercise. Furthermore, the frequently administered non-steroid anti-inflammatory drugs (NSAIDs) in order to alleviate muscle and joint complaints have a detrimental effect on gastrointestinal mucosal integrity, causing gastritis, duodenitis and often (unobserved) gastrointestinal blood loss. The administration of NSAIDcontaining suppositories does not prevent these complications as these drugs exert their effect systemically through the inhibition of prostaglandin synthesis. The suppositories may in fact also induce proctitis and hence rectal symptoms such as urge to defecate.

\section{The effect of exercise on GI hormones}

Gastrointestinal function is partially under hormonal control. Therefore exerciseinduced changes in Gl hormones and peptides may play a role in the etiology of exercise-induced Gl symptoms. There are many hormones associated with GI function that can be influenced by physical activity. These hormones and peptides comprise catecholamines, which has been discussed earlier, vasoactive intestinal polypeptide (VIP), secretin, pancreatic polypeptide, somatostatin, gastrin, motilin, glucagon, polypeptide YY (PYY), cholecystokinin (CCK), glucagonlike peptide-1 (GLP-1), endorphins and prostaglandins. Several of these hormones have a metabolic function as well, which makes exerciseinduced alterations in plasma levels very difficult to interpret. The possible effect of exercise. on circulating GI hormones has been studied by Hilsted ${ }^{86}$. He 
observed significant increases in VIP, pancreatic polypeptide, somatostatin, glucagon and secretin in subjects during $3 \mathrm{~h}$ of low intensity cycling. These observations were confirmed by Sullivan ${ }^{87}$, who studied runners during a $30 \mathrm{~km}$ run. He also found an increase in plasma gastrin and motilin. Øktedalen ${ }^{88}$ also found increases in secretin and VIP during a $90 \mathrm{~km}$ ski race. Riddoch ${ }^{3,89}$ found an increase in VIP, motilin gastrin, pancreatic polypeptide and secretin, besides elevations in some neuropeptides, such as histidine, methionine and neurotensin after a marathon. Although these observations suggest a relationship between the plasma elevation of several hormones and the occurrence of Gl symptoms, it was unclear whether these hormonal elevations were caused by GI dysfunction, or that hormonal elevations were the underlying reason for $\mathrm{Gl}$ dysfunction. The increase in $G$ l hormones may have been more from a metabolic origin, in the response to energy demands, rather than being specifically related to alterations in Gl function. In a study of MacLaren ${ }^{90}$, gastrin and VIP were elevated after 90 min treadmill running and VIP was more increased if no fluid was ingested, compared with ingestion of a $8 \%$ maltodextrin solution. This suggests that carbohydrate drinks can counteract possible adverse effects of accumulating VIP levels on Gl function. Philipp et al. ${ }^{91}$ studied the influence of long-distance running on the secretion of CCK and gastrin. Several stress hormones were measured as well. The hormones were measured before and after a competitive marathon run, and a few weeks later as a control measurement. CCK and the stress hormones were elevated under pre-exercise conditions compared with control conditions. It is suggested that CCK may induce the type of endocrine response normally associated with the action of a stressful stimulus. The endocrine effect of CCK in relation to stress could be explained by a direct action at the level of the pituitary, where it may stimulate ACTH release. Therefore this study suggests that CCK, which delays gastric emptying, inhibits gastric acid secretion, lowers the LES pressure, enhances small bowel motility, and stimulates gallbladder contraction ${ }^{92}$, may be an important regulatory factor in response to anticipatory stress. Therefore it may play a role in the occurrence of Gl symptoms during stressful competitive events. O'Connor et al. ${ }^{39}$ studied $\mathrm{Gl}$ hormones in relationship to $\mathrm{Gl}$ symptoms immediately after finishing a marathon run and $30 \mathrm{~min}$ after finishing. They measured VIP, gastrin, secretin, pancreatic polypeptide, neurokinin A, pancreastatin, insulin and GLP-1. All these hormones, except insulin, were increased after the race. It could be speculated that some hormones were secreted in quantities which may be linked to a variety of Gl symptoms. Elevated levels of VIP can induce watery diarrhea, by reducing absorption of water and electrolytes and enhancing water, chloride and bicarbonate secretion. The VIP levels after the marathon exceed the VIP levels seen in patients suffering from watery diarrhea hydrochloracidemia (WDHA-syndrome). However, no relationship between VIP levels and exercise-induced diarrhea could be observed. Gastroesophageal reflux, nausea and vomiting have been suggested to be caused by an increased gastric acid production, which, in turn, 
may be caused by an elevated gastrin level. Banfi et al. ${ }^{93}$ studied plasma gastrin and cortisol combined with plasma pepsinogen in mountain marathon runners before, and immediately after the race, with the aim to establish their interrelationship with exercise-induced Gl symptoms. They concluded that, after endurance exercise, correlations between Gl symptoms and a change in plasma levels of $\mathrm{Gl}$ hormones do not exist. Therefore it can be concluded that exerciseinduced Gl symptoms do not necessarily correlate with plasma levels of GI hormones. This is surprising if the magnitude of the hormonal changes is taken into account. Other factors may contribute including duration of elevation of GI hormones, sensitivity to the Gl hormones, intestinal contents and adaptation. Further intervention studies are required to elucidate the mechanisms of release and action of $\mathrm{Gl}$ hormones during exercise, and possibly under other physiological conditions. 


\section{References}

1 Brouns F. Etiology of gastrointestinal disturbances during endurance events. Scand J Med Sci Sports 1991; 1: 66-77.

2 Keeffe EB, Lowe DK, Gross JR, Wayne R. Gastrointestinal symptoms of marathon runners. West J Med 1984; 141:481-484.

3 Riddoch $\mathrm{C}$, Trinick TR. Gastrointestinal disturbances in marathon runners. $\mathrm{Br} \mathrm{J}$ Sports Med 1988; 22: 71-74.

4 Worobetz LJ, Gerrard DF. Gastrointestinal symptoms during exercise and endurance athletes: prevalence and speculations of the etiology. NZ Med J 1985; 98: 644-646.

Rehrer NJ, Beckers EJ, Brouns F, Ten Hoor F. Effects of dehydration on gastric emptying and gastrointestinal distress while running. Med Sci Sports Exerc 1990; 22: 790-795.

Peters HPF, van Schelven FW, Verstappen PA, de Boer RW, Bol E, Erich WB, van der Togt CR, de Vries WR. Gastro-intestinal problems as a function of carbohydrate supplements and mode of exercise. Med Sci Sports Exerc 1993; 25: $1211-1225$.

Sandell RC, Pascoe MD, Noakes TD. Factors associated with collaps during and after ultramarathon foot races: a preliminary study. Physician Sports Med 1988; 16: 86-94.

8 Brouns F, Beckers EJ. Is the gut an athletic organ? Digestion, absorption and exercise. Sports Med 1993; 15(4): 242-257.

9 Konturek S, Falser J, Obtulowicz W. Effect of exercise on gastrointestinal secretions. J Appl Physiol 1973; 34 324-328.

10 Wade OL, Combes B, Chilos AW, et al. The effect of exercise on the splanchnic blood flow and splanchnic blood volume in normal men. Clin Sci 1956; 15: 457 . 463.

11 Rowell LR, Blackmon JR, Bruce RA. Indocyanin green clearance and estimated blood flow during mild to maximal exercise in upright man. J Clin Invest 1964; 43: $1677-1690$.

12 Clausen JP. Effect of physical training on cardiovascular adjustments to exercise in man. Physiol Rev 1977; 57: 779-815.

13 Galbo H. Gastroenteropancreatic hormones. In: Galbo H. (Ed.) Hormonal and metabolic adaptation to exercise. New York: Thieme 1983; pp 59-61.

14 Vandewalle HC, Lacombe JC, Lereivre A, Poirot C. Blood viscosity after $1 \mathrm{hr}$ submaximal exercise with and without drinking. Int J Sports Med 1988; 9: 104 . 107.

15 Moses FM. The effect of exercise on the gastrointestinal tract. Sports Med 1990: 9: 159-172.

16 Shawdon A. Gastro-oesophageal reflux and exercise. Important pathology to consider in the athletic population. Sports Med 1995; 20(2): 109-116.

17 Clark CS, Kraus BB, Sinclair J, Castell DO. Gastroesophageal reflux induced by exercise in healthy volunteers. J Am Med Ass 1989; 261: 3599-3601.

18 Kraus BB, Sinclair JW, Castell DO. Gastroesophageal reflux in runners. Characteristics and treatment. Ann Int Med 1990; 112: 429-433.

19 Soffer EE, Merchant RK, Duethman G, Launspach J, Gisolfi C, Adrian TE. Effect of graded exercise on esophageal motility and gastroesophageal reflux in trained athletes. Dig Dis Sci 1993; 38(2): 220-224. 
20 Soffer EE, Wilson J, Duethman G, Launspach J, Adrian TE. Effect of graded exercise on esophageal motility and gastroesophageal reflux in nontrained subjects. Dig Dis Sci 1994; 39(1): 193-198.

21 Peters O, Peters P, Clarys JP, De Meirleir K, Devis G. Esophageal motility and exercise. Gastroenterology 1988; 94: A351.

22 Schoeman MN, Tippett MD, Akkermans LMA, Dent J, Holloway RH. Mechanisms of gastroesophageal reflux in ambulant healthy human subjects. Gastroenterology 1995; 108: 83-91.

23 Brouns F, Saris WHM, Rehrer NJ. Abdominal complaints and gastrointestinal function during long-lasting exercise. Int J Sports Med 1987; 8: 175-189.

24 Costill DL. Gastric emptying of fluids during exercise: Perspectives in exercise science and sports medicine. Fluid homeostasis during exercise. C.V. Gisolfi and D.R. Lambs (Eds). Benchmark Press, 1990.

25 Maughan RJ. Fluid and electrolyte loss and replacement in exercise. J Sports Sci 1991; 7: 117-142.

26 Murray R. The effects of consuming carbohydrate-electrolyte beverages on gastric emptying and fluid absorption during and following exercise. Sports Med 1987; 4: 322-351.

27 Noakes TD, Rehrer NJ, Maughan RJ. The importance of volume in regulating gastric emptying. Med Sci Sports Exerc 1991; 23: 307-313.

28 Rehrer NJ, Brouns F, Beckers EJ, Saris WHM. The influence of beverage composition and gastrointestinal function on fluid and nutrient availability during exercise. Scand J Med Sci Sports 1994; 4: 159-172.

29 Moore JG, Datzl FL, Christian PE. Exercise increases solid meal gastric emptying rates in men. Dig Dis Sci 1990; 35(4): 428-432.

30 Brouns F, Senden J, Beckers EJ, Saris WHM. Osmolarity does not affect the gastric emptying rate of oral rehydration solutions. J Parent Enteral Nutr 1995; 19: 403-406.

31 Vist GE, Maughan RJ. Gastric emptying of ingested solutions in man: effect of beverage glucose concentration. Med Sci Sports Exerc 1994; 26: 1269-1273.

32 Vist GE, Maughan RJ. The effect of osmolality and carbohydrate content on the rate of gastric emptying of liquids in man. J Physiol 1995; 486: 523-531.

33 Noakes TD, Adams BA, Myburgh KH, Greeff C, Lotz T, Nathan M. The danger of an inadequate water intake during prolonged exercise. Eur J Appl Physiol 1988; 57: 210-219.

34 Hawley JA, Dennis SC, Noakes TD. Oxidation of carbohydrate ingested during prolonged endurance exercise. Sports Med 1992; 14: 27-42.

35 Rehrer NJ, Brouns F, Beckers EJ, Ten Hoor F, Saris WHM. Gastric emptying with repeated drinking during running and bicycling. Int J Sports Med 1990; 11: 238243.

36 Notivol R, Carrio 1, Cano L, Estorch M, Vilardell F. Gastric emptying of solid and liquid meals in healthy young subjects. Scand J Gastroenterol 1984; 19: 11071113.

37 Beckers EJ, Rehrer NJ, Brouns F, Ten Hoor F, Saris WHM. Determination of total gastric volume, gastric secretion and residual meal using the double sampling technique of George. Gut 1988; 29: 1725-1729.

38 McMurray RG, Forsythe WA, Mar MH, Hardy CJ. Exercise intensity-related responses of beta-endorphin and catecholamines. Med Sci Sports Exerc 1987; 19(6): $570-574$. 
39 O'Connor AM, Johnston CF, Buchanan KD, Boreham C, Trinick TR, Riddoch CJ. Circulating gastrointestinal hormone changes in marathon running. Int $J$ Sports Med 1995; 16(5): 283-287.

40 Cammack JN, Read W, Cann PA, Greenwood B, Holgate AM. Effect of prolonged exercise on the passage of a solid meal through the stomach and the small intestine. Gut 1982; 23: 957-962.

41 Keeling WF, Martin BJ. Gastrointestinal transit during mild exercise. J Appl Physiol 1987: 63(3): 978-981.

42 Keeling WF, Harris A, Martin BJ. Orocecal transit during mild exercise in women. J Appl Physiol 1990; 68(4): 1350-1353.

43 Meshkinpour $H$, Kemp C. Fairshter R. Effect of aerobic exercise on mouth-tocecum transit time. Gastroenterology 1989; 96: 938-941.

44 Soffer EE, Summers RW, Gisolfi C. Effect of exercise on intestinal motility and transit time in athletes. Am J Physiol 1991; 260: G698-G702.

45 Peters HPF. Gastrointestinal symptoms and dysfunction during prolonged exercise. Thesis Utrecht University, 1995.

46 Koffler KH, Menkes A, Redmon RA, Whitehead WE, Pratley RE, Hurley BF. Strength training accelerates gastrointestinal transit in middle-aged and older man. Med Sci Sports Exerc 1992; 24(4): 415-419.

47 Liu $F$, Toda $Y$. Brief physical inactivity prolongs colonic transit time in elderly men. Int J Sports Med 1993; 14: 465-467.

48 Harrison RJ, Leeds AR, Bolster NR. Exercise and wheat bran: effect on whole gut transit. Proc Nutr Soc 1980; 32: 22A.

49 Evans DF, Foster GE, Hardcastle DJ. Does exercise affect the migrating motor complex in man? In Roman (Ed.) Gastrointestinal Motility, pp 277-284. MTP Press, Boston, 1984.

50 Evans DF, Foster GE, Hardcastle DJ. Does exercise affect small bowel motility in man? Gut 1989; 24: A1012.

51 Ollerenshaw KJ, Norman S, Wilson CG, Hardy JG. Exercise and small intestinal transit. Nucl Med Comm 1987; 8: 105-110.

52 Fordtran JS, Saltin B. Gastric emptying and intestinal absorption during prolonged severe exercise. J Appl Physiol 1967; 23: 331-335.

53 Barclay GR, Turnberg LA. Effect of moderate exercise on salt and water transport in the human jejunum. Gut 1988; 29: 816-820.

54 Winne $D$. Models of the relationship between drug absorption and the intestinal blood flow. In Shepherd \& Granger (eds). Physiology of intestinal circulation. pp 289. Raven Press, New York, 1984.

55 Maughan RJ, Leiper JB, McGaw A. Effects of exercise intensity on absorption of ingested fluids in man. Exp Physiol 1990; 75: 419-421.

56 Sladen GEG. Methods of studying intestinal absorption in man: intestinal absorption in man. Academic Press, London, 1975; 1-49.

57 Hargraves M, Costill D, Burke L, McConnell G, Febbraio M. Influence of sodium on glucose bioavailability during exercise. Med Sci Sports Exerc 1994; 26: 365 368.

58 Rehrer NJ. Wagenmakers AJM, Beckers EJ, Halliday D, Leiper JB, Brouns F. Maughan RJ, Westerterp K, Saris WHM. Gastric emptying, absorption and carbohydrate oxidation during prolonged exercise. J Appl Physiol 1992; 72(2): 468-475. 
59 Shi X, Summers RW, Schedl HP, Chang RT, Lambert GP. Gisolfi CV. Effects of solution osmolality on absorption of select fluid replacement solutions in human duodenojejunum. J Appl Physiol 1994; 77(3): 1178-1184.

60 Gisolfi CV, Duchman SM. Guidelines for optimal replacement beverages for different athletic events. Med Sci Sports Exerc 1992; 24(6): 679-687.

61 Hunt JB, Elliott EJ, Fairclough PD, Clark ML, Farthing MJ. Water and solute absorption from hypotonic glucose-electrolyte solutions in the human jejunum. Gut 1992; 33: 479-483.

62 Leiper JB, Maughan RJ. Comparison of absorption rates from two hypotonic and two isotonic rehydration solutions in the intact human jejunum. Clin Sci 1988; 75: 22P.

63 Haglund U. Gut Ischemia. Gut 1994; 35: S73-S76.

64 Bulkley GB, Kvietys PR, Parks DA, Perry MA, Granger DN. Relationship of blood flow and oxygen consumption to ischemic injury in the canine small intestine. Gastroenterology 1985; 89: 852-857.

65 Schoenberg $\mathrm{MH}$, Fredholm BB, Haglund $U$, Jung $H$, Sellin $D$, Younes $M$, Schildberg FW. Studies on the oxygen radical mechanism involved in the small intestinal reperfusion damage. Acta Physiol Scand 1985; 124: 581-589.

66 Øktedalen O, Lunde OC, Opstad PK, Aabakken L, Kvernebo K. Changes in the gastrointestinal mucosa after long-distance running. Scand J Gastroenterol 1992; 27: $270-274$.

67 Travis S, Menzies I. Intestinal permeability: functional assessment and significance. Clin Sci 1992; 82: 471-488.

68 Moses F, Singh A, Smoak B, Hollander D, Deuster P. Alterations in intestinal permeability during prolonged high-intensity running. Gastroenterology 1991; 100: A472.

69 Ryan AJ, Chang R-T, Gisolfi CV. Gastrointestinal permeability following aspirin intake and prolonged running. Med Sci Sports Exerc 1996; 28(6): 698-705.

70 Donald IP, Smith RG, Cruickahank JG, Elton RA, Stoddart ME. A study of constipation in the elderly living at home. Gerontology 1985: 31:112-118.

71 Colditz GA, Cannuscio CC. Frazier AL. Physical activity and reduced risk of colon cancer: implications for prevention. Cancer Causes Control 1997; 8: 649-667.

72 Sullivan SN. The gastrointestinal symptoms of running. N Engl J Med 1981; 304 : 915.

73 Cordain L, Latin RW, Behnke JJ. The effects of an aerobic running program on bowel transit time. J Sports Med 1986; 26: 101-104.

74 Bingham SA, Cummings JH. Effect of exercise and physical fitness on large intestine function. Gastroenterology 1989; 97: 1389-1399.

75 Robertson G, Meshkinpour H, Vandenberg K, James N, Cohen A, Wilson A. Effects of exercise on total and segmental colon transit. J Clin Gastroenterol 1993; 16: 300-303.

76 Robertson G, Meshkinpour H, Vandenberg K, James N, Cohen A, Wilson A. Effects of exercise on total and segmental colon transit. Gastroenterology 1990; 98: A385.

77 Sesboue B, Arhan P, Devroede G, Lecointe-Besancon I, Congard P, Bouchoucha M, Fabre J. Colonic transit in soccer players. J Clin Gastroenterol 1995; 20: 211 214.

78 Cheskin LJ, Crowell MD, Kamal N, Rosen B, Schuster MM, Whitehead WE. The effects of acute exercise on colonic motility. J Gastrointestinal Motility 1992; 4: 173-177. 


\section{Abstract}

\section{Introduction}

The gastric emptying rate of liquids can be determined non-invasively using the $\left[{ }^{13} \mathrm{C}\right]$ acetate breath test at rest.

The aim of our study was to validate this test during physical exercise against the double sampling method, and to evaluate the time needed for intestinal absorption and the delay between absorption and appearance of ${ }^{13} \mathrm{CO}_{2}$ in breath, both at rest and during exercise.

\section{Methods}

Fifteen well-trained male subjects were investigated. Gastric emptying was determined simultaneously measuring the ${ }^{13} \mathrm{CO}_{2}$-enrichment in breath after intragastric administration of 0.5 I carbohydrate solution with added $150 \mathrm{mg}\left[{ }^{13} \mathrm{C}\right]$-acetate, and by the double sampling technique $(n=9)$. In separate tests $150 \mathrm{mg}\left[{ }^{13} \mathrm{C}\right]$-acetate was also applied intraduodenally and intravenously $(n=6)$, both at rest and during exercise. Time to Peak (TTP) ${ }^{13} \mathrm{CO}_{2}$-enrichment was determined using a curve fit, and was considered as the parameter for gastric emptying.

\section{Results}

TTP-enrichment derived from the breath test significantly correlated with the gastric emptying half-time obtained from the gastric aspirates. During exercise, median TTPenrichment values after intragastric, intraduodenal and intravenous administration of $\left[{ }^{13} \mathrm{C}\right]$-acetate were $22.3,10.3$ and $5.4 \mathrm{~min}$, respectively. During exercise intraduodenal and intravenous values were reached significantly earlier than at rest.

\section{Conclusion}

The $\left[{ }^{13} \mathrm{C}\right]$-acetate breath test can be used as a non-invasive method to determine relative gastric emptying rates of liquids during exercise, but the results are influenced by the rate of absorption and the time needed for subsequent oxidation of $\left[{ }^{13} \mathrm{C}\right]-$ acetate, and exhalation of ${ }^{13} \mathrm{CO}_{2}$. 


\section{Introduction}

The gastric emptying rate of liquids is known to be influenced by several factors. The most important are volume ${ }^{1}$, temperature ${ }^{2}$, energy content of the drink $^{3}$ and physical activity of the subject ${ }^{4}$.

Scintigraphy is regarded as the "gold standard" for determining the gastric emptying of solids and liquids ${ }^{5.6}$. This technique, however, includes the risk of radiation exposure to the subject and sophisticated and expensive equipment is required for accurate data collection and analysis. The determination of gastric emptying during physical exercise on a bicycle is not possible using scintigraphy, as a gamma camera needs to be positioned in front of the stomach, and movements of the subject should be avoided.

During strenuous physical exercise, liquids are the major energy source consumed. Many athletes suffer from nausea and vomiting during exercise, probably caused by a gastrointestinal motility disturbance?. To study the pathophysiology of these disturbances a gastric emptying test for liquids during exercise is required. The double sampling aspiration technique described by George $^{8}$, and modified by Beckers ${ }^{9}$ is a validated method of determining the gastric emptying of liquids during physical exercise, and is regarded as the "reference" method for use under these conditions. This technique is based on the determination of dye concentration in the gastric samples obtained by aspiration through a nasogastric catheter, before and after the addition of a known amount of dye to the gastric content. Although this technique results in highly reproducible data ${ }^{9}$, it has the disadvantage of being an invasive procedure. A naso-gastric catheter during exercise is uncomfortable and the method requires experienced subjects and investigators in order to obtain adequate reproducibility.

Alternative methods of determining gastric emptying non-invasively comprise the paracetamol absorption test ${ }^{10}$, the sulfamethizole absorption test ${ }^{11}$, magnetic resonance imaging $(\mathrm{MRI})^{12}$, applied potential tomography $(\mathrm{APT})^{13}$, and ultrasound measurements ${ }^{14}$.

Recently, methods using stable non-radioactive isotope methods have been proposed. $\left[{ }^{13} \mathrm{C}\right]$-octanoic acid has been described as a useful label to determine the gastric emptying of solids ${ }^{15}$, and the same authors recently improved their mathematical model to calculate gastric half-emptying time $(\mathrm{T} 1 / 2\rangle$, and lagphase of solid gastric emptying ${ }^{16}$. However, a recent study by Choi et al. ${ }^{17}$ failed to show any relationship between the scintigraphic gastric half-emptying time and the half-emptying time calculated from the breath test. In an other recent study these investigators demonstrated that gastric emptying of solids can only be predicted accurately after $6 \mathrm{~h}$ collection of breath samples, instead of the usual $4 \mathrm{~h}$ of sampling ${ }^{18}$.

$\left[{ }^{13} \mathrm{C}\right]$-acetate has been described as a molecule to determine the gastric emptying rate of liquids under rest conditions ${ }^{19.20,21}$. This method has recently 
been used in soldiers during field exercise in the heat ${ }^{22}$.

The principle of the breath test is based upon the measurement of ${ }^{13} \mathrm{CO}_{2}$ breath enrichment after consumption of a ${ }^{13} \mathrm{C}$-labeled test meal. It has been observed that the ${ }^{13} \mathrm{C}$-labeled substrate is not absorbed in the stomach ${ }^{23}$; it is furthermore assumed that the substrate is rapidly absorbed in the intestine after gastric emptying, and that the delay between intestinal absorption, intracellular oxidation and appearance of ${ }^{13} \mathrm{CO}_{2}$ is small. A half-emptying time can then be calculated, assuming that the time needed for absorption and oxidation of the $\left[{ }^{13} \mathrm{C}\right]$-acetate is constant. If all these assumptions are valid then it is axiomatic that the time needed for the appearance of ${ }^{13} \mathrm{CO}_{2}$ in the breath would be directly proportional to the gastric emptying rate of the substrate. However, none of the studies published to date have validated these assumptions at rest, or during exercise.

As physical exercise decreases splanchnic blood flow ${ }^{7}$, it may influence intestinal absorption ${ }^{24}$. Exercise also increases the rate of substrate oxidation in general, and it increases the rate of turnover of ${ }^{13} \mathrm{CO}_{2}$ in the body bicarbonate pool, which leads to a delay in the appearance of ${ }^{13} \mathrm{CO}_{2}$ in the breath after substrate oxidation. It is to be expected therefore that the pattern of ${ }^{13} \mathrm{CO}_{2}$ appearance is different during exercise, compared with resting conditions, and that the T1/2 can not be calculated according to the formula of Braden et al. ${ }^{20}$. in which a constant time for absorption and metabolism was assumed. Moreover, a gastric emptying breath test that requires $4 \mathrm{~h}$ or even $6 \mathrm{~h}$ of breath sampling is not very useful for exercise studies, especially not during high intensity exercise.

Consequently, the aims of this study were: i) to monitor breath ${ }^{13} \mathrm{CO}_{2}$ appearance after intragastric administration of slow and fast emptying liquids, containing $\left[{ }^{13} \mathrm{C}\right]$-acetate, and to define a mathematical model for the breath enrichment curves; ii) to correlate the point of time of maximal breath enrichment obtained from the enrichment curves with the gastric half-emptying time measured by the double sampling aspiration technique; iii) to evaluate the relative time needed for intestinal absorption, transport and oxidation of $\left[{ }^{13} \mathrm{C}\right]$ acetate by measuring the appearance rate of ${ }^{13} \mathrm{CO}_{2}$ in the breath after intraduodenal and intravenous administration of the tracer; iv) to investigate the effect of exercise on intestinal absorption, transport and oxidation of $\left[{ }^{13} \mathrm{C}\right]$ acetate.

\section{Subjects and methods}

\section{Subjects}

Nine healthy well-trained male subjects participated (median 22.6 years, ranging from 18-25 years). Nine subjects were studied with intragastric (IG) administration and six out of the nine subjects with intraduodenal (ID) and intravenous (IV) delivery of $\left[1-{ }^{13} \mathrm{C}\right]$-acetate. None of the subjects had a history 
of chronic gastrointestinal disease. All subjects were familiar with gastric intubation and exercise testing. The maximal power output (Wmax) of each subject was assessed with a Wmax cycling test ${ }^{25}$.

The study was approved by the local Ethics Committee, and written informed consent was obtained from all subjects.

\section{Study design}

The subjects were asked to abstain from ${ }^{13} \mathrm{C}$-rich carbohydrate food during the test period, and the week prior to the tests. The subjects were not allowed to perform heavy physical training, or to consume alcoholic beverages or fiber-rich food the day before the test. All studies were performed after an overnight fast. Three sets of experiments were conducted:

1. The intragastric studies

2. The intraduodenal studies

3. The intravenous studies

\section{Intragastric administration of $\left[1-{ }^{13} \mathrm{C}\right]$-acetate}

The subjects were studied on 2 different occasions. The exercise protocol consisted of 10 min warming-up at $100 \mathrm{~W}$, followed by $1 \mathrm{~h}$ cycling on a cycle ergometer (Lode, Groningen, the Netherlands) at $60 \%$ Wmax. $500 \mathrm{ml}$ of a solution containing $4.5 \%$ or $9.0 \%$ (weight) carbohydrate $(\mathrm{CHO})$, respectively, with the addition of $150 \mathrm{mg}$ sodium $\left[1-{ }^{13} \mathrm{C}\right]$-acetate $(99 \%$; Cambridge Isotope Laboratories, Andover, MA, USA) and $7.5 \mathrm{mg}$ phenol red was introduced by a nasogastric catheter after the warming-up. The $4.5 \%$ and $9.0 \%$ solutions are known to empty at significantly different rates ${ }^{3}$. Gastric samples were collected at $10 \mathrm{~min}$ intervals for $1 \mathrm{~h}$. No corrections were made for $\left[{ }^{13} \mathrm{Cl}\right.$-acetate tracer loss. Breath samples were drawn from a mixing chamber into Vacutainer tubes at $5 \mathrm{~min}$ intervals during the initial $30 \mathrm{~min}$, and at $10 \mathrm{~min}$ intervals during the final $30 \mathrm{~min}$ of the test. Gastric emptying was determined using the double sampling aspiration technique and the $\left[{ }^{13} \mathrm{C}\right]$-acetate breath test simultaneously. The body- $\mathrm{CO}_{2}$ production was continuously monitored (SensorMedics 2900), and appeared to reach a constant value after the warming-up in each experiment.

\section{Assessment of gastric emptying using the double sampling technique}

A nasogastric catheter was placed and the stomach was emptied from any residue, subsequently rinsed with water and emptied again via the catheter. The correct position of the catheter was verified by administration of $100 \mathrm{ml}$ water and subsequent aspiration of at least $80 \mathrm{ml}$ water. The test solutions were at room temperature and administered within $1.5 \mathrm{~min}$ via the nasogastric catheter. The various tests were separated by at least $48 \mathrm{~h}$ to prevent carryover of ${ }^{13} \mathrm{C}$ label. Gastric samples $(2 \mathrm{ml})$ were taken by aspiration at 10 min intervals for 1 
h. Determination of total gastric volume and gastric emptying was performed using the modified double sampling technique of George ${ }^{9}$. From the phenol red concentrations in the gastric aspirates a gastric emptying curve was fitted by non-linear regression analysis (Prism, GraphPad Software Inc. San Diego) according to the formula:

a: if $t=0$, then $y=100 \%$

$y(t)=a e^{(\cdot \cdot b)}$

Where $a$ is the percentage of administered solution, present in the stomach, $t$ is the time, $b$ is a constant. From this curve, the gastric half-emptying time (T1/2 GE) was interpreted ${ }^{9}$.

\section{Intraduodenal administration of $\left[1-{ }^{13} \mathrm{Cl}\right.$-acetate}

The subjects were studied on 2 different occasions: during $1 \mathrm{~h}$ cycling at $60 \%$ Wmax and during $1 \mathrm{~h}$ rest, respectively. A charriere 12 Bengmark-type nasointestinal catheter (Flocare, The Netherlands) was placed in the duodenum. The correct position of the catheter was confirmed using fluoroscopy. In the exercise test the subjects received $50 \mathrm{ml}$ of an iso-osmolar solution containing $150 \mathrm{mg}$ of sodium $\left[1-{ }^{13} \mathrm{C}\right]$-acetate in $50 \mathrm{ml} 0.9 \% \mathrm{NaCl}$ via the catheter at the end of the warming-up period. At rest the subjects received the same solution at $\mathrm{t}=0$. The solutions were administered in exactly $1 \mathrm{~min}$. Breath samples were collected at $2 \mathrm{~min}$ intervals during the initial $15 \mathrm{~min}$, at $5 \mathrm{~min}$ intervals during the subsequent $15 \mathrm{~min}$, and at $10 \mathrm{~min}$ intervals during the final $30 \mathrm{~min}$ of the test. The appearance rate of ${ }^{13} \mathrm{CO}_{2}$ in the breath was determined, and compared with the results obtained after intragastric and intravenous administration.

\section{Intravenous administration of $\left[1-{ }^{13} \mathrm{C}\right]$-acetate}

The subjects were studied on 2 different occasions: during $1 \mathrm{~h}$ cycling at $60 \%$ Wmax and during $1 \mathrm{~h}$ at rest, respectively. A Teflon catheter was placed in an antecubital vein. During exercise the subject received an intravenous bolus with a dosage of $150 \mathrm{mg}$ sodium $\left[1-{ }^{13} \mathrm{C}\right]$-acetate dissolved in $2 \mathrm{ml} 0.9 \% \mathrm{NaCl}$. During the rest test the subjects received the same intravenous bolus at $t=0$. Breath samples were collected at 2 min intervals during the initial $15 \mathrm{~min}$, at 5 min intervals during the subsequent $15 \mathrm{~min}$ and at $10 \mathrm{~min}$ intervals during the final $30 \mathrm{~min}$ of the test. The appearance rate of ${ }^{13} \mathrm{CO}_{2}$ in the breath was determined, and compared with results obtained after intragastric and intraduodenal administration. 


\section{Breath sample analysis}

During all tests the breath samples for the determination of background enrichment were collected in Vacutainer tubes before any test solution was administered. In the case of an exercise test this was done during the warmingup period, prior to the administration of the test solutions. In the case of a test at rest, collection took place prior to the administration of the test solutions.

\section{Assessment and Mathematica/ Evaluation of ${ }^{13} \mathrm{C}$-enrichment}

The collected breath samples were analyzed for ${ }^{13} \mathrm{C}$-isotopic enrichment of the expired $\mathrm{CO}_{2}$ using Isotope Ratio Mass Spectrometry (Finnigan MAT 252, USA). The ${ }^{13} \mathrm{C}$-enrichment of $\mathrm{CO}_{2}$ was expressed as the delta $(\delta)$ per mil difference between the ${ }^{13} \mathrm{C} /{ }^{12} \mathrm{C}$-ratio of the breath sample and a known laboratory reference standard according to the formula:

$\delta^{13} \mathrm{C}($ per mil $)=\left(\left({ }^{13} \mathrm{C} /{ }^{12} \mathrm{C}\right)\right.$ sample $/\left({ }^{13} \mathrm{C} /{ }^{12} \mathrm{C}\right)$ standard -1$) \times 10^{3}$

The $\delta$-value was then related to an international standard, Pee Dee Belemnite (PDB).

The data from the breath enrichment were fitted by non-linear regression analysis according to a single exponential and a dual exponential function, respectively.

The single exponential function is the only function described in the literature so far, and has the following features ${ }^{15}$ :

$y(t)=a t^{b}\left(e^{-c t}\right)$

The first factor $\left(a t^{b}\right)$ describes the increase of ${ }^{13} \mathrm{CO}_{2}$ in the breath; the second factor $\left(e^{-c t}\right)$ describes the washout of the ${ }^{13} \mathrm{CO}_{2}$ from the breath. $a, b$ and $c$ are constants, and $t$ is the time.

In order to improve the goodness of fit, a dual exponential function was developed. This function has the following features:

$y(t)=a t^{b}\left[c e^{i-t d)}\right]+f t^{g}\left[h e^{(-t i)}\right]+j$

A dual compartment description of ${ }^{13} \mathrm{CO}_{2}$-production (at ${ }^{\mathrm{b}}$ and $\mathrm{ft}^{\mathrm{g}}$ ) is applied because acetate is oxidized both in the splanchnic area and in the working muscles. The decrease in ${ }^{13} \mathrm{CO}_{2}$-enrichment is also described in 2 factors; the 1st factor (ce ${ }^{1-\text { td })}$ describes washout of ${ }^{13} \mathrm{CO}_{2}$ through the body bicarbonate pool via the breath, and the 2nd factor (he $\left.e^{(-t)}\right)$ describes other processes of ${ }^{13} \mathrm{CO}_{2}$ - 
removal; sequestration of ${ }^{13} \mathrm{CO}_{2}$ in bone, excretion via urine and incorporation into glucose $e^{24}$. In this equation $a, b, c, d, f, g, h$ and $i$ are constants, $t$ is the time and $j$ is the background enrichment.

In the present study the results are based on the Time to Peak ${ }^{13} \mathrm{C}$-enrichment in the breath samples $\left({ }^{13} \mathrm{C}\right.$-TTP) derived from the dual exponential function. The ${ }^{13} \mathrm{C}$-TTP was interpreted from the curve using the GraphPad software, and was considered as the parameter of gastric emptying.

\section{Statistics}

All data are presented as median (range). The $R^{2}$ (Goodness of Fit) for both curve fitting functions of the ${ }^{13} \mathrm{CO}_{2}$-enrichment was determined, and compared using a paired t-test. The T1/2 GE from the double sampling technique was compared with the ${ }^{13} \mathrm{C}$-TTP from the gastric emptying breath test using Pearson correlation coefficient. Differences in both T1/2 GE and ${ }^{13} \mathrm{C}$-TTP for the $4.5 \%$ and $9 \%$ carbohydrate solutions were determined using an ANOVA.

Differences in ${ }^{13} \mathrm{C}$-TTP between rest and exercise were analyzed using Wilcoxon's Signed Rank test for the intraduodenal and intravenous experiments separately.

\section{Results}

\section{Intragastric studies}

The results of the intragastric experiments are displayed in Table 3.1.

Table $3.1{ }^{13} \mathrm{C}$-TTP (median min (range)) after intragastric (IG, $n=9$ ), intraduodenal $(I D, n=6$ ) and intravenous administration (IV, $n=6$ ) of $150 \mathrm{mg}\left[{ }^{13} \mathrm{C}\right]$-acetate, and the $\mathrm{T} 1 / 2$ $\mathrm{GE}$ (median min (range)) derived from the double sampling technique.

\begin{tabular}{lrlll}
\hline Test & \multicolumn{2}{l}{${ }^{13} \mathrm{C}$-TTP } & \multicolumn{1}{c}{ T1/2 GE } \\
\hline IVrest & 11.5 & $(9.8-16.5)$ & & \\
IVexc & 5.4 & $(5.0-6.0)$ & & \\
IDrest & 18.1 & $(15.2-22.2)$ & & \\
IDexc & 10.3 & $(9.5-12.8)$ & & \\
IG4.5\% & 16.8 & $(11.0-30.5)$ & 13.4 & $(6.2-28.2)$ \\
IG9.0\% & 23.3 & $(11.4-32.5)$ & 22.3 & $(9.8-36.9)$ \\
\hline
\end{tabular}

A significant linear correlation $(P<0.05)$ was found between the ${ }^{13} \mathrm{C}-\mathrm{TTP}$ and the $\mathrm{T} 1 / 2 \mathrm{GE}$, and is displayed in Figure 3.1. 


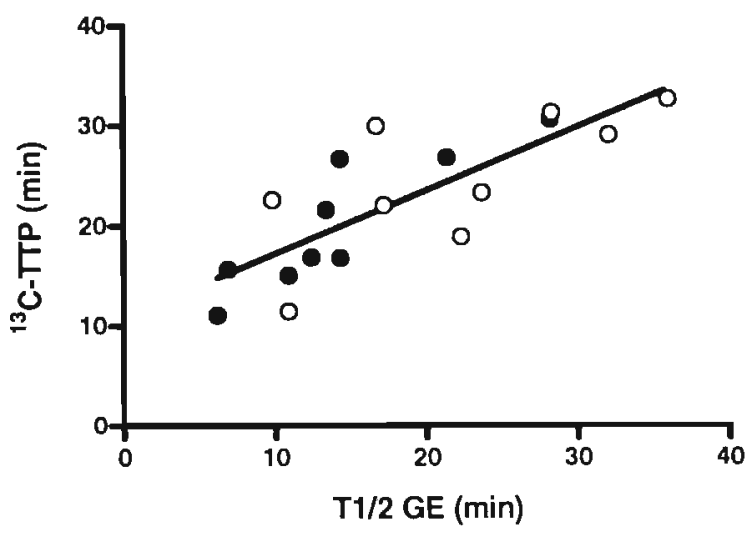

Figure 3.1 Correlation between the T1/2 GE and the ${ }^{13} \mathrm{C}$-TTP for the $4.5 \%$ (closed symbols) and $9 \%$ (open symbols) $\mathrm{CHO}$ solution during exercise $(n=9, r=0.82, \mathrm{P}<0.05)$.

Both the double sampling technique and the breath test indicated that the $9.0 \%$ solutions emptied significantly more slowly than the $4.5 \%$ solutions ( $P<0.05$ ). It was observed that the dual exponential function fitted the curves significantly better than the single exponential function for both solutions $(P<0.05)$, as shown in Table 3.2.

Table 3.2 Differences $(P<0.05)$ in $R^{2}$ values (goodness of fit) from breath enrichment data between a single and a dual exponential curve fit function.

\begin{tabular}{lllll}
\hline & \multicolumn{2}{l}{ Exercise, 9.0\% CHO } & \multicolumn{2}{l}{ Exercise, 4.5\% CHO } \\
Subject No. & Dual exponent fit & Single exponent fit & Dual exponent fit & Single exponent fit \\
\hline 1 & 0.996834 & 0.947098 & 0.993982 & 0.940611 \\
2 & 0.998384 & 0.969382 & 0.992959 & 0.985549 \\
3 & 0.994620 & 0.960550 & 0.997928 & 0.913609 \\
4 & 0.991078 & 0.985855 & 0.995458 & 0.973104 \\
5 & 0.986244 & 0.861923 & 0.973395 & 0.973347 \\
6 & 0.997188 & 0.992191 & 0.999398 & 0.979549 \\
7 & 0.987741 & 0.953655 & 0.993488 & 0.992561 \\
8 & 0.993913 & 0.980554 & 0.998624 & 0.979915 \\
9 & 0.995177 & 0.966514 & 0.998925 & 0.976183 \\
Mean & 0.993762 & 0.968270 & 0.993464 & 0.957525 \\
\hline
\end{tabular}

\section{Intraduodenal and intravenous studies}

Results of the intraduodenal and intravenous experiments are displayed in Table 3.1. During exercise the ${ }^{13} \mathrm{C}$-TTP was reached significantly earlier than at rest 
after ID and IV administration ( $P<0.05)$. Mean breath enrichment curves are displayed in Figure 3.2 (IV) and Figure 3.3 (ID).

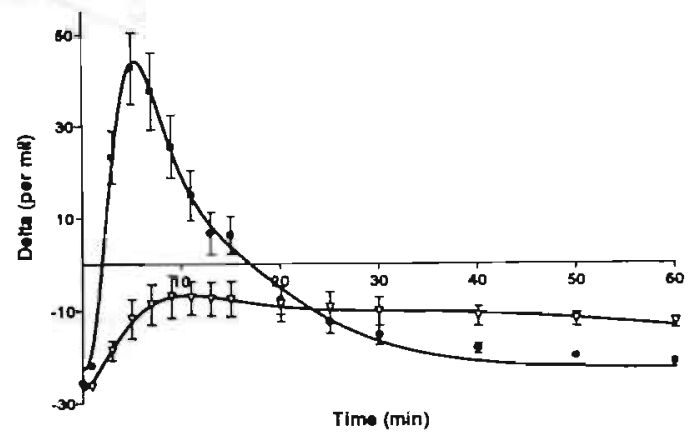

Figure $3.2{ }^{13} \mathrm{CO}_{2}$-breath enrichment curves (mean $\pm s d, n=6$ ) after intravenous administration of $150 \mathrm{mg}\left[{ }^{13} \mathrm{Cl}\right.$-acetate at rest $(\nabla)$, and during exercise

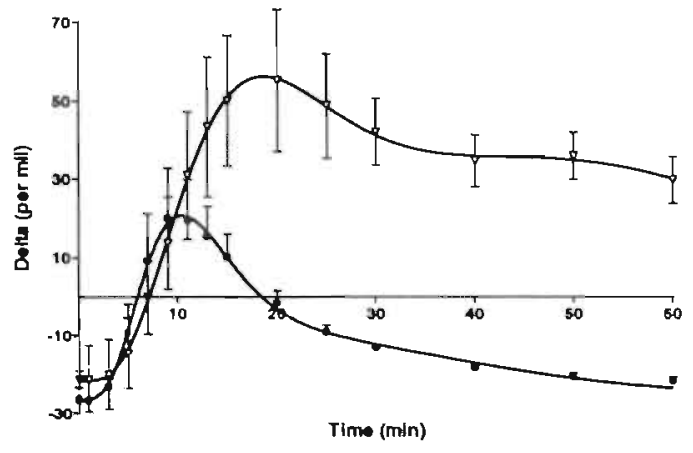

Figure 3.3 ${ }^{13} \mathrm{CO}_{2}$-breath enrichment curves (mean $\pm \mathrm{sd}, \mathrm{n}=6$ ) after intraduodenal administration of $150 \mathrm{mg}\left[{ }^{13} \mathrm{C}\right]$-acetate at rest $(\nabla)$, and during exercise $(\bullet)$.

Comparison of the various routes of $\left[{ }^{13} \mathrm{Cl}\right.$-acetate administration

During exercise, it took the shortest time to reach the ${ }^{13} \mathrm{C}$-TTP after intravenous administration, it took a longer time to reach the ${ }^{13} \mathrm{C}$ - TTP after intraduodenal administration, and it took the longest time to reach the ${ }^{13} \mathrm{C}$-TTP after intragastric administration. Breath enrichment curves of one subject after intragastric, intraduodenal and intravenous administration respectively are displayed in Figure 3.4. 


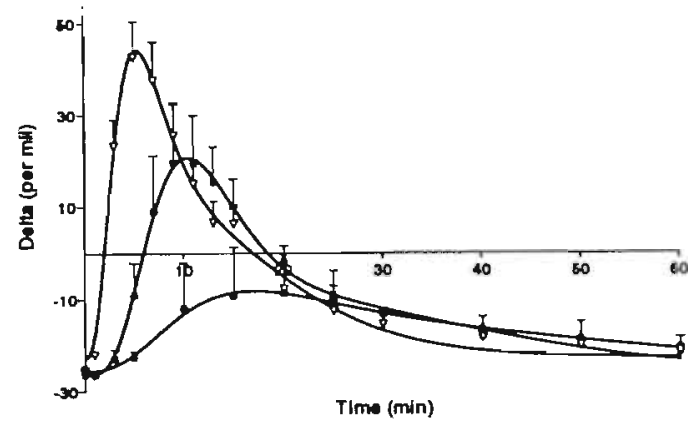

Figure $3.4{ }^{13} \mathrm{CO}_{2}$-breath enrichment curves (mean $\pm s d$ ), after intragastric $(\bullet, \mid G, n=9)$, using the $4.5 \% \mathrm{CHO}$ solution, intraduodenal ( $* \mathrm{ID}, \mathrm{n}=6)$ and intravenous $(\nabla, \mathrm{IV}, \mathrm{n}=6)$ administration of $150 \mathrm{mg}\left[{ }^{13} \mathrm{C}\right]$-acetate during exercise.

\section{Discussion}

The purpose of the present study was to investigate whether the non-invasive $\left[{ }^{13} \mathrm{C}\right]$-acetate breath test can be used for determining the relative rates of gastric emptying of liquids during physical exercise. Comparisons were made with the T1/2 GE obtained from the double sampling technique. Using the latter technique it has been shown that solutions with a high energy density empty more slowly than solutions with a low energy density ${ }^{26}$. It has also been shown that training status does not affect the gastric emptying of liquids ${ }^{27}$, neither does the osmolarity of a solution in the range of $243-374 \mathrm{mOsm} / \mathrm{kg}^{3}$. The major disadvantage of the double sampling technique is its invasive character, which may cause discomfort for the subjects, and may disturb normal gastrointestinal physiology.

Recently, non-invasive stable isotope breath tests have been developed to measure the gastric emptying rate of solids using $\left[{ }^{13} \mathrm{C}\right]$-octanoic acid as the label ${ }^{10}$, and liquids using $\left[1-{ }^{13} \mathrm{C}\right]$-acetate as the label ${ }^{19 \cdot 21}$. Good correlations were found between the results obtained using scintigraphy and the ${ }^{13} \mathrm{C}$-breath test. In these studies not only the Time to Peak enrichment of the breath was used as a parameter for gastric emptying, but also a half-emptying time, mathematically derived from a ${ }^{13} \mathrm{CO}_{2}$-recovery percentage per minute curve. This curve displays the cumulative breath enrichment for $4 \mathrm{~h}$ after ingestion of a test meal. Because of the fact that most of the gastric emptying takes place within $30 \mathrm{~min}$, it is clear that only the first part of this cumulative curve is associated 
with gastric emptying, and that the remainder of the curve mainly reflects the result of absorption and metabolism of the $\left[{ }^{13} \mathrm{C}\right]$-acetate and the release 0 : ${ }^{13} \mathrm{CO}_{2}$ from the body bicarbonate pool. The conventional calculation of the $\mathrm{T} 1 / 2$; however, assumes that both the absorption and the oxidation of the label after gastric emptying are constant and rapid processes. The gastric emptying studies of solids and liquids using $\left[{ }^{13} \mathrm{C}\right]$-octanoic acid and $\left[{ }^{13} \mathrm{C}\right]$-acetate, respectively, showed that the calculated $\mathrm{T} 1 / 2$ of the ${ }^{13} \mathrm{C}$-breath tests was substantially longer than the scintigraphic $T 1 / 2^{15,20}$. This observation suggests that the calculated $\mathrm{T} 1 / 2$ is not a result of gastric emptying only, but that it is also strongly affected by the time needed for absorption and oxidation of the $\left[{ }^{13} \mathrm{C}\right]$-acetate, and the subsequent exhalation of ${ }^{13} \mathrm{CO}_{2}$. We propose the ${ }^{13} \mathrm{C}$-TTP as an attractive alternative to the calculated $\mathrm{T} 1 / 2$, because less assumptions are made, $1 \mathrm{~h}$ of breath sampling is sufficient, which is especially important for exercise studies, and IG, ID and IV data can easily be compared, both at rest and during exercise. In this study the subjects exercised for $1 \mathrm{~h}$, and breath samples are collected for $1 \mathrm{~h}$. Sampling for more than $1 \mathrm{~h}$ would result in breath samples, originating from 2 metabolic conditions; exercise and rest. Hence a calculation according to Braden et al. ${ }^{20}$ could not be carried out. However, our study showed that the $\left[{ }^{3} \mathrm{C}\right]$-acetate breath test can be used to estimate relative rates of gastric emptying of liquids during exercise, using the ${ }^{13} \mathrm{C}$-TTP as the parameter for gastric emptying. Good correlations were observed between T1/2 GE and the ${ }^{13} \mathrm{C}$ - TTP for the 2 different liquids. The present study also showed that the dual exponential curve fit yielded better goodness of fit compared with the single exponential curve fit, which was used in previous studies under resting conditions ${ }^{15,20}$. An optimal curve fit is important, especially if the ${ }^{13} \mathrm{C}$-TTP is used as the parameter for gastric emptying.

During exercise it is likely that the absorption rate of $\left[{ }^{13} \mathrm{C}\right]$-acetate is altered, due to a changed splanchnic blood flow, and the oxidation rate is increased, due to an increased rate of metabolism in the liver and/or working muscles. The delay in appearance of ${ }^{13} \mathrm{CO}_{2}$ in breath due to the entrapment in the body bicarbonate pool is reduced during exercise ${ }^{28}$. For this reason the time needed for intraduodenal absorption and oxidation of $\left[{ }^{13} \mathrm{C}\right]$-acetate, and the subsequent appearance of ${ }^{13} \mathrm{CO}_{2}$-enrichment in the breath was investigated. The ${ }^{13} \mathrm{C}$-TTP after intraduodenal administration of $150 \mathrm{mg}\left[{ }^{13} \mathrm{C}\right]$-acetate was reached significantly earlier during exercise than at rest, probably due to the increased metabolic rate. The time needed for transport of absorbed $\left[{ }^{13} \mathrm{C}\right]$-acetate to the site of oxidation and the subsequent appearance of ${ }^{13} \mathrm{CO}_{2}$ in the breath was estimated by intravenous administration. Theoretically, intraportal administration would have reflected more accurately the metabolic route of acetate after intraduodenal absorption, but this was not ethically feasible in our study subjects. After intravenous administration, ${ }^{13} \mathrm{C}$-TTP was reached in an average of 7 min earlier during exercise than at rest.

The results of our study provide evidence that exercise changes the post-gastric emptying metabolism of $\left[{ }^{13} \mathrm{C}\right]$-acetate, as demonstrated by intraduodenal or 
intravenous administration of $\left[{ }^{13} \mathrm{C}\right]$-acetate. This implies that a conventionally calculated T1/2 from the breath test can not be used. Although a T1/2 is a widely used parameter of gastric emptying, it seems not to serve as a useful parameter under conditions of physical exercise. We propose the ${ }^{13} \mathrm{C}$-TTP as the alternative.

The present study proves that the time needed for intestinal absorption and metabolism of the label had a substantial influence on the time of appearance of the ${ }^{13} \mathrm{C}$-TTP in the breath after gastric emptying. Hence, if the $\left[{ }^{13} \mathrm{C}\right]$-acetate breath test is used in conditions where the time needed for absorption and/or oxidation of the tracer is altered due to (patholphysiologic changes, or the use of drugs, a separate validation is necessary. We validated the $\left[{ }^{13} \mathrm{C}\right]$-acetate breath test versus the double sampling technique during exercise, and observed a good correlation between the ${ }^{13} \mathrm{C}-\mathrm{TTP}$ and the T1/2 GE. Therefore it may be concluded that the $\left[{ }^{13} \mathrm{C}\right]$-acetate breath test is a valid technique to determine relative differences in the gastric emptying rate of liquids during physical exercise. A short period of $1 \mathrm{~h}$ of breath sampling with 5 min interval is sufficient, using the ${ }^{13} \mathrm{C}$-TTP as the parameter of gastric emptying. 


\section{References}

1. Mitchell JB, Voss $\mathrm{KW}$. The influence of volume on gastric emptying and fluid balance during prolonged exercise. Med Sci Sports Exerc 1991; 23: 314-319.

2. Fone DR, Horowitz $M$, Maddox A, Akkermans LM, Read NW, Dent J. Gastroduodenal motility during the delayed gastric emptying induced by cold stress. Gastroenterology 1990; 98: 1155-1161.

3. Brouns F, Senden J, Beckers EJ, Saris WHM. Osmolarity does not affect the gastric emptying rate of oral rehydration solutions. J Parent Enter Nutr 1995; 19: 403-406.

4. Marzio L, Formica P, Fabiani F, LaPenna D, Vecchiett L, Cuccurullo F. Influence of physical activity on gastric emptying of liquids in normal human subjects. Am $J$ Gastroenterol 1991; 86(10): 1433-1436.

5. Collins PJ, Horowitz M, Cook DJ, Harding PE, Shearman DJC. Gastric emptying in normal subjects - a reproducible technique using a single scintillation camera and computer system. Gut 1983; 24: $1117-1125$.

6. Jonderko $\mathrm{K}$. Short- and long- term reproducibility of radioisotopic examination of gastric emptying. Nucl Med Biol 1990; 17(3): 297-301.

7. Brouns F. Etiology of gastrointestinal disturbances during endurance events. Scand J Med Sci Sports 1991; 1: 66-77.

8. George JD. New clinical method for measuring the rate of gastric emptying: the double sampling test meal. Gut 1968; 9: 237-242.

9. Beckers EJ, Rehrer NJ, Brouns F, Ten Hoor F, Saris WHM. Determination of total gastric volume, gastric secretion and residual meal using the double sampling technique of George. Gut 1988; 29: 1725-1729.

10. Heading RC, Nimmo J, Prescott LF, Tothill P. The dependence of paracetamol absorption on the rate of gastric emptying. Br J Pharmacol 1973; 47: 415-421.

11. Hirakawa $K$, lida $M$, Fuchigami $T$, Murata $S$, Matsumoto $T$, Fujishama $M$. Sulfamethizole absorption test for the assessment of gastric emptying. Scand $J$ Gastroenterol 1995; 30: 133-138.

12. Schwizer W, Fraser R. Borovická J. Crelier G, Boesiger P, Fried M. Measurement of gastric emptying and gastric motility by magnetic resonance imaging (MRI). Dig Dis Sci December 1994 Suppl; 39(12): 101S-103S.

13. Nour S, Mangnall YF, Dickson JAS, Johnson AG, Pearse RG. Applied potential tomography in the measurement of gastric emptying in infants. $J$ Pediatr Gastroenterol Nutr 1995; 20: 65.72.

14. Holt S, Cervantes J, Wilkinson AA, Wallace JHK. Measurement of gastric emptying rate in humans by real-time ultrasound. Gastroenterology 1986; 90: 918-923.

15. Ghoos YF, Maes BD, Geypens BJ, Mys G, Hiele MI, Rutgeerts PJ, VanTrappen G. Measurement of gastric emptying rate of solids by means of a carbon-labeled octanoic acid breath test. Gastroenterology 1993; 104: 1640-1647.

16. Maes BD, Mys G, Geypens BJ Evenepoel P, Ghoos YF, Rutgeerts PJ. Gastric emptying flow curves separated from carbon-labeled octanoic acid breath test results. Am J Physiol 1998; 275: G169-G175.

17. Choi M-G, Camilleri M, Burton DD, Zinsmeister AR, Forstrom LA, Spreekumaran Nair K. Gastroenterology 1997; 112: 1155-1162.

18. Choi M-G, Camilleri M, Burton DD, Zinsmeister AR, Forstrom LA, Spreekumaran Nair K. Am J Gastroenterol 1998; 93: 92-98. 
19. Leese GP, Bowtell J, Mudambo S, Reynolds M, Thompson J, Scrimgeour CM, Rennie MJ. Post-exercise gastric emptying of carbohydrate solutions determined using the ${ }^{13} \mathrm{C}$-acetate breath test. Eur J Appl Physiol 1995; 71: 306-310.

20. Braden B, Adams S, Duan L-P, Orth K-H, Maul F-D, Lembcke B, Hör G, Caspary WF. The $\left[{ }^{13} \mathrm{Cl}\right.$-acetate breath test accurately reflects gastric ennptying of liquids in both liquid and semisolid test meals. Gastroenterology 1995; 108: 1048-1055.

21. Mossi S, Meyer-Wyss B, Beglinger C, Schwizer W, Fried M, Ajami A, Brignoli R. Gastric emptying of liquid meals measured noninvasively in humans with $\mathrm{I}^{13} \mathrm{Cl}$ acetate breath test. Dig Dis Sci December 1994 Suppl; 39(12): 107S-109S.

22. Mudambo KSMT, Leese GP, Rennie, MJ. Gastric emptying in soldiers during and after field exercise in the heat measured with the $\left[{ }^{13} \mathrm{C}\right]$-acetate breath test. Eur $\mathrm{J}$ Appl Physiol 1997; 75: 109-114.

23. Meyer-Wyss B, Mossi S, Beglinger C, Schwizer W, Fried M, Ajami A. Gastric emptying measured non-invasively in humans with a ${ }^{13} \mathrm{C}$-acetate breath test (Abstr). Gastroenterology 1991; 100: A469.

24. Maughan RJ, Leiper JB, McGaw A. Effects of exercise intensity on absorption of ingested fluids in man. Exp Physiol 1990; 75: 419-421.

25. Kuipers $H$, Verstappen FTJ, Keizer HA, Geurten P, Van Kranenburg G. Variability of aerobic performance in the laboratory and its physiologic correlates. Int $J$ Sports Med 1985; 6: 197-201.

26. Beckers EJ, Leiper JB, Davidson J. Comparison of aspiration and scintigraphic techniques for the measurement of gastric emptying rates of liquids in humans. Gut 1992; 33: 115-117.

27. Rehrer NJ, Beckers E, Brouns F, Ten Hoor F, Saris WHM. Exercise and training effects on gastric emptying of carbohydrate beverages. Med Sci Sports Exerc 1989; $21(5)$ : 540-549.

28. Wolfe RR. Radioactive and stable isotope tracers in biomedicine. John Wiley \& Sons, New York, 1992. 


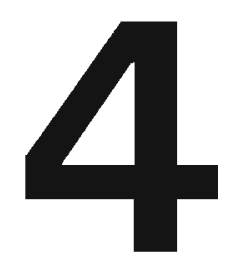

\section{The sensitivity of the lactulose/rhamnose gut permeability test}

MA van Nieuwenhoven, BJ Geerling, NEP Deutz, F Brouns, R-JM Brummer

European Journal of Clinical Investigation 1999; 29: 160-165. 


\section{Abstract}

\section{Introduction}

The lactulose/rhamnose intestinal permeability test is widely used. However, different quantities and proportions of lactulose and rhamnose are used.

The aim was to determine whether a low dosage of lactulose is able to discriminate between normal and increased permeability.

\section{Methods}

Two groups of 10 healthy subjects were studied. Group 1: 3 different iso-osmolar test solutions on 3 days were administered. The solutions consisted of $10 \mathrm{~g}$ lactulose with $1 \mathrm{~g}$ rhamnose, $5 \mathrm{~g}$ lactulose with $0.5 \mathrm{~g}$ rhamnose and $1 \mathrm{~g}$ lactulose with $0.1 \mathrm{~g}$ rhamnose in $65 \mathrm{ml}$ water. Group 2 ingested these solutions $1 \mathrm{~h}$ after ingestion of 750 $\mathrm{mg}$ chenodeoxycholeic acid (CDCA), which is known to increase permeability. Urinary lactulose/rhamnose ratio was determined using HPLC. Data are presented as median (range).

\section{Results}

Group 1: No differences were observed between the 3 solutions. Group 2: There was a significant difference $(P=0.045)$ between the 3 solutions. The lactulose/rhamnose ratio's were $0.0079(0.0024-0.0152)(1 \mathrm{~g}$ lactulose- $0.1 \mathrm{~g}$ rhamnose), $0.0138(0.0066$ $0.0192)(5 \mathrm{~g}$ lactulose- $0.5 \mathrm{~g}$ rhamnose) and $0.0144(0.0074-0.0374)(10 \mathrm{~g}$ lactulose-1 $\mathrm{g}$ rhamnose), respectively. The lactulose/rhamnose-ratio between Group 1 and 2 differed significantly $(\mathrm{P}<0.001)$ using the $5 \mathrm{~g}$ lactulose-0.5 $\mathrm{g}$ rhamnose and $10 \mathrm{~g}$ lactulose $1 \mathrm{~g}$ rhamnose solutions, respectively.

\section{Conclusion}

If the permeability is increased, the urinary lactulose/rhamnose ratio depends on the quantity of lactulose and rhamnose administered in equal proportion. Five $\mathrm{g}$ lactulose with $0.5 \mathrm{~g}$ rhamnose is sufficient to discriminate between a normal and a moderate increased permeability. 


\section{Introduction}

The intestinal permeability can be evaluated by measuring urinary excretion of orally administered water soluble, non-degradable test molecules. This barrier function test is based on the comparison of intestinal permeation of a larger molecule with that of a smaller molecule by measuring the ratio of urinary excretion of these molecules. These two molecules follow different routes of intestinal permeation; the larger molecules are assumed to permeate paracellular, the smaller molecules are assumed to permeate transcellular. Preabsorption factors such as gastric emptying, dilution by secretion and intestinal transit time, and postabsorption factors such as systemic distribution and renal clearance are assumed to equally affect both molecules. Therefore the urinary excretion ratio is considered to be a parameter for intestinal permeability per $\mathrm{se}^{\mathrm{r} \cdot 3}$.

Knowledge about the intestinal barrier function has implications for the etiology and the pathogenesis of various intestinal and systemic disorders, such as celiac disease $e^{4 \cdot 6}$, inflammatory bowel disease ${ }^{7 \cdot 10}$, immunodeficiency syndromes ${ }^{11-13}$, ankylosing spondylitis ${ }^{14}$, cystic fibrosis ${ }^{15.16}$, iron deficiency $y^{17}$, atopic eczema ${ }^{18.19}$, cardiopulmonary bypass ${ }^{20-22}$, kwashiorkor ${ }^{23,24}$, ileostomy $y^{25}$, viral hepatitis ${ }^{26}$, viral gastro-enteritis ${ }^{27}$, diabetes mellitus ${ }^{28}$, and food allergy ${ }^{29}$.

Some drugs such as non-steroid anti-inflammatory drugs (NSAIDs) ${ }^{30-32}$, cytostatics $^{33.34}$, and choleretics ${ }^{35}$ have been reported to increase intestinal permeability. Other factors that can increase intestinal permeability comprise alcohol abuse ${ }^{36}$, enteral feeding ${ }^{37.38}$, prolonged parenteral nutrition ${ }^{39}$ and strenuous exercise ${ }^{40.43}$.

Several molecules for the determination of intestinal permeability have been described. The larger molecules are usually disaccharides, such as lactulose or cellobiose. Other molecules such as ${ }^{51} \mathrm{Cr}$ - EDTA, ${ }^{94 \mathrm{rr}} \mathrm{TC}-\mathrm{DPTA}$, polyethylene glycols (PEG) and Dextran have also been used. The smaller molecules are usually the monosaccharides rhamnose or mannitol ${ }^{1-3}$.

A comprehensive search through Medline up till 1997 revealed more than 1200 publications in which intestinal permeability was studied. In more than 280 human studies mannitol was used as the smaller molecule. However, if the search was restricted to studies in which human intestinal permeability was determined using lactulose and rhamnose as the test molecules, more than 60 publications were retrieved. After a detailed examination of these publications it was found that lactulose and rhamnose were used in various dosages. The most common used combination of lactulose and rhamnose was $5 \mathrm{~g}$ lactulose with 1 $g$ rhamnose $e^{4,7.8,12-15.20 \cdot 23.25,26.33,37.38,44-55}$. Other regimens were $5 \mathrm{~g}$ lactulose with $0.75 \mathrm{~g}$ rhamnose $\mathrm{r}^{18.56}, 5 \mathrm{~g}$ lactulose with $0.5 \mathrm{~g}$ rhamnose ${ }^{11}, 2.3 \mathrm{~g}$ lactulose with $0.5 \mathrm{~g}$ rhamnose $\mathrm{e}^{5.6}, 3.5 \mathrm{~g}$ lactulose with $0.5 \mathrm{~g}$ rhamnose $\mathrm{e}^{17.27 .57}, 7.5 \mathrm{~g}$ lactulose with $1 \mathrm{~g}$ rhamnose ${ }^{9}, 5 \mathrm{~g}$ lactulose with $5 \mathrm{~g}$ rhamnose ${ }^{5,8}, 11.25 \mathrm{~g}$ lactulose with $1 \mathrm{~g}$ rhamnose ${ }^{10}, 0.1 \mathrm{~g} / \mathrm{kg}$ body weight lactulose with $0.02 \mathrm{~g} / \mathrm{kg}$ body weight 
rhamnose ${ }^{19}, 6.7 \mathrm{~g}$ lactulose with $1 \mathrm{~g}$ rhamnose $\mathrm{s}^{59}, 13.7 \mathrm{mmol}$ lactulose with 6.1 mmol rhamnose ${ }^{60}, 10 \mathrm{~g}$ lactulose with $5 \mathrm{~g}$ rhamnose ${ }^{35}, 10 \mathrm{~g}$ lactulose with $1 \mathrm{~g}$ rhamnose $^{61}, 7 \mathrm{~g}$ lactulose with $1 \mathrm{~g}$ rhamnose ${ }^{27}$ and $5.3 \mathrm{~g}$ lactulose with $0.75 \mathrm{~g}$ rhamnose ${ }^{16}$. The reason for these differences may be lying in the local availability of analysis techniques.

The question arises whether the quantity of lactulose and rhamnose affects the sensitivity of the lactulose/rhamnose permeability test for determination of a condition in which the intestinal permeability is increased; in other words: it is unknown whether the administered dosage of lactulose/rhamnose influences the outcome of this test under conditions of an increased intestinal permeability. Therefore the aim of the present study was to investigate which dosage of lactulose and rhamnose is optimal for determination of an increased permeability. Therefore we compared the urinary lactulose/rhamnose ratio after administration of 3 different dosages of lactulose/rhamnose in a constant proportion to each other under normal conditions, and under conditions of an increased permeability, which was artificially induced by administration of 750 $\mathrm{mg}$ of a choleretic compound, chenodeoxycholic acid (chenodiol) ${ }^{35}$.

\section{Subjects and methods}

Two groups of 10 healthy, non-smoking subjects (5 males and 5 females) were studied (age 18-36 years). The study was approved by the Medical Ethical Committee of the University Hospital. All subjects gave their written informed consent to participate in the study.

Group 1 (Control): Three different test solutions were randomly administered on 3 different testing days. All tests were separated by a washout period from at least $72 \mathrm{~h}$, and were performed in the morning after an overnight fast. The test solutions consisted of $1 \mathrm{~g}$ lactulose (Centrafarm syrup, $670 \mathrm{mg} / \mathrm{ml}$, Etten-Leur) with $0.1 \mathrm{~g}$ L-rhamnose (Sigma Chemical Co., USA) (solution A), $5 \mathrm{~g}$ lactulose with $0.5 \mathrm{~g}$ rhamnose (solution $\mathrm{B}$ ) and $10 \mathrm{~g}$ lactulose with $1 \mathrm{~g}$ rhamnose (solution $\mathrm{C}$ ) dissolved in $65 \mathrm{ml}$ water. The test solutions were made iso-osmolar using sucrose (Sigma Chemical Co., USA).

Group 2 (chenodiol): In order to evaluate the effect of chenodiol on the lactulose/rhamnose ratio, solution B was administered as a control solution. Subsequently the subjects randomly ingested the same tests solutions as Group 1 on 3 different testing days, one hour after ingestion of a single dosage of 750 mg chenodiol (three $250 \mathrm{mg}$ tablets, Chenofalk ${ }^{\circledR}$, Germany), known to increase intestinal permeability ${ }^{35}$. The subjects were not allowed to consume alcoholic beverages, to use drugs, except oral contraceptives, or to perform intensive physical exercise the day prior to the testing days. Before each solution was ingested, the subjects emptied their bladder. Urine was collected for $\mathbf{5} \mathrm{h}$, and during this period the subjects were not allowed to eat or drink. The volume 
was recorded, and urine samples were stored at $-80^{\circ} \mathrm{C}$. The urinary lactulose: and rhamnose excretion was determined by a validated, sensitive, newiy developed fluorescent detection HPLC system $^{62}$, and the lactulose/rhamnose ratio was calculated.

\section{Statistics}

Data are presented as median (range). Comparisons between the test solutions were carried out using Friedman and Wilcoxon's nonparametric tests. Differences between Group 1 and 2 were assessed using Mann-Whitney's and Kruskal-Wallis nonparametric tests. All statistical analyses were performed using the SPSS 7.5 for Windows package.

\section{Results}

Figure 4.1 shows the effect of $750 \mathrm{mg}$ chenodiol on the lactulose/rhamnose ratio in the individuals from Group 2 using $5 \mathrm{~g}$ of lactulose with $0.5 \mathrm{~g}$ rhamnose. Seven subjects had a strong response on chenodiol administration, 2 subjects had a small response, and 1 subject had no response. The lactulose/rhamnose ratio increased from $0.0081(0.0012-0.013)$ to 0.0138 (0.0066-0.0190), $(P=0.007)$.

Differences in lactulose/rhamnose ratio were determined between the 3 test solutions (Figure 4.2). In Group 1 (control) no significant differences could be observed between the 3 testing solutions (solution A: 0.0031 (0.0009-0.0198), solution B: 0.0035 (0.0016-0.0080), solution C: 0.0018 (0.0012-0.0039), $P=0.26$ ). Group 2 (chenodiol): After ingestion of chenodeoxycholic acid there was a significant difference $(P=0.045)$ in lactulose/rhamnose ratio between the 3 testing solutions (solution A: 0.0079 (0.0024-0.0152), solution B: 0.0138 (0.0066-0.0192), solution C: 0.0144 (0.0074-0.0374)). Wilcoxon's analysis showed a significant difference between solution $A$ and solution $B(P=0.013)$, and between solution $A$ and solution $C(P=0.022)$. The lactulose/rhamnose ratio between Group 1 and Group 2 after chenodiol administration differed significantly using solution $B \quad(P<0.001)$ and solution $C \quad(P<0.001)$, respectively, but not when solution $A$ was used $(P=0.096)$.

The urinary recoveries of lactulose and rhamnose in both groups are displayed in Table 4.1. There was a significant difference in rhamnose recovery between the 3 different solutions in Group $1 \quad(P=0.025)$ and Group $2 \quad(P<0.001)$, respectively. Wilcoxon's analysis showed in Group 1 a difference in rhamnose recovery between solution $A$ and solution $B(P=0.017)$, and between solution $A$ and solution $C(P=0.009)$. In Group 2 there was also a difference between solution $A$ and solution $B(P=0.005)$, and between solution $A$ and solution $C$ 
$(P=0.008)$.

Kruskal-Wallis comparisons between the groups showed a significant difference in lactulose recovery between solution $B(P=0.002)$ and solution $C(P<0.001)$.

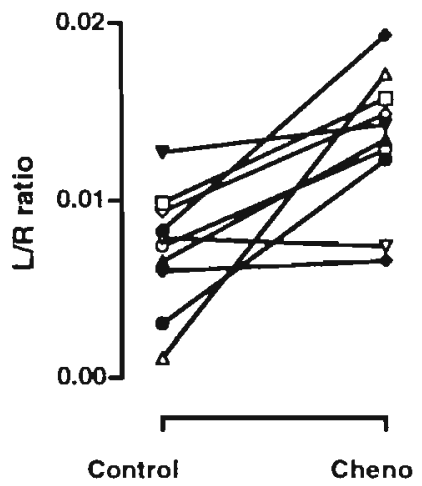

Figure 4.1 The effect of a single dosage of $750 \mathrm{mg}$ chenodiol on the lactulose/rhamnose ratio in the individuals from Group $2(n=10)$.

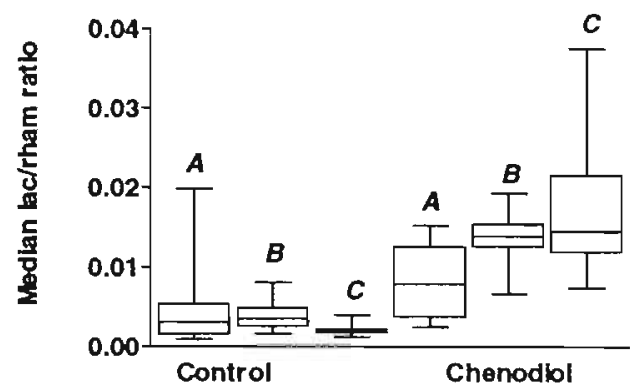

Figure 4.2 The median lactulose/rhamnose ratio's of Group 1 (control, $n=10$ ) and Group 2 (chenodiol, $n=10$ ) for the three different solutions. Group 1 shows no significant difference between the three test solutions. Group 2 shows a significant difference between solution $A$ and $B(P=0.013)$ and between solution $A$ and $C(P=0.022)$. There was a significant difference in the lactulose/rhamnose ratio between Group 1 and Group 2 for solution $B$ $(P<0.001)$ and solution $C(P<0.001)$.

Table 4.1 Urinary recoveries (median (range)) of lactulose and rhamnose in both groups after ingestion of 3 different solutions.

\begin{tabular}{lllllll}
\hline & \multicolumn{2}{l}{ Solution A } & \multicolumn{2}{l}{ Solution B } & \multicolumn{2}{l}{ Solution C } \\
\hline $\begin{array}{l}\text { Group 1 } \\
\text { \% lac recovery }\end{array}$ & 0.11 & $(0.55-0.83)$ & 0.075 & $(0.04-0.14)$ & 0.049 & $(0.028-0.83)$ \\
\% rham recovery & 12.4 & $(6.8-24.1)$ & 7.3 & $(2.1-9.4)$ & 7.0 & $(4.2-10.1)$ \\
& & & & & & \\
Group 2 & & & & & & \\
\% lac recovery & 0.17 & $(0.11-0.81)$ & 0.30 & $(0.03-0.39)$ & 0.28 & $(0.09-0.80)$ \\
\% rham recovery & 11.9 & $(2.6-17.9)$ & 5.7 & $(1.4-8.6)$ & 5.6 & $(2.0-9.7)$ \\
\hline
\end{tabular}




\section{Discussion}

Measurement of small bowel permeability by quantifying the urinary excretion of water soluble, non-degradable test molecules is widely used as a non-invasive method to determine alterations of the intestinal mucosal integrity in various diseases. Literature search showed that lactulose and rhamnose have been used. However, various quantities of these molecules are used. Other molecules, such as mannitol, have also been used in various quantities for the determination of changes in intestinal permeability. Since it is unknown whether the test molecule, administered in a certain dosage, have an identical sensitivity to determine changes in intestinal permeability, we performed a study in which we restricted ourselves to a comparison of three different dosages of lactulose and rhamnose, administered in equal proportion, under normal conditions and under conditions of increased permeability.

We artificially increased the lactulose/rhamnose ratio, using oral chenodeoxycholeic acid administration. This is an unconjugated bile acid used for the medical dissolution of gallstones. In the majority of healthy subjects a single dosage of chenodiol acutely injures the small intestinal mucosa, leading to an increased permeability.

Under conditions of a normal permeability, no difference in lactulose/rhamnose ratio could be observed after administration of $10 \mathrm{~g}$ lactulose with $1 \mathrm{~g}$ of rhamnose, compared to $5 \mathrm{~g}$ of lactulose with $0.5 \mathrm{~g}$ rhamnose, and to $1 \mathrm{~g}$ of lactulose with $0.1 \mathrm{~g}$ rhamnose. The proportion to which lactulose and rhamnose is absorbed, as reflected by the recovery data, is equal after administration of all three test solutions, suggesting a linear dosage-absorption kinetics for both molecules. Under conditions of an increased permeability, however, the ability of the intestinal mucosa to absorb rhamnose is decreased relative to lactulose absorption, reflected by an increased lactulose/rhamnose ratio. If the quantity of lactulose and rhamnose which is presented to the intestinal mucosa is increased, the ability of the intestinal mucosa to absorb lactulose appears to be relatively higher than the ability to absorb rhamnose. This is reflected by the recovery data, which shows an unchanged lactulose recovery at higher dosages of lactulose and rhamnose. The rhamnose recovery, however, decreases if the dosages of lactulose and rhamnose are higher, thus leading to an increasing lactulose/rhamnose ratio. This suggests that, if intestinal permeability is increased, lactulose and rhamnose show different absorption kinetics.

Rhamnose absorption is assumed to be a passive, paracellular process with linear dosage-absorption kinetics. Lactulose, however, is assumed to pass the intestinal mucosa via the paracellular route, between the intestinal cells via the tight junctions ${ }^{1.3}$. The present study shows that the dosage-absorption kinetics is a non-linear function; if the permeability is increased, the lactulose/rhamnose ratio is higher if higher dosages of the molecules in equal proportion are applied. Although it is assumed that pre-and postabsorptive factors do not influence the 
outcome of the lactulose/rhamnose permeability test, the recovery data demonstrate that, under a condition of an increased permeability, a higher dosage of lactulose and rhamnose lead to an unchanged lactulose recovery, and a decreased rhamnose recovery. This suggests a possible involvement of other pre- or postabsorptive factors than only paracellular diffusion if the permeability is increased. Lactulose, for instance, accelerates the intestinal transit ${ }^{63}$, thus leading to a decreased time of exposure of both molecules to the intestinal mucosal surface.

The present study clearly demonstrates, that in a situation in which the permeability was increased in a controlled setting, the quantity of administered lactulose and rhamnose is an important factor in the assessment of a change in lactulose/rhamnose ratio. Since other molecules as mannitol, PEG, ${ }^{51} \mathrm{Cr}$-EDTA, ${ }^{99 m}$ TC-DPTA, Dextran and cellobiose share the same paracellular and transcellular permeation routes as lactulose and rhamnose, it may be reasonable to assume that the absolute quantities of these other molecules and their proportions are also an important factor in the assessment of a change in permeability.

Because of the prokinetic effect of lactulose ${ }^{63}$, it is recommended to reduce as much as possible the quantity of lactulose administered in the measurement of intestinal permeability in order to prevent gastrointestinal symptoms. In our study a dosage of $5 \mathrm{~g}$ lactulose with $0.5 \mathrm{~g}$ rhamnose showed to be sufficient to discriminate significantly between a moderate increased permeability induced by chenodiol, and a normal permeability.

Further studies to reveal the mechanism of lactulose and rhamnose absorption under conditions of an increased permeability are warranted. 


\section{References}

1. Bjarnason I, MacPherson A, Hollander D. Intestinal permeability, an overview. Gastroenterology 1995; 108: 1566-1581.

2. Hollander D. The intestinal permeability barrier. Scand J Gastroenterol 1992; 27: 721-726.

3. Travis S. Menzies I. Intestinal permebility: functional assessment and significance. Clin Sci 1992; 82: 471-488.

4. Bjarnason I, Maxton D, Reynolds AP, Catt S, Peters TJ, Menzies IS. Comparison of 4 markers of intestinal permeability in control subjects and patients with celiac disease. Scand J Gastroenterol 1994; 28: 630-639.

5. Stenhammar L, Falth Magnusson K, Jansson G, Magnusson KE, Sundqvist TJ. Intestinal permeability to inert sugars and different sized polyethyleneglycols in children with celiac disease. Pediatr Gastroenterol Nutr 1989; 9: 281-289.

6. Stenhammar L, Stromberg $\mathrm{S}$. Intestinal permeability to lactulose/L-rhamnose in children with celiac disease and other gastrointestinal disorders. Pediatr Gastroenterol Nutr 1988; 7: 304-306.

7. Teahon K, Smethurst P, Levi AJ, Menzies IS, Bjarnason I. Intestinal permeability in patients with Crohn's disease and their first degree relatives. Gut 1992; 33: 320-323.

8. Howden CW, Gillanders I, Morris AJ, Duncan A, Danesh B, Russell RI. Comparison of different measurements of intestinal permeability in inflammatory bowel disease. Am J Gastroenterol 1991: 86: 1445-1449.

9. Katz KD, Hollander D, Vadheim CM, McElree C, Delahunty T, Dadufalza VD, Krugliak P, Rotter JI. Intestinal permeability in patients with Crohn's disease and their healthy relatives. Gastroenterology 1989; 97: 927-931.

10. Munkholm P, Langholz E, Hollander D, Thornberg K, Orholm M, Katz KD, Binder $\checkmark$. Intestinal permeability in patients with Crohn's disease and ulcerative colitis and their first degree relatives. Gut 1994; 35: 68-72.

11. Pignata C, Budillon G, Monaco G, Nani E, Cuomo R, Parrilli G, Ciccimarra F. Jejunal bacterial overgrowth and intestinal permeability in children with immunodeficiency syndromes. Gut 1990: 31: 879-882.

12. Lim SG, Menzies IS, Lee CA, Johnson MA, Pounder RE. Intestinal permeability and function in patients infected with human immunodefficiency virus. A comparison with coeliac disease. Scand J Gastroenterol 1993; 28: 573-580.

13. Keating J, Bjarnason I, Somasundaram S, Macpherson A, Francis N, Price AB, Sharpstone D; Smithson J, Menzies IS, Gazzard BG. Intestinal absorptive capacity, intestinal permeability and jejunal histology in HIV and their relation to diarrhoea. Gut 1995; 37: 623-629.

14 Morris AJ, Howden CW, Robertson C, Duncan A, Torley H, Sturrock RD, Russell RI. Increased intestinal permeability in ankylosing spondylitis; primary lesion or drug effect? Gut 1991; 32: 1470-1472.

15. Leclercq-Foucart J, Forget PP, Van Cutsem JL. Lactulose, rhamnose intestinal permeability in children with cystic fibrosis. J Pediatr Gastroenterol Nutr 1987; 6: 66-70.

16. Penny DJ, Ingall CB, Boulton P, Walker-Smith JA, Basheer SM. Intestinal malabsorption in cystic fibrosis. Arch Dis Child 1986; 61(11): 1127-1128.

17. Berant $M$, Khourie $M$, Menzies IS. Effect of iron deficiency on small intestinal permeability in infants and young children. J Pediatr Gastroenterol Nutr 1992; 14: 17-20. 
18. Caffarelli C, Cavagni G, Menzies IS, Bertolini P. Atherton DJ. Elimination diet and intestinal permeability in atopic eczema: a preliminary study. Clin Exp Allergy 1993; 23: 28-31.

19. Pike MG, Heddle RJ, Boulton P, Turner MW, Atherton DJ. Increased intestinal permeability in atopic eczema. J Invest Dermatol 1986; 86: 101-104.

2C. Ohri SK, Somasundaram S, Koak Y, MacPherson A, Keogh BE, Taylor KM Menzies IS, Bjarnason I. Cardiopulmonary bypass impairs small intestinal transport and increases gut permeability. Ann Thorac Surg 1993; 55: 1080-1086.

21. Ohri SK, Somasundaram S, Koak Y, Macpherson A, Keogh BE, Taylor KM, Menzies IS, Bjarnason 1. The effect of intestinal hypoperfusion on intestinal absorption and permeability during cardiopulmonary bypass. Gastroenterology 1994: 106: $318-323$.

22. Sinclair DG, Houldsworth PE, Keogh B, Pepper J, Evans TW. Gastrointestinal permeability following cardiopulmonary bypass: a randomised study comparing the effects of dopamine and dopexamine. Intensive Care Med 1997; 23: 510516.

23. Brewster DR, Manary MJ, Menzies IS, Henry RL, O'Loughlin EV. Comparison of milk and maize based diets in kwashiorkor. Arch Dis Child 1997; 76(3): 242-248.

24. Brewster DR, Manary MJ, Menzies IS, O'Loughlin EV, Henry RL. Intestinal permeability in kwashiorkor. Arch Dis Child 1997; 76(3): 236-241.

25. Jenkins AP, Menzies IS, Nukajam WS, Creamer B. The effect of ingested lactulose on absorption of L-rhamnose, D-xylose, and 3-O-methyl-D-glucose in subjects with ileostomies. Scand J Gastroenterol 1994; 29(9): 820-825.

26. Parrilli G, Cuomo R, Nardone G, Maio G, Izzo CM, Budillon G. Investigation of intestine function during acute viral hepatitis using combined sugar oral loads. Gut 1987: 28(11): 1439-1444.

27. Noone C. Menzies IS, Banatvala JE, Scopes JW. Intestinal permeability and lactose hydrolysis in human rotaviral gastroenteritis assessed simultaneously by non-invasive differential sugar permeation. Eur J Clin Invest 1986; 16(3): 217 225.

28. Mooradian AD, Morley JE, Levine AS, Prigge WF, Gebhard RL. Abnormal intestinal permeability to sugars in diabetes mellitus. Diabetologia $1986 ; 29(4)$ : 221-224.

29. Du-Mont GC, Beach RC, Menzies IS. Gastrointestinal permeability in food, allergic eczematous children. Clin Allergy 1984; 14(1): 55-59.

30. Bjarnason I. Intestinal permeability. Gut 1994; suppl. 1: S18, S22.

31. Bjarnason I, Williams P, So A, Zanelli G, Lev AJ, Gumpel MJ. Intestinal inflammation and permeability in rheumatoid arthritis, effects of non-steroidal antiinflammatory drug. Lancet 1984; ii: 1171-1174.

32. Bjarnason I, Zanelli G, Prouse P. Smethurst P, Smith T, Levi S, Gumpel MJ, Levi AJ. Blood and protein loss via small intestinal inflammation induced by nonsteroid anti-inflammatory drugs. Lancet 1987; 2(8561): 711-714.

33. Parrilli G, Iaffaioli RV, Martorano M, Cuomo R, Tafuto S, Zampino MG, Budillon G, Bianco AR. Effects of anthracycline therapy on intestinal absorption in patients with advanced breast cancer. Cancer Research 1989; 49: 3689-3691.

34. Keefe DM, Cummins AG, Dale BM, Kotasek D, Robb TA, Sage RE. Effect of highdose chemotherapy on intestinal permeability in humans. Clin Sci Colch 1997; 92(4): $385 \cdot 389$.

35. Erickson RA, Epsten RM Jr. Oral chenodeoxycholic acid increases small intestinal permeability to lactulose in humans. Am J Gastroenterol 1988; 83: 541-544. 
36. Bjarnason I, Ward K, Peters TJ. The leaky gut of alcoholism: possible route of entry for toxic compounds. Lancet 1984; 1: 179-182.

37. Maxton DG, Menzies IS, Slavin B, Thompson RP. Small-intestinal function during enteral feeding and starvation in man. Clin Sci 1989; 77: 401-406.

38. Cummins A, Chu G, Faust L, Chandy G, Argyrides J, Robb T, Wilson P. Malabsorption and villous atrophy in patients receiving enteral feeding. J Parent Enteral Nutr 1995; 19: 193-198.

39. Van der Hulst RR, Van Kreel BK, Von Meyenfeldt MF, Brummer RJM, Arends JW. Deutz NEP, Soeters PB. Glutamine and the preservation of gut integrity. Lancet 1993 (29); 341: 1363-1365.

40. Pals KL, Chang RT, Ryan AJ, Gisolfi CV. Effect of running intensity on intestinal permeability. J Appl Physiol 1997; 82(2): 571-576.

41. Ryan AJ, Chang RT. Gisolfi CV. Gastrointestinal permeability following aspirin intake and prolonged running. Med Sci Sports Exerc 1996; 28(6): 698-705.

42. Øktedalen $O$, Lunde OC, Opstad PK, Aabakken L, Kvernebo $K$. Changes in the gastrointestinal mucosa after long-distance running. Scand J Gastroenterol 1992; 27: $270-274$.

43. Moses F, Singh A, Smoak B, Hollander D, Deuster P. Alterations in intestinal permeability during prolonged high intensity running. Gastroenterology 1991; 100: A472 (Abstract).

44. Fernandez Calle P, Codoceo R, Polanco I, Gomez Cerezo J, Orsi M, Tenias JM. Is an intestinal permeability test a valid marker for slight dietary transgression in adolescents with coeliac disease? Gut 1993; 34: 774-777.

45. Menzies IS, Laker MF, Pounder R, Bull J, Heyer S, Wheeler PG, Creamer B. Abnormal intestinal permeability to sugars in villous atrophy. Lancet $1979 ; 24$ : 1107-1109.

46. Dinmore AJ, Edwards JS, Menzies IS, Travis SP. Intestinal carbohydrate absorption and permeability at high altitude $(5,730 \mathrm{~m})$. J Appl Physiol 1994; 76(5): 1903-1907.

47. Hadfield RJ, Sinclair DG, Houldsworth PE, Evans TW. Effect of enteral and parenteral nutrition on gut mucosal permeability in the critically ill. Am $\mathrm{J}$ Respir Crit Care Med 1995; 152: 1545-1548.

48. Johnston JD, Harvey CJ, Menzies IS. Treacher DF. Gastrointestinal permeability and absorptive capacity in sepsis. Crit Care Med 1996; 24(7): 1144-1149.

49. Miki K, Butler R, Moore D, Davidson G. Rapid and simultaneous quantification of rhamnose, mannitol, and lactulose in urine by HPLC for estimating intestinal permeability in pediatric practice. Clin Chem 1996; 42(1): 71-75.

50. Sinclair DG, Haslam PL, Quinlan GJ, Pepper JR, Evans TW. The effect of cardiopulmonary bypass on intestinal and pulmonary endothelial permeability. Chest 1995; 108(3): 718.724.

51. Gardner ML, Illingworth KM, Kelleher J, Wood D. Intestinal absorption of the intact peptide carnosine in man, and comparison with intestinal permeability to lactulose. J Physiol London 1991; 439: 411-422.

52. Greco L, D'Adamo G, Truscelli A, Parrilli G, Mayer M, Budillon G. Intestinal permeability after single dose gluten challenge in coeliac disease. Arch Dis Child $1991 ; 66(7)$ : 870-872.

53. Menzies IS, Jenkins AP, Heduan E, Catt SD, Segal MB, Creamer B. The effect of poorly absorbed solute on intestinal absorption. Scand J Gastroenterol 1990; 25(12): 1257-1264. 
54. Griffiths CE, Menzies IS, Barrison IG, Leonard JN, Fry L. Intestinal permeability in dermatitis herpetiformis. J Invest Dermatol 1988; 91(2): 147-149.

55. Hallberg K, Grzegorczyk A, Larson G, Strandvik B. Intestinal permeability in Cystic Fibrosis in relation to genotype. J Ped Gastroenterol Nutr 1997; 25: 290-295.

56. Sanderson IR, Boulton P, Menzies I, Walker Smith JA. Improvement of abnormal lactulose/rhamnose permeability in active Crohn's disease of the small bowel by an elemental diet. Gut 1987; 28: 1073-1076.

57. Ford RP, Menzies IS, Phillips AD, Walker Smith JA, Turner MW. Intestinal sugar permeability: relationship to diarrhoeal disease and small bowel morphology. $J$ Pediatr Gastroenterol Nutr 1985; 4: 568-574.

58 Finzi-Smith J, Cooper E, Bennett F. Lactulose-rhamnose permeability test in Jamaican children. Lancet 1991: 338 (30): 1404.

59. Maxton DG, Catt SD, Menzies IS. Combined assessment of intestinal disaccharidases in congenital asucrasia by differential urinary disaccharide excretion. J Clin Pathol 1990; 43: 406-409.

60. Maxton DG, Bjarnason I, Reynolds AP, Catt SD, Peters TJ, Menzies IS. Lactulose, ${ }^{51} \mathrm{Cr}$-labelled ethylenediamine tetra-acetate, L-rhamnose and polyethyleneglycol 500 as probe markers for assessment in vivo of human intestinal permeability. Clin Sci 1986; 71: 71-80.

61. Ott M, Lembcke B, Staszewski S, Helm EB, Caspary WF. Intestinale Permeabilität bei Patienten mit erworbenem Immundefekt, syndrom (AIDS). [Intestinal permeability in patients with acquired immunodeficiency syndrome (AIDS)]. Klin Wochenschr 1991; 69(15): 715-721.

62. Rooyakkers DR, van Eijk HM, Deutz NEP. Simple and sensitive multi-sugar-probe gut permeability test by high-performance liquid chromatography with fluorescence labelling. J Chromatogr A 1996; 730(1, 2): 99-105.

63. Miller MA, Parkman HP, Urbain JL, Brown KL, Donahue DJ, Knight LC, Mrer AH, Fisher, RS. Comparison of scintigraphy and lactulose breath hydrogen test for assessment of orocecal transit: lactulose accelerates small bowel transit. Dig Dis Sci $1997 ; 42(1): 10-18$. 


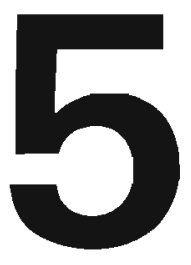

The effect of pre- and postabsorptive factors on the lactulose/rhamnose gut permeability test

MA van Nieuwenhoven, EAM de Swart, HM van Eijk, NEP Deutz, F Brouns, R-JM Brummer 


\section{Abstract}

\section{Introduction}

It is assumed that the outcome of the lactulose/rhamnose gut permeability test is not influenced by pre- and postabsorptive factors.

The aim of our study was to investigate the role of a pre-absorptive factor, i.e. small intestinal transit, and a postabsorptive factor, i.e. renal clearance.

\section{Methods}

Ten healthy male subjects were studied.

Urinary lactulose and rhamnose excretion was measured after intravenous administration of either a regular $(50 \mathrm{mg}$ and $50 \mathrm{mg}$ ), or a high dose $(250 \mathrm{mg}$ and 250 $\mathrm{mg}$ ) of lactulose and rhamnose, as well as after intraduodenal administration of $5 \mathrm{~g}$ lactulose and $0.5 \mathrm{~g}$ rhamnose under a control condition, a condition of an artificially increased intestinal permeability and under a condition of an increased intestinal permeability and an accelerated intestinal transit.

\section{Results}

The lactulose recovery was significantly lower $(P=0.025)$ after intravenous administration of a high dose of the sugars. There was no significant difference in urinary rhamnose recovery $(P=0.575)$ between the high and regular dose. This resulted in a significantly lower lactulose/rhamnose ratio $(P=0.021)$ after intravenous administration of a high dose, compared to a regular dose of the sugars. The intraduodenal experiments showed that a combination of accelerated small bowel transit and increased permeability did not lead to a significant difference in lactulose $(P=0.647)$ and rhamnose recovery $(P=0.889)$ and lactulose/rhamnose ratio, compared to increased permeability alone $(P=0.68)$.

\section{Conclusion}

The assumption that postabsorptive processes do not influence the outcome of the lactulose/rhamnose permeability test appears to be not valid. 


\section{Introduction}

The intestinal permeability can be evaluated by measuring urinary excretion of orally administered water soluble, non-degradable test molecules. This barrier function test is based on the comparison of intestinal permeation of a larger molecule with that of a smaller molecule by measuring the ratio of urinary excretion of these molecules. These two molecules follow different routes of intestinal permeation; the larger molecules are assumed to permeate paracellular, the smaller molecules are assumed to permeate transcellular.

Preabsorptive factors such as gastric emptying, dilution by secretion and small bowel transit time, and postabsorptive factors such as systemic distribution and renal clearance are assumed to equally affect both molecules. Therefore the urinary excretion ratio is considered to be a parameter for intestinal permeability per $\mathrm{se}^{1-3}$.

Recently, we demonstrated that under conditions of an increased intestinal permeability, the outcome of the lactulose/rhamnose test is influenced by the administered dose of lactulose/rhamnose ${ }^{4}$. This suggests a possible involvement of pre- and/or postabsorptive factors besides the process of intestinal permeation if the permeability is increased, which determines the outcome of the test. Lactulose, for instance, accelerates small bowel transit ${ }^{5}$, hence leading to a decreased time of exposure of both molecules to the intestinal mucosal surface. The effect of the duration of small bowel transit on the outcome of the lactulose/rhamnose test has never been studied before. Renal clearance of the sugars have only been studied after intravenous administration of a single dose of either lactulose or rhamnose ${ }^{6}$. The lactulose/rhamnose ratio has never been studied after intravenous administration of the sugars.

Therefore the aim of the present study was to investigate whether small bowel transit, which determines the duration of the exposure of the lactulose and rhamnose to the intestinal mucosal surface, as well as the process of renal clearance of the sugars affect the outcome of the lactulose/rhamnose permeability test. Firstly, we compared the urinary recovery of lactulose and rhamnose after intraduodenal administration of the sugars in a normal condition, in a condition of an increased permeability, which was artificially induced by oral administration of $750 \mathrm{mg}$ chenodeoxycholic acid (chenodiol)? , and in a condition of both an increased permeability and accelerated small bowel transit, which was artificially induced by oral administration of $10 \mathrm{mg}$ cisapride, a prokinetic compound which itself does not influence intestinal permeability. Secondly, we compared the urinary lactulose/rhamnose ratio after intravenous administration of a regular and high dose of the sugars, respectively. 


\section{Subjects and methods}

\section{Subjects}

A group of 10 healthy, non-smoking male subjects (median age 25 years (range 18-29)) were studied in the morning after an overnight fast. The subjects were not allowed to consume alcoholic beverages, to use drugs or to perform intensive physical exercise the day prior to the testing days. The study was approved by the Ethics Committee of the University Hospital Maastricht. All subjects gave their written informed consent to participate in the study.

\section{Design of the study}

The subjects were studied at 5 occassions. Firstly they underwent at random 2 renal clearance experiments. Secondly they underwent at random 3 small bowel transit experiments.

\section{Renal clearance experiments}

A Teflon catheter was placed in an antecubital vein. Two different test solutions were randomly administered on 2 separate test days. The test solutions, packaged in infusion bags, contained either $50 \mathrm{mg}$ lactulose and $50 \mathrm{mg}$ rhamnose in $100 \mathrm{ml}$ saline solution, or $250 \mathrm{mg}$ lactulose and $250 \mathrm{mg}$ rhamnose in $100 \mathrm{ml}$ saline solution. The infusion bags were prepared and examined to exclude microbiological and pyrogenic contamination by the Department of Clinical Pharmacy of the University Hospital Maastricht. The test solutions were admistered intravenously during a period of $60 \mathrm{~min}$. Total urine production was collected up to $5 \mathrm{~h}$ after the start of the infusion, its volume was measured and small portions were stored at $-80^{\circ} \mathrm{C}$ until analysis. All tests were separated by a washout period of at least $72 \mathrm{~h}$.

\section{Small bowel transit experiments}

A charriere 12 Bengmark-type naso-intestinal catheter (Flocare, The Netherlands) was placed in the duodenum. The correct position of the catheter was confirmed using fluoroscopy. The subjects were randomly studied in 3 separate experiments;

1 Control experiment: A standard test solution containing $5 \mathrm{~g}$ lactulose (lactulose, Centrafarm, Etten-Leur, The Netherlands) and $0.5 \mathrm{~g}$ L-rhamnose (Sigma Chemical, USA) in $50 \mathrm{ml}$ saline solution was administered in $1 \mathrm{~min}$.

2 Increased permeability experiment: The subjects received orally $750 \mathrm{mg}$ chenodiol (Ch) (three $250 \mathrm{mg}$ tablets, Chenofalk ${ }^{\circledR}$, Falk, Germany), known to increase intestinal permeability ${ }^{7}$, one hour before the administration of the standard test solution as in the control experiment.

3 Increased permeability and accelerated small bowel transit experiment: The 
subjects received orally $750 \mathrm{mg}$ chenodiol as well as $10 \mathrm{mg}$ cisapride (cis) (Prepulsid ${ }^{\oplus}$, Janssen-Cilag BV. The Netherlands) to accelerate small bowel transit. One hour after administration of these compounds the same solution as in the control experiment was administered.

In each experiment total urine production was collected during $5 \mathrm{~h}$ after administration of the lactulose/rhamnose solution, its volume was measured and small portions were stored at $-80^{\circ} \mathrm{C}$ until analysis. All tests were separated by a washout period of at least $72 \mathrm{~h}$. The urinary lactulose and rhamnose excretion was determined by a validated, sensitive, newly developed fluorescent detection HPLC system ${ }^{8}$, and the lactulose/rhamnose ratio was calculated.

\section{Small bowel transit time (SBTT)}

The solution that was administered intraduodenally contained $5 \mathrm{~g}$ lactulose, which is a non-digestible soluble carbohydrate allowing the measurement of the small bowel transit time (SBTT) using $\mathrm{H}_{2}$-measurement in exhaled breath. As soon as the lactulose enters the colon, bacterial fermentation will take place, and $\mathrm{H}_{2}$-gas will be produced ${ }^{9}$. Each $15 \mathrm{~min}$ the subject breathed for $2 \mathrm{~min}$ through a mouthpiece, which was connected to a mixing chamber. Breath samples for $\mathrm{H}_{2}$-analysis were collected from the mixing chamber at $15 \mathrm{~min}$ intervals, starting at $t=0$, using a $140 \mathrm{ml}$ syringe, and were analyzed for $\mathrm{H}_{2}$ enrichment using a sensitive electrochemical exhaled hydrogen monitor (GMI Medical Ltd., Renfrew, Scotland). The SBTT was determined as elapsed time till onset of a sustained increase in breath $\mathrm{H}_{2}$, which was defined as the first breath sample that shows a higher breath $\mathrm{H}_{2}$ than the preceding one, followed by two or more breath samples showing a further increase.

\section{Statistics}

Data are presented as median (range). Comparisons between the intraduodenal experiments were carried out using Friedman and Wilcoxon's nonparametric tests. Comparisons between the intravenous experiments were carried out using Wilcoxon's nonparametric test. All statistical analyses were performed using the SPSS 7.5 for Windows package.

\section{Results}

\section{Intravenous experiments}

The results of the intravenous experiments are displayed in Table 5.1.

The urinary lactulose recovery was significantly lower if a high dose of the sugars was administered. However, there was no significant difference in 
urinary rhamnose recovery between the high and regular dose. This resulted in a significantly lower lactulose/rhamnose ratio after intravenous administration of a high dose, compared to a regular dose of the sugars.

Table 5.1 Results of intravenous experiments.

\begin{tabular}{lllllll}
\hline & \multicolumn{2}{c}{$\%$ Lactulose recovery } & \multicolumn{2}{c}{$\%$ Rhamnose recovery } & \multicolumn{2}{l}{ Lac/rham ratio } \\
\hline Intravenous regular & 26.36 & $(1.82-44.43)$ & 70.77 & $(4.67-88.50)$ & 0.0378 & $(0.0162-0.0736)$ \\
Intravenous high & 16.85 & $(9.81-25.29)$ & 61.75 & $(51.1-81.31)$ & 0.0268 & $(0.0167-0.0452)$ \\
P.value & $0.025^{*}$ & & 0.575 & & $0.021 *$ & \\
\hline
\end{tabular}

\section{Small bowel transit time (SBTT)}

The results of the SBTT measurements are displayed in Figure 5.1. Friedmans's analyses showed a significant difference between the 3 experiments $(\mathrm{P}=0.009)$. The SBTT was $82.5 \mathrm{~min}(45.0-195.0)$ (Control), $90.0 \mathrm{~min}(45.0$ 150.0) (Ch), and $60.0 \mathrm{~min}$ (30.0-165.0) (Ch + cis), respectively. Wilcoxon's analysis demonstrated a significantly accelerated small bowel transit in the chenodiol + cisapride experiment, compared with the chenodiol experiment $(\mathrm{P}=0.047)$.

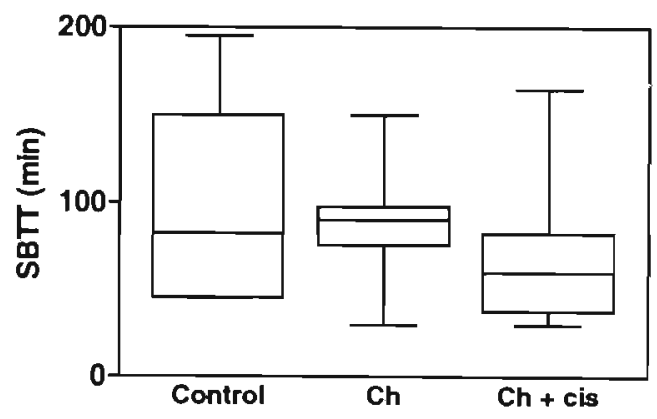

Figure 5.1. Box-and whiskers plot of the small bowel transit times from the 3 experiments (n=10, $=$ significant difference).

\section{Small bowel transit experiments}

The results of the small bowel transit experiments are displayed in Table 5.2.

As expected, administration of chenodiol, either alone or in combination with cisapride, $1 \mathrm{~h}$ before ingestion of the lactulose/rhamnose solution, resulted in a significantly increased permeability compared with the control experiment (Control vs. Ch: $P=0.021$, Control vs. $C h+$ cis: $P=0.022$ ). This was due to a significantly increased lactulose recovery $(P=0.018)$, while rhamnose recovery remained unchanged. Wilcoxon's analysis demonstrated that administration of 
cisapride leading to acceleration of small bowel transit did not lead to a significant difference in lactulose recovery $(P=0.647)$, rhamnose recovery $(P=0.889)$ and lactulose/rhamnose ratio $(P=0.68)$, respectively, compared to administration of chenodiol alone.

Table 5.2

Results of the small bowel transit experiments.

\begin{tabular}{lllllll}
\hline & \multicolumn{2}{l}{$\%$ Lac recovery } & \multicolumn{2}{l}{$\%$ Rham recovary } & \multicolumn{2}{l}{ Lac/rham ratio } \\
\hline Control & 0.11 & $(0.05-0.72)$ & 14.93 & $(4.38-30.48)$ & 0.0101 & $(0.0026-0.0461)$ \\
Ch & 0.43 & $(0.13-0.84)$ & 9.06 & $(2.98-13.04)$ & 0.0438 & $(0.0241-0.1170)$ \\
Ch + cis & 0.27 & $(0.03-2.43)$ & 8.93 & $(2.59-21.04)$ & 0.0219 & $(0.0031-0.2241)$ \\
P-value Friedman & 0.05 & & 0.65 & & 0.021 & \\
\hline
\end{tabular}

\section{Discussion}

In a previous study ${ }^{4}$ we demonstrated that the dose-absorption kinetics of lactulose and rhamnose follow a non-linear function; if the permeability is increased, the lactulose/rhamnose ratio is higher if larger quantities of the molecules are applied. Although it is assumed that pre- and postabsorptive factors do not influence the outcome of the lactulose/rhamnose permeability test, the recovery data demonstrate that, under a condition of an increased permeability, the administration of a higher dose of lactulose and rhamnose results in an unchanged lactulose recovery, and a decreased rhamnose recovery. This suggests a possible involvement of pre- and/or postabsorptive factors besides only paracellular absorption if the permeability is increased, for instance a lactulose-induced accelerated small bowel transit ${ }^{5}$. In a recent study ${ }^{10}$, lactulose and rhamnose were administered intravenously in rats in a normal condition, and in a condition in which the animals were given fluid support. Their results demonstrated that urinary lactulose excretion increases dramatically if the animals receive a fluid load, which suggests that renal clearance may influence the outcome of the test as well.

In the present study we investigated the role of small bowel transit, by administering lactulose and rhamnose directly into the duodenum, thus avoiding possible disturbances due to gastric dilution and the process of gastric emptying. Small bowel transit was accelerated using cisapride; a prokinetic compound which is not likely to interact with chenodiol and does not affect intestinal permeability. In this study we also investigated the combined role of systemic distribution and renal clearance of the sugars, by administering 2 different doses of the sugars intravenously, during a period of $1 \mathrm{~h}$. The quantities of the administered sugars $150 \mathrm{mg}$ and $250 \mathrm{mg}$, respectively) were chosen arbitrarily, but both doses represented quantities that may occur in the circulation after ingestion of a lactulose/rhamnose solution. The period of $1 \mathrm{~h}$, in 
which the sugars were administered, was also chosen arbitrarily to represent more or less the duration of exposure and permeation of lactulose and rhamnose to the small intestinal mucosal surface. If renal clearance equally affects both molecules, as assumed in literature', it may be expected that adminstration of either a low or a higher dose of the sugars will not result in a change of the lactulose/rhamnose ratio's.

The results of the present study demonstrated that an acceleration of small bowel transit from $90 \mathrm{~min}$ to $60 \mathrm{~min}$ does not significantly influence the outcome of the test, as reflected by the lactulose/rhamnose ratio's of the chenodiol experiment versus the chenodiol + cisapride experiment. It can, however, not be excluded that small bowel transit influences the outcome of the lactulose/rhamnose test if the acceleration of small bowel transit is more pronounced.

Our data showed lower lactulose recoveries if a higher quantity of lactulose is administered, while the rhamnose recovery remains unchanged, which demonstrated that the process of renal clearance does not equally affect both molecules under all conditions. This is reflected by a higher lactulose/rhamnose ratio after intravenous administration of a low dose of the sugars. This observation suggests that the process of renal clearance is different for both sugars. Data available in the literature regarding the recoveries of the sugars are not entirely unequivocal. Maxton et al. ${ }^{6}$ observed a urinary lactulose recovery of $75 \%$ and a rhamnose recovery of $62 \%, 5 \mathrm{~h}$ after intravenous bolus injection of $500 \mathrm{mg}$ lactulose and $500 \mathrm{mg}$ rhamnose which are very large quantities. In our study we observed similar rhamnose recoveries, but much lower lactulose recoveries. This difference may at least partially be explained by the different administration regimens of the sugars; a $10 \mathrm{ml}$ bolus injection versus a $100 \mathrm{ml}$ infusion for $1 \mathrm{~h}$, and by the difference in analytical techniques; estimation via thin-layer chromatography (Maxton) versus measurement using HPLC, respectively.

Summarising, we provided evidence that a moderate acceleration of small bowel transit does not influence the outcome of the lactulose/rhamnose permeability test. Since gastric emptying of liquids is normally a rapid process, one may conclude that the processes preceding intestinal uptake of the sugars do not influence the outcome of the lactulose/rhamnose permeability test. Renal clearance of rhamnose is not dependent on the quantity of rhamnose present in the circulation. However, the renal clearance of lactulose is dependent on the quantity of lactulose present in the circulation, as a higher quantity of lactulose results in a lower $5 \mathrm{~h}$ recovery and a lower lactulose/rhamnose ratio, thus underestimating a possible increase in permeability if more lactulose and rhamnose are absorbed by the small intestine. Therefore the assumption that postabsorptive factors do not influence the outcome of the lactulose/rhamnose permeability test, appears to be not valid, which may be of consequence for the usefulness and reliability of the test in patients. 


\section{References}

1. Bjarnason I, MacPherson A, Hollander D. Intestinal permeability, an overview. Gastroenterology 1995; 108: 1566-1581.

2. Hollander D. The intestinal permeability barrier. Scand J Gastroenterol 1992; 27: 721-726.

3. Travis S, Menzies I. Intestinal permeability: functional assessment and significance. Clin Sci 1992; 82: 471-488.

4. Van Nieuwenhoven MA, Geerling BJ, Deutz NEP, Brouns F, Brummer R-JM. The sensitivity of the lactulose/rhamnose gut permeability test. Eur J Clin Invest 1999; 29: 160-165.

5. Miller MA, Parkman HP, Urbain JL, Brown KL, Donahue DJ, Knight LC, Mrer AH, Fisher, RS. Comparison of scintigraphy and lactulose breath hydrogen test for assessment of orocecal transit: lactulose accelerates small bowel transit. Dig Dis Sci $1997 ; 42(1): 10-18$.

6. Maxton DG, Bjarnason I, Reynolds AP, Catt SD, Peters TJ, Menzies IS. Lactulose. ${ }^{51} \mathrm{Cr}$-labelled ethylenediamine tetra-acetate, L-rhamnose and polyethyleneglycol 500 as probe markers for assessment in vivo of human intestinal permeability. Clin Sci 1986; 71: 71-80.

7. Erickson RA, Epsten RM Jr. Oral chenodeoxycholic acid increases small intestinal permeability to lactulose in humans. Am J Gastroenterol 1988; 83: 541-544.

8. Rooyakkers DR, van Eijk HM, Deutz NEP. Simple and sensitive multi-sugar-probe gut permeability test by high-performance liquid chromatography with fluorescence labelling. J Chromatogr A 1996; 730(1,2): 99-105.

9. Levitt MD. Production and excretion of hydrogen gas in man. The New England J Med 1969; 281 (3): 122-7.

10. Hallemeesch MM, Deutz NEP, Soeters PB. Increased lactulose/rhamnose ratio during fluid administration is caused by increased renal lactulose excretion. Clin Nutr 1998; 17(Supp 1): 1. 


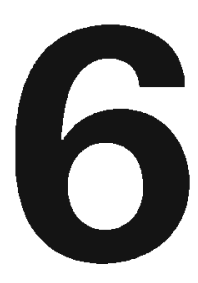

\section{The effect of physical} exercise on parameters of gastrointestinal function

MA van Nieuwenhoven, F Brouns, R-JM Brummer

Neurogastroenterology and Motility (in press) 


\section{Abstract}

\section{Background}

Exercise decreases splanchnic blood flow. Therefore exercise may induce alterations in gastrointestinal (GI) function. In the present study we investigated the effect of highintensity exercise on esophageal motility, gastroesophageal reflux, gastric $\mathrm{pH}$, gastric emptying, orocecal transit time (OCTT), intestinal permeability and glucose absorption simultaneously, using an ambulatory protocol.

\section{Methods}

Ten healthy well-trained male subjects underwent a rest-cycling-rest, and a rest-restrest protocol (60-90-210 $\mathrm{min})$. Esophageal motility, gastroesophageal reflux and intragastric $\mathrm{pH}$ were measured using a transnasal catheter. OCTT was measured via breath $\mathrm{H}_{2}$-measurement. A sugar absorption test was applied to determine intestinal permeability and glucose absorption. Gastric emptying was measured using the ${ }^{13} \mathrm{C}$ acetate breath test.

\section{Results}

Peristaltic velocity was increased during cycling, compared to rest $(4.92$ (4.22-7.08) vs. $4.03(3.19 .4 .67) \mathrm{cm} / \mathrm{s}, P=0.015)$. Peristaltic contraction pressure at the midesophagus and the duration of the peristaltic contractions at the mid- and distal esophagus was lower during cycling. There were no differences between the preexercise, the exercise and the postexercise episodes for gastric $\mathrm{pH}$, and for both the number and duration of reflux episodes, in both the rest and cycling trials. Neither gastric emptying nor OCTT showed differences between rest and cycling. The lactulose/rhamnose ratio and intestinal glucose absorption were significantly decreased in the cycling trial.

\section{Conclusion}

Our model enables multiple GI measurements during exercise. Cycling at $70 \% \mathrm{Wmax}$ does not lead to differences in reflux, gastric $\mathrm{pH}$ or gastrointestinal transit in healthy trained individuals. The distal esophageal pressure decreases and peristaltic velocity increases. The lactulose/rhamnose ratio and jejunal glucose absorption are decreased during exercise. 


\section{Introduction}

Strenuous exercise is able to alter parameters of gastrointestinal function. A number of studies have reported an increase of gastroesophageal reflux during exercise ${ }^{1.4}$.

The effect of exercise on esophageal motility has been studied by Soffer et al. ${ }^{2.3}$. They reported an intensity-dependent decline in duration, amplitude and number of esophageal contractions, which reached significance at near-maximal exercise intensities.

The effect of exercise on gastric $\mathrm{pH}$ is yet unknown. Feldman et al. ${ }^{5}$ studied the effect of exercise on postprandial gastric secretion, and reported little effect on postprandial gastric secretory function. Zach et al. ${ }^{6}$ found that in healthy subjects a $1 \mathrm{~h}$ exercise at a constant load of $50 \% \mathrm{VO}_{2 \max }$ (maximal oxygen uptake) significantly decreased the volume of gastric juice, the concentration of hydrochloride acid, leading to a higher $\mathrm{pH}$, and decreased basal acid output (BAO).

Gastric emptying may also be altered as a result of physical exercise, but is also dependent upon factors such as composition and volume of the meal. During exercise predominantly liquids are consumed. From studies performed at rest and during exercise it appears that up to exercise intensity levels of $70-80 \%$ $\mathrm{VO}_{2 \max }$ there is no difference between both conditions in the regulation of gastric emptying. At higher intensities, which can not been maintained very long, the gastric emptying rate (GER) has been found to be retarded. In relation to exercise, the GER of liquids mainly depends on: exercise intensity, volume of the drink, and energy density of the drink?

There is no consensus about the effect of exercise on the orocecal transit time (OCTT). This is the time, which elapses between oral ingestion and the arrival of the non-absorbed fraction of the meal in the proximal colon ${ }^{8}$. Intense exercise reduces intestinal blood flow ${ }^{9}$, and leads to elevated plasma concentrations of catecholamines, endorphins ${ }^{10}$, and all types of GI hormones ${ }^{11}$, each of which may affect intestinal motility. However, the few reports concerning the effect of exercise on intestinal transit time show conflicting results ${ }^{12-15}$.

There is also not much data available concerning the effect of exercise on intestinal permeability. Øktedalen et al. $^{16}$ and Moses et al. ${ }^{17}$ reported an increased permeability after running. In contrast, Ryan et al. ${ }^{18}$ evaluated the effect of running and aspirin intake on intestinal permeability, and observed no change in permeability in relation to exercise.

It has been suggested that a reduction of mesenteric blood flow by more than $50 \%$ causes a linear fall in the rate of glucose absorption ${ }^{19}$. In contrast, Fordtran et al. ${ }^{20}$ reported that severe exercise did not influence the intestinal glucose uptake, as measured with a triple lumen perfusion technique.

All studies concerning the effect of physical exercise on gastrointestinal function, which have been published so far, focus on one or two parameters of 
Gl function. Therefore the aim of the present study was to investigate the effect of high-intensity exercise on esophageal motility, GI reflux, gastric acid, gastric emptying, orocecal transit time, intestinal permeability and intestinal glucose absorption simultaneously, using a maximally non-invasive restexercise-rest protocol in a controlled laboratory setting.

\section{Subjects and methods}

\section{Subjects}

Ten healthy well-trained male subjects (age $18-25$ years), who did not suffer from exercise-induced Gl symptoms, were studied on 3 different days. Their diet was standardized during $24 \mathrm{~h}$ preceding the test days. The subjects were not allowed to consume fiber-rich or spicy food products, alcohol, caffeinecontaining products, drugs, or to perform physical exercise the day preceding the test days.

\section{Design of the study}

Firstly the subjects underwent a stationary slow pull-through manometry in order to locate the lower esophageal sphincter (LES) and to exclude gross manometric abnormalities. Subsequently the subjects underwent a cycling test in order to determine their Wmax (maximal power output) ${ }^{22}$. On the 2 actual testing days the subjects underwent in random order either a rest-cycling-rest protocol, or a protocol in which the cycling period was replaced by rest.

\section{Investigation protocol}

A scheme of the investigation protocol is provided in Figure 6.1. After an overnight fast, the subjects arrived at the laboratory at $8.00 \mathrm{AM}$. A thin catheter allowing the registration of esophageal motility, gastroesophageal reflux and intragastric $\mathrm{pH}$ (Koningsberg, USA) was inserted transnasally.

Subsequently the subjects received a standard liquid breakfast $(4 \mathrm{ml} / \mathrm{kg}$ body weight, $\mathrm{pH}=5.8$ ), and remained seated in a chair for $60 \mathrm{~min}$. During this period resting values for esophageal motility, gastric $\mathrm{pH}$ and gastroesophageal reflux were obtained. Subsequently the subjects emptied their bladder, mounted a stationary bicycle ergometer (Lode, Groningen, The Netherlands) in the cycling trial, or remained seated in the resting trial. In the cycling trial a warming-up was performed for $10 \mathrm{~min}$ at $100 \mathrm{~W}$. During the final minute of this warming-up $2 \mathrm{ml}$ of a carbohydrate-electrolyte solution (CES) $/ \mathrm{kg}$ body weight was ingested. The composition of the CES and the used liquid meal is displayed in Table 6.1.

At $\mathrm{t}=0$ of the subsequent exercise period, the cycling intensity was increased to a load of $70 \%$ of the previously determined individual maximal power output 
(Wmax $70 \%$, which is equivalent to $\left.>80 \% V_{2 \max }\right)$, which was maintained for $90 \mathrm{~min}$. If the subjects were not able to maintain the cycling load, the load was decreased with $5 \%$. If necessary, this was repeated, until the subject had completed the 90 min cycling period. During this period, the subjects received $2 \mathrm{ml} \mathrm{CES} / \mathrm{kg}$ body weight at $\mathrm{t}=20$, and $5 \mathrm{mlCES} / \mathrm{kg}$ body weight at $\mathrm{t}=40$, in order to compensate for sweat losses and to minimise dehydration. All drinks were at room temperature $\left(19^{\circ} \mathrm{C}\right)$. At $\mathrm{t}=90$ the subjects dismounted the cycle ergometer after which they remained normally seated in a comfortable chair for 210 min to obtain postexercise resting values. At $t=150$ the subjects received a standard liquid lunch $(4 \mathrm{ml} / \mathrm{kg}$ body weight). For each breath sample the subjects breathed for 2 min through a mouthpiece, which was connected to a mixing chamber. Breath samples for $\mathrm{H}_{2}$ and ${ }^{13} \mathrm{CO}_{2}$ analysis were collected from the mixing chamber at $15 \mathrm{~min}$ and at $5 \mathrm{~min}$ intervals, respectively. From $\mathrm{t}=0$ to $\mathrm{t}=300$ the total urine production was collected.

\section{Testing procedures}

\section{Esophageal parameters}

Two solid-state pressure sensors measured esophageal pressure at 13 (P1) and 3 (P3) cm, respectively, above the LES. The catheter was connected with an ambulatory datarecorder (MMS, Enschede, The Netherlands), thus allowing continuous registration of $\mathrm{pH}$ and pressure. The stored data were transferred from the ambulatory datalogger to a personal computer system, and edited using specialised manometry software (MMS, Enschede, The Netherlands).

In each episode of the trials the following parameters were evaluated: the number of peristaltic contractions, the mean peristaltic pressure at P1 and P3, the mean duration of peristaltic pressure events at P1 and P3, and the peristaltic velocity.

Table 6.1 Composition of the carbohydrate-electrolyte solution (CES) and the liquid meal

\begin{tabular}{ll}
\hline Content CES/100 ml & Content liquid meal/100 ml \\
\hline $30.0 \mathrm{Kcal}$ & $122.4 \mathrm{Kcal}$ \\
CHO $6.88 \mathrm{~g}$ & CHO $17.5 \mathrm{~g}$ \\
Vitamins $10.6 \mathrm{mg}$ & Fat $3.4 \mathrm{~g}$ \\
Electrolytes $119 \mathrm{mg}$ & Protein $5.4 \mathrm{~g}$ \\
Amino acids $21 \mathrm{mg}$ & Lactose $0.27 \mathrm{~g}$ \\
Myoinositol $5.1 \mathrm{mg}$ & Fiber $1.08 \mathrm{~g}$ \\
Choline $10 \mathrm{mg}$ & Electrolytes $130 \mathrm{mg}$ \\
pH 3.95 & Vitamins $3.9 \mathrm{mg}$ \\
& pH 5.8 \\
\hline
\end{tabular}




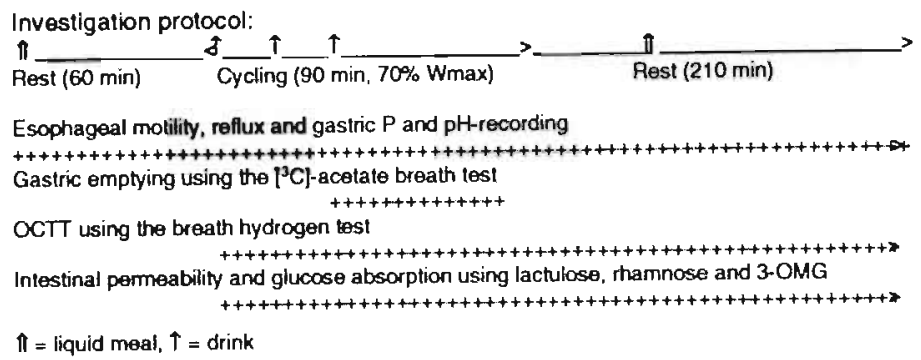

Figure 6.1 An overview of the investigation protocol

\section{Gastroesophageal reflux}

A reflux episode was defined as a period in which the $\mathrm{pH}$ in the esophagus, at 5 $\mathrm{cm}$ above the LES, was lower than 4. The following parameters were determined:

- The number of reflux episodes.

- The duration of the reflux episodes as a percentage of time.

\section{Gastric $p H$}

The intraluminal $\mathrm{pH}$ was measured $5 \mathrm{~cm}$ above the LES, and in the fundus of the stomach at $10 \mathrm{~cm}$ below the LES simultaneously. The following parameters were determined during each episode of the experiments:

- Median $\mathrm{pH}$ in the fundus. This was determined during the pre-exercise episode, the exercise episode, and the postexercise episode. No corrections were made for $\mathrm{pH}$ changes due to the ingested drinks and liquid meals, as they were similar in the cycling and rest protocol.

- Percentage of time in which the $\mathrm{pH}$ in the fundus was lower than 4.

\section{Gastric emptying}

Assessment and mathematical evaluation of ${ }^{13} \mathrm{C}$-enrichment

The drink administered at $\mathrm{t}=40$ during the exercise episode contained $150 \mathrm{mg}$ sodium $\left[1-{ }^{13} \mathrm{C}\right.$-acetate (99\%; Cambridge Isotope Laboratories, Andover, MA, USA) in order to determine the gastric emptying rate using the ${ }^{13} \mathrm{C}$-acetate breath test. Breath samples for ${ }^{13} \mathrm{CO}_{2}$-enrichment analysis were drawn from the mixing chamber at 5 min intervals from $t=40$ to $t=90$, using Vacutainer tubes. One breath sample was taken before administration of the drink at $t<40$, in order to determine background enrichment. The collected breath samples were analyzed for ${ }^{13} \mathrm{C}$-isotopic enrichment of the expired $\mathrm{CO}_{2}$ using Isotope Ratio Mass Spectrometry (Finnigan MAT 252, USA). The ${ }^{13} \mathrm{C}$-enrichment of $\mathrm{CO}_{2}$ was expressed as the delta $(\delta)$ per mil difference between the ${ }^{13} \mathrm{C} /{ }^{12} \mathrm{C}$-ratio of the breath sample and a known laboratory reference standard according to the 
formula:

$\delta^{13} \mathrm{C}$ (per mil) $=\left(\left({ }^{13} \mathrm{C} /{ }^{12} \mathrm{C}\right)\right.$ sample $/\left({ }^{13} \mathrm{C} /{ }^{12} \mathrm{C}\right)$ standard -1$) \times 10^{3}$

The $\delta$-value was then related to an international standard, Pee Dee Belemnite (PDB). The data from the breath enrichment were fitted by non-linear regression analysis according to a dual exponential function with the following features:

$y(t)=a t^{b}\left[c e^{(-t)}\right]+f t^{g}\left[h e^{(-t)}\right]+j$

A dual compartment description of ${ }^{13} \mathrm{CO}_{2}$-production $\left(\mathrm{at}^{\mathrm{b}}\right.$ and $\mathrm{ft}^{\mathrm{g}}$ ) is applied because acetate is oxidised both in the splanchnic area and in the working muscles. The decrease in ${ }^{13} \mathrm{CO}_{2}$-enrichment is also described in 2 factors; the 1st factor (c $\left.\mathrm{e}^{(-\mathrm{t} d)}\right)$ describes washout of ${ }^{13} \mathrm{CO}_{2}$ through the body bicarbonate pool via the breath and the 2nd factor (he ${ }^{(-t))}$ describes other processes of ${ }^{13} \mathrm{CO}_{2}$ removal; sequestration of ${ }^{13} \mathrm{CO}_{2}$ in bone, excretion via urine and incorporation into glucose $e^{26}$. In this equation $a, b, c, d, f, g, h$ and $i$ are constants, $t$ is the time and $j$ is the background enrichment.

In the present study the results are based on the Time to Peak ${ }^{13} \mathrm{C}$-enrichment in the breath samples $\left({ }^{13} \mathrm{C}\right.$-TTP) derived from the dual exponential function. The ${ }^{13} \mathrm{C}$-TTP was considered as the parameter of gastric emptying?". A correction factor of $5.9 \mathrm{~min}$ was added to the ${ }^{13} \mathrm{C}$-TTP derived from the exercise experiments. This was done to correct for the increased rate of oxidation of the $\left[{ }^{13} \mathrm{C}\right]$-acetate and exhalation of the ${ }^{13} \mathrm{CO}_{2}$ during exercise conditions ${ }^{23}$.

\section{Orocecal transit time (OCTT)}

The drink administered at $\mathrm{t}=0$ of the exercise episode contained a nondigestible soluble carbohydrate $(5 \mathrm{~g}$ lactulose, Centrafarm syrup, $670 \mathrm{mg} / \mathrm{ml}$, Etten-Leur, The Netherlands) allowing the measurement of OCTT via $\mathrm{H}_{2}$-measurement in breath. As soon as the lactulose enters the colon, bacterial fermentation will take place, and $\mathrm{H}_{2}$-gas will be produced ${ }^{24}$. Breath samples for $\mathrm{H}_{2}$-analysis were collected from the mixing chamber at 15 min intervals, starting at $\mathrm{t}=0$, using a $140 \mathrm{ml}$ syringe, and were analyzed for $\mathrm{H}_{2}$-enrichment using a sensitive electrochemical exhaled hydrogen monitor (GMI Medical Ltd., Renfrew, Scotland). The OCTT was determined using the time of onset of a sustained increase in breath $\mathrm{H}_{2}$, which is the first breath sample that shows a higher breath $\mathrm{H}_{2}$ than the preceding one, followed by two or more breath samples that show a further increase. 


\section{Intestinal permeability and glucose absorption}

The drink administered at $\mathrm{t}=0$ of the exercise episode contained $5 \mathrm{~g}$ lactulose (Centrafarm syrup, $670 \mathrm{mg} / \mathrm{ml}$, Etten-Leur, The Netherlands), $0.5 \mathrm{~g}$ rhamnose and $0.35 \mathrm{~g}$ 3-O-D-methyl-M-glucose (3-OMG) (Sigma Chemical Co., USA), allowing the measurement of intestinal permeability and intestinal glucose absorption ${ }^{25}$. At the end of the experiment, at $t=300$, total urine was collected, its volume was determined, and a small portion was stored at $-80^{\circ} \mathrm{C}$ for lactulose, rhamnose and 3-OMG determination. The urinary lactulose, rhamnose and 3-OMG-excretion was determined by a validated, sensitive, newly developed fluorescent detection HPLC system ${ }^{25}$. Subsequently the lactulose and rhamnose recoveries, and the lactulose/rhamnose and 3-OMG/rhamnose ratio's were calculated.

\section{Statistics}

Differences between the respective episodes of the two trials were analyzed using Wilcoxon's nonparametric tests. Data are presented as median (range). The level of confidence was set at $P<0.05$. All statistical analyses were performed using SPSS 7.5 for Windows statistical package.

\section{Results}

All the subjects were able to complete the 90 min cycling episode. It was, however, frequently necessary to decrease the cycling load in $5 \%$ steps. The course of the relative median cycling loads was: at $t=0: 70 \%$ Wmax (70-70), at $\mathrm{t}=30: 65 \% \mathrm{Wmax}(65-70)$, at $\mathrm{t}=60: 60 \% \mathrm{Wmax}(60-65)$ and $\mathrm{tat} \mathrm{t}=90$ : $60 \% \mathrm{Wmax}$ (55-65). The median initial load (70\% Wmax) was 243.5 (217$350) \mathrm{W}$, and the median load at the end of the $90 \mathrm{~min}$ cycling period was $215.5(185-325) \mathrm{W}$. Body weight in the rest experiment decreased $0.3 \mathrm{~kg}$. It was $71.3(56.4-89.1) \mathrm{kg}$ at the start and $71.0(55.8-88.7) \mathrm{kg}$ at the end of the testing day. The body weight in the exercise experiment decreased $0.8 \mathrm{~kg}$, from $72.3(55.7-88.7) \mathrm{kg}$ at the start to $71.5(54.5-87.8) \mathrm{kg}$ at the end of the testing day.

\section{Esophageal motility}

The data from the esophageal motility measurements are displayed in Table 6.2. The peristaltic velocity appeared to be increased during cycling, compared to rest. The number of peristaltic contractions, the peristaltic pressure at P1 and the duration of the peristaltic contractions at $\mathrm{P} 1$ and $\mathrm{P} 3$ was lower during cycling. 
Table 6.2 Results of the manometric measurements in median (range) of the esophagus during the exercise and postexercise episodes of the rest and the cycling trial ( $n=10, *$ significant difference $)$.

\begin{tabular}{|c|c|c|c|c|c|c|}
\hline & \multicolumn{3}{|c|}{ Exercise episodes } & \multicolumn{3}{|c|}{ Postexercise epirodes } \\
\hline & Cycling trial & Rest trial & P-value & Cycling trial & Rest trial & P.value \\
\hline Number of contractions & $\begin{array}{l}24.0 \\
(13.0-73.0)\end{array}$ & $\begin{array}{l}68.0 \\
(34.0-106.0)\end{array}$ & $0.011^{\prime}$ & $\begin{array}{l}95.5 \\
(21.0-146.0)\end{array}$ & $\begin{array}{l}108.0 \\
(61.0 .203 .0)\end{array}$ & $0.038^{*}$ \\
\hline Prossure P1 $\left(\mathrm{cm} \mathrm{H} \mathrm{H}_{2} \mathrm{O}\right)$ & $\begin{array}{l}73.4 \\
(45.3-89.0)\end{array}$ & $\begin{array}{l}78.0 \\
(58.0-121.4)\end{array}$ & $0.028^{*}$ & $\begin{array}{l}73.5 \\
(49.2-129.9)\end{array}$ & $\begin{array}{l}71.4 \\
(58.1-103.1)\end{array}$ & 0.575 \\
\hline Pressure $\mathrm{P} 3\left(\mathrm{~cm} \mathrm{H}_{2} \mathrm{O}\right)$ & $\begin{array}{l}74.8 \\
(62.9-162.5)\end{array}$ & $\begin{array}{l}77.5 \\
(61.8-127.9)\end{array}$ & 0.859 & $\begin{array}{l}69.7 \\
(54.3-118.7)\end{array}$ & $\begin{array}{l}73.3 \\
(56.4-112.8)\end{array}$ & 0.594 \\
\hline Duration P1 (sec) & $\begin{array}{l}1.72 \\
(1.29-2.03)\end{array}$ & $\begin{array}{l}1.99 \\
(1.63-2.73)\end{array}$ & $0.021^{\prime}$ & $\begin{array}{l}1.99 \\
(1.36-2.57)\end{array}$ & $\begin{array}{l}1.83 \\
(1.45-2.38)\end{array}$ & 0.161 \\
\hline Duration P3 (sec) & $\begin{array}{l}1.68 \\
(1.33-2.73)\end{array}$ & $\begin{array}{l}2.30 \\
(2.04-3.33)\end{array}$ & $0.015^{\prime}$ & $\begin{array}{l}2.26 \\
(1.72-4.14)\end{array}$ & $\begin{array}{l}2.35 \\
(1.92-3.31)\end{array}$ & 0.859 \\
\hline Peristaltic velocity $(\mathrm{cm} / \mathrm{sec})$ & $\begin{array}{l}4.92 \\
(4.22-7.08)\end{array}$ & $\begin{array}{l}4.03 \\
(3.19 \cdot 4.67)\end{array}$ & $0.015^{\prime}$ & $\begin{array}{l}3.58 \\
(3.01-5.45)\end{array}$ & $\begin{array}{l}3.74 \\
(2.85-4.80)\end{array}$ & 0.859 \\
\hline
\end{tabular}

\section{Gastric pH}

The results of the gastric $\mathrm{pH}$ measurements are displayed in Table 6.3. There were no significant differences between the pre-exercise, the exercise and the postexercise episodes in both median gastric $\mathrm{pH}(\mathrm{P}=0.767,0.208$ and 0.933 , respectively) and the percentage of time in which the gastric $\mathrm{pH}$ was lower than $4(P=0.314,0.889$ and 0.612 , respectively).

Table 6.3 Results of the gastric $\mathrm{pH}$ measurements in median (range) in the pre-exercise, exercise and postexercise episodes of the rest and the cycling trial (n $\cdots 10$ ).

\begin{tabular}{|c|c|c|c|c|c|c|}
\hline & \multicolumn{2}{|c|}{ Pre-exercise episodes } & \multicolumn{2}{|c|}{ Exercise episodes } & \multicolumn{2}{|c|}{ Postexercise episodes } \\
\hline & Cycling trial & Rest trial & Cycling trial & Rest trial & Cycling trial & Rent trial \\
\hline \multirow[t]{2}{*}{ Median pH } & 5.5 & 5.5 & 3.6 & 2.7 & 3.3 & 2.1 \\
\hline & $(4.8-6.9)$ & $(2.3-7.6)$ & $(2.8-6.0)$ & $(0.3-5.6)$ & $(2.2 \cdot 5.9)$ & $(0.2-6.3)$ \\
\hline \multirow[t]{2}{*}{$\% \mathrm{pH}<4$} & 2.6 & 6.0 & 62.2 & 93.3 & 60.8 & 69.5 \\
\hline & $(0.0-27.4)$ & $(0.0 .67 .9)$ & $(4.2-100.0)$ & $(0.0-100.0)$ & $(23.1+77.9)$ & $(0.0-94.1)$ \\
\hline
\end{tabular}

\section{Gastroesophageal reflux}

The results of the gastroesophageal reflux measurements are displayed in Figure 6.2. There were no significant differences between the pre-exercise, the exercise and the postexercise episodes in both the number of reflux episodes $(P=0.129,0.610$ and 0.786 , respectively $)$ and the duration of reflux as a percentage of time ( $P=0.237,0.612$ and 0.463 , respectively).

\section{Gastric emptying and orocecal transit time (OCTT)}

Neither gastric emptying nor the OCTT show differences between the rest and the cycling trials. ${ }^{13} \mathrm{C}$-TTP in the rest trial was $29.3 \mathrm{~min}(17.4-42.2)$ and in the cycling trial $28.7 \mathrm{~min}(21.6-34.2),(P=0.33)$. OCTT in the rest trial was 
$117.5 \mathrm{~min}$ (105.0-165.0), and in the cycling trial $140.0 \mathrm{~min}$ (105.0-195.0), $(\mathrm{P} \cdot 0.17)$.

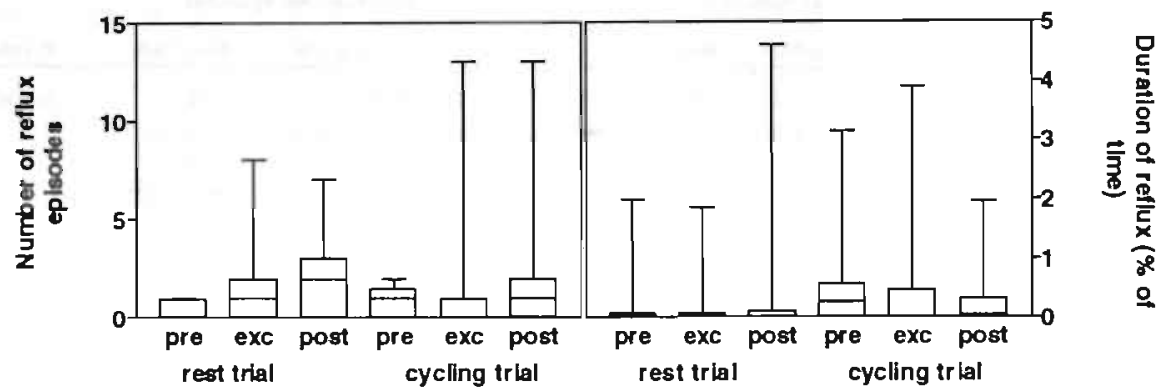

Figure 6.2 Number and duration of gastroesophageal reflux episodes in median (upper range) in both the rest and the cycling trial, during the pre-exercise, exercise and postexercise episodes, respectively. No significant differences could be observed $(n=10)$.

\section{Intestinal permeability and glucose absorption}

The results of the intestinal permeability and the 3-OMG absorption measurements are displayed in Figure 6.3. The lactulose/rhamnose ratio was significantly higher in the rest trial, compared to the cycling trial 10.015 (0.0076-0.027) and 0.0067 (0.0017-0.0141), respectively $(P=0.009)$. The changes in individual values between rest and cycling are displayed in Figure 6.4. Nine out of ten subjects showed a decrease in the lactulose/rhamnose ratio in the cycling trial, compared to the rest trial. The 3-OMG/rhamnose ratio was also significantly higher in the rest trial compared to the cycling trial (3.51 (2.63-4.77) and $2.64(2.03-3.91)$, respectively $(P=0.007)$.

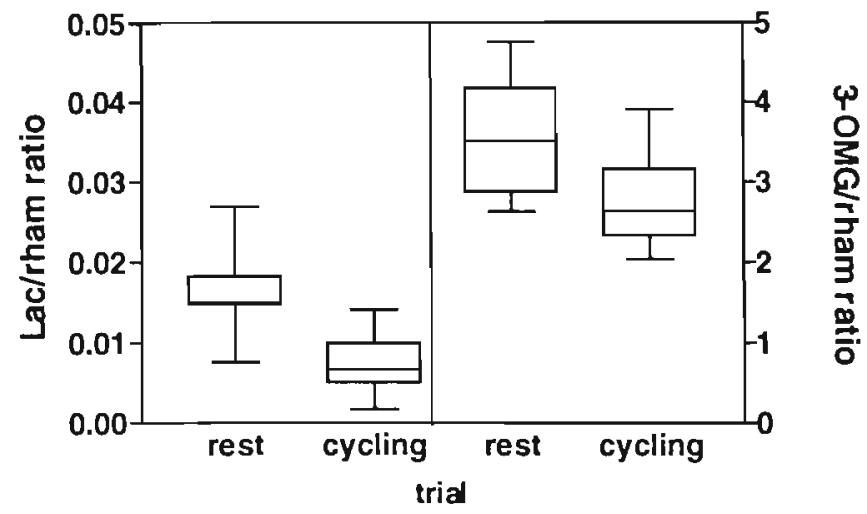

Figure 6.3 The lactulose irhamnose $(n=10, P=0.009)$ and the $3-0 M G / r h a m n o s e$ ratio in the rest and in the cycling trial $\ln =10, P=0.007$ ). 


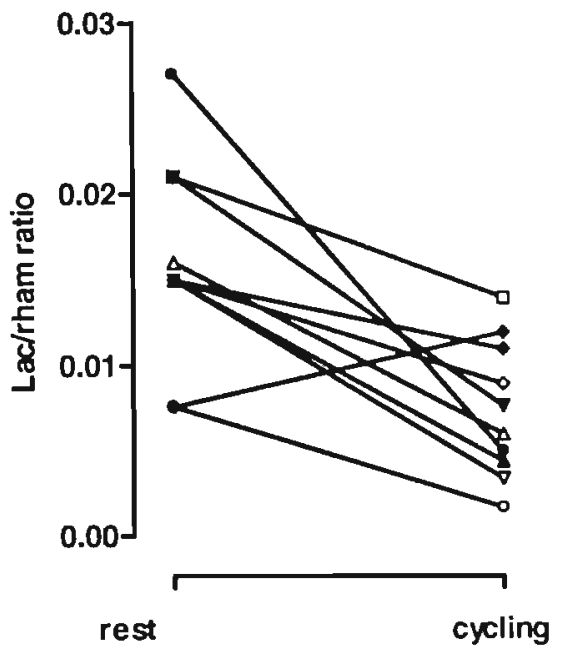

Figure 6.4 The individual changes in the lactulose/rhamnose ratio as a result of cycling.

The urinary recoveries of 3-OMG, rhamnose and lactulose are displayed in Figure 6.5. Lactulose and 3-OMG recoveries were significantly lower in the cycling trial, compared to the rest trial. Rhamnose recovery showed no difference between the trials (lactulose: cycling: $0.09 \%(0.038 \%-0.173 \%)$, rest: $0.22 \%(0.078 \%-0.394 \%), \quad P=0.009$; rhamnose: cycling: $15.0 \%$ (8.54\%-23.99\%), rest: $14.0 \%(9.64 \%-22.37 \%), P=0.65 ; 3-O M G:$ cycling: $35.15 \%(21.06 \%-62.12 \%)$, rest: $46.67 \%(38.35 \%-58.83 \%), P=0.028)$.

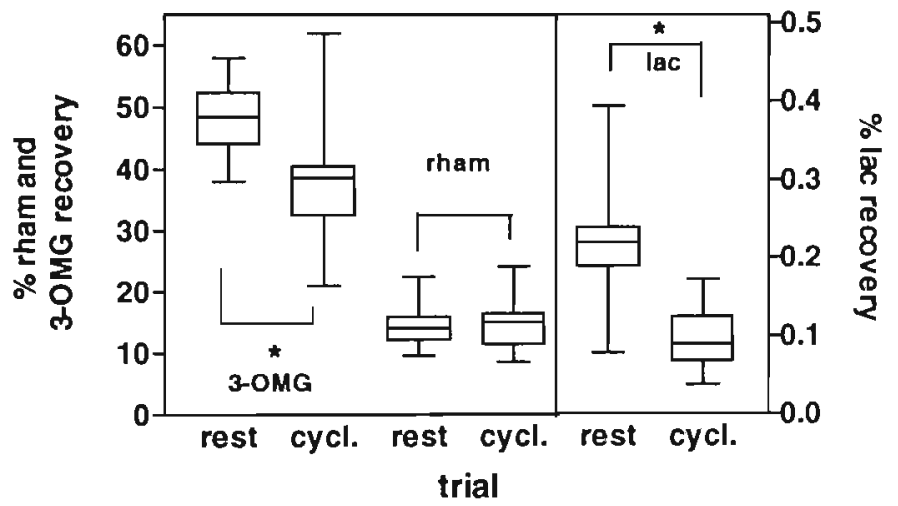

Figure 6.5 Urinary recoveries of 3-OMG, rhamnose and lactulose in the rest and the cycling trials $\left(n=10, P=0.028^{*}, P=0.65\right.$, and $P=0.009^{*}$, respectively). 


\section{Discussion}

Our study demonstrates that physical exercise has an effect on esophageal function. Esophageal function was measured at $3 \mathrm{~cm}$ (P3) and $13 \mathrm{~cm}$ (P1) above the LES. At $3 \mathrm{~cm}$ above the LES the esophagus is entirely composed of smooth muscle tissue. At $13 \mathrm{~cm}$ above the LES, however, the esophagus also contains striated muscle tissue. It is known that the peristaltic velocity wave is slower in striated muscle $(3 \mathrm{~cm} / \mathrm{sec})$ than in smooth muscle $(5 \mathrm{~cm} / \mathrm{sec})$, and that the amplitude of the peristaltic waves in the lower part of the esophagus are higher than in the upper part, and the duration of smooth muscle waves are longer than in striated muscle ${ }^{26}$. The difference in control and innervation and the difference in motility characteristics of striated and smooth esophageal muscle might explain some of the observed differences between rest and cycling. Exercise leads to an increase in sympathic, and a decrease in parasympathic activity. This may lead to a decreased vagal stimulation which is restricted to the striated muscle component of the muscle tissue in the $\mathrm{P1}$ region (mixed striated and smooth muscle tissue) of the esophagus, thus explaining the decreased pressure at $\mathrm{P} 1$ of the peristaltic waves during exercise. It may also explain why the pressure at P3 is not changed during exercise, since this region is entirely composed of smooth muscle. Nitric oxide synthase inhibition leads to decreased swallow-induced contraction amplitude in the distal esophagus, and also diminishes swallow-induced contraction latencies, predominantly in the distal esophagus, thereby decreasing the latency gradient and increasing the peristaltic velocity ${ }^{27}$. We observed a similar pattern during exercise, which might be explained by an exercise-induced increased activity of the enteral nerve system (ENS), due to a decreased ENS inhibition via nitric oxide.

Exercise may lead to a substantial decrease in Gl blood flow of more than $50 \%{ }^{28,29}$. Rowell et al. ${ }^{30}$ demonstrated a $60-70 \%$ reduction in splanchnic blood flow in subjects exercising at an intensity of $70 \% \mathrm{VO}_{2 \mathrm{max}}$, and Clausen ${ }^{9}$ reported a reduction in splanchnic blood flow of $80 \%$ of the resting level during maximal exercise. Therefore exercise may induce alterations in Gl function. This might be a factor in the pathophysiology of exercise-induced GI symptoms. These symptoms indicate changes in both the upper and the lower Gl tract. Training status, exercise intensity, hydration state and nutrition seem to play an important role. Gl symptoms during strenuous physical activity occur more frequently in untrained people, compared to trained people, and more in females than in males. In "gliding" sports like cycling, skating and swimming the prevalence of $\mathrm{Gl}$ symptoms is lower compared to running ${ }^{8}$.

The results of the present study indicate that there are no differences in gastroesophageal reflux, gastrointestinal transit time or gastric $\mathrm{pH}$ between a resting and a cycling trial. This is neither the case during the exercise episode, or during the postexercise episode. 
It has been hypothesised that intense exercise may provoke gastroesophageal reflux. Earlier studies at our department, however, showed that exercise at $70 \%$ Wmax on a stationary bicycle itself does not increase either the number of gastroesophageal reflux episodes, or the percentage of time of reflux, if the experiments are conducted in a well-controlled laboratory setting ${ }^{31}$. These observations are confirmed by the results of the present study. This, however, does not rule out the possibility that reflux may occur more often at near maximal exercise intensities, or at different types of exercise, such as during running. In this respect, Soffer et al. ${ }^{2.3}$ demonstrated that a significant increase in reflux occurred only at the highest intensity $\left(90 \% V_{2 \max }\right.$ for $10 \mathrm{~min}$ ) in a graded cycling exercise protocol and Kraus et al. ${ }^{1}$ demonstrated an increase in reflux in runners. Peters et al. ${ }^{32}$ studied the LES pressure in healthy volunteers before and immediately after $30 \mathrm{~min}$ of cycling at an increasing intensity. They observed a decreased LES pressure during severe exercise. Schoeman et al. ${ }^{33}$ studied reflux and LES pressure in ambulatory subjects who performed a standardized exercise program consisting of three 10 min periods of exercise. They observed an increase in gastroesophageal reflux during exercise and a decrease in basal LES pressure during exercise, which was, however, unrelated to the occurrence of reflux. The majority of the reflux episodes were associated with transient LES relaxations (TLESR). The number of TLESR's was not increased during exercise.

Reflux has also been suggested to be associated with increased gastric acid production. The present study demonstrates that the gastric $\mathrm{pH}$ does not change as a result of exercise. It can, however, not be excluded that the basal acid output was altered during exercise.

During an exercise/rest investigation, significant differences were observed between the percentages of time in which the gastric $\mathrm{pH}$ was lower than 4 . This can, however, be explained by the $\mathrm{pH}$ of the ingested drinks, and by the effect of the ingested pre- and postexercise liquid meals on the gastric $\mathrm{pH}$.

Our results demonstrated that the gastric emptying rate was not affected by exercise at a cycling load of $70 \%$ Wmax, which corresponds to approximately $80 \% \mathrm{VO}_{2 \max }$. This observation is in accordance with other studies, which showed that exercise intensities up to $70-80 \% \mathrm{VO}_{2 \max }$ do not affect gastric emptying ${ }^{7}$. The relation between the gastric emptying rate, gastric acid production and reflux at high intensity exercise, which may lead to an increase in gastroesophageal reflux, should be clarified in the future.

The liquid OCTT was also unchanged in our experiments. This is in accordance with the observations of Soffer et al. ${ }^{34}$, who measured the effect of cycling at different intensities on duodeno-jejunal motor activity and OCTT in cyclists. They observed an unchanged OCTT and an increase in intestinal postprandial motor activity (phase III) during exercise at higher intensities. This effect was intensity-dependent and not related to gastrointestinal symptoms. The latter observation was confirmed by Peters et al. ${ }^{35}$, who observed an unexpected early reappearance of phase III motor activity during exercise, especially if a 
carbohydrate liquid was consumed. These results suggest that exercise-induced phase III activity of the small bowel is not related to the OCTT. The possible relationship between an exercise-induced alteration in the gastric emptying rate and the OCTT requires further investigation.

The intestinal permeability can be measured using the lactulose/rhamnose test. This test is based on the comparison of intestinal permeation of lactulose, which follows a paracellular permeation route, with that of rhamnose, which follows a transcellular permeation route, by measuring the ratio of urinary excretion of these molecules ${ }^{36}$. An exercise-induced reduction of splanchnic blood flow might be expected to lead to an impairment of intestinal blood supply, resulting in an increased intestinal permeability, reflected by an increased lactulose/rhamnose ratio. In this respect, the observed effect of cycling on the lactulose/rhamnose ratio is surprising and in contrast to the findings of Pals et al. ${ }^{37}$. They studied athletes who run on a treadmill for $1 \mathrm{~h}$ at an intensity of $80 \% \mathrm{VO}_{2 \max }$, which is a comparable intensity to our experiments, and observed an increased lactulose/rhamnose ratio, due to increased lactulose absorption. Lower intensities did not result in a change of permeability. They administered the lactulose/rhamnose solution after $30 \mathrm{~min}$ of running, which means that the solution, after emptying from the stomach, is predominantly exposed to the intestinal lumen in the postexercise period. It can, however, not be excluded that the difference in results between our experiments and those of Pals et al. ${ }^{37}$ may also be explained by the different types of exercise; running vs. cycling. The lactulose/rhamnose permeability test is based on the assumption that both pre- and postabsorptive factors do not influence the outcome of the test. Rhamnose, which is passively absorbed via the transcellular route, serves as a control probe for lactulose, which is absorbed via the paracellular route ${ }^{36}$. It can be debated whether these assumptions are valid under exercise conditions, since our results show no difference in rhamnose recoveries between the rest and exercise experiments, but show a significant decrease in lactulose recovery in the exercise experiment. Since pre-absorptive factors such as gastric emptying and OCTT appeared not be influenced by exercise as indicated by our experiments, the results might suggest a possible impairment in renal lactulose clearance in the exercise experiment, rather than a change in intestinal permeability.

Intestinal glucose uptake is a carrier-mediated transport process. Our results demonstrated a decreased absorptive capacity for glucose uptake in the cycling trial, as reflected by a decreased 3-OMG/rhamnose ratio. This decrease in absorptive capacity may be explained by the decreased splanchnic blood flow, leading to a lower activity of the jejunal $\mathrm{Na}^{+} / \mathrm{K}^{+}$-ATPase, necessary for glucose absorption.

In summary, it can be concluded that cycling at $70 \%$ Wmax does not lead to differences in gastroesophageal reflux, gastric $\mathrm{pH}$ or gastrointestinal transit in healthy trained individuals, in a controlled experimental setting. However, esophageal motility is affected by cycling. The distal esophageal pressure is 
decreased and the peristaltic velocity is increased. The lactulose/rhamnose ratio is decreased, due to decreased lactulose absorption. Jejunal glucose absorption is also decreased during cycling. The pathophysiological mechanisms of the exercise-induced changes in gastrointestinal parameters are hypothetical, and require further investigation. 


\section{References}

1. Kraus BB, Sinclair JW, Castell DO. Gastroesophageal reflux in runners. Characteristics and treatment. Ann Int Med 1990; 112: 429-433.

2. Soffer EE, Merchant RK, Duethman G, Launspach J, Gisolfi C, Adrian TE. Effect of graded exercise on esophageal motility and gastroesophageal reflux in trained athletes. Dig Dis Sci 1993; 38(2): 220-224.

3. Soffer EE, Wilson J, Duethman G, Launspach J, Adrian TE. Effect of graded exercise on esophageal motility and gastroesophageal reflux in nontrained subjects. Dig Dis Sci 1994; 39(1); 193-198.

4. Clark CS, Kraus BB, Sinclair J, Castell DO. Gastroesophageal reflux induced by exercise in healthy volunteers. J Am Med Ass 1989: 261: 3599-3601.

5. Feldman $M$, Nixon JV. Effect of exercise on postprandial gastric secretion and emptying in humans. J Appl Physiol 1982: 53(4): 851-854.

6. Zach E, Markiewicz K, Lukin M, Cholewa M. The behaviour of basal gastric secretion during exercise and restitution in chronic gastric and duodenal ulcer patients. Dtsch Z Verdauungs- Stoffwechselkr 1982; 42(2-3): 53-63.

7. Brouns F. Gastric emptying as a regulatory factor in fluid uptake. Int $J$ Sports Med 1998; 19(suppl 2): S125-S128.

8. Brouns F, Beckers EJ. Is the gut an athletic organ? Digestion, absorption and exercise. Sports Med 1993; 15(4): 242-257.

9. Clausen JP. Effect of physical training on cardiovascular adjustments to exercise in man. Physiol Rev 1977; 57: 779-815.

10. McMurray RG, Forsythe WA, Mar MH, Hardy CJ. Exercise intensity-related responses of beta-endorphin and catecholamines. Med Sci Sports Exerc 1987; 19(6): 570-574.

11. O'Connor AM, Johnston CF, Buchanan KD, Boreham C, Trinick TR, Riddoch CJ. Circulating gastrointestinal hormone changes in marathon running. Int $\mathrm{J}$ Sports Med 1995; 16(5): 283-287.

12. Cammack JN, Read W, Cann PA. Greenwood B, Holgate AM. Effect of prolonged exercise on the passage of a solid meal through the stomach and the small intestine. Gut 1982; 23: 957-962.

13. Keeling WF, Martin BJ. Gastrointestinal transit during mild exercise. J Appl Physiol 1987; 63(3): 978-981.

14. Keeling WF, Harris A, Martin BJ. Orocecal transit during mild exercise in women. J Appl Physiol 1990; 68(4): 1350-1353.

15. Meshkinpour H, Kemp C, Fairshter R. Effect of aerobic exercise on mouth-tocecum transit time. Gastroenterology 1989; 96: 938-941.

16. Øktedalen O, Lunde OC, Opstad PK, Aabakken L, Kvernebo K. Changes in the gastrointestinal mucosa after long-distance running. Scand J Gastroenterol 1992; 27: 270-274.

17. Moses F, Singh A, Smoak B, Hollander D, Deuster $P$. Alterations in intestinal permeability during prolonged high-intensity running. Gastroenterology 1991; 100: A472.

18. Ryan AJ, Chang R-T, Gisolfi CV. Gastrointestinal permeability following aspirin intake and prolonged running. Med Sci Sports Exerc 1996; 28(6): 698-705.

19. Winne D. Models of the relationship between drug absorption and the intestinal blood flow. In Shepherd \& Granger (Eds.). Physiology of intestinal circulation. pp 289. Raven Press New York 1984. 
20. Fordtran JS, Saltin B. Gastric emptying and intestinal absorption during prolonged severe exercise. J Appl Physiol 1967; 23(3): 331-335.

21. Kuipers H, Verstappen FTJ, Keizer HA, Geurten P, Van Kranenburg G. Variability of aerobic performance in the laboratory and its physiologic correlates. Int $J$ Sports Med 1985; 6: 197-201.

22. Van Nieuwenhoven MA, Wagenmakers AJM. Senden JMG, Brouns F, Brummer R-JM. The assessment of gastric emptying of liquids during exercise using $a\left[{ }^{13} \mathrm{C}\right]$ acetate breath test. Eur J Physiol 1997; 434: R39-R46, A12.

23. Van Nieuwenhoven MA, Wagenmakers AJM, Brouns F, Brummer R-JM. Effect of mode of administration of $\left[{ }^{13} \mathrm{C}\right]$-acetate on $\left[{ }^{13} \mathrm{C}\right]$-appearance in breath: implications for the gastric emptying breath test. Gastroenterology 1997; 112(4): A843.

24. Levitt MD. Production and excretion of hydrogen gas in man. N Engl J Med 1969; 281 (3): $122-127$.

25. Rooyakkers DR, van Eijk HM, Deutz NEP. Simple and sensitive multi-sugar-probe gut permeability test by high-performance liquid chromatography with fluorescence labelling. J Chromatogr A 1996; 730(1-2): 99-105.

26. Yamada T. Textbook of Gastroenterology, volume 1. J.B. Lippincott Company Philadelphia, USA, 1991.

27. Anand N, Paterson WG. Role of nitric oxide in esophageal peristalsis. Am $J$ Physiol 1994; 266: G123-G131.

28. Konturek S, Falser J, Obtulowicz W. Effect of exercise on gastrointestinal secretions. J Appl Physiol 1973; 34: 324-328.

29. Wade OL, Combes B, Chilos AW, et al. The effect of exercise on the splanchnic blood flow and splanchnic blood volume in normal men. Clin Sci 1956; 15: 457-43.

30. Rowell LR, Blackmon JR, Bruce RA. Indocyanin green clearance and estimated blood flow during mild to maximal exercise in upright man. J Clin Invest 1964; 43: $1677-1690$.

31. Van Nieuwenhoven MA, Brouns F, Brummer R-JM. Ambulatory measurement of esophageal motility. LES pressure and gastroesophageal reflux during exercise. Gastroenterology 1996; 110 : A704.

32. Peters O, Peters P, Clarys JP, De Meirleir K, Devis G. Esophageal motility and exercise. Gastroenterology 1988; 94: A351.

33. Schoeman MN, Tippett MD, Akkermans LMA, Dent J, Holloway RH. Mechanisms of gastroesophageal reflux in ambulant healthy human subjects. Gastroenterology 1995; 108: 83-91.

34. Soffer EE, Summers RW, Gisolfi C. Effect of exercise on intestinal motility and transit time in athletes. Am J Physiol 1991; 260: G698-G702.

35. Peters HPF. Gastrointestinal symptoms and dysfunction during prolonged exercise. Thesis Utrecht University, 1995.

36. Bjarnason I, MacPherson A, Hollander D. Intestinal permeability, an overview. Gastroenterology 1995; 108: 1566-1581.

37. Pals KL, Chang R-T, Ryan AJ, Gisolfi CV. Effect of running on intestinal permeability. J Appl Physiol 1997; 82(2): 571-576. 
94 


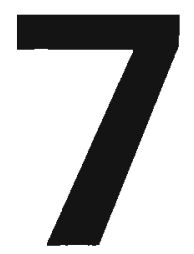

\section{Gastrointestinal function} during exercise: a comparison between water, a sports drink and a sports drink with caffeine

MA van Nieuwenhoven, R-JM Brummer, F Brouns 


\section{Abstract}

\section{Introduction}

Caffeine is suspected to affect gastrointestinal function. We therefore investigated whether supplementation of a sports drink (CES) with $150 \mathrm{mg} / \mathrm{L}$ caffeine leads to alterations in gastrointestinal variables, compared to a normal CES and water, using a standardized rest-exercise-rest protocol.

\section{Methods}

Ten well-trained subjects underwent 3 times a rest-cycling-rest protocol. Esophageal motility, gastroesophageal reflux and intragastric $\mathrm{pH}$ were measured using a transnasal catheter. Orocecal transit time (OCTT) was measured using breath $\mathrm{H}_{2}$-measurements. A sugar absorption test was applied to determine intestinal permeability and glucose absorption. Gastric emptying was measured using the ${ }^{13} \mathrm{C}$-acetate breath test.

\section{Results}

In the postexercise episode, mid-esophageal pressure was significantly lower in the CES + caffeine trial, compared to water $(P=0.017)$. There were no significant differences between the three drinks for gastric $\mathrm{pH}$ and reflux during the pre-exercise, the cycling and the postexercise episode, respectively. Gastric emptying, orocecal transit time and intestinal permeability showed no significant differences between the three trials. However, glucose absorption was significantly increased in the CES + caffeine trial. comprared to CES $(P=0.017)$.

\section{Conclusion}

No significant differences in gastroesophageal reflux, gastric $\mathrm{pH}$ or gastrointestinal transit could be observed between the CES, the CES + caffeine and the water trial, in a controlled rest-cycling-rest protocol. However, intestinal glucose uptake was increased in the CES + caffeine trial. 


\section{Introduction}

Participants in endurance events frequently suffer from gastrointestinal (GI) symptoms such as abdominal pain, urge to defecate, diarrhea, heartburn, nausea and vomiting. This suggests that exercise can influence gastrointestinal function.

The underlying etiology of Gl symptoms associated with exercise has been little studied and remains speculative. One of the most common theories includes an exercise-induced reduction in $\mathrm{Gl}$ blood flow. Although it is very difficult to measure Gl blood flow during exercise, it has been reported that at maximal exercise intensity the flow may be reduced to $20 \%$ of the resting value in both trained and untrained people ${ }^{1}$. Sympathic output plays an important role in redistributing blood flow during exercise. Blood flow may be decreased to critical levels during maximal sympathic stimulation. As a result, gastrointestinal motility, intestinal absorption and mucosal integrity may be disturbed. This may be a cause for exercise-induced GI symptoms. Training status, exercise intensity, hydration state and nutrition seem to play an important role. GI symptoms during strenuous physical activity occur more frequently in untrained people, compared to trained people and more in females than in males. In "gliding" sports like cycling, skating and swimming the prevalence of GI symptoms is lower, compared to running ${ }^{3}$.

Several studies have reported an increase of gastroesophageal reflux during exercise $^{3-6}$. Gastric emptying may also be altered as a result of physical exercise $^{7}$. There is no consensus about the effect of exercise on the orocecal transit time (OCTT); i.e. the time which elapses between oral ingestion and the arrival of the non-absorbed fraction of the meal in the proximal colon ${ }^{2}$. Data concerning the effect of exercise on intestinal permeability is also scarce. $\emptyset$ ktedalen et al. $^{8}$ and Moses et al. $^{9}$ observed an increase in intestinal permeability. Ryan et al. ${ }^{10}$ observed no change in permeability in relation to exercise. It has been suggested that a reduction of mesenteric blood flow by more than $50 \%$ causes a linear fall in the rate of glucose absorption ${ }^{11}$.

During strenuous physical exercise, liquids are the major energy source consumed. Liquids are also necessary for rehydration. An ideal sports drink is a good thirst quencher, provides sufficient energy and electrolytes, is rapidly absorbed and has a good palatability. Recently it has been established that caffeine enhances endurance performance, even below the IOC-limit ${ }^{12.13}$. Hence, supplementation of sports drinks with caffeine is a logical step, with the prerequisite that the resulting levels in urine remain below the reference limit of $12 \mathrm{mg} / \mathrm{L}$, as indicated by the International Olympic Committee, Lausanne, Switzerland. In this respect, widely used and available commercial sports drinks are nowadays supplemented with $150 \mathrm{mg} / \mathrm{L}$ caffeine.

A second prerequisite for beneficial use of caffeine ingestion during exercise is that caffeine does not induce gastrointestinal upset. There are no recent studies 
on the effect of caffeine on the GI tract. Studies carried out in the seventies and earlier indicate that caffeine may increase gastric acid secretion ${ }^{14.15}$. Other researchers did not find an effect of caffeine on acid secretion ${ }^{16.17}$.

Caffeine has also been suspected to induce gastroesophageal reflux by lowering the lower esophageal sphincter pressure ${ }^{18}$. However, this characteristic is not very well established. Caffeine in high doses has been suggested to induce jejunal secretion ${ }^{19}$. Wald and co-workers carried out a triple lumen intestinal perfusion study, in which they observed a net jejunal secretion in all subjects after administration of a test solution containing a caffeine dose of $1000 \mathrm{mg} / \mathrm{L}$ and $2000 \mathrm{mg} / \mathrm{L}$. It was suggested that this secretion might accelerate small bowel transit and hence give rise to lower Gl symptoms. The effect of caffeine on esophageal motor function, gastrointestinal motility, intestinal permeability and jejunal glucose absorption is unknown.

The aim of the present study was to investigate whether a sports drink, or supplementation of a sports drink with caffeine leads to alterations in gastrointestinal variables, compared to water. We compared a carbohydrateelectrolyte solution (CES) and a CES with the addition of $150 \mathrm{mg}$ caffeine/L with water, in a standardized rest-cycling-rest protocol, which was as noninvasive as possible.

\section{Subjects and methods}

\section{Subjects}

Ten well-trained male subjects (age 18-25 years), who did not suffer from exercise-induced GI symptoms, were studied on 4 different days. Their diet was standardized during $24 \mathrm{~h}$ preceding the test days. This period is sufficient for removal of most of the caffeine which might be present in the plasma of the subjects. The subjects were not allowed to consume fiber-rich or spicy food products, alcohol, caffeine-containing products, drugs, or to perform physical exercise the day preceding the test days.

\section{Design of the study}

Firstly, the subjects underwent a slow pull-through manometry in order to locate the lower esophageal sphincter (LES) and to exclude gross manometric abnormalities. Subsequently the subjects underwent a Wmax cycling test in order to determine their maximal power output ${ }^{20}$. On the three actual testing days the subjects underwent a rest-cycling-rest protocol. The test drinks were studied in randomised order. 


\section{Test protocol}

After an overnight fast, the subject arrived at the laboratory at $8.00 \mathrm{AM}$. A thin catheter allowing the registration of esophageal motility, gastroesophageal reflux and intragastric $\mathrm{pH}$ (Koningsberg, USA) was inserted transnasally. The $\mathrm{pH}$ was simultaneously measured $5 \mathrm{~cm}$ above the LES and in the fundus of the stomach, $10 \mathrm{~cm}$ below the LES. Esophageal pressure was measured at 13 (P1) and 3 (P3) $\mathrm{cm}$ above the LES. The catheter was connected with an ambulatory datarecorder (MMS, Enschede, The Netherlands), thus allowing continuous registration of $\mathrm{pH}$ and pressure. Subsequently the subjects received a standard liquid breakfast $(4 \mathrm{ml} / \mathrm{kg}$ body weight, $\mathrm{pH}=5.8)$ and remained seated in a chair for $60 \mathrm{~min}$. During this period resting values for esophageal motility, gastric $\mathrm{pH}$ and gastroesophageal reflux were obtained. Subsequently the subjects emptied their bladder and mounted a stationary bicycle ergometer (Lode, Groningen, The Netherlands). A warming-up was performed for $10 \mathrm{~min}$ at $100 \mathrm{~W}$. During the final minute of this warming-up, $2 \mathrm{ml} / \mathrm{kg}$ body weight of the test drink was ingested. The composition of the test and of the liquid meal is displayed in Table 7.1. These drinks, which were commercially available sports drinks, contained some other compounds, besides carbohydrates and electrolytes, as well. These compounds, however, are not very likely to affect Gl function. At $\mathrm{t}=0$ of the subsequent exercise episode, the cycling intensity was increased to a load of $70 \%$ of the subjects previously determined maximal power output (Wmax $70 \%$ ), which was maintained for $90 \mathrm{~min}$. However, if the subject was not able to maintain this load, the exercise intensity was decreased in $5 \%$ steps until the subject was able to complete the 90 min cycling. During this period, the subjects received $2 \mathrm{ml} / \mathrm{kg}$ body weight of the test drink at $t=20$, and 5 $\mathrm{ml} / \mathrm{kg}$ body weight of the test drink at $\mathrm{t}=40$, in order to compensate for sweat loss and to minimise dehydration. All drinks were at room temperature $\left(19^{\circ} \mathrm{C}\right)$. At $\mathrm{t}=90$ the subjects dismounted the cycle ergometer after which they remained normally seated in a comfortable chair for $210 \mathrm{~min}$ to obtain postexercise resting values. At $t=150$ the subjects received a standard liquid lunch $(4 \mathrm{ml} / \mathrm{kg}$ body weight). For each breath sample the subjects breathed for 2 min through a mouthpiece, which was connected to a mixing chamber. Breath samples for $\mathrm{H}_{2-}$ and ${ }^{13} \mathrm{CO}_{2}$ analysis were collected from the mixing chamber at $15 \mathrm{~min}$ and at $5 \mathrm{~min}$ intervals, respectively. From $\mathrm{t}=0$ to $\mathrm{t}=300$ the total urine production was collected. 
Table 7.1 Composition of the CES, the CES + caffeine and the liquid meal.

\begin{tabular}{lll}
\hline Content CES/100 ml & Content CES + caf/100 ml & Content liquid meal/100 ml \\
\hline & Caffeine $15 \mathrm{mg}$ & $122.4 \mathrm{Kcal}$ \\
$30.0 \mathrm{Kcal}$ & $30.0 \mathrm{Kcal}$ & CHO $17.5 \mathrm{~g}$ \\
$\mathrm{CHO} 6.88 \mathrm{~g}$ & CHO $6.88 \mathrm{~g}$ & Fat $3.4 \mathrm{~g}$ \\
Vitamins $10.6 \mathrm{mg}$ & Vitamins $10.6 \mathrm{mg}$ & Protein $5.4 \mathrm{~g}$ \\
Electrolytes $119 \mathrm{mg}$ & Electrolytes $119 \mathrm{mg}$ & Lactose $0.27 \mathrm{~g}$ \\
Amino acids $21 \mathrm{mg}$ & Amino acids $21 \mathrm{mg}$ & Fiber $1.08 \mathrm{~g}$ \\
Myoinositol $5.1 \mathrm{mg}$ & Myoinositol $5.1 \mathrm{mg}$ & Electrolytes $130 \mathrm{mg}$ \\
Choline $10 \mathrm{mg}$ & Choline $10 \mathrm{mg}$ & Vitamins $3.9 \mathrm{mg}$ \\
pH 3.95 & pH 3.75 & pH 5.8 \\
\hline
\end{tabular}

\section{Testing procedures}

\section{Esophageal manometric variables}

Two solid-state pressure sensors measured esophageal pressure at 13 (P1) and 3 (P3) cm above the LES, respectively. The catheter was connected with an ambulatory datarecorder (MMS, Enschede, The Netherlands), thus allowing continuous registration of $\mathrm{pH}$ and pressure. The stored data were transferred from the ambulatory datalogger to a personal computer system, and edited using specialised manometry software (MMS, Enschede, The Netherlands).

In each episode of the experiments the following variables were evaluated:

The number of peristaltic contractions.

- The mean peristaltic pressure at P1 and P3.

The mean duration of peristaltic pressure events at P1 and P3.

- The peristaltic velocity.

\section{Gastroesophageal reflux}

Esophageal $\mathrm{pH}$ was measured using a solid state $\mathrm{pH}$ electrode, at $5 \mathrm{~cm}$ above the LES. A reflux episode was defined as a period in which the $\mathrm{pH}$ in the esophagus, at $5 \mathrm{~cm}$ above the LES, was lower than $\mathrm{pH} 4$. The following variables were determined during each episode of the experiments:

- The number of reflux episodes.

- The duration of the reflux episodes as a percentage of time.

\section{Gastric $\boldsymbol{p H}$}

The intragastric $\mathrm{pH}$ was measured in the fundus of the stomach at $10 \mathrm{~cm}$ below the LES, using a solid state $\mathrm{pH}$ electrode. The following variables were determined during each episode of the experiments:

- Median $\mathrm{pH}$ in the fundus.

- Percentage of time in which the $\mathrm{pH}$ in the fundus was lower than 4 . 
These variables were determined during the pre-exercise episode, the cycling episode, and the postexercise episode. No corrections were made for $\mathrm{pH}$ changes due to the ingested drinks and liquid meals, as they were similar for the three trials.

\section{Gastric emptying}

\section{Assessment and mathematical evaluation of ${ }^{13} \mathrm{C}$-enrichment}

The drink administered at $\mathrm{t}=40$ during the cycling episode contained $150 \mathrm{mg}$ sodium $\left[1-{ }^{13} \mathrm{C}\right.$-acetate (99\%; Cambridge Isotope Laboratories, Andover, MA, USA) in order to determine the gastric emptying rate using the ${ }^{13} \mathrm{C}$-acetate breath test. Breath samples for ${ }^{13} \mathrm{CO}_{2}$-enrichment analysis were drawn from the mixing chamber at 5 min intervals from $t=40$ to $t=90$, using Vacutainer tubes. One breath sample was taken before administration of the drink at $t<40$, in order to determine background enrichment. The collected breath samples were analyzed for ${ }^{13} \mathrm{C}$-isotopic enrichment of the expired $\mathrm{CO}_{2}$ using Isotope Ratio Mass Spectrometry (Finnigan MAT 252, USA). The ${ }^{13} \mathrm{C}$-enrichment of $\mathrm{CO}_{2}$ was expressed as the delta $(\delta)$ per mil difference between the ${ }^{13} \mathrm{C} /{ }^{12} \mathrm{C}$-ratio of the breath sample and a known laboratory reference standard according to the formula:

$\delta^{13} \mathrm{C}$ (per mil) $=\left(\left({ }^{13} \mathrm{C} /{ }^{12} \mathrm{C}\right)\right.$ sample $/\left({ }^{13} \mathrm{C} /{ }^{12} \mathrm{C}\right)$ standard -1$) \times 10^{3}$

The $\delta$-value was then related to an international standard, Pee Dee Belemnite (PDB).

The data from the breath enrichment were fitted by non-linear regression analysis according to a dual exponential function with the following features:

$y(t)=a t^{b}\left[c e^{(-t d)}\right]+\mathrm{ft}^{\mathrm{g}}\left[h e^{(-t)}\right]+j$

A dual compartment description of ${ }^{13} \mathrm{CO}_{2}$-production (at ${ }^{\mathrm{b}}$ and $\mathrm{ft}^{\mathrm{g}}$ ) is applied because acetate is oxidised both in the splanchnic area and in the working muscles. The decrease in ${ }^{13} \mathrm{CO}_{2}$-enrichment is also described in 2 factors; the 1 st factor (ce ${ }^{(-t)}$ ) describes washout of ${ }^{13} \mathrm{CO}_{2}$ through the body bicarbonate pool via the breath and the 2 nd factor $\left(\mathrm{he}^{(-\mathrm{ti})}\right)$ describes other processes of ${ }^{13} \mathrm{CO}_{2}$ removal; sequestration of ${ }^{13} \mathrm{CO}_{2}$ in bone, excretion via urine and incorporation into glucose. In this equation $a, b, c, d, f, g, h$ and $i$ are constants, $t$ is the time and $j$ is the background enrichment.

In the present study the results are based on the Time to Peak ${ }^{13} \mathrm{C}$-enrichment in the breath samples $\left({ }^{13} \mathrm{C}-T T P\right)$ derived from the dual exponential function. The ${ }^{13} \mathrm{C}$ - TTP was interpreted from the curve using the GraphPad software and was considered as the parameter of gastric emptying ${ }^{21}$. 


\section{Orocecal transit time (OCTT)}

The drink administered at $\mathrm{t}=0$ of the cycling episode contained a non-digestible soluble carbohydrate $15 \mathrm{~g}$ lactulose, Centrafarm syrup, $670 \mathrm{mg} / \mathrm{ml}$, Etten-Leur, The Netherlands) allowing the measurement of OCTT via $\mathrm{H}_{2}$-measurement in breath. As soon as the lactulose enters the colon, bacterial fermentation will take place, and $\mathrm{H}_{2}$-gas will be produced ${ }^{22}$. Breath samples for $\mathrm{H}_{2}$-analysis were collected from the mixing chamber at 15 min intervals, starting at $\mathrm{t}=0$, using a $140 \mathrm{ml}$ syringe, and were analyzed for $\mathrm{H}_{2}$-enrichment using a sensitive electrochemical exhaled hydrogen monitor (GMI Medical Ltd., Renfrew, Scotland). The OCTT was determined using the time of onset of a sustained increase in breath $\mathrm{H}_{2}$, which is the first breath sample that shows a higher breath $\mathrm{H}_{2}$ than the preceding one, followed by two or more breath samples that show a further increase.

\section{Intestinal permeability and glucose absorption}

The drink administered at $\mathrm{t}=0$ of the cycling episode contained $5 \mathrm{~g}$ lactulose (Centrafarm syrup, $670 \mathrm{mg} / \mathrm{ml}$, Etten-Leur, The Netherlands), $0.5 \mathrm{~g}$ rhamnose and $0.35 \mathrm{~g}$ 3-O-D-methyl-M-glucose (3-OMG) (Sigma Chemical Co., USA), allowing the measurement of intestinal permeability and intestinal glucose absorption $^{1 \theta}$. At the end of the experiment, at $t=300$, total urine production was collected, its volume was determined, and a small portion was stored at $-80^{\circ} \mathrm{C}$ for lactulose, rhamnose and 3-OMG determination. The urinary lactulose, rhamnose and 3-OMG excretion was determined by a validated, sensitive, newly developed fluorescent detection HPLC method, which is extensively described by Rooyakkers et al. ${ }^{23}$. Subsequently the lactulose and rhamnose recoveries and the lactulose/rhamnose and 3-OMG/rhamnose ratio's were calculated.

\section{Statistics}

Differences between the episodes between the three trials were analyzed using Friedman's nonparametric tests. The level of confidence was set at $P=0.05$. If Friedman's analysis demonstrated a significant difference, Wilcoxon's Signed Rank test was performed, corrected for multiple comparisons using a Bonferroni correction, which is the level of confidence $(P=0.05)$, divided by the number of comparisons, in this case 3 . This correction results in a level of confidence of $\mathrm{P}=0.017$. Differences between two related samples were analyzed using Wilcoxon's Signed Rank test. The level of confidence was set at $P=0.05$. Data are presented as median (range). All statistical analyses were performed using SPSS 7.5 for Windows statistical package. 


\section{Results}

All the subjects were able to complete the 90 min cycling episode. However, it was frequently necessary to decrease the cycling load in $5 \%$ steps. The course of the relative median cycling loads was: at $t=0: 70 \% W \max (70-70)$, at $t=30$ : $65 \% W \max (65-70)$, at $t=60: 60 \% W \max (60-65)$ and at $t=90: 60 \% W \max$ (55-65). The median initial load (70\% Wmax) was $243.5 \mathrm{~W}$ (217-350), and the median load at the end of the 90 min cycling episode was $215.5 \mathrm{~W}$ (185-325). During the experiments the body weight decreased $0.8 \mathrm{~kg}$; from $72.3 \mathrm{~kg}(55.7$ 88.7) at the start to $71.5 \mathrm{~kg}(54.5-87.8)$ at the end of the experiment, indicating that dehydration almost not occurred.

\section{Esophageal motility}

The data from the esophageal measurements and the P-values from the Friedman tests are displayed in Table 7.2. In the postexercise episode the peristaltic pressure at P1 was significantly lower in the CES + caffeine trial. After Bonferroni correction Wilcoxon's Signed Rank test demonstrated no significant difference between CES + caffeine and CES $(P=0.028)$, and a significant difference between CES + caffeine and water $(P=0.017)$, respectively.

Table 7.2 Results of the manometry measurements in median (range) of the esophagus in the three trials, both during cycling and postexercise episodes $\left(n=10,{ }^{\circ}=\right.$ significant difference).

\begin{tabular}{|c|c|c|c|c|c|c|c|c|}
\hline & \multicolumn{2}{|l|}{ CES } & \multicolumn{2}{|l|}{ CES + caffaine } & \multicolumn{2}{|l|}{ Water } & \multicolumn{2}{|c|}{ Statirticu } \\
\hline & Cycling & Post-exc & Exarcise & Post-exc & Cycling & Po:t-oxc & Exc & Port-exc \\
\hline Numb. of contract. & $\begin{array}{l}24.0 \\
(17.0-73.0)\end{array}$ & $\begin{array}{l}95.5 \\
(21.0-146.0)\end{array}$ & $\begin{array}{l}35.0 \\
15.0-144.01\end{array}$ & $\begin{array}{l}97.0 \\
(41.9 \cdot 183.0)\end{array}$ & $\begin{array}{l}31.0 \\
(8.0-64.0)\end{array}$ & $\begin{array}{l}101.0 \\
(38.0 \cdot 153.0)\end{array}$ & 0.687 & 0.175 \\
\hline $\begin{array}{l}\text { Pressure } \mathrm{Pl} \\
\left(\mathrm{cm} \mathrm{H}_{2} \mathrm{O}\right)\end{array}$ & $\begin{array}{l}73.4 \\
(45.3-89.0)\end{array}$ & $\begin{array}{l}73.5 \\
(49.2 \cdot 129.9)\end{array}$ & $\begin{array}{l}71.3 \\
|55.6-103.8|\end{array}$ & $\begin{array}{l}63.5 \\
(48.1-99.7)\end{array}$ & $\begin{array}{l}68.2 \\
(50.2-78.8)\end{array}$ & $\begin{array}{l}73.4 \\
(49.7-115.3)\end{array}$ & 0.417 & $0.044^{*}$ \\
\hline $\begin{array}{l}\text { Pressure P3 } \\
\left(\mathrm{cm} \mathrm{H}_{2} \mathrm{O}\right)\end{array}$ & $\begin{array}{l}74.8 \\
(62.9-162.5)\end{array}$ & $\begin{array}{l}69.7 \\
(54.3-118.7)\end{array}$ & $\begin{array}{l}87.4 \\
(53.9-148.0)\end{array}$ & $\begin{array}{l}59.6 \\
(43.4-142.9)\end{array}$ & $\begin{array}{l}73.8 \\
(49.5-160.9)\end{array}$ & $\begin{array}{l}70.9 \\
(48.2-151.7)\end{array}$ & 0.882 & 0.196 \\
\hline $\begin{array}{l}\text { Duration P } \\
\text { (sec) }\end{array}$ & $\begin{array}{l}1.72 \\
(1.29-2.03)\end{array}$ & $\begin{array}{l}1.99 \\
(1.36-2.57)\end{array}$ & $\begin{array}{l}1.68 \\
\{1.43 \cdot 2.22\}\end{array}$ & $\begin{array}{l}1.82 \\
(1.27-2.57)\end{array}$ & $\begin{array}{l}1.52 \\
(1.27-2.03)\end{array}$ & $\begin{array}{l}1.91 \\
(1.31-2.57)\end{array}$ & 0.446 & $0.030^{\circ}$ \\
\hline $\begin{array}{l}\text { Duration P3 } \\
\text { (sec) }\end{array}$ & $\begin{array}{l}1.68 \\
(1.33 \cdot 2.73)\end{array}$ & $\begin{array}{l}2.26 \\
(1.72-4.14)\end{array}$ & $\begin{array}{l}1.84 \\
\{1.41 \cdot 2.51\}\end{array}$ & $\begin{array}{l}2.44 \\
\{1.65-3.19\}\end{array}$ & $\begin{array}{l}1.52 \\
(1.05-2.38)\end{array}$ & $\begin{array}{l}2.16 \\
(1.78-4.88)\end{array}$ & 0.687 & 0.412 \\
\hline $\begin{array}{l}\text { Velocity } \\
(\mathrm{cm} / \mathrm{sec})\end{array}$ & $\begin{array}{l}4.92 \\
(4.22 \cdot 7.08)\end{array}$ & $\begin{array}{l}3.58 \\
(3.0 \uparrow-5.45)\end{array}$ & $\begin{array}{l}4.80 \\
(3.15-5.89)\end{array}$ & $\begin{array}{l}3.82 \\
(2.37-5.29)\end{array}$ & $\begin{array}{l}5.30 \\
\{4.62-8.461\end{array}$ & $\begin{array}{l}3.28 \\
(2.88-4.52)\end{array}$ & 0.223 & 0.328 \\
\hline
\end{tabular}




\section{Gastric pH}

The results of the gastric $\mathrm{pH}$ measurements are displayed in Table 7.3.

Table 7.3 Results of the gastric $\mathrm{pH}$ measurements in median (range) in the three trials, during the pre-exercise, cycling and postexercise episodes $(n=10)$.

\begin{tabular}{|c|c|c|c|c|c|c|c|c|c|}
\hline & \multicolumn{3}{|l|}{ CES } & \multicolumn{3}{|c|}{ CES + cafteine } & \multicolumn{3}{|l|}{ Water } \\
\hline & Pre-exc & Cycling & Post+exc & Pre-exc & Cycillng & Post-exc & Pre-exc & Cycling & Post-exc \\
\hline \multirow[t]{2}{*}{ Median $\mathrm{pH}$} & 5.5 & 3.6 & 3.3 & 58 & 4.3 & 3.0 & 5.7 & 3.1 & 2.9 \\
\hline & $(4.8-6.9)$ & $(2.8 \cdot 6.0)$ & $(2,2-5.9)$ & $\{4.4-6.3\}$ & $(2.8-5.5)$ & $(2.3-5.8)$ & $(1.5 \cdot 7.1)$ & $(2.2-5.2)$ & $(2.1-6.1\}$ \\
\hline \multirow[t]{2}{*}{$\% \mathrm{pH}<4$} & 2.6 & 62.2 & 60.8 & 9.6 & 14.9 & 56.7 & 3.8 & 99.8 & 75.8 \\
\hline & $(0.0 \cdot 27.4)$ & $(4.2 \cdot 100)$ & $\{23.1-77.9\}$ & $(0.1-33.2)$ & $(0.0-97.4)$ & $\mid 0.0-93.41$ & $(0,0-93.41$ & $(8.2-100)$ & $(23.0-97.9)$ \\
\hline
\end{tabular}

\section{Between the trials}

Friedman's analysis showed no significant difference between the three drinks for median gastric $\mathrm{pH}$ during the pre-exercise $(P=0.924)$, cycling $(P=0.060)$ and the postexercise episodes $(P=0.531)$, respectively. Friedman's analysis showed also no significant difference between the three drinks for the percentage of time in which the gastric $\mathrm{pH}<4$ during the pre-exercise $(P=0.497)$, cycling $(P=0.062)$ and the postexercise episodes $(P=0.325)$, respectively.

\section{Within the trials}

Friedman's analysis demonstrated a significant difference in median gastric $\mathrm{pH}$ within the CES trial $(P=0.002)$, the CES + caffeine trial $(P=0.001)$ and the water trial $(P=0.02)$. After Bonferroni correction, Wicoxon's Signed Rank test demonstrated significant differences in, the CES trial between the pre-exercise and the cycling episode $(P=0.008)$ and between the pre-exercise and the postexercise episode $(P=0.012)$, the CES + caffeine trial between the preexercise and the cycling episode $(P=0.005)$ and between the pre-exercise and the postexercise episode $(P=0.007)$, the water trial between the pre-exercise and cycling episode $(P=0.012)$ and between the pre-exercise and postexercise episode (P $=0.017)$.

Friedman's analysis demonstrated a significant difference in the percentage of time in which the gastric $\mathrm{pH}<4$ in the CES trial $(P=0.002)$ and in the water trial $(P=0.004)$, but not in the CES + caffeine trial $(P=0.273)$. After Bonferroni correction, Wicoxon's Signed Rank test demonstrated significant differences in: the CES trial between the pre-exercise and the cycling episode $(P=0.008)$ and between the pre-exercise and postexercise episode $(P=0.012)$ : the water trial between the pre-exercise and cycling episode $(P=0.005)$ and between the preexercise and postexercise episode $(P=0.011)$. However, these results could be expected as a result of ingestion of the drinks and liquid meals. 


\section{Gastroesophageal reflux}

The results of the gastroesophageal reflux measurements are displayed in Figure 7.1. Friedman's analysis showed no significant differences between the preexercise, the cycling and the postexercise episodes in both the number of reflux episodes $(P=0.129,0.610$ and 0.786 , respectively) and the duration of reflux as a percentage of time $(P=0.237,0.612$ and 0.463 , respectively).

The results of the analyses of differences in gastroesophageal reflux as a percentage of time within the trials are displayed in Table 7.4. The P-values from Wilcoxon's Signed Rank test show no significant difference in reflux duration as a percentage of time within the 3 trials.

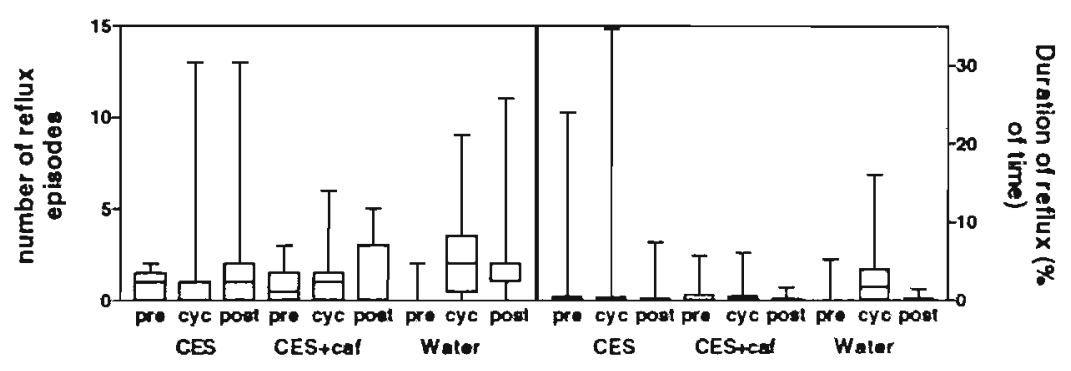

Figure 7.1 Results of the gastroesophageal reflux measurements displayed in a box-and whiskers plot (median with quartiles and rangel, in the three trials, during the preexercise, cycling and postexercise episodes, respectively $(n=10)$. No significant differences were observed.

Table 7.4 P-values of Wilcoxon's Signed Rank test; comparison of relative reflux time within the trials $(n=10)$.

\begin{tabular}{lll}
\hline Trial & Analysis & Peflux time, signif. \\
\hline CES & Pre vs. exc. & $P=0.6$ \\
& Pre vs. post & $P=0.25$ \\
CES + caffeine & Exc vs. post & $P=0.89$ \\
& Pre vs. exc. & $P=1.0$ \\
& Pre vs. post & $P=0.50$ \\
Water & Exc vs. post & $P=0.37$ \\
& Pre vs. exc. & $P=0.09$ \\
& Pre vs. post & $P=0.31$ \\
\hline
\end{tabular}

\section{Gastric emptying and orocecal transit time (OCTT)}

Neither gastric emptying nor the OCTT show differences between the three trials. ${ }^{13} \mathrm{C}$-TTP in the CES trial was $22.8 \mathrm{~min}$ (15.7-50.0), in the CES + caffeine trial it was $24.2 \mathrm{~min}(19.8-26.4)$, and in the water trial it was $19.2 \mathrm{~min}(14.2$ 44.1) $(P=0.066)$. OCTT in the CES trial was $140.0 \mathrm{~min}(105.0-195.0)$, in the 
CES + caffeine trial it was $120.0 \mathrm{~min}$ (95.0-180.0) and in the water trial it was $110.0 \mathrm{~min}(95.0-200.0),(P=0.772)$.

\section{Intestinal permeability and glucose absorption}

The results of the intestinal permeability and the 3-OMG absorption measurements are displayed in Figure 7.2. There was no significant difference in the lactulose/rhamnose ratio between the three trials (CES: 0.0067 10.0017$0.0141)$, CES + caffeine: 0.0080 (0.0047-0.0112) and water: 0.0093 (0.0042-0.0181), respectively, $P=0.301)$. No significant difference could be observed in the urinary lactulose, rhamnose and 3-OMG recoveries (lactulose: CES: 0.089 (0.038-0.173), CES + caffeine: $0.093(0.006-0.149)$ and water: $0.106(0.055-0.249), P=0.497$; rhamnose: CES: 15.00 (8.54-23.99), CES + caffeine: $13.24(0.70-15.68)$ and water: $12.01(6.09-16.66), P=0.061$; 3-OMG: CES 36.15 (21.06-62.12), CES + caffeine: 40.18 (2.10-50.45) and water: 39.23 (15.93-55.76), $P=0.905)$. Friedman's analysis, however, demonstrated a significant difference in the 3-OMG/rhamnose ratio between the three trials (CES: 2.64 (2.03-3.91), CES + caffeine: 3.24 (2.36-4.34) and water: 2.91 (2.45-4.69), $P=0.007)$. After Bonferroni correction, Wilcoxon's Signed Rank test demonstrated a significant increase in the 3-OMG/rhamnose ratio in the CES + caffeine trial, compared to CES $(P=0.017)$, and reached almost significance in the CES compared to water $(P=0.037)$, respectively.

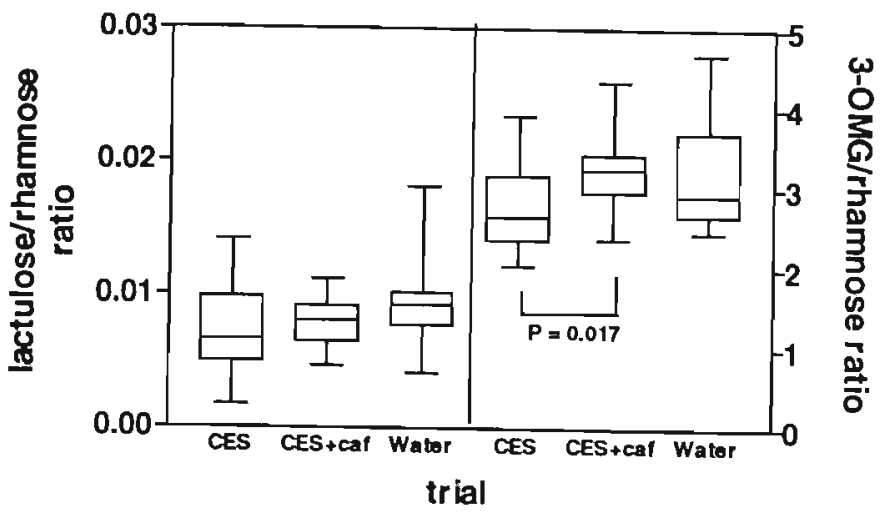

Figure 7.2 The lactulose/rhamnose $(n=10, P=0,301)$ and the 3-OMG/rhamnose ratio $(n=10$, $P-0.007$ ) in the three trials displayed in a box-and whiskers plot (median with quartiles and range). 


\section{Discussion}

The esophagus is composed of skeletal (striated) and smooth muscle. The proximal $5 \%$ of the esophagus is striated. The proportion of smooth muscle increases distally. The distal 50-60\% consists entirely of smooth muscle. The results of the present study indicate that caffeine decreases the peristaltic pressure in the mixed striated and smooth muscle part of the esophagus (P1) in the postexercise episode. The control mechanisms of esophageal motor function are complex and not completely elucidated yet. The extrinsic innervation of the esophagus occurs via the vagal fibers. The striated muscle part of the esophagus is innervated by axons of cholinergic lower motor neurons with their cell bodies in the nucleus ambiguus. The smooth muscle of the esophagus is innervated by the dorsal motor nucleus of the vagus.

This observation might be explained by caffeine-induced inhibition of the cholinergic innervation of the striated muscle component, since no changes in the distal esophagus (P3), which is entirely composed of smooth muscle, could be observed. The alteration found in the simultaneous and non-transmitted pressure events during the cycling episode are unlikely to be of physiological significance, because of the small number of simultaneous contractions.

The present study showed no significant differences in gastroesophageal reflux, gastrointestinal transit time or gastric $\mathrm{pH}$ during a rest-cycling-rest protocol between a CES, a caffeine-supplemented CES and water. It has been hypothesised that both exercise and caffeine can induce gastroesophageal reflux. Earlier studies at a our department, however, showed that exercise on a stationary bicycle itself does not increase either the number of gastroesophageal reflux episodes, or the percentage of time of reflux, if the experiments are conducted in a well-controlled laboratory setting ${ }^{24}$. These observations are confirmed by the results of the present study, for all three test drinks. The results obtained in the present study do not rule out the possibility that changes in reflux may occur at near maximal exercise intensities, or at higher dosages of caffeine. In this respect, Soffer et al. ${ }^{5.6}$ demonstrated that a significant increase in reflux occurred only at the highest intensity $\left(90 \% \mathrm{VO}_{2 \max }\right.$ for $\left.10 \mathrm{~min}\right)$ in a graded exercise protocol.

Gastroesophageal reflux has also been associated with increased gastric acid production. Some studies in the past reported an increase in acid secretion due to caffeine. Our $\mathrm{pH}$ measurements failed to confirm these observations. This may be due to the relatively low dosage of caffeine (approximately $120 \mathrm{mg}$ ). It can, however, not be excluded that exercise and/or caffeine induce an alteration in basal gastric acid output.

Within the trials, significant differences for both the median gastric $\mathrm{pH}$ and the percentage of time in which the gastric $\mathrm{pH}$ was lower than 4 , were observed. This is possibly explained by the $\mathrm{pH}$ of the used drinks and by the effect of the ingested pre- and postexercise liquid meals on the gastric $\mathrm{pH}$ and not by an 
effect of caffeine or exercise on the gastric $\mathrm{pH}$.

Ingestion of caffeine in dosages from $75-300 \mathrm{mg} / 150 \mathrm{ml}$ is known to induce jejunal secretion, which lasts at least $15 \mathrm{~min}$. This, however, does not result in a change of the liquid $\mathrm{OCTT}{ }^{19}$. This is in contrast with the small intestinal secretion induced by an osmotic load ${ }^{25}$ or cholera enterotoxins ${ }^{26}$. The latter conditions do lead to a decrease of the OCTT. The explanation for the present observation that caffeine does not affect intestinal transit might be that caffeine induced a relaxation of the intestinal smooth muscle, which, in turn, induced an increased intestinal volume capacity, resulting in an unchanged intestinal flow rate.

Caffeine did not induce a significant change in urinary lactulose and rhamnose recovery and lactulose/rhamnose ratio. Intestinal glucose absorption, however, was affected by caffeine. Intestinal glucose uptake is a carrier-mediated transport process. There was a significant difference in rhamnose/3-OMG ratio between water and the CES, and between the CES and the CES + caffeine, respectively. The 3-OMG uptake in the water trial was higher than in the CES trial. This observation may be explained by the fact that the CES contains glucose. The uptake from glucose from the CES is competitive with uptake from 3-OMG, which has a lower affinity for the glucose transport protein, leading to a lower 3-OMG uptake compared to a situation in which glucose is not available. The uptake of 3-OMG was significantly higher in the caffeine supplemented CES, compared to the CES. This might be explained by caffeine-induced enhancement of sodium-glucose-linked transporter (SGLT-1) protein activity, thus leading to an increased jejunal glucose uptake. Each glucose molecule is transported together with 2 sodium ions, which is an energy-requiring transport process involving later basolateral removal of sodium in exchange for potassium through the $\mathrm{Na}^{+} / \mathrm{K}^{+}$-ATPase, creating a gradient for the SGLT-1. A second transporter, GLUT2, is responsible for glucose transport from the enterocyt to the blood. A possible effect of caffeine may also involve the latter two mechanisms. These possible mechanisms might explain the observations of Pizziol et al. ${ }^{27}$, who recently observed that oral caffeine intake induces a rise in blood glucose levels which is insulin-independent. This mechanism may contribute to the ergogenic effect of caffeine on endurance performance.

Summarising, it was demonstrated that 90 min cycling at an intensity of $70 \%$ Wmax does not induce gastroesophageal reflux, or alterations in gastric $\mathrm{pH}$. It can be concluded that ingestion of water, a CES, or addition of caffeine (150 $\mathrm{mg} / \mathrm{L}$ ) to a CES does not lead to significant differences in gastroesophageal reflux, gastric $\mathrm{pH}$ or gastrointestinal transit in a controlled experimental restcycling-rest protocol, in healthy trained individuals. It appeared that caffeine inhibits the cholinergic innnervation of the striated muscle component of the esophagus, leading to a lower peristaltic pressure in the mid-esophagus and that caffeine stimulates glucose uptake in the small bowel. 


\section{References}

1. Clausen JP. Effect of physical training on cardiovascular adjustments to exercise in man. Physiol Rev 1977; 57: 779-781.

2. Brouns F, Beckers E. Is the gut an athletic organ? Sports Med 1993; 15(4): 242-257.

3. Clark CS, Kraus BB, Sinclair J, Castell DO. Gastroesophageal reflux induced by exercise in healthy volunteers. J Am Med Ass 1989; 261: 3599-3601.

4. Kraus BB, Sinclair JW, Castell DO. Gastroesophageal reflux in runners. Characteristics and treatment. Ann Int Med 1990; 112: 429-433.

5. Soffer EE, Merchant RK, Duethman G, Launspach J, Gisolfi C, Adrian TE. Effect of graded exercise on esophageal motility and gastroesophageal reflux in trained athletes. Dig Dis Sci 1993; 38(2): 220-224.

6. Soffer EE, Wilson J, Duethman G, Launspach J, Adrian TE. Effect of graded exercise on esophageal motility and gastroesophageal reflux in nontrained subjects. Dig Dis Sci 1994; 39(1): 193-198.

7. Brouns F. Gastric emptying as a regulatory factor in fluid uptake. Int $J$ Sports Med 1998; 19(2): S125-S128.

8. Øktedalen O, Lunde OC, Opstad PK, Aabakken L, Kvernebo K. Changes in the gastrointestinal mucosa after long-distance running. Scand J Gastroenterol 1992; 27: $270-274$.

9. Moses F, Singh A, Smoak B, Hollander D, Deuster P. Alterations in intestinal permeability during prolonged high-intensity running. Gastroenterology 1991; 100: A472.

10. Ryan AJ, Chang RT, Gisolfi CV. Gastrointestinal permeability following aspirin intake and prolonged running. Med Sci Sports Exerc 1996; 28(6): 698-705.

11. Winne $D$. Models of the relationship between drug absorption and the intestinal blood flow. In Shepherd \& Granger (Eds). Physiology of intestinal circulation. New York, Raven Press 1984; 289.

12. Clarkson PM. Nutrition for improved sports performance. Sports Med 1996; 21(6): 393-401.

13. Tarnopolsky MA. Caffeine and endurance performance. Sports Med 1994; 18(2): 109-125.

14. Roth JA, Ivy AC. The effect of caffeine upon the gastric secretion in the dog. cat and man. Am J Physiol 1944; 141: 454-461.

15. Wright LF, Gibson RG, Hirschowitz RI. Lack of caffeine stimulation of gastrin release in man. Proc Soc Exp Biol Med 1977: 154: 538-539.

16. Börger HW, Schafmayer A, Arnold R, Becker HD, Creutzfeldt W. Der Einfluß van Kaffee und Coffein auf den Serumgastrinspiegel und die Säuresekretion beim Menschen. Dtsch Med Wschr 1976; 101: 455-457.

17. Cohen S, Booth GH. Gastric acid secretion and lower esophageal sphincter pressure in response to coffee and caffeine. New Engl J Med 1975; 293: 897-899.

18. Dennish GW, Castell DO. Caffeine and the lower esophageal sphincter. Am J Dig Dis 1972; 17: 993-996.

19. Wald A, Cack C, Bayless TM. Effect of caffeine on the human small intestine. Gastroenterology 1976; 71: 738-742. 
20. Kuipers H, Verstappen FTJ, Keizer HA, Geurten P, Van Kranenburg G. Variability of aerobic performance in the laboratory and its physiologic correlates. Int $J$ Sports Med 1985; 6: 197-201.

21. Van Nieuwenhoven MA, Wagenmakers AJM, Senden JMG, Brouns F, Brummer R$J M$. The assessment of gastric emptying of liquids during exercise using a $\left[{ }^{13} \mathrm{C}\right]-$ acetate breath test. Eur J Physiol 1997; 434: A12.

22. Levitt MD. Production and excretion of hydrogen gas in man. New Eng $J$ Med 1969; 281(3): 122-127.

23. Rooyakkers DR, van Eijk HM, Deutz NEP. Simple and sensitive multi-sugar-probe gut permeability test by high-performance liquid chromatography with fluorescence labelling. J Chromatogr A 1996; 730(1,2): 99-105.

24. Van Nieuwenhoven MA, Brouns F, Brummer R-JM. Ambulatory measurement of esophageal motility, LES pressure and gastroesophageal reflux during exercise. Gastroenterology 1996; 110: A704.

25. Launiala $K$. The effect of unabsorbed sucrose and mannitol on the small intestinal flow rate and mean transit time. Scand J Gastroenterol 1968; 3: 665-671.

26. Brigham KL, Banwell JG, Pierce NF, Mitra RC, Fedson DS, Mondal A. Indicator dilution studies in the small bowel of patients with cholera diarrhea. The John Hopkins Med J 1970; 127: 97-106.

27. Pizziol A, Tikhonoff V, Paleari CD, Mazza A, Ginococchio G, Onesto C, Pavan L, Casiglia E, Pessina AC. Effects of caffeine on glucose tolerance: A placebocontrolled study. Eur J Clin Nutr 1998; 52: 846-849. 


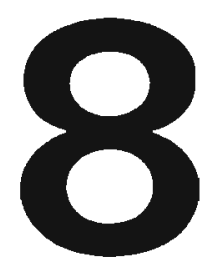

\section{Effects of the degree of} dehydration and hyperthermia on gastrointestinal function at rest and during exercise

MA van Nieuwenhoven, BEPJ Vriens, F Brouns, R-JM Brummer 


\section{Abstract}

\section{Introduction}

Dehydration leads to aggravation of gastrointestinal (GI) complaints during exercise. The aim was to study the effect of dehydration on various Gl parameters during strenuous exercise.

\section{Methods}

Ten healthy well-trained males were investigated in a dehydrated and in an euhydrated condition, respectively. Each experiment consisted of $1 \mathrm{~h}$ pre-exercise, $1.5 \mathrm{~h}$ cycling at $70 \% \mathrm{Wmax}$, and $3.5 \mathrm{~h}$ postexercise, respectively. During cycling, liquid gastric emptying (GE), orocecal transit time (OCTT), intestinal permeability and glucose absorption were measured. Gl symptoms were scored using a questionnaire. Body temperature, plasma volume and vasopressin were measured before and after cycling. Data are presented as median (rang)e.

\section{Results}

Gastric emptying was significantly slower during dehydration (17.1 $\mathrm{min} ; 9.8-38.4)$ than in the control situation (23.6 min (13.7-50.0), $P=0.02)$. OCTT was unchanged (128 min (98-195) vs. $173 \mathrm{~min}$ (98-263), $P=0.18$ ). Dehydration did not change plasma volume, rectal temperature, plasma vasopressin concentration, intestinal permeability or glucose absorption. In the dehydrated experiment, exercise induced a significant increase in nausea $(P=0.01)$ and epigastric cramps $(P=0.05)$, in contrast to the control situation. In both experiments, exercise led to a significant increase in rectal temperature and plasma vasopressin and a significant decrease in plasma volume. The increase in plasma vasopressin was significantly higher in the dehydration experiment $(P=0.015)$. There was no significant difference between postexercise rectal temperatures and plasma volumes. The difference in gastric emptying between the two experiments was significantly correlated with the difference in nausea score $(r=0.87$, $P=0.002$ ).

\section{Conclusion}

Dehydration leads to a delayed gastric emptying during intense cycling, which is significantly associated with an increase in exercise-induced nausea. 


\section{Introduction}

Gastrointestinal (GI) distress is commonly reported by $30-50 \%$ of endurance athletes, especially during marathons, triathlons and other endurance events such as the Tour De France ${ }^{1}$. These symptoms seem to occur more frequently during competition in a warm environment.

Exercise leads to a decreased splanchnic blood flow ${ }^{2}$. It has been suggested that an impaired splanchnic blood flow and oxygen supply may induce changes in nutrient absorption, motility and mucosal integrity of the Gl tract, resulting in gastrointestinal symptoms ${ }^{1}$. Training status, type and intensity of the exercise and pre- and per-exercise diet seem to play an important role in the etiology of this GI distress. Gl symptoms during strenuous physical activity occur more frequently in untrained people, compared to trained subjects and more in females than in males. In "gliding" sports like cycling, skating, swimming and cross-country skiing, the prevalence of serious complaints is lower than in "nongliding" sports such as running. Athletes who compete at the utmost of their physical abilities suffer more from Gl symptoms. Some food substances such as fat, protein and fiber may induce Gl symptoms ${ }^{3}$. Exercise may also induce elevation of plasma concentration of a number of hormones, and many of these hormones are involved in Gl function ${ }^{3.5}$.

There appears to be a relationship between dehydration during endurance exercise and $\mathrm{Gl}$ dysfunction ${ }^{6}$. Prolonged exercise leads to fluid-and electrolyte loss in the form of sweat, which originates from both intracellular and extracellular water compartments.

Dehydration results in hypovolumia, serum hyperosmolarity, an increase in plasma sodium concentration and a stronger rise in the rate of perceived exertion. A significant dehydration may lead to cellular and systemic disturbances. The most serious consequence of dehydration is hyperthermia, with the ultimate risk of a heat stroke?

All studies concerning the effect of physical exercise on Gl function, which have been published so far, focus on only a couple of parameters of Gl function. Therefore, the aim of the present study was to obtain a comprehensive picture of Gl function, comprising gastric emptying, orocecal transit time (OCTT). intestinal permeability, intestinal glucose absorption, plasma vasopressin, plasma volume, rectal body temperature and prevalence of $\mathrm{Gl}$ symptoms simultaneously, during exercise. We used a standard rest-exercise-rest study protocol under a condition in which the subjects started the exercise in either an euhydrated state, or in a dehydrated state, respectively. 


\section{Subjects and methods}

\section{Subjects}

Ten healthy well-trained male subjects (age 18-25 years), who never suffered from exercise-induced GI symptoms, were studied on 3 different days. Their diet was standardized during $24 \mathrm{~h}$ preceding the test days. The subjects were not allowed to consume fiber-rich or spicy foods, alcohol, caffeine-containing foods or drinks, drugs, or to perform physical exercise exceeding normal daily activities the day preceding the test days.

\section{Design of the study}

In a pretest-screening period, all subjects performed a Wmax cycling test ${ }^{8}$ in order to determine their individual maximal power output. On the 2 actual testing days the subjects underwent in random order either a rest-exercise-rest protocol in a euhydrated condition or in a dehydrated condition. The study was approved by the local ethics committee. All subjects received a complete written description of the experiment and were provided with an informed consent form to sign.

\section{Investigation protocol}

\section{Euhydrated experiment}

The test protocol comprised of $60 \mathrm{~min}$ pre-exercise (rest), $90 \mathrm{~min}$ exercise at $70 \%$ Wmax, and $210 \mathrm{~min}$ postexercise (rest). The subjects arrived at the laboratory at $8.00 \mathrm{am}$ in a fasted state. A standard semi-liquid breakfast was provided $(4 \mathrm{ml} / \mathrm{kg}$ body weight, see Table 8.1$)$. A thin catheter was placed in an antecubital vein and the subjects remained seated for $60 \mathrm{~min}$. Subsequently the bladder was emptied, and the body weight was measured.

After this period, the subjects mounted a bicycle ergometer (Lode, Groningen, The Netherlands). A warming-up was performed for $5 \mathrm{~min}$ at a load of $100 \mathrm{~W}$. During the final minute of this warming-up, $2 \mathrm{ml} / \mathrm{kg}$ body weight carbohydrate electrolyte solution (CES) was ingested. The composition of the CES is displayed in Table 8.1. The exercise intensity was increased to $70 \%$ of the subjects maximal workload (70\% Wmax) and the subjects cycled for $90 \mathrm{~min}$. A ventilator provided fresh air on the subject's request. After $20 \mathrm{~min}$ of cycling, the subjects ingested $2 \mathrm{ml} / \mathrm{kg}$ body weight CES, and after $40 \mathrm{~min}$ of cycling, the subjects ingested $5 \mathrm{ml} / \mathrm{kg}$ body weight CES, respectively. All drinks were at room temperature $\left(19^{\circ} \mathrm{C}\right)$. At $t=90$ the subjects dismounted the cycle ergometer after which they remained normally seated in a comfortable chair for $210 \mathrm{~min}$ to obtain postexercise rest values. At $t=150$ the subjects received a standard liquid lunch $(4 \mathrm{ml} / \mathrm{kg}$ body weight, see Table 8.1). Breath samples for ${ }^{13} \mathrm{CO}_{2}$ - and $\mathrm{H}_{2}$-measurements were collected from the mixing chamber at $5 \mathrm{~min}$ and at $15 \mathrm{~min}$ intervals, respectively. For each breath sample, the subjects 
breathed for 2 min through a mouthpiece, which was connected to a mixing chamber. From $\mathrm{t}=0$ to $\mathrm{t}=300$ the total urine production was collected. The body temperature was monitored using a rectal thermometer at $t=0, t=30$, $t=60$, and $t=90$. Blood samples were drawn in order to measure plasma vasopressin, and for determination of hemoglobin and hematocrite to calculate changes in plasma volume at $t=0$ and at $t=90$. Body weight, corrected for the ingested drinks, was determined at $\mathrm{t}=0$ and $\mathrm{t}=90$.

\section{Dehydrated experiment}

The subjects followed a sauna dehydration-regimen, which comprised of subsquent 15 min intervals in a dry sauna with intermittent cooling-off periods of $10 \mathrm{~min}$. After each sauna-exposure, the subjects dried off and the body weight was measured. When $2.5 \%$ body weight loss was achieved or after $2 \mathrm{~h}$ of the dehydration-regimen, the subjects dried off, returned to the laboratory and followed exactly the same procedure as described in the initially euhydrated experiment.

Table 8.1. Composition of the carbohydrate-electrolyte solution (CES) and the liquid meal $/ 100 \mathrm{ml}$.

\begin{tabular}{lll}
\hline & CES & Liquid meal \\
\hline Kcal & $30.0 \mathrm{Kcal}$ & $122.4 \mathrm{Kcal}$ \\
Carbohydrate & $6.88 \mathrm{~g}$ & $17.8 \mathrm{~g}$ \\
Fat & $0 \mathrm{~g}$ & $3.4 \mathrm{~g}$ \\
Protein/amino acids & Amino acids $21 \mathrm{mg}$ & Protein $5.4 \mathrm{~g}$ \\
Electrolytes & $119 \mathrm{mg}$ & $130 \mathrm{mg}$ \\
Vitamins & $10.6 \mathrm{mg}$ & $3.9 \mathrm{mg}$ \\
Fiber & $0 \mathrm{~g}$ & $1.08 \mathrm{~g}$ \\
$\mathrm{pH}$ & 3.95 & 5.8 \\
\hline
\end{tabular}

\section{Data analyses}

\section{Gastric emptying}

Assessment and mathematical evaluation of ${ }^{13} \mathrm{C}$-enrichment

The drink administered at $\mathrm{t}=40$ during the exercise episode contained $150 \mathrm{mg}$ sodium $\left[1{ }^{13} \mathrm{C}\right]$-acetate $199 \%$; Cambridge Isotope Laboratories, Andover, MA, USA) in order to determine the gastric emptying rate using the ${ }^{13} \mathrm{C}$-acetate breath test. Breath samples for ${ }^{13} \mathrm{CO}_{2}$-enrichment analysis were drawn from the mixing chamber at 5 min intervals from $t=40$ to $t=90$, using Vacutainer tubes. One breath sample was taken before administration of the drink at $t<40$, in order to determine background enrichment. The collected breath samples were analyzed for ${ }^{13} \mathrm{C}$-isotopic enrichment of the expired $\mathrm{CO}_{2}$ using Isotope Ratio Mass Spectrometry (Finnigan MAT 252, USA). The ${ }^{13} \mathrm{C}$-enrichment of $\mathrm{CO}_{2}$ was expressed as the delta $\langle\delta\rangle$ per mil difference between the ${ }^{13} \mathrm{C} /{ }^{12} \mathrm{C}$-ratio of the 
breath sample and a known laboratory reference standard according to the formula:

$\delta^{13} \mathrm{C}$ (per mil) $=\left(\left({ }^{13} \mathrm{C} /{ }^{12} \mathrm{C}\right)\right.$ sample $/\left({ }^{13} \mathrm{C} /{ }^{12} \mathrm{C}\right)$ standard -1$) \times 10^{3}$

The $\delta$-value was then related to an international standard, Pee Dee Belemnite (PDB).

The data from the breath enrichment were fitted by non-linear regression analysis (Prism, GraphPad Software Inc. San Diego, USA) according to a dual exponential function with the following features:

$y(t)=a t^{b}\left[c e^{(\cdot t d)}\right]+\mathrm{ft}^{\mathrm{g}}\left[h \mathrm{e}^{(-\mathrm{tit})}\right]+j$

A dual compartment description of ${ }^{13} \mathrm{CO}_{2}$-production (at ${ }^{b}$ and $\mathrm{ft}^{\mathrm{g}}$ ) was applied because acetate is oxidised both in the splanchnic area and in the working muscles. The decrease in ${ }^{13} \mathrm{CO}_{2}$-enrichment was also described in 2 factors; the 1st factor ( $\mathrm{Ce}^{(-\mathrm{td})}$ ) described washout of ${ }^{13} \mathrm{CO}_{2}$ through the body bicarbonate pool via the breath and the 2 nd factor $\left(h e^{(-t)}\right)$ described other processes of ${ }^{13} \mathrm{CO}_{2^{-}}$ removal; sequestration of ${ }^{13} \mathrm{CO}_{2}$ in bone, excretion via urine and incorporation into glucose. In this equation $a, b, c, d, f, g, h$ and $i$ are constants, $t$ is the time and $\mathrm{j}$ is the background enrichment.

In the present study the results were based on the Time to Peak ${ }^{13} \mathrm{C}$-enrichment in the breath samples $\left({ }^{13} \mathrm{C}\right.$-TTP) derived from the dual exponential function. The ${ }^{13} \mathrm{C}$-TTP was derived from the curve using the GraphPad software and was considered as the parameter of gastric emptying ${ }^{9}$.

\section{Orocecal transit time (OCTT)}

The drink administered at $\mathrm{t}=0$ of the exercise episode contained a nondigestible soluble carbohydrate $15 \mathrm{~g}$ lactulose, Centrafarm syrup, $670 \mathrm{mg} / \mathrm{ml}$, Etten-Leur, The Netherlands) allowing the measurement of OCTT using $\mathrm{H}_{2}$-measurement in exhaled breath. As soon as the lactulose enters the colon, bacterial fermentation will take place and $\mathrm{H}_{2}$-gas will be produced ${ }^{10}$. Breath samples for $\mathrm{H}_{2}$-analysis were collected from the mixing chamber at $15 \mathrm{~min}$ intervals, starting at $t=0$, using a $140 \mathrm{ml}$ syringe and were analyzed for $\mathrm{H}_{2}$-enrichment using a sensitive electrochemical exhaled hydrogen monitor (GMI Medical Ltd., Renfrew, Scotland). The OCTT was determined using the time of onset of a significant and sustained increase in breath $\mathrm{H}_{2}$.

\section{Intestinal permeability and glucose absorption}

The drink administered at $\mathrm{t}=0$ of the exercise episode contained $5 \mathrm{~g}$ lactulose (Centrafarm syrup, $670 \mathrm{mg} / \mathrm{ml}$, Etten-Leur, The Netherlands), $0.5 \mathrm{~g}$ rhamnose and $0.35 \mathrm{~g}$ 3-O-D-methyl-M-glucose (3-OMG) (Sigma Chemical Co., USA), 
allowing the measurement of intestinal permeability and intestinal glucose absorption ${ }^{11}$. Urine was collected between $t=0$ and $t=300$. After determining the volume, a small portion was stored at $-80^{\circ} \mathrm{C}$ for lactulose, rhamnose and 3-OMG determination. The urinary lactulose, rhamnose and 3-OMG excretion was determined by a validated, sensitive, newly developed fluorescent detection HPLC system". Subsequently, the lactulose and rhamnose recoveries and the lactulose/rhamnose and 3-OMG/rhamnose ratio's were calculated.

\section{Gastrointestinal symptoms}

After each episode (pre-exercise, exercise and postexercise) of the protocol, the subjects were asked to complete a standard questionnaire on gastrointestinal complaints during that episode. The following symptoms were scored on a visual analogue scale ranging from 0 to 10: Upper $\mathrm{Gl}$ symptoms; nausea/vomiting, epigastrical cramps, heartburn. Lower Gl symptoms: bloating, flatulence, abdominal cramps, urge to defecate, diarrhea. General symptoms: headache, dizziness, muscle cramps. Rate of perceived exhaustion was assessed using a standardized visual analogue scale ranging from $6-20^{12}$.

\section{Measurement of plasma volume}

From the blood samples obtained at $\mathrm{t}=0$ and $\mathrm{t}=90$, hemoglobin concentration in the red blood cells was determined using a standard cyanmethemoglobin method. Hematocrit was determined using a microhematocrit centrifuge. From these parameters the proportional change in plasma volume was calculated using the method of Dill and Costill ${ }^{13}$.

\section{Measurement of plasma vasopressin}

From the blood samples obtained at $t=0$ and $t=90$, plasma vasopressin was measured using a radioimmunoassay (Vasopressin Direct RIA-kit, Bühlmann Laboratories, Allschwil, Switzerland).

\section{Statistics}

Differences between the comparative episodes of the euhydrated and dehydrated experiments were analyzed using Wilcoxon's nonparametric tests. Differences in total GI symptom scores between the euhydrated and the dehydrated experiments were analyzed using a one-way ANOVA. Correlations between the $\delta$ (the dehydrated value minus the euhydrated value) Gl symptom scores and $\delta \mathrm{Gl}$ parameter values were determined using Spearman's rho. Data are presented as median (range). The level of confidence was set at $P<0.05$. All statistical analyses were performed using SPSS 7.5 for Windows statistical package. 


\section{Results}

All subjects completed the two 90 min cycling sessions at a load of $70 \%$ Wmax, except for 1 subject who suffered from severe nausea during cycling in a dehydrated state. From this subject the data from the dehydration experiment were omitted. The median maximal power output was $370.5 \mathrm{~W}(305-400)$. The changes in body weight, rectal temperature and plasma volume are displayed in Table 8.2.

Table 8.2. Results of the measurements of rectal temperature, body weight and plasma volume.

\begin{tabular}{lllll}
\hline & Euhydrated & & \multicolumn{2}{c}{ Dehydrated } \\
& Pre-exercise & Postexercise & Pre-exercise & Postexercise \\
\hline Rectal temp. $\left({ }^{\circ} \mathrm{C}\right)$ & 36.5 & 38.8 & 36.6 & 38.6 \\
& $(36.2-36.8)$ & $(37.8-39.5)$ & $(36.4-37.1)$ & $(37.9-39.1)$ \\
Relative body weight loss $(\%)$ & & 1.6 & 2.9 & 4.3 \\
& & $(0.6-2.3)$ & $(2.5-3.7)$ & $(4.0-6.2)$ \\
Relative plasma volume $(\%)$ & 60.0 & 54.3 & 58.8 & 56.8 \\
& $(57.5-65.0)$ & $(45.7-57.5)$ & $(58.2-67.0)$ & $(50.1-68.8)$ \\
\hline
\end{tabular}

There was no significant difference in rectal temperature between the euhydrated and the dehydrated experiments at both the beginning and the end of the cycling session (pre-exercise: $P=0.080$, postexercise: $P=0.189$ ). During cycling, the body temperature increased significantly in both experiments (euhydrated: $P=0.005$, dehydrated: $P=0.008$ ). The body weight loss was significantly higher in the dehydrated experiment at the end of the cycling sessions $(P=0.008)$ compared to the euhydrated experiment. There was no significant difference $(P=0.126)$ in plasma volume between the two experiments before cycling. In the euhydrated experiment the plasma volume decreased significantly $(P=0.005)$, and in the dehydrated experiment the decrease in plasma volume was not significant $(P=0.173)$. No corrections were made for the ingested liquid meals and drinks.

\section{Gastric emptying and orocecal transit time (OCTT)}

The results of the gastric emptying and OCTT measurements are displayed in Table 8.3. Gastric emptying was significantly delayed $(\mathbf{P}=0.021)$ in the dehydration experiment reflected by an increased ${ }^{13} \mathrm{C}$-TTP. The difference in OCTT between the euhydrated and the dehydrated experiment did not reach significance $(P=0.176)$. 
Table 8.3. Results of the gastric emptying $\left({ }^{13} \mathrm{C}-\mathrm{TTP}\right)$ and orocecal transit time (OCTT) measurements.

\begin{tabular}{lll}
\hline & Euhydrated & Dehydrated \\
\hline${ }^{13} \mathrm{C}-$ TTP $(\min )$ & $17.1(9.8-38.4)$ & $23.6(13.7-50.0)$ \\
OCT $(\min )$ & $127.5(97.5-195)$ & $172.5(97.5-262.5)$ \\
\hline
\end{tabular}

\section{Intestinal permeablity and glucose absorption}

In two urine samples the 3-OMG could not adequately be detected and these samples were therefore omitted from analyses. There were no significant differences in both intestinal permeability and intestinal glucose absorption between the euhydrated and the dehydrated experiments. The lactulose/rhamnose ratio's were 0.0083 (0.0065-0.0154) (euhydrated) vs. $0.0090(0.0062-0.0295)$ (dehydrated), $(P=0.590, n=9)$. The 3-OMG/rhamnose ratio's were 3.07 (2.53-4.32) (euhydrated) vs. 2.71 (1.94-3.53) (dehydrated), $(P=0.176, n=7)$. There were no significant differences in lactulose and rhamnose recovery between the euhydrated and the dehydrated experiments. Urinary lactulose recovery was $0.075 \%$ (0.022-0.158) (euhydrated) vs. $0.078 \%(0.030-0.118)$ (dehydrated), $(P=1.00)$. Urinary rhamnose recovery was $8.75 \%(3.12-15.38)$ (euhydrated) vs. 9.03\% (1.02-16.14) (dehydrated), $(P=0.89)$.

\section{Plasma vasopressin}

The plasma vasopressin values are displayed in Table 8.4. There was no difference in pre-exercise values between the two conditions ( $P=0.386)$. During exercise, however, plasma vasopressin levels increased significantly in both conditions. Postexercise vasopressin levels were significantly higher in the dehydration experiment, compared with the euhydrated experiment $(P=0.015)$.

Table 8.4. Plasma vasopressin concentrations (pmol/L).

\begin{tabular}{lll}
\hline & Euhydrated & Dehydrated \\
\hline Pre-exercise & $7.32(3.30-15.00)$ & $7.55(3.68-15.73)$ \\
Postexercise & $11.01(6.62-24.56)$ & $17.39(13.52-100.36)$ \\
P-value & 0.007 & 0.011 \\
\hline
\end{tabular}

\section{Gastrointestinal symptoms}

The results of the Gl and general symptom scores are displayed in Table 8.5.

Rest versus exercise

In an euhydrated state, exercise did not induce any increase in Gl symptoms. 
Only the rate of perceived exhaustion was increased, as expected $(P=0.005)$. In a dehydrated state, however, exercise induced a significant increase in nausea $(P=0.008)$ and epigastrical cramps $(P=0.049)$. The subjects also reported an increased headache $(P=0.012)$, dizziness $(P=0.01)$, and rate of perceived exhaustion $(P=0.005)$.

Table 8.5. Symptom scores in the 3 different episodes of the 2 experiments.

\begin{tabular}{|c|c|c|c|c|c|c|}
\hline & \multicolumn{2}{|c|}{ Euhydrated experiment } & \multirow[b]{2}{*}{ Postexerciso } & \multicolumn{2}{|c|}{ Dehydrated experiment } & \multirow[b]{2}{*}{ Postexarcise } \\
\hline & Pre-oxercise & Exercise & & Pre-exercise & Exercise & \\
\hline \multirow[t]{2}{*}{ Heartburn } & 0.25 & 0.25 & 0.25 & 0.35 & 0.5 & 0.5 \\
\hline & $(0.0-0.5)$ & $(0.0-5.7)$ & $(0.0-1.8)$ & $(0.0-0.5)$ & $(0.0-0.8)$ & $(0.0-0.7)$ \\
\hline \multirow[t]{2}{*}{ Belching } & 0.25 & 0.7 & 0.35 & 0.25 & 0.75 & 0.5 \\
\hline & $(0.0-0.5)$ & $(0.0 \cdot 6.3)$ & $(0.0-0.7)$ & $(0.0-0.6)$ & $(0.0 \cdot 7.8)$ & $(0.0-1.1)$ \\
\hline \multirow{2}{*}{ Epigastrical cramps } & 0.35 & 0.4 & 0.45 & 0.4 & 0.7 & 0.3 \\
\hline & $(0.0 \cdot 0.6)$ & $(0.0-2.3)$ & $(0.0-1.1)$ & $(0.0-1.7)$ & $(0.0-3.3)$ & $(0.0-3.4)$ \\
\hline \multirow[t]{2}{*}{ Nausea } & 0.3 & 0.15 & 0.2 & 0.25 & 0.95 & 0.4 \\
\hline & $(0.0-2.6)$ & $10.0-2.51$ & $(0.0-1.2)$ & $10.0-2.11$ & $(0.0-9.3)$ & $(0.0-1.8)$ \\
\hline \multirow[t]{2}{*}{ Bloating } & 0.25 & 0.4 & 0.15 & 0.25 & 0.35 & 0.2 \\
\hline & $\mid 0.0-3.7)$ & $(0.0-4.5)$ & $(0.0-2.0)$ & $(0.0-4.2)$ & $(0.0-7.6)$ & $(0.0-3.3)$ \\
\hline \multirow[t]{2}{*}{ Abdominal cramps } & 0.4 & 0.25 & 0.3 & 0.3 & 0.4 & 0.3 \\
\hline & $(0.0-1.5)$ & $(0.0-2.9)$ & $(0.0-0.7)$ & $(0.0-4.5)$ & $(0.0-2.9)$ & $(0.0-3.4)$ \\
\hline \multirow[t]{2}{*}{ Urge to defecate } & 0.5 & 0.25 & 0.15 & 0.65 & 0.55 & 0.4 \\
\hline & $(0.0-2.2)$ & $(0.0-1.9)$ & $(0.0-0.7)$ & $(0.0-1.9)$ & $(0.0-2.3)$ & $(0.0-1.3)$ \\
\hline \multirow[t]{2}{*}{ Flatulancen } & 0.5 & 0.3 & 0.25 & 0.35 & 0.45 & 0.5 \\
\hline & $(0.0 \cdot 1.7)$ & $(0.0-0.8)$ & $(0.0-1.1)$ & $(0.0-1.2)$ & $(0.0-5.2)$ & $(0.0-0.8)$ \\
\hline \multirow[t]{2}{*}{ Dizziness } & 0.25 & 0.2 & 0.2 & 0.5 & 3.1 & 0.3 \\
\hline & $(0.0-2.6)$ & $(0.0-3.5)$ & $(0.0 \cdot 1.8)$ & $(0.0 .4 .2)$ & $(0.1-9.3)$ & $(0.0-4.5)$ \\
\hline \multirow[t]{2}{*}{ Healdache: } & 0.35 & 0.4 & 0.25 & 0.7 & 2.3 & 1.3 \\
\hline & $(0.0 \cdot 1.8)$ & $(0.0-2.6)$ & $(0.0 \cdot 1.0)$ & $\{0.2-3.1\}$ & $(0.2-8.5)$ & $(0.0-5.9)$ \\
\hline \multirow[t]{2}{*}{ Muscle eramps } & 0.3 & 0.2 & 0.35 & 0.3 & 0.5 & 0.55 \\
\hline & $(0.0-0.6)$ & $(0.0-5.5)$ & $(0.0-1.4)$ & $(0.0-0.8)$ & $(0.1-5.8)$ & $(0.3-0.9)$ \\
\hline \multirow[t]{2}{*}{ Rate of exhaustion } & 7.5 & 15.5 & 11 & 9.5 & 18 & 13 \\
\hline & $(6-13)$ & $(12.18)$ & $(7-13)$ & $(7-12)$ & $(13-19)$ & $(9.13)$ \\
\hline
\end{tabular}

\section{Euhydrated versus dehydrated}

One-way ANOVA for all GI symptoms in the pre-exercise episode showed no significant difference between the euhydrated and the dehydrated experiments $(P=0.535)$. The sauna dehydration regimen resulted in an increased rate of perceived exhaustion ( $P=0.019$ ).

One-way ANOVA for all Gl symptoms in the exercise episode showed a significant difference between the euhydrated and the dehydrated experiments $(P=0.014)$. Wilcoxon's analysis demonstrated that dehydration resulted in an increase in nausea $(P=0.008)$ and epigastrical cramps $(P=0.025)$. The sauna dehydration regimen resulted in an increased headache $(P=0.021)$, dizziness $(P=0.005)$, and rate of perceived exhaustion $(P=0.017)$.

One-way ANOVA for all Gl symptoms in the postexercise episode showed a significant difference between the euhydrated and the dehydrated experiments $(P=0.050)$. Wilcoxon's analysis demonstrated that dehydration resulted in an increased bloating $(P=0.026)$ and flatulence $(P=0.031)$. The sauna dehydration regimen resulted in an increased headache $(P=0.012)$, dizziness $(P=0.010)$ and rate of perceived exhaustion $(P=0.048)$. 


\section{Correlation between delta (ס) Gl function parameter values and $\delta$ Gl symptom scores}

The correlation analyses between the $\delta$ Gl function parameter values and $\delta \mathrm{Gl}$ symptom scores demonstrated an almost significant negative correlation between the $\delta$ gastric emptying rate and $\delta$ plasma vasopressin values $(r=0.633, P=0.067, n=9)$. However, there was no significant relationship between the $\delta$ nausea score and the $\delta$ plasma vasopressin values $(P=0.488)$.

There was a significant correlation between the $\delta$ gastric emptying rate and $\delta$ nausea score during exercise $(r=0.867, P=0.002)$. The correlation plot is displayed in Figure 8.1.

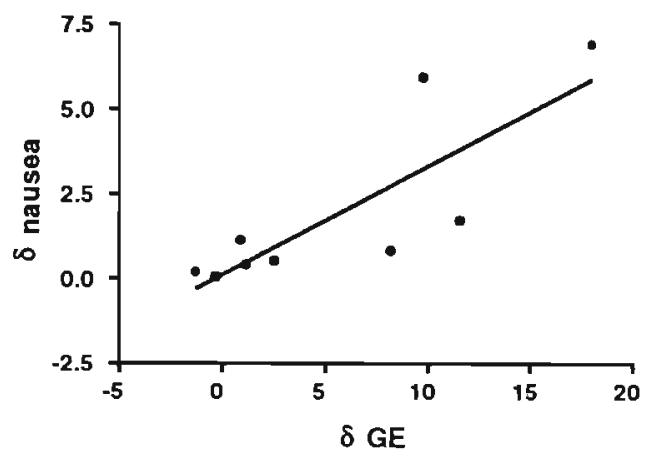

Figure 8.1 Correlation between the $\delta$ gastric emptying rate and $\delta$ nausea score during exercise $(r=0.867, P=0.002, n=9)$.

\section{Discussion}

Rehrer et al. ${ }^{6}$ demonstrated that a combination of dehydration $14 \%$ body weight loss) and exercise delayed gastric emptying of a carbohydrate-electrolyte solution. They also observed a higher prevalence of gastrointestinal disturbances, due to dehydration. In contrast, however, Ryan et al. ${ }^{14}$ did not observe an impaired gastric emptying of water during exercise at moderate intensity under a dehydrated condition of $3 \%$ body weight loss. The results of the present study confirmed that exercise in a dehydrated condition results in a slower gastric emptying. Our study also demonstrated that pre-exercise dehydration followed by intense physical exercise, leading to further dehydration, resulted in an increase of Gl symptoms such as nausea and epigastrical cramps and also in non-Gl symptoms such as headache, dizziness and fatigue. In the postexercise episode, dehydration resulted in increased bloating and flatulence. There appeared to be a significant relationship between the delay in gastric emptying and the degree of nausea during exercise. It is, however, not clear whether the occurrence of nausea during physical exercise 
might be explained by a delayed gastric emptying resulting from dehydration, or that dehydration-related nausea results in a slower gastric emptying. Preexercise dehydration appeared not to influence other parameters of Gl function.

Orocecal transit time, intestinal glucose absorption and intestinal permeability were not significantly affected by pre-exercise dehydration. This might be explained by the lack of plasma volume changes. It is known that heat-induced hypohydration will increase the osmotic pressure in the plasma ${ }^{7.15}$. Eccrine sweat is normally hypotonic to plasma ${ }^{16}$. Therefore the plasma becomes hypertonic and this hypertonicity mobilizes fluid from the intracellular to the extracellular compartments enabling to retain the plasma volume in hypohydrated subjects ${ }^{17}$. Evidence exists that plasma volume can at least partially be retained despite progressive dehydration during intense exercise, possibly due to release of metabolic water ${ }^{18}$ and redistribution of water from inactive muscle tissue towards the circulation? ${ }^{7}$. In the present study, the plasma volumes were not different between the two conditions. Plasma volume was measured before cycling, which is approximately two hours after the sauna dehydration session. These two hours, during which period the subjects also consumed a semi-liquid breakfast, were probably sufficient to compensate for the body water loss by means of redistribution. One may assume that if plasma volumes are equal in both conditions, the splanchnic blood flow do not differ either. The lack of change in plasma volume between the two conditions after cycling might explain why there was no difference in intestinal permeability, intestinal glucose absorption and orocecal transit time between the two conditions. The fact that gastric emptying was delayed and only epigastric symptoms occurred, suggests that gastric function and exercise-induced epigastrical symptoms such as cramps and nausea, were unrelated to changes in splanchnic blood flow.

Hormonal factors may be involved in exercise-induced Gl symptoms. It is known that the plasma concentration of vasopressin is increased in relation to exercise intensity ${ }^{14.20 .23}$. In the present study no significant differences were observed in plasma vasopressin concentrations two hours after a dehydration regimen, compared to a euhydrated condition. Our results suggest that the plasma vasopressin concentrations increased rather as a result of exercise than as a result of dehydration. Since the subjects have lost more body weight after cycling following sauna exposure compared to the body weight loss after cycling in a normal condition, our data also suggest that plasma vasopressin is influenced by the magnitude of water deficit.

It is also known that increased plasma vasopressin concentration is associated with nausea ${ }^{24}$. However, in our study, the rise in plasma vasopressin was not related to the extent of nausea that the subjects experienced. Based on our data, a negative relationship between plasma vasopressin and the gastric emptying rate can not be excluded, since we observed an almost significant negative correlation between the change in gastric emptying rate and the change in plasma vasopressin values. 
The rise in rectal temperature during cycling did not differ significantly between the euhydrated and the dehydrated experiments. It has been suggested that hypohydration results in an increased core temperature during exercise, compared to an euhydrated condition ${ }^{25}$. The lack of this observation in our study might be explained by the fact that the subjects could request a ventilator during cycling and by the fact that the decrease in plasma volumes during cycling did not differ significantly during cycling between the euhydrated and the dehydrated experiments.

We conclude that the findings of this study confirm that a dehydration regimen associated with a $3 \%$ body weight reduction, two hours before $90 \mathrm{~min}$ of cycling at an intensity of $70 \%$ Wmax, leads to a decrease in the gastric emptying rate of liquids. This appears to be related to a rise in nausea and epigastrical cramps. Intestinal permeability, intestinal glucose absorption and orocecal transit time did not significantly change, probably due to a plasma volume retainment mechanism following sauna exposure. The increase in plasma vasopressin concentration was significantly larger after cycling in a dehydrated condition. This was, however, not related to an increase in nausea. We recommend that endurance athletes should avoid a dehydrated condition during exercise as much as possible, not only to perform optimally, but to avoid exercise-induced nausea and epigastrical cramps resulting from dehydration as well. 


\section{References}

1. Brouns F, Beckers E. Is the gut an athletic organ? Digestion, absorption and exercise. Sports Med 1993; 15: 242-257.

2. Rowell LR, Blackmon JR, Bruce RA. Indocyanin green clearance and estimated blood flow during mild to maximal exercise in upright man. $J$ Clin Invest 1964; 43: 1677-1690.

3. Riddoch C. Trinick TR. Gastrointestinal disturbances in marathon runners. $\mathrm{Br} J$ Sports Med 1988; 22: 71-74.

4. Riddoch CJ. Exercise-induced gastrointestinal symptoms, hormonal involvement. Thesis Queens University, 1990, Belfast, Ireland.

5. Hilsted J, Galbo M, Sonne B, Schwarz T, Fahrenkrug J, Schaffalitzky de Muckadel O. Lauritzen K, Trouier B. Gastroenteropancreatic hormonal changes during exercise. Am J Physiol 1980; 239: G136-G140.

6. Rehrer NJ, Beckers EJ, Brouns F, ten Hoor F, Saris WHM. Effects of dehydration on gastric emptying and gastro-intestinal distress while running. Med Sci Sports 1990; 22: 790-795.

7. Sawka MN. Body fluid responses and hypohydration during exercise-heat stress. In: Human performance physiology and environmental medicine at terrestrial extremes. Benchmark Press, Indianapolis USA 1988; 227-266.

8. Kuipers H, Verstappen FTJ, Keizer HA, Geurten P, Van Kranenburg G. Variability of aerobic performance in the laboratory and its physiologic correlates. Int $J$ Sports Med 1985; 6: 197-201.

9. Van Nieuwenhoven MA, Wagemakers AJM, Senden J, Brouns F, Brummer R-JM. The assessment of gastric emptying of liquids during exercise using a $\left[{ }^{13} \mathrm{C}\right]-$ acetate breath test. Eur J Physiol 1997; 434: R39-R46, A12.

10. Levitt MD. Production and excretion of hydrogen gas in man. The New England $J$ Med 1969; 281 (3): 122-127.

11. Rooyakkers DR, van Eijk HMH, Deutz NEP. Simple and sensitive multi-sugar-probe gut permeability test by high-performance liquid chromatography with fluorescence labelling. J Chromatography A 1996; 730: 99-105.

12. Borg G. Perceived exertion as an indication of somatic stress. Scand $J$ Rehab Med 1970; 23: 92-98.

13. Dill DB, Costill DL. Calculation of percentage changes in volumes of blood, plasma and red cells in dehydration. J Appl Physiol 1974; 37: 247-248.

14. Ryan AJ, Lambert GP, Shi X, Chang RT, Summers RW, Gisolfi CV. Effect of hypohydration on gastric emptying and intestinal absorption during exercise. J Appl Physiol 1998; 84(5): $1581-1588$.

15. Senay LC, Christensen ML. Changes in blood plasma during progressive dehydration. J Appl Physiol 1965; 20: 1136-1140.

16. Kirby CR, Convertino VA. Plasma aldosterone and sweat sodium concentrations after exercise dehydration. J Appl Physiol 1986; 61: 967-870.

17. Nose H, Mack GW, Shi X. Nadel ER. Shift in body fluid compartments after dehydration in humans. J Appl Physiol 1988; 65: 318-324.

18. Pivarnik JM, Leeds EM, Wilkerson JE. Effects of endurance exercise on metabolic water production and plasma volume. J Appl Physiol 1984; 56: 613-618.

19. Convertino VA, Keil LC, Bernauer EM, Greenleaf JE. Plasma volume, osmolality, vasopressin, and renin activity during graded exercise in man. J Appl Physiol 1981; 50: 123-128. 
20. Convertino VA, Keil LC, Greenleaf JE. Plasma volume, renin and vasopressin responses to graded exercise after training. J Appl Physiol 1983; 54: 508-514.

21. Brandenberger G, Candas V, Follenius M, Libert JP, Kahn JM. Vascular fluid shifts and endocrine responses to exercise in the heat. Eur $J$ Appl Physiol 1986; 55: 123-129.

22. Francesconi RP, Sawka MN, Pandolf BD. Hypohydration and heat acclimation: plasma renin and aldosterone during exercise. J Appl Physiol 1983; 55: 1790-1794.

23. Francesconi RP, Sawka MN, Pandolf BD, Hubbard RW, Young AJ, Muza S. Plasma hormonal responses at graded hypohydration levels during exercise-heat stress. J Appl Physiol 1985; 59: 1855-1860.

24. Caras SD, Soykan I, Beverly V, Lin Z, McCallum RW. The effect of intravenous vasopressin on gastric myoelectrical activity in human subjects. Neurogastroenterol Motil 1997; Sep 9(3): 151-156.

25. Sawka MN. Physiological consequences of hypohydration: exercise performance and thermoregulation. Med Sci Sports Exerc 1992; 24(6): 657-670. 


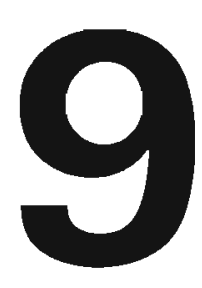

\section{The effect of physical exercise on gastrointestinal function in symptomatic subjects}

MA van Nieuwenhoven, F Brouns, R-JM Brummer 


\section{Abstract}

\section{Introduction}

A considerable number of athletes in endurance events frequently suffer from gastrointestinal (GI) symptoms. In the present study we investigated the effect of highintensity exercise on esophageal motility, gastroesophageal reflux, gastric emptying, orocecal transit time (OCTT), intestinal permeability and glucose absorption simultaneously, in a group of symptomatic athletes and a group of asymptomatic athletes, using an ambulatory protocol.

\section{Methods}

Group 1 consisted of 10 healthy well-trained symptom-free males, and Group 2 consisted of 9 males and 1 female who frequently suffered from Gl symptoms during exercise. Group 1 underwent a rest-cycling-rest, and a rest-rest-rest protocol. Group 2 underwent a rest-running-rest protocol as well. Esophageal motility and reflux were measured at rest and during cycling using a transnasal catheter. OCTT was measured via breath $\mathrm{H}_{2}$-measurement. A sugar absorption test was applied to determine intestinal permeability and glucose absorption. Gastric emptying was measured using the ${ }^{13} \mathrm{C}$ acetate breath test.

\section{Results}

In both groups peristaltic velocity was increased during cycling, compared to rest (Group 1, $P=0.015$, Group 2, $P=0.025$ ). No important differences could be observed between the 2 groups. During cycling, both the number and duration of reflux episodes was increased in Group 2, compared to Group $1(P=0.032$ and $P=0.036$, respectively). Gastric emptying showed no differences between the two groups. OCTT was increased in the cycling trial in Group 2, and reached significance in the running trial, compared to the rest trial $(P=0.005)$. No differences in OCTT could be observed between the two groups. In Group 1, The lactose/rhamnose ratio was significantly decreased in the cycling trial, compared to rest $(P=0.009)$, whereas in Group 2 the lactose/rhamnose ratio was higher in the cycling trial and reached significance in the running trial, compared to rest $(P=0.008)$. In the cycling trial, the lactose/rhamnose ratio was significantly higher in Group 2, compared to Group $1(P=0.001)$. Intestinal glucose absorption was significantly increased in the rest trial, compared to the cycling trial $(P=0.007)$ in Group 1. There were no significant differences in intestinal glucose absorption between the 2 groups.

\section{Conclusion}

There were no differences in GI profile between the two groups at rest. During cycling, symptomatic subjects have a slower orocecal transit and a higher intestinal permeability, which is more pronounced during running. 


\section{Introduction}

Participants in endurance events frequently suffer from gastrointestinal (GI) symptoms such as abdominal pain, urge to defecate, diarrhea, heartburn, nausea and vomiting. This suggests that exercise may influence gastrointestinal function. Exercise-induced Gl symptoms have gained scientific attention only over the last two decades. Dozens of case reports have been published as anecdotical evidence of the influence of physical exercise on Gl function. A number of studies have been carried out in which questionnaires on GI symptoms have been applied to participants in endurance events. Keeffe et al. ${ }^{1}$ surveyed 1700 participants in a marathon race, and observed that up to $50 \%$ of the participants suffered from 1 or more $\mathrm{Gl}$ symptoms. Gl symptoms of predominantly lower Gl tract origin, such as diarrhea, abdominal cramps, urge to defecate, flatulence and Gl bleeding were found to be more common than upper Gl symptoms, such as nausea, vomiting, heartburn, bloating and side pain. The most common symptom experienced was urge to defecate $136-39 \%$ of the participants), both during and immediately after running. Riddoch ${ }^{2}$ surveyed 371 questionnaires from 1750 competitors in a running endurance event, and reported also lower Gl symptoms as the most commonly experienced symptoms. In total $38 \%$ of the participants suffered from 1 or more $\mathrm{Gl}$ symptoms. Worobetz et al. $^{3}$ compared the effect of swimming, cycling and running on the prevalence of Gl symptoms. They observed a low frequency of Gl symptoms during cycling and swimming. Running, however, was associated with a high frequency of both gastroesophageal and colonic symptoms, which may be caused by mechanical stress due to the up-and-down movements of the abdominal organs during running. This indicates that the type of exercise is involved in the pathophysiology of exercise-induced Gl symptoms.

Nutritional factors such as the frequency of meals, and consumption of specific food products during exercise, such as fiber-rich food, coffee or orange juice may also play a role. Rehrer et al. ${ }^{4}$ made an attempt to correlate dietary intake (including food and fluid intake) and the occurrence of $\mathrm{Gl}$ symptoms during triathlon competition. They observed that triathletes, who consumed hypertonic carbohydrate solutions during exercise and those who consumed food products high in dietary fibers, fat or protein before competition, suffered more from GI symptoms. Peters et al. ${ }^{5}$ investigated the relationship between $\mathrm{Gl}$ symptoms and the type of consumed meal during exercise. They observed a small increase in duration of nausea after ingestion of a water placebo compared to a semisolid carbohydrate meal. There are other factors that may play a role in the occurrence of exercise-induced Gl symptoms. Sandell et al. ${ }^{6}$ reported that inadequate training, omittance of the consumption of a carbohydrate-rich meal consumption before exercise, hypoglycemia, omittance of a breakfast on the race day, pre-race illness and hypothermia may play a role in the cause of exercise-induced $\mathrm{Gl}$ symptoms.

Although a large number of endurance athletes frequently suffer from exercise- 
induced Gl symptoms, the studies published so far do not explain why some athletes usually have complaints and other athletes never have complaints. It may be possible that the athletes who frequently suffer from exercise-induced Gl symptoms have a profile of $\mathrm{Gl}$ parameters that is different from the profile of Gl parameters of athletes without complaints. Consequently, such a different profile may not result in symptoms in a resting situation, but it may lead to GI symptoms during physical exercise.

Hence, the aim of the present study was to obtain a profile of Gl parameters at rest and during high-intensity cycling and running from a group of well-trained subjects who frequently suffer from general exercise-induced GI symptoms, and to compare this with the profile from subjects from a group of well-trained athletes who usually do not suffer from exercise-induced Gl symptoms. Parameters that were studied comprised esophageal motility, gastroesophageal reflux, gastric emptying, orocecal transit time, intestinal permeability and intestinal glucose absorption. The subjects were studied in a controlled laboratory setting during a rest-exercise-rest protocol.

\section{Subjects and methods}

\section{Subjects}

Two groups of 10 healthy well-trained subjects were studied. Group 1 consisted of 10 males (age 18-25 years) who did not suffer from exercise-induced GI symptoms, and Group 2 consisted of 9 males and 1 female (age 21-50 years), who frequently suffered from general gastrointestinal symptoms during exercise (Table 9.1), but not at rest. Inclusion was not restricted to a certain profile of complaints. These subjects were recruited via advertisements in local newspapers and athletic clubs. Their diet was standardized during $24 \mathrm{~h}$ preceding the test days. The subjects were not allowed to consume fiber-rich or spicy food products, alcohol, caffeine-containing products, drugs, or to perform physical exercise the day preceding the test days.

Table 9.1 Characteristics of the subjects from Group 2.

\begin{tabular}{lccll}
\hline Subject & Gender & Age & Branch of sport & Usual symptoms during exercise \\
\hline 1 & $M$ & 44 & Ultra long-distance running & Abdominal cramps, diarrhea \\
2 & $M$ & 43 & Ultra long-distance running & Abdominal cramps, diarrhea \\
3 & $M$ & 50 & Long-distance running & Urge, diarrhea \\
4 & $M$ & 25 & Triathlon & Epigastrical cramps, vomiting \\
5 & $M$ & 31 & Run-bike-run & Nausea, bloating \\
6 & $M$ & 23 & Rowing & Epigastrical cramps, vomiting \\
7 & $M$ & 40 & Long-distance running & Abdominal cramps, diarrhea \\
8 & $M$ & 49 & Triathlon & Abdominal cramps, diarrhea \\
9 & $\mathrm{~F}$ & 46 & Long-distance running & Abdominal cramps, diarrhea \\
10 & $\mathrm{M}$ & 47 & Long-distance running & Heartburn / reflux \\
\hline
\end{tabular}




\section{Design of the study}

Table 9.2 displays the design of the study for both groups. Firstly, all subjects in both groups underwent a cycling test in order to determine their maximal power output (Wmax) ${ }^{7}$. The subjects in Group 2 also underwent a running test in order to determine their maximal running speed (Vmax). In the running test the same protocol as in the cycling test was used. On the actual testing days the subjects from Group 1 underwent in random order either a rest-cycling-rest protocol or a protocol in which the exercise period was replaced by rest. The subjects from Group 2 underwent in random order either a rest-cycling-rest protocol, a rest-running-rest protocol or a protocol in which the exercise period was replaced by rest.

Table 9.2. Design of the study for both groups.

\begin{tabular}{cccccc}
\hline & Wmax test & Vmax test & Rest-rest-rest & Rest-cycling-rest & Rest-running-rest \\
\hline Group 1 & $\checkmark$ & & $\checkmark$ & $\checkmark$ & \\
Group 2 & $\checkmark$ & $\checkmark$ & $\checkmark$ & $\checkmark$ & $\checkmark$ \\
\hline
\end{tabular}

\section{Investigation protocol}

After an overnight fast, the subjects arrived at the laboratory at 8.00 AM. Before the rest and the cycling experiments a thin catheter allowing the registration of esophageal motility and gastroesophageal reflux (Koningsiberg, USA) was inserted transnasally. Esophageal motility and $\mathrm{pH}$ measurements during running were not performed due to movement artefacts.

Subsequently, the subjects received a standard liquid breakfast $(4 \mathrm{ml} / \mathrm{kg}$ body weight, see Table 9.3), and remained seated in a chair for $60 \mathrm{~min}$. During this period resting values for esophageal motility and gastroesophageal reflux were obtained. Subsequently, the subjects emptied their bladder, mounted either a stationary bicycle ergometer (Lode, Groningen, The Netherlands) or a treadmill, respectively, in the exercise experiments, or remained seated in the resting experiment. In the exercise experiments a warming-up was performed for 10 $\min$ at $100 \mathrm{~W}$ cycling, or at $10 \mathrm{~km} / \mathrm{h}$ running. During the final minute of this warming-up $2 \mathrm{ml}$ of a carbohydrate-electrolyte solution (CES) $/ \mathrm{kg}$ body weight, was ingested. The composition of the CES is displayed in Table 9.3.

At $t=0$ of the subsequent exercise period, the exercise intensity was increased to a load of $70 \%$ of the previously determined individual maximal power output (Wmax $70 \%$, which is equivalent to approximately $80 \% \mathrm{VO}_{2 \text { max }}$ ), or maximal running speed (Vmax 70\%), respectively, which was maintained for $90 \mathrm{~min}$. If the subjects were not able to maintain the $70 \%$ Wmax or Vmax, the load was decreased in 5\% steps, until the subject was able to maintain the load and to complete the $90 \mathrm{~min}$ exercise period. During this period, the subject received 2 $\mathrm{ml} \mathrm{CES} / \mathrm{kg}$ body weight at $\mathrm{t}=20$, and $5 \mathrm{ml} \mathrm{CES} / \mathrm{kg}$ body weight at $\mathrm{t}=40$, in 
order to compensate for sweat losses and to minimise dehydration. All drinks were at room temperature $\left(19^{\circ} \mathrm{C}\right)$. At $\mathrm{t}=90$ the subjects dismounted the cycle ergometer or treadmill after which they remained normally seated in a comfortable chair for $210 \mathrm{~min}$ to obtain postexercise rest values. At $t=150$ the subjects received a standard liquid lunch $(4 \mathrm{ml} / \mathrm{kg}$ body weight, see Table 9.3). For each breath sample the subjects breathed for $2 \mathrm{~min}$ through a mouthpiece, which was connected to a mixing chamber. Breath samples for $\mathrm{H}_{2}-$ and ${ }^{13} \mathrm{CO}_{2}$ analysis were collected from the mixing chamber at 15 and at 5 min intervals, respectively. From $\mathrm{t}=0$ to $\mathrm{t}=300$ the total urine production was collected.

Table 9.3. Composition of the carbohydrate-electrolyte solution (CES) and the liquid meal $/ 100 \mathrm{ml}$.

\begin{tabular}{lll}
\hline & CES & Liquid meal \\
\hline Kcal & $30.0 \mathrm{Kcal}$ & $122.4 \mathrm{Kcal}$ \\
Carbohydrate & $6.88 \mathrm{~g}$ & $17.8 \mathrm{~g}$ \\
Fat & $0 \mathrm{~g}$ & $3.4 \mathrm{~g}$ \\
Protein/amino acids & Amino acids $21 \mathrm{mg}$ & Protein $5.4 \mathrm{~g}$ \\
Electrolytes & $119 \mathrm{mg}$ & $130 \mathrm{mg}$ \\
Vitamins & $10.6 \mathrm{mg}$ & $3.9 \mathrm{mg}$ \\
Fiber & $0 \mathrm{~g}$ & $1.08 \mathrm{~g}$ \\
pH & 3.95 & 5.8 \\
\hline
\end{tabular}

\section{Testing procedures}

\section{Esophageal parameters}

Two solid-state pressure sensors measured esophageal pressure at 13 (P1) and 3 (P3) cm above the LES, respectively ${ }^{8}$. The catheter was connected with an ambulatory datarecorder (UPS 2020, MMS, Enschede, The Netherlands), thus allowing continuous registration of pressure and $\mathrm{pH}$. The stored data were transferred from the ambulatory datalogger to a personal computer system, and edited using specialised manometry software (MMS, Enschede, The Netherlands). In each episode of the experiments the following parameters were evaluated: the number of peristaltic contractions, the mean peristaltic pressure at P1 and P3, the mean duration of peristaltic pressure events at P1 and P3 and the peristaltic velocity.

\section{Gastroesophageal reflux}

The $\mathrm{pH}$ in the esophagus was measured at $5 \mathrm{~cm}$ above the LES using a solid state $\mathrm{pH}$ sensor. A reflux episode was defined as a period in which the $\mathrm{pH}$ in the esophagus, at $5 \mathrm{~cm}$ above the LES, was lower than 4 . The following parameters were determined:

- The number of reflux episodes.

- The duration of the reflux episodes as a percentage of time. 


\section{Gastric emptying}

\section{Assessment and mathematical evaluation of ${ }^{13} \mathrm{C}$-enrichment}

The drink administered at $\mathrm{t}=40$ during the exercise episode contained $150 \mathrm{mg}$ sodium $\left[1 .{ }^{13} \mathrm{C}\right]$-acetate (99\%; Cambridge Isotope Laboratories, Andover, MA, USA) in order to determine the gastric emptying rate using the ${ }^{13} \mathrm{C}$-acetate breath test. Breath samples for ${ }^{13} \mathrm{CO}_{2}$-enrichment analysis were drawn from the mixing chamber at 5 min intervals from $\mathrm{t}=40$ to $\mathrm{t}=90$, using Vacutainer tubes. One breath sample was taken before administration of the drink at $t<40$, in order to determine background enrichment. The collected breath samples were analyzed for ${ }^{13} \mathrm{C}$-isotopic enrichment of the expired $\mathrm{CO}_{2}$ using Isotope Ratio Mass Spectrometry (Finnigan MAT 252, USA). The ${ }^{13} \mathrm{C}$-enrichment of $\mathrm{CO}_{2}$ was expressed as the delta $(\delta)$ per mil difference between the ${ }^{13} \mathrm{C} /{ }^{12} \mathrm{C}$-ratio of the breath sample and a known laboratory reference standard according to the formula:

$\delta^{13} \mathrm{C}$ (per mil) $=\left(\left({ }^{13} \mathrm{C} /{ }^{12} \mathrm{C}\right.\right.$ ) sample $/\left({ }^{13} \mathrm{C} /{ }^{12} \mathrm{C}\right)$ standard -1$) \times 10^{3}$

The $\delta$-value was then related to an international standard, Pee Dee Belemnite (PDB).

The data from the breath enrichment were fitted by non-linear regression analysis (Prism, GraphPad Software Inc. San Diego, CA, USA) according to a dual exponential function with the following features:

$y(t)=a t^{b}\left[c e^{(-t)}\right]+f t^{\theta}\left[h e^{(-t)}\right]+j$

A dual compartment description of ${ }^{13} \mathrm{CO}_{2}$-production $\left(a t^{b}\right.$ and $\mathrm{ft}^{\mathrm{g}}$ ) is applied because acetate is oxidised both in the splanchnic area and in the working muscles. The decrease in ${ }^{13} \mathrm{CO}_{2}$-enrichment is also described in 2 factors; the 1st factor (ce ${ }^{\mid-t d)}$ ) describes washout of ${ }^{13} \mathrm{CO}_{2}$ through the body bicarbonate pool via the breath, and the $2^{\text {nd }}$ factor $\left(\right.$ he $\left.{ }^{(-t)}\right)$ describes other processes of ${ }^{13} \mathrm{CO}_{2}$ removal; sequestration of ${ }^{13} \mathrm{CO}_{2}$ in bone, excretion via urine and incorporation into glucose $e^{26}$. In this equation $a, b, c, d, f, g, h$ and $i$ are constants, $t$ is the time and $j$ is the background enrichment.

In the present study the results are based on the Time to Peak ${ }^{13} \mathrm{C}$-enrichment in the breath samples $\left({ }^{13} \mathrm{C}\right.$-TTP) derived from the dual exponential function. The ${ }^{13} \mathrm{C}$-TTP was considered as the parameter of gastric emptying ${ }^{9}$. A correction factor of $5.9 \mathrm{~min}$ was added to the ${ }^{13} \mathrm{C}$-TTP values derived from the exercise experiments. This was done to correct for the increased rate of oxidation of the $\left[{ }^{13} \mathrm{C}\right]$-acetate and exhalation of the ${ }^{13} \mathrm{CO}_{2}$ during exercise conditions ${ }^{10}$.

\section{Orocecal transit time (OCTT)}

The drink administered at $\mathrm{t}=0$ of the exercise episode contained a nondigestible soluble carbohydrate $15 \mathrm{~g}$ lactulose, Centrafarm, Etten-Leur, The 
Netherlands) allowing the measurement of OCTT using $\mathrm{H}_{2}$-measurement in exhaled breath. As soon as the lactulose enters the colon, bacterial fermentation will take place, and $\mathrm{H}_{2}$-gas will be produced ${ }^{11}$. Breath samples for $\mathrm{H}_{2}$-analysis were collected from the mixing chamber at 15 min intervals, starting at $t=0$, using a $140 \mathrm{ml}$ syringe, and were analyzed for $\mathrm{H}_{2}$-enrichment using a sensitive electrochemical exhaled hydrogen monitor (GMI Medical Ltd., Renfrew, Scotland). The OCTT was determined using the elapsed time till onset of a sustained increase in breath $\mathrm{H}_{2}$, defined as the first breath sample that shows a higher breath $\mathrm{H}_{2}$ than the preceding one, followed by two or more breath samples showing a further increase.

\section{Intestinal permeability and glucose absorption}

The drink administered at $\mathrm{t}=0$ of the exercise episode contained $5 \mathrm{~g}$ lactulose (Centrafarm, Etten-Leur, The Netherlands), $0.5 \mathrm{~g}$ rhamnose and $0.35 \mathrm{~g}$ 3-O-Dmethyl-M-glucose (3-OMG) (Sigma Chemical Co., USA), allowing the measurement of intestinal permeability and intestinal glucose absorption ${ }^{12}$. Total urine production was collected between $t=0$ and $t=300$. After determining the volume, a small portion was stored at $-80^{\circ} \mathrm{C}$ for lactulose, rhamnose and 3OMG determination. The urinary lactulose, rhamnose and 3-OMG-excretion was determined by a validated, sensitive, newly developed fluorescent detection HPLC system ${ }^{12}$. Subsequently, the lactulose and rhamnose recoveries and the lactulose/rhamnose and 3-OMG/rhamnose ratio's were calculated.

\section{Statistics}

Differences between the respective episodes of the trials were analyzed using Friedman's nonparametric test. If Friedman's analysis demonstrated a significant difference, Wilcoxon's Signed Rank test was performed, corrected for multiple comparisons using a Bonferroni correction, which is the level of confidence $(P=0.05)$, divided by the number of comparisons, in this case 3 . This correction results in a level of confidence of $P=0.017$. Differences between two related samples were analyzed using Wilcoxon's Signed Rank test. The level of confidence was set at $P=0.05$. Differences between the two groups of subjects were analyzed using Kruskall-Wallis or Mann-Whitney's nonparametric tests. The reflux data and esophageal manometry data were also analyzed using a three-way ANOVA (exc/post-exc episodes vs. rest/cycling experiment vs. Group $1 / 2$ ). Data are presented as median (range). The level of confidence was set at $P<0.05$. All statistical analyses were performed using SPSS 7.5 for Windows statistical package. 


\section{Results}

All the subjects were able to complete the 90 min cycling and/or running episodes, except for subject No 3 in Group 2, who suffered from severe urge to defecate during cycling. From this subject the data from the cycling experiment were omitted. In most athletes it appeared to be necessary to decrease the cycling load in 5\% steps, in order to avoid exhaustion before the $90 \mathrm{~min}$ exercise was completed. Mann-Whitney's analysis demonstrated no significant difference in maximal power output (Wmax) between the two groups $(P=0.075)$.

In Group 1 the median initial load (70\% Wmax) was 243.5 W (217-350) and the median load at the end of the 90 min cycling period was $215.5 \mathrm{~W}$ (185-325). The course of the median relative cycling loads was: at $t=0: 70 \%$ $W \max (70-70)$, at $t=30: 65 \% W \max (65-70)$, at $t=60: 60 \% W \max (60-65)$ and at $t=90: 60 \% \mathrm{Wmax}(55-65)$.

In Group 2 The median initial load (70\% Wmax) was 205.1 W (129-294), and the median load at the end of the 90 min cycling period was $184 \mathrm{~W}$ (111-252). The course of the median relative cycling loads was: at $t=0: 70 \% \mathrm{Wmax}$ (70$70)$, at $\mathrm{t}=30: 70 \% \mathrm{Wmax}(65-70)$, at $\mathrm{t}=60: 65 \% \mathrm{Wmax}(60-70)$ and $\mathrm{m} t=90$ : $60 \%$ Wmax (55-70). Kruskal-Wallis analysis demonstrated no significant differences in the median load at $t=0,30,60$ and 90 between the two groups $(P=1.0,0.232,0.261$ and 0.571 , respectively $)$.

The running speed could be maintained for 90 min at $70 \%$ Vmax, except for subject No 6. His running speed was decreased to $65 \% \mathrm{Vmax}$ after $20 \mathrm{~min}$. The median running speed was $11.6 \mathrm{~km} / \mathrm{h}$ (9.9-14.7).

\section{Esophageal motility}

The data from the esophageal motility measurements in the rest and in the cycling trials from both athlete groups are displayed in Table 9.4. Three-way ANOVA (episode vs. experiment vs. Group) demonstrated significant differences in the duration of the peristaltic pressure wave at $P 3(P=0.025)$ and in the peristaltic velocity $(P<0.001)$. Non-parametric analysis demonstrated that the peristaltic velocity and the number of peristaltic contractions appeared to be increased during cycling in both groups, compared to rest. In the asymptomatic group the peristaltic pressure at $\mathrm{P} 1$ and the duration of the peristaltic contractions at P1 and P3 were significantly lower during cycling. In Group 2 the peristaltic pressure at P3 was significantly higher during cycling. No important differences between the two trials could be observed in the postexercise episode. Mann-Whitney's comparisons between the two athlete groups demonstrated a significantly lower pressure in Group 2 at P1 in the exercise episode of the rest trial. 
Table 9.4 Results of both groups for the manometric measurements in the esophagus in median (range) during the exercise and postexercise episodes of the rest and the cycling trials $\left(n=10,{ }^{\circ}=\right.$ significant difference).

\begin{tabular}{|c|c|c|c|c|c|c|}
\hline & \multicolumn{3}{|c|}{ Exercise episodes } & \multicolumn{3}{|c|}{ Postexercise episodes } \\
\hline & Cycling trial & Rest trial & P-value & Cycling trial & Rest trial & P-value \\
\hline \multicolumn{7}{|l|}{ Group 1} \\
\hline Number of contractions & $\begin{array}{l}24.0 \\
(13.0-73.0)\end{array}$ & $\begin{array}{l}68.0 \\
(34.0-106.0)\end{array}$ & $0.011^{\circ}$ & $\begin{array}{l}95.5 \\
(21.0-146.0)\end{array}$ & $\begin{array}{l}108.0 \\
(61.0-203.0)\end{array}$ & $0.038^{\circ}$ \\
\hline $\begin{array}{l}\text { Pressure P1 } \\
\left\{\mathrm{cm} \mathrm{H}_{2} \mathrm{O}\right\rangle\end{array}$ & $\begin{array}{l}73.4 \\
(45.3-89.0)\end{array}$ & $\begin{array}{l}78.0 \\
(58.0-121.4)\end{array}$ & $0.028^{\circ}$ & $\begin{array}{l}73.5 \\
(49.2-129.0)\end{array}$ & $\begin{array}{l}71.4 \\
(58.1-103.1)\end{array}$ & 0.575 \\
\hline $\begin{array}{l}\text { Pressure P3 } \\
\left(\mathrm{cm} \mathrm{H}_{2} \mathrm{O}\right)\end{array}$ & $\begin{array}{l}74.8 \\
(62.9-162.5)\end{array}$ & $\begin{array}{l}77.5 \\
(61.8-127.9)\end{array}$ & 0.859 & $\begin{array}{l}69.7 \\
(54.3-118.7)\end{array}$ & $\begin{array}{l}73.3 \\
(56.4-112.8)\end{array}$ & 0.594 \\
\hline $\begin{array}{l}\text { Duration P1 } \\
\text { (sec) }\end{array}$ & $\begin{array}{l}1.72 \\
(1.29-2.03)\end{array}$ & $\begin{array}{l}1.99 \\
(1.63-2.73)\end{array}$ & $0.021^{\circ}$ & $\begin{array}{l}1.99 \\
(1.36-2.57)\end{array}$ & $\begin{array}{l}1.83 \\
(1.45-2.38)\end{array}$ & 0.161 \\
\hline $\begin{array}{l}\text { Duration P3 } \\
\text { (sec) }\end{array}$ & $\begin{array}{l}1.68 \\
(1.33-2.73)\end{array}$ & $\begin{array}{l}2.30 \\
(2.04-3.33)\end{array}$ & $0.015^{\circ}$ & $\begin{array}{l}2.26 \\
(1.72-4.14)\end{array}$ & $\begin{array}{l}2.35 \\
(1.72 \cdot 4.14)\end{array}$ & 0.859 \\
\hline $\begin{array}{l}\text { Peristaltic velocity } \\
(\mathrm{cm} / \mathrm{sec})\end{array}$ & $\begin{array}{l}4.92 \\
(4.22-7.08)\end{array}$ & $\begin{array}{l}4.03 \\
(3.19-4.67)\end{array}$ & $0.015^{\circ}$ & $\begin{array}{l}3.58 \\
(3.01-5.45)\end{array}$ & $\begin{array}{l}3.74 \\
(2.85-4.80)\end{array}$ & 0.859 \\
\hline \multicolumn{7}{|l|}{ Group 2} \\
\hline Number of contractions & $\begin{array}{l}28.5 \\
(6.0-48.0)\end{array}$ & $\begin{array}{l}54.5 \\
(7.0-116.0)\end{array}$ & $0.035^{\circ}$ & $\begin{array}{l}115.5 \\
(65.0-282.0)\end{array}$ & $\begin{array}{l}111 \\
(15.0-284.0)\end{array}$ & 0.624 \\
\hline $\begin{array}{l}\text { Pressure P1 } \\
\left\{\mathrm{cm} \mathrm{H}_{2} \mathrm{O}\right\}\end{array}$ & $\begin{array}{l}63.9 \\
(52.1-115.1)\end{array}$ & $\begin{array}{l}63.4 \\
(45.4-85.0)\end{array}$ & 0.575 & $\begin{array}{l}68.1 \\
(46.5-87.7)\end{array}$ & $\begin{array}{l}63.1 \\
(47.1 \cdot 76.0)\end{array}$ & 0.161 \\
\hline $\begin{array}{l}\text { Pressure P3 } \\
\left\{\mathrm{cm} \mathrm{H}_{2} \mathrm{O}\right)\end{array}$ & $\begin{array}{l}79.3 \\
(52.0-106.1)\end{array}$ & $\begin{array}{l}69.5 \\
(41.1-85.2)\end{array}$ & $0.043^{\circ}$ & $\begin{array}{l}83.7 \\
(44.6-103.3)\end{array}$ & $\begin{array}{l}65.5 \\
(44.2 \cdot 105.5)\end{array}$ & 0.310 \\
\hline $\begin{array}{l}\text { Duration P1 } \\
\text { (sec) }\end{array}$ & $\begin{array}{l}1.64 \\
(1.32-2.84)\end{array}$ & $\begin{array}{l}1.74 \\
(1.52-2.47)\end{array}$ & 0.484 & $\begin{array}{l}1.90 \\
(1.36-2.28)\end{array}$ & $\begin{array}{l}1.72 \\
(1.51-2.22)\end{array}$ & 0.183 \\
\hline $\begin{array}{l}\text { Duration P3 } \\
\text { (sec) }\end{array}$ & $\begin{array}{l}2.02 \\
(1.23-2.73)\end{array}$ & $\begin{array}{l}1.98 \\
(1.64-3.08)\end{array}$ & 0.237 & $\begin{array}{l}2.91 \\
(1.61-3.29)\end{array}$ & $\begin{array}{l}2.50 \\
(1.55-3.28)\end{array}$ & 0.612 \\
\hline $\begin{array}{l}\text { Peristaltic velocity } \\
(\mathrm{cm} / \mathrm{sec})\end{array}$ & $\begin{array}{l}6.05 \\
(4.16-8.29)\end{array}$ & $\begin{array}{l}4.66 \\
(2.33-5.58)\end{array}$ & $0.025^{\circ}$ & $\begin{array}{l}5.07 \\
(3.25-6.80)\end{array}$ & $\begin{array}{l}4.22 \\
(2.63-6.35)\end{array}$ & 0.401 \\
\hline \multicolumn{7}{|l|}{ Group 1 vs. Group 2} \\
\hline Number of contractions & $P=0.696$ & $P=0.842$ & & $P=0.315$ & $P=0.78$ & \\
\hline Pressure P1 & $P=0.633$ & $P=0.028^{\circ}$ & & $P=0.274$ & $P=0.095$ & \\
\hline Pressure P3 & $P=0.325$ & $P=0.077$ & & $P=0.696$ & $P=0.222$ & \\
\hline Duration P1 & $P=0.633$ & $P=0.156$ & & $P=0.573$ & $P=0.549$ & \\
\hline Duration P3 & $P=0.274$ & $P=0.222$ & & $P=0.633$ & $P=0.853$ & \\
\hline Peristaltic velocity & $P=0.173$ & $P=0.356$ & & $P=0.068$ & $P=0.278$ & \\
\hline
\end{tabular}




\section{Gastroesophageal reflux}

The results of the gastroesophageal reflux measurements are displayed in Table 9.5. Three-way ANOVA (episode vs. experiment vs. Group) demonstrated a significant difference in the number of reflux episodes $(P=0.004)$, but not in the duration $(P=0.108)$. Non-parametric analyses demonstrated in both groups no significant differences between the exercise and the postexercise episodes in both the number of reflux episodes (Group 1: $\mathrm{P}=0.610$ and 0.786 , respectively, Group 2: $\mathrm{P}=0.104$ and 0.078 , respectively) and the duration of reflux as a percentage of time (Group 1: $P=0.612$ and 0.463 , respectively. Group 2: $P=0.080$ and 0.500 , respectively). Comparisons between the groups demonstrated a significant higher number, as well as a longer duration of reflux episodes in Group 2 during the exercise episode in the cycling experiment (Number of reflux episodes: Group 1: 0.0 (0.0-13.0), Group 2: 3.5 (0.0-24.0). $P=0.032$. Duration of reflux episodes as percentage of time: Group 1: 0.0 (0.034.6), Group 2: $3.1(0.0-23.6), P=0.036)$.

Table 9.5. Results of the reflux measurements in both groups $\left(n=2 \times 10,{ }^{*}=\right.$ significant difference).

\begin{tabular}{lllll}
\hline & \multicolumn{2}{l}{ Exercise episodes } & \multicolumn{2}{l}{ Postexercise episodes } \\
& Cycling trial & Rest trial & Cycling trial & Rest trial \\
\hline $\begin{array}{l}\text { Group 1 } \\
\text { Number of reflux }\end{array}$ & $0.0(0.0-13.0)$ & $1.0(0.0-0.8)$ & $1.0(0.0-13.0)$ & $2.0(0.0-7.0)$ \\
Duration of reflux & $0.0(0.0-34.6)$ & $0.1(0.0-5.9)$ & $0.1(0.0-7.4)$ & $0.0(0.0-4.6)$ \\
Group 2 & & & & \\
$\begin{array}{l}\text { Number of reflux } \\
\text { Duration of reflux }\end{array}$ & $3.5(0.0-24.0)$ & $1.0(0.0-5.0)$ & $2.5(0.0-8.0)$ & $2.0(0.0-8.0)$ \\
Group 1 vs. Group 2 & $3.1(0.0-23.6)$ & $0.4(0.0-2.0)$ & $0.4(0.0-2.0)$ & $0.3(0.0-5.3)$ \\
Number of reflux & $P=0.032^{*}$ & $P=0.928$ & $P=0.459$ & $P=0.892$ \\
Duration of reflux & $P=0.036^{*}$ & $P=0.444$ & $P=0.765$ & $P=0.242$ \\
\hline
\end{tabular}

\section{Gastric emptying and orocecal transit time (OCTT)}

The results of the gastric emptying and OCTT measurements are displayed in Figure 9.1. No significant differences could be observed for the ${ }^{13} \mathrm{C}$-TTP between the rest and the cycling trials in both groups (Group 1: rest: $29.3 \mathrm{~min}$ (17.4-42.2), cycling: $28.7 \mathrm{~min}(21.6-34.2), P=0.33$. Group 2: rest: $31.0 \mathrm{~min}$ (12.9-57.4), cycling: $36.6 \mathrm{~min}$ (19.6-55.9), running: $26.8 \mathrm{~min}$ (20.3-39.6), $P=0.236$ ). No significant differences could be observed for the OCT between the rest and the cycling trials in Group 1 (rest: $117.5 \mathrm{~min}$ (105.0-165.0), cycling: $140.0 \mathrm{~min}(105.0-195.0), P=0.17)$. In Group 2 the ОСТT showed a significant difference between the three trials (rest: $137.8 \mathrm{~min}$ (90.0-180.0), cycling: $192.9 \mathrm{~min}$ (110.0-305.0), running: $240.0 \mathrm{~min}(112.5-305.0)$, 
$\mathrm{P}=0.032$ ), and Wilcoxon's analyses demonstrated a significant increase in OCTT during running, compared to rest $(P=0.005)$. No significant differences could be observed between the rest and the cycling trial $(P=0.086)$ and between the cycling and the running trial $(P=0.598)$. Mann-Whitney comparisons between Group 1 and Group 2 for the rest and the cycling trials showed no significant differences $\left({ }^{13} \mathrm{C}\right.$-TTP: rest: $P=0.414$, cycling: $P=0.447$, OCTT: rest: $P=0.494$, cycling: $P=0.219$ ).

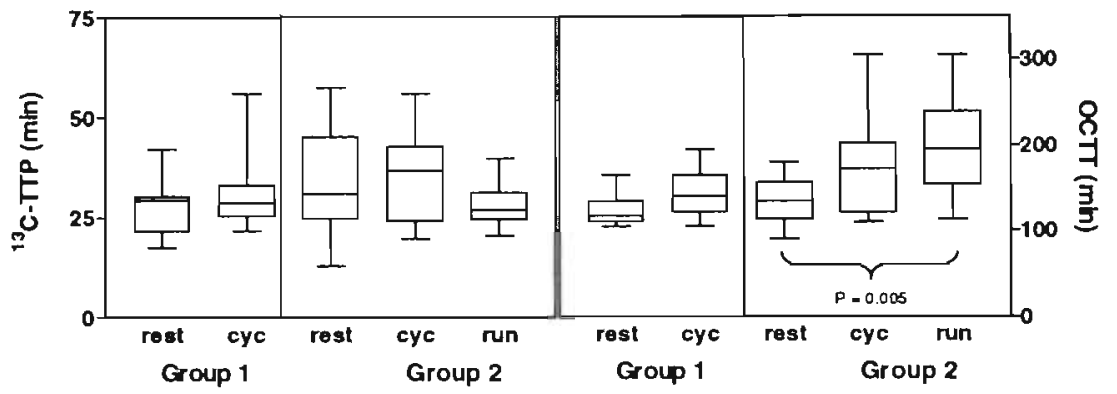

Figure 9.1. Box- and whiskers plots of the gastric emptying $\left({ }^{13} \mathrm{C}-\mathrm{TTP}\right)$ and orocecal transit time (OCTT) measurements in both groups.

\section{Intestinal permeability}

The results of the intestinal permeability measurements are displayed in Figure 9.2. In Group 1, the lactulose/rhamnose ratio was significantly higher in the rest trial, compared to the cycling trial $(0.015(0.0076-0.027)$ and $0.0067(0.0017$. 0.0141 ) respectively, $P=0.009$ ). In Group 2, Friedman's analyses demonstrated a significant difference $(P=0.018)$ in lactulose/rhamnose ratio between the three experiments. Wilcoxon's analyses demonstrated a significant increase in lactulose/rhamnose ratio in the running experiment, compared with rest (lactulose/rhamnose ratio running: 0.0361 (0.0234-0.0516), rest: 0.0206 (0.0087-0.0431), $P=0.008$ ). The urinary recoveries of lactulose and rhamnose are displayed in Table 9.6. In Group 1, lactulose recovery was significantly lower in the cycling trial, compared to the rest trial. Rhamnose recovery showed no difference between the 2 trials. In Group 2, neither the lactulose, nor the rhamnose recovery showed significant differences between the 3 trials. MannWhitney's comparisons between the 2 groups showed a significantly higher lactulose/rhamnose ratio and lactulose recovery in Group 2 in the exercise trial. 


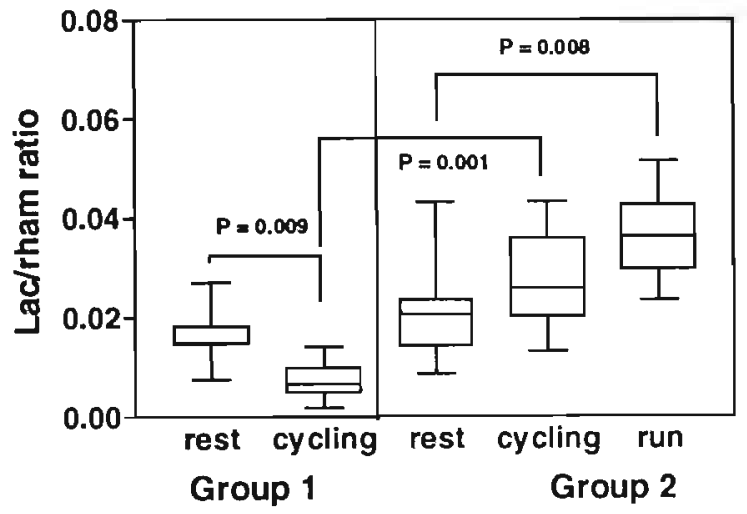

Figure 9.2. Box- and whiskers plots of the lactulose/rhamnose ratio's in both groups.

Table 9.6. Sugar recoveries and lactulose/rhamnose ratio's in both groups $\ln =2 \times 10$, $^{*}=$ significant difference).

\begin{tabular}{|c|c|c|c|c|}
\hline & Rest trial & Cycling trial & Running trial & \\
\hline Group 1 & & & & Wilcoxon \\
\hline \multirow[t]{2}{*}{ Lac recovery $(\%)$} & 0.220 & 0.089 & & $P=0.009^{\bullet}$ \\
\hline & $(0.078-0.394)$ & $(0.038-0.173)$ & & \\
\hline \multirow[t]{2}{*}{ Rham recovery $(\%)$} & 14.01 & 15.00 & & $P=0.646$ \\
\hline & (9.64-22.37) & (8.54-23.99) & & \\
\hline \multirow[t]{2}{*}{ Lac/rham ratio } & 0.015 & 0.007 & & $P=0.009^{\circ}$ \\
\hline & $(0.008-0.270)$ & $(0.002-0.014)$ & & \\
\hline Group 2 & & & & Friedman \\
\hline \multirow[t]{2}{*}{ Lac recovery $(\%)$} & 0.263 & 0.333 & 0.424 & $P=0.097$ \\
\hline & $(0.039-0.491)$ & $(0.232-0.595)$ & $(0.225-0.576)$ & \\
\hline \multirow[t]{2}{*}{ Rham recovery $(\%)$} & 12.25 & 14.54 & 12.48 & $P=0.368$ \\
\hline & $(4.42-22.90)$ & $(9.12-19.54)$ & $(6.26-21.08)$ & \\
\hline \multirow[t]{2}{*}{ Lac/rham ratio } & 0.021 & 0.026 & 0.036 & $P=0.018^{*}$ \\
\hline & $(0.009-0.043)$ & $(0.013-0.043)$ & $(0.024-0.051)$ & \\
\hline \multicolumn{5}{|l|}{ Group 1 vs. Group 2} \\
\hline Lac recovery & $P=0.597$ & $P=0.000^{*}$ & & \\
\hline Rham recovery & $P=0.199$ & $P=0.929$ & & \\
\hline Lac/rham ratio & $P=0.199$ & $P=0.001^{*}$ & & \\
\hline
\end{tabular}




\section{Intestinal glucose absorption}

In Group 1, the 3-OMG/rhamnose ratio was significantly higher in the rest trial compared to the cycling trial (3.51 (2.63-4.77) and 2.64 (2.03-3.91), respectively, $P=0.007)$. In Group 2, Friedman's analysis did not show a significant difference between the three trials (rest: 4.53 (1.48-3.27), cycling: 3.27 (1.13-7.34), running: 3.20 (1.73-6.20), $P=0.565)$. Mann-Whitney's analysis did not show significant differences between the 2 groups (rest: $P=0.257$, cycling: $P=0.218$.

\section{Discussion}

The underlying etiology of $\mathrm{Gl}$ symptoms associated with exercise, especially running, has been little studied and remains speculative. One of the most common theories includes an exercise-related reduction in mesenteric blood flow. Sympathic output plays an important role in the regulation of redistribution of blood flow during exercise. Mesenteric blood flow may be decreased to critical levels during maximal sympathic stimulation. Although it is very difficult to measure mesenteric blood flow during exercise, it has been reported that at maximal exercise intensity the flow may be reduced to only $20 \%$ of the resting value in both trained and untrained people ${ }^{13}$. As a result, gastrointestinal motility, intestinal absorption and mucosal integrity may be disturbed.

An other possible mechanism for the cause of exercise-induced GI symptoms includes the massive neuroendocrine changes and the alterations in plasma hormone concentrations associated with exercise. Although a number of studies have been carried out, in which the relationship between exercise-induced hormonal changes and Gl symptoms has been investigated ${ }^{14-18}$, there is a lack of consistency between the different findings. This suggests that exercise-induced Gl symptoms do not necessarily correlate with plasma levels of GI hormones.

Exercise-induced Gl symptoms point to alterations in Gl motility. The motility of the Gl tract is under control of both hormonal and neural systems. Since these systems change during exercise, this direct effect of exercise on Gl motility, leading to, for instance, changes in gastric emptying and intestinal transit, may be involved in symptoms such as heartburn, vomiting, Gl cramps, urge to defecate and diarrhea.

In the present study we made an attempt to compare the profile of selected GI parameters from asymptomatic subjects with that of subjects who frequently suffer from exercise-induced Gl symptoms, both at rest and during exercise. Moreover, we compared two modes of exercise; running and cycling in the symptomatic subjects.

Our results demonstrated that there were almost no significant differences in Gl profile of the two groups at rest. On the level of the esophagus, however, some small differences in peristaltic pressure at P1, which is the mixed smooth and 
striated muscle part of the esophagus, were observed. It appeared that symptomatic subjects show a lower peristaltic pressure in the rest trial, which reaches significance during the exercise episode. This is the period in which the subjects ingested the three drinks, which led to a relatively large number of wet swallows. During the postexercise episode there was an almost significant difference in pressure at $\mathrm{P} 1$. In this period, however, only a liquid meal was provided, hence most of the peristaltic pressure waves were associated with dry swallows.

At rest, no significant differences between the two groups could be observed in both the number and the duration of gastroesophageal reflux episodes, for gastric emptying, orocecal transit time, intestinal permeability and intestinal glucose absorption. These findings indicate that exercise-induced Gl symptoms are not a result of aggravation of pre-existing differences in GI paramoters between the 2 groups.

During cycling, however, some differences in Gl parameters within and between the 2 groups could be observed. From a previous study it is known that cycling induced some significant differences in duration, amplitude and velocity of peristalsis ${ }^{8}$. The small differences observed between Group 1 and Group 2 during cycling can not be explained and probably do not have clinical significance.

From our previous study it is known that cycling at $70 \%$ Wmax does not influence gastroesophageal reflux in symptom-free subjects ${ }^{8}$. In Group 2, cycling did not significantly increase gastroesophageal reflux, but during cycling a significantly higher number and duration of reflux episodes could be observed, compared to Group 1. Since there were no differences in esophageal motility parameters between the two groups during cycling, this increase in reflux can not be explained by an impaired esophageal acid clearance. It can be hypothesised that some subjects in Group 2 tend to have a higher number of transient LES relaxations during cycling, leading to an increase in gastroesophageal reflux. However, based on the available literature it is unclear yet how exercise affects the characteristics of LES moti!:iy.

According to studies performed at rest and during exercise it appeared that exercise intensity levels up to $70-80 \% \mathrm{VO}_{2 \max }$ do not affect the regulation of gastric emptying ${ }^{19}$. A recent study demonstrated that gastric emptying during cycling is delayed as a result of dehydration leading to a body weight loss of $3 \%{ }^{20}$. However, it appeared that plasma volumes were not significantly different between a normal and a dehydrated condition, due to plasma redistribution. Hence this delay might be related to hormonal changes ${ }^{21}$. The fact that in the present study gastric emptying did not significantly differ between the two groups, neither at rest, nor during cycling or running, suggests that possible changes in Gl blood flow probably do not affect gastric emptying.

At present, the effect of exercise, or exercise type and/or intensity on small intestinal transit remains unclear. Studies which have been carried out so far, show conflicting results. In our previous study ${ }^{8}$ we demonstrated that in normal 
subjects, 90 min cycling at $70 \%$ Wmax did not influence the OCTT. In the present study there were no significant differences in orocecal transit time between the two groups at rest. During cycling, however, it appeared that the subjects from Group 2 showed an almost significant delay ( $P=0.08$ ) in small intestinal transit. If cycling was replaced by running, this delay reached significance. This effect of exercise on intestinal transit might be somewhat unexpected, since diarrhea and urge to defecate are frequently reported exercise-induced GI symptoms, suggesting an accelerating effect of exercise on intestinal transit. It might be possible, however, that exercise and especially running, delays small bowel transit, but accelerates colonic transit, leading to an abnormal defecation pattern in symptomatic subjects. Colonic transit normally lasts for about 20-60 hours with a large inter- and intra-individual variation. Hence, oroanal transit is mainly a colonic event, and therefore it seems reasonable to consider exercise-induced diarrhea and urge to defecate the result of a change in colonic motility.

In an animal study it has been shown that reduction of the small intestinal blood supply of more than $50 \%$ may induce detectable mucosal tissue injury ${ }^{22}$. Exercise may lead to a substantial decrease in GI blood flow of more than $50 \%{ }^{13.23 .24}$. Therefore intense and prolonged exercise may lead to an increased mucosal permeability, which eventually may lead to translocation of bacteria and/or endotoxins. Intestinal permeability can be measured using the lactulose/rhamnose permeability test. This test is based on the assumption that both pre- and postabsorptive factors do not influence the outcome of the test, since rhamnose, which is passively absorbed via the transcellular route, serves as a control probe for lactulose, which is absorbed via the paracellular route ${ }^{25}$. It can be debated whether these assumptions are valid under exercise conditions, since the results from Group 1 show no difference in rhamnose recoveries between the rest and exercise experiments, but show a significant decrease in lactulose recovery in the exercise experiment ${ }^{8}$. Since pre-absorptive factors such as gastric emptying and OCTT appeared not be influenced by exercise as indicated by our experiments, the results might suggest a possible impairment in renal lactulose clearance in the exercise experiment, rather than a change in intestinal permeability. In the present study, no significant difference in intestinal permeability between the two groups could be observed at rest. During cycling, however, the lactulose/rhamnose ratio was significantly increased in Group 2, compared to Group 1, which was, at least partially, due to the decreased lactulose/rhamnose ratio in Group 1. Running induced a larger increase in the lactulose/rhamnose ratio than cycling. This increase reached significance, compared to rest. Apart from mechanical stress due to the up-anddown movements of the abdominal organs during running, it might be possible that, if the athletes perform at their maximal capacities, running leads to a stronger decrease in intestinal blood flow than cycling. Our results suggest that exercise, leading to a decreased Gl blood flow, results in an increased intestinal permeability in Group 2. Even if lactulose clearance is relatively impaired during 
exercise, the increased quantity of lactulose that permeates the intestinal mucosa seems to exceed the possible relative impairment of lactulose clearance, leading to a higher lactulose recovery, and an unchanged rhamnose recovery, and as a result, an increased lactulose/rhamnose ratio. Although renal clearance is assumed to equally affect lactulose and rhamnose clearance ${ }^{25}$, the results of the present study strongly suggest that different renal clearance processes exist for lactulose and rhamnose, respectively.

Small bowel glucose absorption is an ATP-dependent process. It has been suggested that a reduction of mesenteric blood flow of more than $50 \%$ causes a linear fall in the rate of glucose absorption ${ }^{26}$. Our results demonstrated a significantly decreased absorptive capacity for glucose uptake in Group 1 in the cycling trial, compared to rest, as reflected by a decreased 3-OMG/rhamnose ratio. In Group 2, the 3-OMG/rhamnose ratio's were also decreased during cycling and running, compared to rest, although significance was not reached. It can be debated whether this decrease in absorptive capacity is caused by a decreased splanchnic blood flow, leading to a lower activity of the jejunal $\mathrm{Na}^{+} / \mathrm{K}^{+}$-ATPase, necessary for glucose absorption. Since there was no significant difference in glucose absorption between the two groups, both at rest and during cycling, exercise-induced Gl symptoms seem not to be related with intestinal glucose absorption.

The protocol that we used in the present study was designed with the aim to perform initial investigations on the difference in $\mathrm{Gl}$ profile between normal and symptomatic subjects at rest and during physical exercise. This has never been done earlier in a standardized controlled laboratory setting. Moreover, we aimed to investigate whether running and cycling lead to differences in Gl parameters. In a previous study we showed that 90 min cycling at $70 \%$ Wmax did not influence parameters of $\mathrm{Gl}$ function in non-symptomatic subjects, except some parameters of esophageal motility ${ }^{8}$. Hence, we choose to perform the comparison between cycling and running only in subjects who frequently suffer from exercise-induced Gl symptoms.

The inclusion criteria that we used in the present study comprised a rather nonspecific definition for exercise-induced Gl symptoms. This means that it can not be excluded that we have missed specific changes in GI function that may occur if the type of exercise-induced symptoms would be more strictly defined. For instance, it is likely that more pronounced differences in gastroesophageal reflux would be observed if the symptomatic subjects all suffered from exerciseinduced heartburn. Therefore we recommend for future studies specific inclusion criteria for subjects who suffer from exercise-induced Gl symptoms, matched for age and gender with a control subject. We propose separate inclusion criteria such as heartburn, nausea and diarrhea.

In summary we conclude that there were no differences in the profile of the selected Gl parameters between normal and symptomatic subjects at rest, except for some small differences in esophageal pressure. During exercise, however, symptomatic subjects have a slower orocecal transit, which is more 
pronounced during running than during cycling. Intestinal permeability is increased in symptomatic subjects, which is also more pronounced during running than during cycling. Gastric emptying and intestinal glucose absorption appeared not to be different between the two groups. We hypothesize that the delay in small intestinal transit and the increase in intestinal permeability in Group 2 are related to a larger decrease in Gl blood flow than in Group 1. We also hypothesize that gastric emptying is not affected by moderate changes in Gl blood flow. Running induced more pronounced differences in Gl parameters than cycling. In order to investigate the effect of exercise on $\mathrm{Gl}$ parameters in symptomatic subjects in more detail, we propose stricter inclusion criteria, based on the type of Gl symptom. 


\section{References}

1. Keeffe EB, Lowe DK, Gross JR, Wayne R. Gastrointestinal symptoms of marathon runners. West J Med 1984; 141: 481-484.

2. Riddoch $\mathrm{C}$, Trinick TR. Gastrointestinal disturbances in marathon runners. $\mathrm{Br} \mathrm{J}$ Sports Med 1988; 22: 71-74.

3. Worobetz LJ, Gerrard DF. Gastrointestinal symptoms during exercise and endurance athletes: prevalence and speculations of the etiology. NZ Med J 1985; 98: 644-646.

4. Rehrer NJ, Beckers EJ, Brouns F, Ten Hoor F. Effects of dehydration on gastric emptying and gastrointestinal distress while running. Med Sci Sports Exerc 1990; 22: 790-795.

5. Peters HPF, van Schelven FW, Verstappen PA, de Boer RW, Bol E, Erich WB, van der Togt CR, de Vries WR. Gastro-intestinal problems as a function of carbohydrate supplements and mode of exercise. Med Sci Sports Exerc 1993; 25: 1211-1225.

6. Sandell RC, Pascoe MD, Noakes TD. Factors associated with collaps during and after ultramarathon foot races: a preliminary study. Physician Sports Med 1988; 16: 86-94.

7. Kuipers H, Verstappen FTJ, Keizer HA, Geurten P, Van Kranenburg G. Variability of aerobic performance in the laboratory and its physiologic correlates. Int $J$ Sports Med 1985; 6: 197-201.

8. Van Nieuwenhoven MA, Brouns F, Brummer R-JM. The effect of physical exercise on parameters of gastrointestinal function. Neurogastroenterology and Motility 1999 , in press.

9. Van Nieuwenhoven MA, Wagenmakers AJM, Senden JMG, Brouns F, Brummer R$J M$. Performance of the $\left[{ }^{13} \mathrm{C}\right]$-acetate gastric emptying breath test during physical exercise. Eur J Clin Invest 1999, in press.

10. Van Nieuwenhoven MA, Wagenmakers AJM, Brouns F, Brummer R-JM. Effect of mode of administration of $\left[{ }^{13} \mathrm{C}\right]$-acetate on $\left[{ }^{13} \mathrm{C}\right]$-appearance in breath: implications for the gastric emptying breath test. Gastroenterology 1997; 112(4): A843.

11. Levitt MD. Production and excretion of hydrogen gas in man. $\mathbf{N}$ Engl J Med 1969; 281 (3): 122-127.

12. Rooyakkers DR, van Eijk HM, Deutz NEP. Simple and sensitive multi-sugar-probe gut permeability test by high-performance liquid chromatography with fluorescence labelling. J Chromatogr A 1996; 730(1-2): 99-105.

13. Clausen JP. Effect of physical training on cardiovascular adjustments to exercise in man. Physiol Rev 1977; 57: 779-815.

14. Riddoch CJ. Exercise-induced gastrointestinal symptoms, hormonal involvement. Thesis Queens University, 1990, Belfast, Ireland.

15. MacLaren DP, Raine NM, O'Connor AM, Buchanan KD. Human gastrin and vasoactive intestinal polypeptide responses to endurance running in relation to training status and fluid ingested. Clin Sci 1995; 89: 137-143.

16. Philipp E, Wilckens T, Friess E, Platte P, Pirke K-M. Cholecystokinin, gastrin and stress hormone responses in marathon runners. Peptides 1992; 13: 125-128.

17. Grider JR. Role of cholecystokinin in the regulation of gastrointestinal motility. J Nutr 1994; 124: 1334S-1339S.

18. Banfi G, Marinelli M, Bonini P, Gritti I, Roi GS. Pepsinogens and gastrointestinal symptoms in mountain marathon runners. Int J Sports Med 1996; 17: 554-558. 
19. Brouns F. Gastric emptying as a regulatory factor in fluid uptake. Int $\mathrm{J}$ Sports Med 1998; 19(suppl 2): S125-S128.

20. Van Nieuwenhoven MA, Vriens B, Brouns F, Brummer R-JM. The effect of dehydration on gastrointestinal function during exercise. Gastroenterology 1999 , (Abstract), in press.

21. Brouns F. Etiology of gastrointestinal disturbances during endurance events. Scand J Med Sci Sports 1991; 1: 66-77.

22. Bulkley GB, Kvietys PR, Parks DA, Perry MA, Granger DN. Relationship of blood flow and oxygen consumption to ischemic injury in the canine small intestine. Gastroenterology 1985; 89: 852-857.

23. Konturek S, Falser J, Obtulowicz W. Effect of exercise on gastrointestinal secretions. J Appl Physiol 1973; 34 324-328.

24. Wade OL, Combes B, Chilos AW, et al. The effect of exercise on the splanchnic blood flow and splanchnic blood volume in normal men. Clin Sci 1956; 15: 457463.

25. Bjarnason I, MacPherson A, Hollander D. Intestinal permeability: an overview. Gastroenterology 1995; 108: 1566-1581.

26. Winne D. Models of the relationship between drug absorption and the intestinal blood flow. In Shepherd \& Granger (Eds). Physiology of intestinal circulation. pp 289. Raven Press, New York, 1984. 

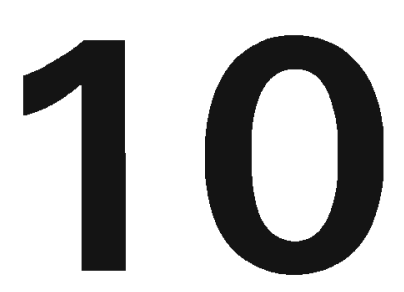

General discussion 


\section{General discussion}

Technological developments have led to an improvement of methods to measure gastrointestinal function. Newly developed techniques, such as stationary and ambulatory manometry and pH-metry, have proven their value in patients. The use of the computer allows fast data acquisition, storage and analysis, and may assist the physician with the diagnosis. Other innovations comprise non-invasive methods such as the gastric emptying breath test and the hydrogen breath test to investigate small intestinal transit and carbohydrate malabsorption. Breath tests for the diagnosis of Helicobacter pylori infection and pancreatic malfunction have been developed. The sugar absorption tests for assessment of the intestinal barrier function and glucose absorption have been extensively used in patients and newly developed analytical techniques provide fast and reliable data for urinary sugar excretion values.

Although these techniques have shown their value in a clinical setting, it has to be proven whether these techniques are valid under conditions of physical exercise.

\section{The core test design; application of techniques}

The basic intention of the research described in this thesis was the development, validation and application of non-invasive test techniques for measuring $\mathrm{Gl}$ function during exercise under standardized/controlled conditions. This resulted in the establishment of a core rest-exercise-rest test design in a laboratory setting. This core test design allows a systematic investigation of the effect of different variables (e.g. nutritional factors, drugs, exercise etc) on GI function during strenuous physical activity. The implementation of the techniques in a standardized rest-exercise-rest protocol is described in Chapter 6. The effect of an intervention with caffeine supplementation is described in Chapter 7, and the effect of an intervention such as dehydration is described in Chapter 8. Different modes of exercise; cycling and running have been studied in Chapter 9.

One of the advantages of our core test design is the controlled setting and the reproducibility of the experiments. Environmental temperature, food and drink intake, exercise intensity and duration can be standardized. The choice of the duration, type and intensity of the exercise that we used in our experiments is based on a number of considerations. On the one hand the exercise intensity should be high enough to induce potential changes in Gl function, on the other hand the exercise should have an intensity which enables the subjects to complete the exercise bout and to reproduce it in a subsequent experiment. Esophageal motility measurements are only possible if the body is in a relatively stable position, because movements induce a large noise. This means that cycling is the most suitable type of exercise, although it is known that running induces the most Gl symptoms. 
The standardized core test design also implies disadvantages. The basic conditions are different from those in the field, where the exercise normally takes place. The laboratory is not a competitive environment, hence the subjects do not experience competition-related emotional stress, which may induce changes in Gl function. Exhaustive efforts and "winning mood" drive, which can make the difference between victory or loss during a competitive race, are hard to be simulated in a laboratory setting.

\section{Methodological aspects}

\section{1a: Esophageal manometry}

The most commonly used technique to investigate esophageal motility is manometry. This can be done both stationary, which is the clinical gold standard, and ambulatory. For stationary manometry a transnasal catheter is used. The catheter contains several lumina, which are connected with pressure transducers. The lumina are continuously perfused with water, at a constant flow of $0.2-0.3 \mathrm{ml} / \mathrm{min}$. The pressure transducers transform a pressure event in the esophagus into an electrical signal, which can be recorded outside the body. The recently developed solid state transducers enable to study esophageal motility in an ambulatory setting, for instance during exercise, even in field studies' and do not require perfusion. In our laboratory setting it was possible to observe the manometric registration continuously via a computer, in real-time, throughout the whole experiment.

Manometric measurements during physical exercise as performed in Chapter 7 and in Chapter 9 are hindered by the increased ventilation rate of the subject. This induces large thoracal pressure differences, at a high frequency, leading to breathing artefacts in the manometric registration. In our studies we used an automated peak detection method, hence proper data analysis algorithms were required to discriminate breathing artefacts from esophageal pressure events, such as simultaneous contractions. It is also important that the subjects can tolerate nasogastric intubation, in order to avoid disturbance of normal esophageal physiology. Moreover, measurements during exercise can only be performed if the body remains in a relatively stable position. We also attempted to perform esophageal manometry during running on a treadmill, but this appeared not to be feasible, since the up-and-down bouncing movements during running induced too many artefacts.

\section{1b: LES-manometry}

The lower esophageal sphincter (LES) is characterized anatomically and manometrically as a zone of approximately $3 \mathrm{~cm}$ of specialized muscle that maintains a tonic activity. It is located between the esophagus and the stomach, and serves as a sphincter muscle, thus preventing reflux of gastric contents back into the esophagus. Swallowing, and the subsequent peristaltic contraction of the esophagus, which transmits distally, induces relaxation of the 
LES. This allows food to enter the stomach. Inappropriate or transient LES relaxations occur spontaneously. These relaxations are not associated with swallowing, and occur especially if the fundus is distended, e.g. to allow the release of ingested air. Spontaneous reflux episodes in healthy persons are almost entirely caused by transient LES relaxations ${ }^{2}$. The LES pressure can be determined by introducing a catheter containing pressure sensors into the fundus of the stomach, and by subsequently pulling the catheter slowly back through the LES, while the pressure is continuously recorded. It is obvious that this technique is not useful for measurements during exercise. Therefore the gold standard for long-term ambulatory LES manometry is measurement at rest using the Dent sleeve ${ }^{3}$. This device consists of a sensor, which contains a membrane of a few centimeters length, which is continuously perfused. This sleeve is positioned in the LES, and enables the registration of the highest pressure in the whole LES section. Recently, solid-state sphinctometers have been developed, which allows ambulatory measurement of LES motility, since no perfusion is required ${ }^{4}$. The circumferential measurement of LES motility using the sphinctometer allows for proper pressure registration even if the LES is asymmetrical, which is not the case if a sleeve sensor is used. Recently, it has been proven that, if a sleeve sensor and a sphinctometer are used simultaneously, the sphinctometer has a lower capacity to register LES relaxations than the sleeve sensor. Hence, the value of the sphinctometer in studying the mechanism of gastroesophageal reflux is limited ${ }^{5}$.

The question arises whether exercise-induced reflux is either caused by an impaired LES function, or is related to swallowing, or to an increased rate of transient LES relaxations. We have performed pilot experiments during cycling using two solid-state circumferential sphinctometers ${ }^{6}$. Although it appeared that almost all reflux episodes during exercise were preceded by transient LES relaxations, we were not satisfied with the reliability and reproducibility of this method, because movements of the diaphragm during exercise could cause dislocation of the sphinctometers. For this reason, the Dent sleeve is probably a more reliable method to measure LES motility and to unravel the etiology of reflux during exercise.

\section{1c: $\rho H$-metry}

The $\mathrm{pH}$ in the esophagus and/or in the stomach can be monitored using a smallcaliber transnasal electrode. Glass antimony and pH-Isfet electrodes are the commonly used electrode types. Esophageal $\mathrm{pH}$ is usually measured at $5 \mathrm{~cm}$ above the LES, which is the standard position for esophageal $\mathrm{pH}$ measurements ${ }^{7}$. The electrode is connected to a portable datalogger, which enables a long-term ambulatory $\mathrm{pH}$ measurement. Recently, advanced thincaliber catheters have been developed, which offer the opportunity to measure esophageal motility, gastric $\mathrm{pH}$ and gastroesophageal reflux simultaneously. These catheters, which we used in Chapter 7 and Chapter 9, contain both solidstate pressure- and $\mathrm{pH}$-sensors and are connected with a portable datalogger, 
which allows ambulatory measurements as well ${ }^{6}$.

A reflux episode is generally defined as an episode in which the $\mathrm{pH}$ in the esophagus, at $5 \mathrm{~cm}$ above the LES, is lower than 4 . The parameters that are clinically used are the number of reflux episodes, and their relative duration. This definition is based on the clinical significance of reflux, with respect to the fact that frequent and prolonged exposure of the esophagus to gastric juice with its low $\mathrm{pH}$ may damage the esophageal mucosa, leading to esophagitis, and eventually to Barrett's metaplasia and esophageal cancer. An important disadvantage of this definition is that exposure of the esophagus to gastric contents with a $\mathrm{pH}$ of 4.1 and higher is ignored in automated clinical analysis, although it is axiomatic that (patho)physiological phenomenons may occur. Pharmacological inhibition of gastric acid production in reflux patients can result in an increase in gastric $\mathrm{pH}$ above $\mathrm{pH} 4$, although the underlying cause of gastroesophageal reflux is still present. This may lead to a "non-acid" reflux, which is not registered during conventional pH-metry.

In order to study the effect of exercise on LES function and gastroesophageal reflux adequately, it is proposed to register all pressure events that occur in the LES, i.e. both the swallow-induced relaxations and the transient LES relaxation, together with all changes that occur in esophageal $\mathrm{pH}$, both at rest and during physical exercise. This allows discrimination between physiological events occurring in both the LES and the esophagus, and possible clinically relevant events, such as an increased number of reflux episodes or a prolonged exposure of the esophagus to gastric acid. This approach allows unambiguous determination of the etiology of reflux during exercise.

\section{2: Measurement of gastric emptying}

The gold standard for the measurement of gastric emptying is scintigraphy ${ }^{8.9}$. This technique provides an excellent possibility to determine gastric emptying of solids and liquids simultaneously. A radionuclide marker is incorporated into the test meal, and its radioactivity in the stomach is measured using an externally positioned gamma-scintillation camera. ${ }^{99 m}$ Technetium and ${ }^{113}$ Indium- DPTA are the most commonly used radionuclide markers for the solid phase and the liquid phase, respectively. The test is physiologic, because ordinary meals can be employed; it is non-invasive, and quantitative. Disadvantages, however, include the expenses of the isotopes and the equipment, and the small radiation load to the subject. Furthermore, ambulatory measurements are not possible using this method.

The double sampling technique, which we used as a reference method in Chapter 3, is a cheap and relatively simple method, which allows the measurement of gastric emptying of liquids ${ }^{10.11}$. The method depends on the serial determination of dye concentration (phenol red) in gastric samples obtained before and after the addition of a known amount of dye to the stomach contents. The technique can be carried out in an ambulatory setting, 
which makes it suitable for gastric emptying measurements during physical exercise. Disadvantages of this method include nasogastric intubation, which is discomfortable and may influence the process of gastric emptying itself in sensitive subjects, as well as the fact that determination of gastric emptying is restricted to liquids.

The paracetamol ${ }^{12}$ and sulfamethizole absorption tests ${ }^{13}$ have been described as useful techniques to measure relative gastric emptying of liquids. The techniques are based on measurement of plasma paracetamol or sulfamethizole concentration after ingestion of a liquid meal labeled with these substances. The advantage of the technique comprises its low costs. However, the method is indirect, it requires blood sampling, and assumes that the rise in plasma concentration only depends on the gastric emptying rate and that the renal clearance and hepatic metabolism of the drugs are constant processes. Since exercise may not only affect gastric emptying, but also plasma volume due to sweat loss, renal and hepatic function due to a shift in blood flow towards the working muscles, these methods may be considered as not very useful during exercise.

A few years ago, methods for the measurement of gastric emptying using stable non-radioactive isotope methods have been developed ${ }^{14}$. The principle of this method is based on the oxidation of a ${ }^{13} \mathrm{C}$-labeled tracer to ${ }^{13} \mathrm{CO}_{2}$ after emptying of the tracer together with the test meal from the stomach and after the subsequent absorption of the tracer in the duodenum. The ${ }^{13} \mathrm{CO}_{2}$-enrichment in the breath then reflects the process of gastric emptying. The method assumes that the substrate is rapidly absorbed in a constant rate by the intestine after gastric emptying and that the delay between intestinal absorption, intracellular oxidation and appearance of ${ }^{13} \mathrm{CO}_{2}$ is small and constant. A half-emptying time can then be calculated. If all these assumptions are valid then it would be axiomatic that the time needed for the appearance of ${ }^{13} \mathrm{CO}_{2}$ in the breath is directly proportional to the gastric emptying rate of the substrate. $\left[{ }^{13} \mathrm{C}\right]$-octanoic acid has been described as a useful label to determine the gastric emptying of solids, while $\left[{ }^{13} \mathrm{C}\right]$-acetate has been described as the appropriate label to determine the gastric emptying rate of liquids and semisolids under resting conditions ${ }^{15}$. The advantages of the stable isotope breath technique include their simplicity, the safety because stable isotopes are used and the possibility for widespread clinical applications. It is also possible to perform gastric emptying studies in children, pregnant women or immobilized patients. The technique can also be applied in field studies, or during physical exercise, because breath samples can easily be obtained and later transported to a mass spectroscopy or infrared spectroscopy facility for analysis. The disadvantage of this technique, however, is apart from the necessary availability of expensive mass spectroscopy or infrared spectroscopy equipment, the fact that the breath enrichment does not only reflect gastric emptying, but the processes of intraduodenal absorption and subsequent oxidation and exhalation via the body bicarbonate pool as well. It is unlikely that a calculated T1/2, 
which assumes a constant rate of absorption, oxidation and exhalation, is valid under all circumstances ${ }^{16}$, as for example during physical exercise. Attempts to improve the reliability of the calculated $\mathrm{T} 1 / 2$ derived from the breath test include a mathematical deconvolution method to correct for post-gastric emptying processes such as absorption, metabolism and subsequent exhalation of the label ${ }^{17}$. Recently, an other, simplified method has been proposed in which a generalized linear model was applied to assess both the duration of the gastric emptying lag phase (Tlag) and the $\mathrm{T1} / 2$ from breath ${ }^{13} \mathrm{CO}_{2}$-data. The method is based on a linear model using only 3 breath samples, followed by a prediction based on normative values obtained from a number of healthy volunteers ${ }^{18}$. These methods appear to be useful and reliable. However, both methods require a separate validation before it can be applied during physical exercise.

In Chapter 3 we described the determination of the Time to Peak breath enrichment $\left({ }^{13} \mathrm{C}\right.$-TTP), which provides a reliable but relative parameter of gastric emptying of liquids, as demonstrated by the good correlations that we observed between the T1/2 obtained with the double sampling technique and the ${ }^{13} \mathrm{C}$ TTP, obtained with the ${ }^{13} \mathrm{C}$-acetate breath test, both at rest and during physical exercise. We also demonstrated that exercise affects the absorption and oxidation rate of the tracer. Therefore this technique can only be used for intraindividual comparisons, at a fixed exercise intensity.

\section{3: Measurement of intestinal transit}

With the use of a radioisotope-labeled meal and dedicated scintigraphic hardware and software it is possible to evaluate small bowel transit ${ }^{19,20}$. A standard ${ }^{99 \mathrm{~m}}$ Tc-labeled meal, as in use for the scintigraphic determination of gastric emptying, is appropriate. Small bowel transit is calculated by subtracting the elapsed time for a certain amount of the marker $(10 \%$ or $50 \%)$ to empty from the stomach from the elapsed time for the same amount of radioisotope to arrive in the colon. Deconvolution analysis may be applied to enhance the validity of the method.

However, scintigraphic measurement of small bowel transit can not be used during excercise, as a steady position in front of the gamma camera must be obtained. The lactulose $\mathrm{H}_{2}$-breath test does not require a fixed position. This technique is based on the principle that, due to the near absence of bacterial flora in the small bowel, fermentation of undigestible carbohydrates will be delayed until arrival in the colon. This fermentation results in production of hydrogen, which will rapidly be absorbed from the intestinal lumen and will subsequently be expired ${ }^{21}$. The orocecal transit time (OCTT) can thus be assessed by the oral administration of a small amount of lactulose and the repeated measurement of end-expiratory $\mathrm{H}_{2}$-concentration ${ }^{22}$. We used this method in Chapter 5, Chapter 6, Chapter 7, Chapter 8 and Chapter 9. A disadvantage, however, is the fact that lactulose, which is clinically prescribed as as a laxative, induces an undesirable acceleration in small bowel transit, due to its osmotic effect ${ }^{23}$. Using a sophisticated breath analyzer and with taking 
care of a number of precautions ${ }^{24}$ we carried out a pilot experiment and established that a lactulose dose as low as $5 \mathrm{~g}$ was sufficient to assess a reliable OCTT.

It is obvious that the outcome of the lactulose $\mathrm{H}_{2}$-breath test reflects both the processes of gastric emptying and small intestinal transit. This means that an extremely delayed gastric emptying wili lead to the observation of a delayed OCTT, which may lead to misinterpretation concerning the rate of the small bowel transit. For this reason, in order to gain insight in the rate of small intestinal transit, it is recommended to study gastric emptying and OCTT simultaneously.

An important aspect of the use of the $\mathrm{H}_{2}$-breath test during exercise, is the highly increased ventilation rate. This leads to a dilution of the produced hydrogen gas, hampering to observe changes in breath $\mathrm{H}_{2}$-enrichment. If one wants to study the effect of continuous exercise on OCTT, it is therefore recommended to measure the background $\mathrm{H}_{2}$ at rest and $\mathrm{H}_{2}$-enrichment in the postexercise period, with the prerequisite that the lactulose does not reach the colon during the exercise period. For this reason the duration of the exercise period is limited. Therefore the $\mathrm{H}_{2}$-breath test is probably not useful for the measurement of OCTT during continuous exercise, unless larger quantities of lactulose are used to overcome the problem of exercise-induced dilution in breath, inducing a disadvantage of possible osmotic effects, or if intermittent periods of rest, lasting long enough to return to a normal resting ventilation, are included.

\section{4: Measurement of the intestinal barrier function/g/ucose absorption}

The intestinal permeability can be evaluated by measuring urinary excretion of orally administered water soluble, non-degradable test probes. This barrier function test is based on the comparison of intestinal permeation of a larger molecule with that of a smaller molecule by measuring the ratio of their urinary excretion. These two probes follow different routes of intestinal permeation; the larger molecules are assumed to permeate paracellularly, the smaller molecules are assumed to permeate transcellularly. Pre-absorption factors such as gastric emptying, dilution by intestinal secretion and intestinal transit rate, and postabsorption factors such as systemic distribution and renal clearance are assumed to affect both molecules equally (Figure 10.1). Therefore, the urinary excretion ratio is considered to be a parameter for intestinal permeability ${ }^{25-27}$. In order to confirm the validity of these assumptions, we performed a study in which we investigated the role of a pre-absorption factor, i.e. small intestinal transit, and of a postabsorptive factor, i.e. the renal clearance, on the urinary excretion of the sugars. This study is described in Chapter 5. 


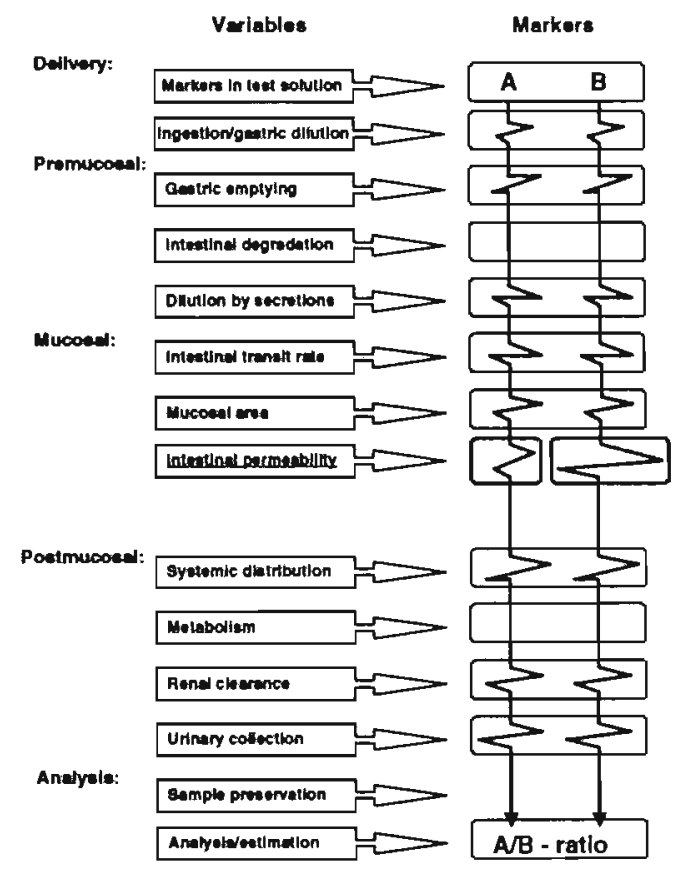

Figure 10.1. The concept of intestinal permeability measurement. Both markers (A and B) are equally affected by pre-and postmucosal factors. The only difference is the intestinal permeation route. This difference is reflected by the urinary excretion ratio.

We demonstrated that this pre-absorptive factor did not influence the lactulose/rhamnose permeability test. We also demonstrated that renal clearance of rhamnose is not dependent on the quantity of rhamnose present in the circulation. However, the renal clearance of lactulose is dependent on the quantity of lactulose present in the circulation. We demonstrated that a higher quantity of lactulose results in a lower $5 \mathrm{~h}$ recovery and a lower lactulose/rhamnose ratio, thus underestimating a possible increase in permeability if more lactulose and rhamnose is absorbed by the small intestine. This observation is supported by the lactulose/rhamnose data in Chapter 9, which strongly suggest that different renal clearance processes exist for lactulose and rhamnose, respectively. Therefore the assumption that postabsorptive factors do not influence the outcome of the lactulose/rhamnose permeability test, appears to be not valid. This may be of consequence for the usefulness and reliability of the test in patients with renal failure, or in people who use diuretics or other drugs which may affect renal function. In this respect it can not be excluded that physical exercise, which may alter renal perfusion and function, especially in conditions of dehydration, influences the outcome of the test, independent from possible effects of exercise on small bowel 
permeability.

The intestinal barrier function may be related to the etiology and the pathogenesis of various intestinal and systemic disorders. Factors that can increase intestinal permeability comprise alcohol abuse, enteral feeding, prolonged parenteral nutrition and probably strenuous exercise ${ }^{25}$. A detailed examination of the more than 1200 studies which have been published on this field revealed that different probes have been used in varying dosages, as described in Chapter 4 . The reason for these differences may be lying in the local availability of analysis techniques. This makes mutual comparisons between the various studies very difficult. The study described in Chapter 4 clearly demonstrated that, if the permeability was increased, the quantity of the administered lactulose and rhamnose was an important factor in the assessment of a change in urinary lactulose/rhamnose ratio. Since other molecules such as mannitol, PEG, ${ }^{51} \mathrm{Cr}$-EDTA, ${ }^{99 m} \mathrm{Tc}$-DPTA, Dextran and cellobiose follow the same paracellular and transcellular permeation routes as lactulose and rhamnose, it is reasonable to assume that the quantities of these other molecules are also an important factor in the assessment of a change in permeability.

Because of the accelerating effect of lactulose on small bowel transit ${ }^{23}$, it is obvious that maximal reduction of the quantity of lactulose administered for the measurement of intestinal permeability is desirable in order to prevent gastrointestinal disturbances. This is especially important if one wants to study OCTT and gastrointestinal complaints during physical exercise as well, as we did in Chapter 6, Chapter 7 and Chapter 8. We demonstrated in Chapter 4 that quantities of $5 \mathrm{~g}$ lactulose with $0.5 \mathrm{~g}$ rhamnose were sufficient to discriminate between a moderately increased and a normal permeability. This relatively small quantity of lactulose appeared to be sufficient for simultaneous measurement of both OCTT and permeability.

\section{Implementation of the core test}

\section{The difference between symptomatic and asymptomatic athletes}

The core test design allows systematical study of the effect of different variables on Gl function during strenuous physical activity. Furthermore, differences between subjects can be studied objectively as well. Some people seem to have Gl symptoms in almost every endurance race, but it is often very difficult to find a specific cause, because many factors may play a role in the etiology of a specific symptom. Moreover, the chance that a participant of an endurance event suffers from a gastrointestinal disease, which is not related to exercise, increases with an increasing number of participants. Such a person may experience Gl symptoms during exercise, although exercise itself is not the causative factor. In this respect it is interesting to compare subjects, who never experience Gl symptoms, with subjects who frequently experience GI symptoms, both at rest and during exercise. This comparison is described in Chapter 9. We studied 10 healthy subjects and 10 subjects who suffer from 
exercise-induced Gl symptoms. It appeared that there were no differences in the selected GI parameters between the groups at rest. However, some differences occurred during exercise. It was observed that more gastroesophageal reflux occurred in subjects suffering from Gl symptoms during exercise. LESmanometry to discriminate between a swallow-induced LES relaxation and a transient LES relaxation using a Dent sleeve might reveal the underlying motor events of this increase in reflux. During exercise, gastric emptying did not significantly differ between the groups. However, it appeared that small intestinal transit was slower, both at rest and during exercise, in the group of subjects who suffer from Gl symptoms. Furthermore, intestinal permeability during exercise was increased in these subjects. The study described in Chapter 9 can be considered as a pilot study, because the selection of our subject was not based on a specific type of Gl symptoms. Comparisons between subjects who never experience Gl symptoms, with a homogenous group of subjects who frequently experience well-defined specific Gl symptoms will probably reveal more differences in Gl parameters, both at rest and during exercise. The establishment of these differences for each type of exercise-induced GI disturbances allows possible nutritional or pharmacological prevention or intervention.

\section{Implications for future research}

Many questions regarding the effect of physical exercise on $\mathrm{Gl}$ function remain to be answered in the future, such as the effect of:

- Different exercise intensities and/or durations.

- Sex specific differences.

- Differences in feeding status: e.g. fasted vs. fed state.

- Differences in nutritional intake during exercise.

- Ergogenic nutritional aids.

- Interventions to alleviate exercise-induced Gl symptoms, for example:

. Amino acids (glutamine, arginine)

. Gastric acid inhibitors

. Motility modulating substances (prokinetics, antikinetics)

. Etc.

In order to properly answer these questions using the core test design, it is desirable to make some modifications in the non-invasive methods used. Possible improvements may include the use of a Dent Sleeve, in order to measure LES motility in relation to gastroesophageal reflux. Hence, a catheter containing a pharyngeal swallow detector, esophageal pressure sensors (preferably solid state), a Dent sleeve and esophageal and gastric $\mathrm{pH}$ sensors is required. A potentially useful, newly developed technique includes measurement of patterns of gas and liquid reflux using intraluminal electrical impedance ${ }^{28}$. This technique is based on changes in electrical impedance between two 
electrodes during passage of a bolus and allows for prolonged monitoring and detection of liquid and/or gas movements within the esophageal lumen. The technique, combined with $\mathrm{pH}$-metry, allows discrimination between acid and non-acid gastroesophageal reflux episodes.

The development of computer algorhitmes to erase manometric artefacts may lead to the possibility to perform esophageal manometry during running.

Ambulatory electrogastrography might be useful to gain more insight in the change of gastroelectrical processes during physical exercise, since nausea, vomiting and gastric motility disorders are often associated with gastric dysrhythmias ${ }^{29}$.

Laser Doppler flowmetry has been used to determine the mesenteric blood flow during low-intensity treadmill walking ${ }^{30}$ and during short-term high intensity cycling $^{31}$. Validation and further development of this technique may provide a useful tool for direct measurements of splanchnic blood flow, not only during exercise, but in a clinical setting as well.

Measurements of the colon, such as motility/transit measurements and colonic permeability using sucralose $e^{32}$ may be useful in studying exercise-induced diarrhea and in elucidating whether exercise-induced diarrhea is predominantly from small bowel or colonic origin.

Finally, as described in Chapter 2, measurements of changes in GI hormones such as motiline, gastrine, cholecystokinin (CCK), vasoactive intestinal polypeptide (VIP), Polypeptide YY (PYY), glucagon-like peptide-1 (GLP-1) and non-Gl hormones such as vasopressin and catecholamines in relation to alterations in parameters of GI funtion may provide further insight in the etiology of $\mathrm{Gl}$ changes during exercise. 


\section{References}

1. Barham CP, Gotley DC, Mills A, Alderson D. A new 24-hour $\mathrm{pH}$ and motility recording system. Gut 1993; 34: 444-449.

2. Dent, JA, Dodds WJ, Friedman RH, Sekiguchi T, Hogan WJ, Arndorfer RC, Petrie DJ. Mechanisms of gastroesophageal reflux in recumbent human subjects. $J$ Clin Invest 1980; 65: 256-267.

3. Dent J, Chir B. A new technique for continuous sphincter pressure measurement. Gastroenterology 1976; 71: 263-267.

4. Gotley DC, Barham CP, Miller R, Arnold R, Alderson D. The sphinctometer: a new device for measurement of lower oesophageal sphincter function. Br J Surg 1991: 78: 933-935.

5. Trudgill NJ, Riley SA. Monitoring the lower oesophageal sphincter: sphinctometer or sleeve? Neurogastroenterol Motil 1999; 11(3): 173-178.

6. Van Nieuwenhoven MA, Brouns F, Brummer RJM. Ambulatory measurement of esophageal motility, LES pressure and gastroesophageal reflux during exercise. Gastroenterology 1996; 110 : A704.

7. Johnson FL, Chapter 2: Methods of testing esophageal clearance. In: Esophageal and gastric emptying. Dubois \& Castrell, 1984. CRC Press Inc., Bocca Raton, Florida, USA.

8. Heading RC, Tothill P, McLoughlin GP, Shearman DJC. Gastric emptying rate measurement in man. A double isotope scanning technique for simultaneous study of liquid and solid components of a meal. Gastroenterology 1976; 71 : 45-50.

9. Collins PJ, Horowitz M, Cook DJ, Harding PE, Shearman DJC. Gastric emptying in normal subjects - a reproducible technique using a single scintillation camera and computer system. Gut 1983; 24: 1117-1125.

10. George JD. New clinical method for measuring the rate of gastric emptying: the double sampling technique. Gut 1968; 9: 237-242.

11. Beckers EJ, Rehrer NJ, Brouns F, Ten Hoor F, Saris WHM. Determination of total gastric volume, gastric secretion and residual meal using the double sampling technique of George. Gut 1988; 29: 1725-1729.

12. Heading RC, Nimmo J, Prescott LF, Tothill P. The dependence of paracetamol absorption on the rate of gastric emptying. Br J Pharmacol 1973; 47:415-421.

13. Hirakawa K, lida $M$, Fuchigami T, Murata $S$, Matsumoto T, Fujishama $M$. Sulfamethizole absorption test for the assessment of gastric emptying. Scand $J$ Gastroenterol 1995; 30: 133-138.

14. Ghoos YF, Maes BD, Geypens BJ, Mys G, Hiele MI, Rutgeerts PJ, VanTrappen G. Measurement of gastric emptying rate of solids by means of a carbon-labeled octanoic acid breath test. Gastroenterology 1993; 104: 1640-1647.

15. Braden B, Adams S, Duan L-P, Orth K-H, Maul F-D, Lembcke B, Hör G, Caspary WF. The $\left[{ }^{13} \mathrm{C}\right]$-acetate breath test accurately reflects gastric emptying of liquids in both liquid and semisolid test meals. Gastroenterology 1995; 108: 1048-1055.

16. Choi M-G, Camilleri M, Burton DB, Zinsmeister AR, Forstrom LA, Spreekumaran Nair K. $\left[{ }^{13} \mathrm{C}\right]$-Octanoic acid breath test for gastric emptying of solids: accuracy, reproducibility, and comparison with scintigraphy. Gastroenterology 1997; 112: 1155-1162.

17. Maes BD, Mys G, Geypens BJ, Evenepoel P, Ghoos YF, Rutgeerts PJ. Gastric emptying flow curves separated from carbon-labeled octanoic acid breath test results. Am J Physiol 1998; 275: G169-G175. 
18. Lee JS, Camilleri M, Zinsmeister AR, Burton DD. A valid, accurate, office-or fieldbased nonradioactive test for gastric emptying of solids. Gastroenterology 1999; 116(4): G4208.

19. Von der Ohe MR, Camilleri M. Measurement of small bowel and colonic transit: Indications and methods. Mayo Clin Proc 1992; 67: 1169-1179.

20. Kamm MA. The small intestine and colon: scintigraphic quantitation of motility in health and disease. Eur J Nucl Med 1992; 19: 902-912.

21. Levitt MD. Production and excretion of hydrogen gas in man. The New England $J$ Med 1969; 281 (3): 122-127.

22. Brummer RJM, Armbrecht U, Bosaeus I, Dotevall G, Stockbrügger RW. The hydrogen $\left(\mathrm{H}_{2}\right)$ breath test. Sampling methods and the influence of dietary fibre on fasting levels. Scand J Gastroenterol 1985; 20: 1007-1013.

23. Miller MA, Parkman HP, Urbain JL, Brown KL, Donahue DJ, Knight LC, Maurer AH, Fisher RS. Comparison of scintigraphy and lactulose breath hydrogen test for assessment of orocecal transit: lactulose accelerates small bowel transit. Dig Dis Sci 1997; 42(1): 10-18.

24. Armbrecht U, Jensen J, Edén $S$, Stockbrügger RW. Assessment of orocoecal transit time by means of a hydrogen $\left(\mathrm{H}_{2}\right)$ breath test as compared with a radiologic control method. Scand J Gastroenterol 1986; 21: 669-677.

25. Bjarnason I, MacPherson A, Hollander D. Intestinal permeability: an overview. Gastroenterology 1995: 108: 1566-1581.

26. Hollander D. the intestinal permeability barrier. A hypothesis as to its regulation and involvement in Crohn's Disease. Scand J Gastroenterol 1992; 27: 721-726.

27. Travis S, Menzies I. Intestinal permeability: functional assessment and significance. Clin Sci 1992; 82: 471-488.

28. Sifrim D, Silny J, Holloway RH, Janssens JJ. Patterns of gas and liquid reflux during transient lower oesophageal sphincter relaxation: a study using intraluminal electrical impedance. Gut 1999; 44: 47-54.

29. Chen JZ, McCallum RW. Electrogastrography. Principles and Applications. Raven Press, Ltd., New York, USA 1984.

30. Qamar MI, Read AE. Effects of exercise on mesenteric blood flow in man. Gut 1987; 28(5): 583-587.

31. Eriksen $M$, Waaler BA. Priority of blood flow to splanchnic organs in humans, during pre- and post-meal exercise. Acta Physiol Scand 1994; 150(4): 363-372.

32. Enns R, Bak A, Meddings J, Sutherland LR. Sucralose: a novel permeability marker for colonic disease. Gastroenterology 1997; $112(4)$ : A967. 


\section{Summary}

This thesis describes the effect of physical exercise on gastrointestinal function. It contains two parts; The first part (Chapter 3,4 and 5) focuses on basic, research on the techniques to measure gastric emptying and intestinal permeability, and the second part (Chapter 6, 7, 8 and 9) focuses on applied research in athletes during intense physical exercise.

It is well-known that physical exercise can induce gastrointestinal symptoms. Chapter 2 critically reviews the current knowledge about the effect of physical exercise on gastrointestinal function. The epidemiology and the proposed etiology are described, and a number of studies are discussed, in which parts of the Gl tract and Gl-related factors such as hormonal and neural aspects, have been studied during exercise.

Chapter 3 describes the validation of the ${ }^{13} \mathrm{C}$-acetate breath test during exercise. This is a novel, non-invasive technique to study gastric emptying of liquids. However, it has only been validated in a resting situation. Exercise leads to an increased oxidation rate of ${ }^{13} \mathrm{C}$-acetate and an increased turnover of ${ }^{13} \mathrm{CO}_{2}$ via the body bicarbonate, therefore it was important to validate the usefulness of this test during physical exercise and to consider the processes of intestinal absorption and subsequent oxidation of the tracer and exhalation of the ${ }^{13} \mathrm{CO}_{2}$ as well. Good correlations between the gastric half-emptying time measured using the double sampling method and the Time to Peak breath enrichment $\left({ }^{13} \mathrm{C}\right.$ TTP) derived from the ${ }^{13} \mathrm{C}$-acetate breath test were observed. Hence, it was concluded that the ${ }^{13} \mathrm{C}$-TTP is a useful parameter to describe the relative gastric emptying rate of liquids.

The intestinal barrier function or intestinal permeability can be assessed using a sugar absorption test. In Chapter 4, different dosages of the sugars; lactulose and rhamnose, were administered in order to determine whether the quantity of lactulose and rhamnose affects the outcome of the test. It was observed that, under a condition of a normal intestinal permeability, the administered quantity of the sugars does not affect the urinary lactulose/rhamnose ratio. However, if the permeability was artificially increased, the lactulose/rhamnose ratio was higher if larger quantities of the sugars were administered, suggesting that preand/or postabsorptive processes may influence the outcome of the test.

In Chapter 5, these pre- and postabsorptive processes were investigated in more detail. The effect of the rate of small intestinal transit as well as the role of renal clearance of the sugars were studied. It was observed that an increased rate of small intestinal transit does not affect the outcome of the lactulose/rhamnose permeability test. 
Renal clearance of rhamnose is not dependent on the quantity of rhamnose present in the circulation. However, renal clearance of lactulose is dependent on the quantity of lactulose present in the circulation, as a higher quantity of lactulose results in a lower $5 \mathrm{~h}$ recovery and a lower urinary lactulose/rhamnose ratio, thus underestimating a possible increase in permeability if more lactulose and rhamnose are absorbed by the smal! intestine. This observation may be of consequence for the usefulness and reliability of the test in patients.

Chapter 6 describes a model in which the effect of physical exercise on a number of selected Gl parameters was studied. Esophageal motility, gastroesophageal reflux, gastric $\mathrm{pH}$, gastric emptying, small intestinal transit time and intestinal permeability and glucose absorption were measured simultaneously in healthy well-trained male subjects in a rest-cycling-rest protocol. It was observed that cycling at $70 \%$ Wmax does not lead to differences in reflux, gastric $\mathrm{pH}$ and gastrointestinal transit. However, we observed a decreased distal esophageal pressure, a decreased urinary lactulose/rhamnose ratio and small intestinal glucose absorption, and an increased peristaltic velocity during cycling.

Chapter 7 describes the effect of supplementation of a sports drink with caffeine on a number of selected $\mathrm{Gl}$ parameters during physical exercise. This study was conducted because caffeine is suspected to affect gastrointestinal function. Ten healthy well-trained subjects underwent the same protocol as in Chapter 6. The effect of supplementation of a sports drink with $150 \mathrm{mg} / \mathrm{L}$ caffeine was compared with a normal sports drink and a water placebo. There were no significant differences in gastroesophageal reflux, gastric $\mathrm{pH}$ or gastrointestinal transit between the sports drink, the sports drink supplemented with caffeine and the water placebo. Intestinal glucose uptake appeared to be increased in the experiment using the sports drink supplemented with caffeine. Hence, it was concluded that supplementation of a sports drink with caffeine does not induce major changes in gastrointestinal function.

Chapter 8 describes the effect of a pre-exercise dehydration regimen on gastrointestinal transit, intestinal permeability and glucose absorption. It is known that dehydration leads to aggravation of gastrointestinal complaints during exercise, suggesting an alteration in gastrointestinal parameters. Ten healthy well-trained subjects were studied twice; under a normal and under a dehydrated condition. They underwent the same protocol as in Chapter 6 , except for the esophageal manometry and pH-metry. Gastrointestinal symptoms, rectal temperture, plasma volume and plasma vasopressin values were measured before and after cycling. It was observed that gastric emptying was significantly slower as a result of dehydration. Small intestinal transit was unchanged. In both experiments, exercise led to a significant increase in rectal temperature and plasma vasopressin and a significant decrease in plasma 
volume. The increase in plasma vasopressin was significantly higher in the dehydration experiment. Dehydration did not change plasma volume, rectal temperature, plasma vasopressin concentration, intestinal permeability or glucose absorption. In the dehydrated experiment, exercise induced a significant increase in nausea and epigastric cramps, in contrast to the control situation. The difference in gastric emptying between the two experiments was significantly correlated with the difference in nausea score.

Chapter 9 describes the effect of cycling and running on a number of selected gastrointestinal parameters in subjects who frequently suffer from exerciseinduced gastrointestinal symptoms (Group 2). The data from these subjects were compared with the data from healthy subjects (Group 1). All subjects underwent the same protocol as in Chapter 6, and the subjects from Group 2 underwent a rest-running-rest protocol as well. No important differences in resting values between the 2 groups could be observed. During cycling, both the number and duration of reflux episodes was increased in Group 2, compared to Group 1. OCTT was increased in the cycling trial in Group 2 and the difference reached significance in the running trial, compared to the rest trial. In Group 1, the lactulose/rhamnose ratio was significantly decreased in the cycling trial, compared to rest, whereas in Group 2, the lactulose/rhamnose ratio was higher in the cycling trial and reached significance in the running trial, compared to rest. It is concluded that there were no differences in Gl profile between the two groups at rest. During exercise, symptomatic subjects have a slower orocecal transit and a higher intestinal permeability, which is more pronounced during running. 



\section{Samenvatting}

Dit proefschrift beschrijft het effect van lichamelijke inspanning op de functie van het gastrointestinale stelsel. Het proefschrift is opgebouwd uit twee delen: het eerste deel (hoofdstuk 3, 4 en 5) betreft basaal onderzoek betreffende technieken om de maaglediging te meten, en om de mate van doarlaatbaarheid van de dunne darm te bepalen. Het tweede deel (hoofdstuk $6, \mathrm{t} / \mathrm{m}$ 9) betreft toegepast gastrointestinaal onderzoek bij atleten tijdens intensieve lichamelijke inspanning.

Het is bekend dat lichamelijke inspanning maag-darmklachten kan veroorzaken. In hoofdstuk 2 wordt een uitgebreid overzicht gegeven van de huidige kennis op het gebied van lichamelijke inspanning en gastrointestinale functie. De epidemiologie en etiologie worden beschreven. Tevens wordt een aantal studies bediscussieerd, waarin afzonderlijke onderdelen van het gastrointestinale stelsel en daaraan gerelateerde aspecten zoals neurale en hormonale regulatie, tijdens inspanning worden beschreven.

In hoofdstuk 3 wordt de validatie van de ${ }^{13} \mathrm{C}$-acetaat ademtest tijdens lichamelijke inspanning beschreven. Dit is een nieuwe, non-invasieve methode om de maaglediging van vloeistoffen te meten, waarbij gebruik wordt gemaakt van een tracer met een stabiele isotoop. Tot dusver werd deze methode alleen gebruikt in een rustsituatie. Lichamelijke inspanning leidt echter tot een verhoogde oxidatie van de ${ }^{13} \mathrm{C}$-actetaat tracer en een verhoogde turnover van ${ }^{13} \mathrm{CO}_{2}$ via de bicarbonaat pool van het lichaam. Daarom was het van belang om de bruikbaarheid van deze test tijdens lichamelijke inspanning te valideren en daarbij tevens de processen van intestinale absorptie en daaropvolgende oxidatie van de tracer en de uitademing van het ${ }^{13} \mathrm{CO}_{2}$ te betrekken. Er vwerden goede correlaties gevonden tussen de maagledigings halfwaarde tijd (T1/2), gemeten met behulp van de zogenaamde "double sampling methode" en het tijdstip van piekverrijking van de adem met ${ }^{13} \mathrm{CO}_{2}\left({ }^{13} \mathrm{C}\right.$-TTP), gemeten met de ${ }^{13} \mathrm{C}$-acetaat ademtest. Op basis hiervan werd geconcludeerd dat de ${ }^{13} \mathrm{C}$-TTP een goed bruikbare parameter is om de relatieve maagledigingssnelheid van vloeistoffen te beschrijven.

De mate van doorlaatbaarheid van het dunne darmslijmvlies kan bepaald worden met behulp van een zogenaamde suiker absorptie test. In hoofdstuk 4 zijn verschillende hoeveelheden van een tweetal specifieke suikers toegediend, in dit geval lactulose en rhamnose, teneinde vast te stellen of de toegediende hoeveelheid van deze suikers de uitkomst van de test beinvloedt. Er werd gevonden dat, in een stuatie waarin de doorlaatbaarheid van het darmslijmvlies ongestoord was, de toegediende hoeveelheid niet de lactulose/rhamnose ratio in de urine beinvloedde. Echter, als de doorlatbaarheid van het darmslijmvlies 
kunstmatig werd verhoogd dan bleek dat de lactulose/rhamnose ratio in de urine hoger was naarmate er meer van de suikers was toegediend. Dit suggereert dat processen die zich afspelen vóór en/of nà de absorptie van de suikers door de darm, de uitkomst van deze test beinvloeden.

In hoofdstuk 5 worden een tweetal van deze pre-en postabsorptieve processen nader bestudeert. Er is gekeken naar zowel het effect van de snelheid van dunne darmpassage (een pre-absorptieve factor), als naar de renale klaring van de suikers (een postabsorptieve factor). Er werd vastgesteld dat de verhoogde snelheid van de dunne darmpassage geen invloed heeft op de uitkomst van de suiker absorptie test. Tevens werd vastgesteld dat de renale klaring van rhamnose niet afhankelijk is van de hoeveelheid rhamnose die in de circulatie aanwezig is. Echter, de renale klaring van lactulose is wel afhankelijk van de hoeveelheid lactulose die in de circulatie aanwezig is. Meer lactulose in de circulatie leidt tot een relatieve verlaging van de 5 uurs-klaring. Dit resulteert in een lagere lactulose/rhamnose ratio in de urine, hetgeen impliceert dat een mogelijke toename van de doorlaatbaarheid van het dunne darmslijmvlies onderschat kan worden als meer lactulose en rhamnose via de darm wordt opgenomen. Deze bevinding kan consequenties hebben voor de betrouwbaarheid en bruikbaarheid van de test in patiënten.

Hoofdstuk 6 beschrijft een experimenteel model waarin het effect van lichamelijke inspanning op een aantal geselecteerde gastrointestinale parameters wordt bestudeerd. Deze parameters waren slokdarmmotoriek, gastroesophagale reflux, $\mathrm{pH}$ in de maag, maaglediging, dunne darm passagesnelheid, de doorlaatbaarheid van het dunne darmslijmvlies en glucoseopname door de dunne darm. Ze werden gelijktijdig gemeten bij goedgetrainde mannelijke proefpersonen tijdens een rust-fiets-rust-protocol. Er werd vastgesteld dat fietsen op een belasting van $70 \%$ van het maximale vermogen niet leidt tot veranderingen in gastroesophageal reflux, maag $\mathrm{pH}$ en gastrointestinale passagesnelheid. Echter, er werd een verlaagde distale slokdarmdruk, een verlaagde lactulose/rhamnose ratio, een verlaagde glucose opname door de dunne darm en een verhoogde propulsiesnelheid van de slokdarmperistaltiek gevonden.

Hoofdstuk 7 beschrijft het effect van supplementatie van een veelgebruikte sportdrank met caffeïne (een ergogene substantie) op een aantal geselecteerde gastrointestinale parameters tijdens lichamelijke inspanning. De studie werd uitgevoerd omdat caffeïne wordt verdacht van het induceren van maagdarmklachten. Tien goedgetrainde mannelijke proefpersonen hebben hetzelfde protocol als beschreven in hoofdstuk 6 ondergaan. Het effect van supplementatie van een sportdrank met $150 \mathrm{mg} / \mathrm{l}$ caffeïne werd vergeleken met een sportdrank zonder caffeïne en een water placebo. Er werden geen 
belangrijke verschillen gevonden in gastroesophagale reflux, maag $\mathrm{pH}$, of gastrointestinale passagesnelheid tussen de drie dranken. Echter, er werd gevonden dat de glucose opname door de dunne darm verhoogd was in het experiment waarin de sportdrank met caffeïne werd gebruikt. $\mathrm{Er}$ kan geconcludeerd worden dat supplementatie van een sportdrank met caffeïne niet leidt tot belangrijke veranderingen in gastrointestinale functie.

Hoofdstuk 8 beschrijft het effect van een dehydratieprocedure middels een sauna, voorafgaande aan lichamelijke inspanning, op gastrointestinale passagesnelheid, de doorlaatbaarheid van het dunne darmslijmvlies en de glucose opname door de dunne darm. Het is bekend dat dehydratie leidt tot vererging van maag-darmklachten tijdens lichamelijke inspanning. Dit suggereert een verandering in gastrointestinale parameters. In deze studie werden 10 gezonde mannelijke proefpersonen twee keer bestudeerd; één keer tijdens een normale conditie en één keer tijdens een gedehydreerde conditie. De proefpersonen ondergingen hetzelfde protocol als in hoofdstuk 6, met uitgezondering van de metingen van de slokdarmmotoriek en de slokdarm-en maag $\mathrm{pH}$. Tevens werden gastrointestinale symptomen, de rectale temperatuur, het plasma volume en het plasma vasopressine zowel voór als nà het fietsen gemeten. Het bleek dat de maaglediging significant vertraagd was als gevolg van dehydratie. De dunne darm passagesnelheid was onveranderd. In beide experimenten resulteerde het fietsen in een significante stijging van de rectale temperatuur en het plasma vasopressine en een significante daling van het plasma volume. De toename van het plasma vasopressine was significant hoger in het dehydratie experiment. Het dehydratieprotocol zelf leidde niet tot veranderingen in het plasma volume, de rectale temperatuur, het plasma vasopressine, de doorlaatbaarheid van het dunne darmslijmvlies en de glucose opname door de dunne darm. In het dehydratie experiment leidde het fietsen tot een significante stijging van de mate van misselijkheid en maagkramp. Het verschil in maagledigingssnelheid en het verschil in misselijkheidscore tussen de twee experimenten correleerde significant.

Hoofdstuk 9 beschrijft het effect van fietsen en hardlopen op een aantal geselecteerde gastrointestinale parameters in atleten die frequent lijden aan inspanningsgeinduceerde maag-darmklachten (groep 2). De data afkomstig van deze atleten werden vergeleken met de data afkomstig van klachtenvrije atleten (groep 1). Alle atleten ondergingen hetzelfde protocol als in hoofdstuk 6 en de atleten uit groep 2 ondergingen daarnaast een rust-hardloop-rust protocol. $\mathrm{Er}$ werden geen belangrijke verschillen in rustwaarden tussen de twee groepen gevonden. Tijdens fietsen bleek echter dat zowel de duur als het aantal gastroesophagale reflux episodes hoger was in groep 2. De dunne darm passagesnelheid bleek in groep 2 in het fietsexperiment vertraagd te zijn en dit bereikte significantie in het hardloopexperiment, vergeleken met het rust. In groep 1 was de lactulose/rhamnose ratio significant verlaagd in het 
tietexperiment, vergeleken met rust, terwijl in groep 2 de lactulose/rhamnose ratio verhoogd was in het fietsexperiment en het verschil significantie bereikte in het hardloopexperiment, vergeleken met rust. Concluderend bleek dat er geen verschil in de geselecteerde gastrointestinale parameters was tussen de twee groepen in rust. Echter, het bleek dat de symptomatische atleten een vertraagde dunne darm passagesnelheid en een hogere doorlaatbaarheid van het dunne darmslijmvlies hebben als gevolg van lichamelijke inspanning. Dit was meer uitgesproken tijdens het hardiopen dan tijdens het fietsen. 


\section{Nawoord}

Het is woensdagnamiddag, 1 september 1999. Het is een prachtige nazomerdag en ik ben in Utrecht. Ik ben net terug van het AZU, waar ik Andre Smout mijn proefschrift heb overhandigt. Hij is lid van de beoordelings-commissie en heeft als laatste het manuscript ontvangen, want hij was in het buitenland. Harm Kuipers heeft het manuscript reeds goedgekeurd. Vorige week heb ik het ook aan Peter Hespel in Leuven gegeven, waarna we in de zon een Hoegaarden hebben gedronken. Marleen van Baak en Reinhold Stockbrügger hebben het manuscript ook al ontvangen. Ik verwacht geen problemen, Wim Saris kan tevreden zijn.

Ik leg mijn skiff in het water om een uurtje te gaan roeien. Dat doe ik wel vaker als ik in Utrecht ben. Jammer dat er in Maastricht geen fatsoenlijke roeivereniging is. Ik stap in. Een paar mensen staat welwillend toe te kijken en stiekem te hopen dat ik om zal slaan, maar die lol gun ik ze niet. Ik zet uit en maak slagklaar. Een rare sport eigenlijk, dat roeien; je ziet niet waar je naar toe gaat, het is heel vermoeiend en tenslotte eindig je weer op de plek waar je bent begonnen. Maar wel met een voldaan gevoel. Wat dat betreft heeft het wel iets weg van het schrijven van een proefschrift, constateer ik, tevreden met deze vergelijking. Ik roei met stevige halen de bocht om en nader de eerste brug. Ik heb voorrang en passeer een acht die ligt te wachten. Ultiem teamwork, zo'n acht! Mijn gedachten gaan terug naar de tijd dat ik zelf in een eerstejaars acht zat en onwillekeurig trek ik opnieuw de vergelijking met promoveren. Niet iedereen komt er voor in aanmerking. Het is veeleisend en succes is niet bij voorbaat verzekerd. Je moet er, zogezegd, de juiste constitutie voor hebben, concludeer ik lichtelijk transpirerend. Ik herinner me mijn coaches van toendertijd. Later ben ik zelf een goede coach van vrouwenploegen geworden.

Tijdens mijn promotieonderzoek in Maastricht had ik ook twee coaches. Net als destijds hadden ook zij ieder hun eigen kwaliteiten en elk op hun eigen manier waren zij belangrijk voor het voltooien van het proefschrift.

Ik realiseer me dat ik aan Robert-Jan Brummer veel te danken heb. Een nietalledaagse man met een grote kennis, makkelijk benaderbaar, zeer veelzijdig, immer goedgehumeurd en een groot gevoel voor humor. Liberalist pur sang. Behalve dat ik van hem geleerd heb hoe je wetenschap bedrijft, weet ik inmiddels ook het geheim van de contrabas, van het taalgebruik van Haagse: Harry, hoe te fietsen in de bergen van Toscane en hoe je iemand efficiënt bewusteloos kunt slaan. Fred Brouns is dan een totaal andere persoon, bedenk ik mij. Vaak weg voor het bedrijf waar hij voor werkte, waardoor ik hem soms weken niet zag. Maar dan kwam er weer een telefoontje met de uitnodiging om te komen eten in Sibbe. Meestal had Martina dan wat lekkers gemaakt en was er een voortreffelijke wijn. En passant werd er dan over het onderzoek gesproken en vrijwel altijd had hij het gelijk aan zijn zijde. Ik bedenk mij dat ik in mijn leven weinig mensen heb meegemaakt met zo'n groot gevoel voor 
kwaliteit, op alle gebieden, als Fred. Ik hoop dat ik nog vaak mag komen eten. Ondanks alles vrees ik dat het mysterie van de taart in Oporto nooit opgelost zal worden.

Terwijl ik verder roei vraag ik mij af of ik ook zo'n goede coach zal worden. Waarom niet eigenlijk? Mijn ervaringen met mijn stagiaires Annemarie, Ellen, Birgit, Esther en Tessa zijn louter positief. Ook allemaal vrouwen trouwens, de geschiedenis herhaalt zich.

Mijn eerstejaars acht was gevuld met mensen van allerlei pluimage. Er was echter wel een gemeenschappelijke doel, wat je alleen maar als team kunt bereiken. Terwijl ik aan het einde van het kilometerstuk ben, dringt de vergelijking met promotieonderzoek zich opnieuw op. Ik heb in Maastricht met veel mensen samengewerkt. In mijn gedachten passeert een rij met namen van collega's die op één of andere manier de afgelopen jaren belangrijk waren. Bijvoorbeeld de mensen van Humane Biologie, zoals Joan Senden, met wie ik de maagledigingstesten heb gedaan en die mij onderwijl op de hoogte bracht van alle "ins en outs" van het dopinggebruik in de wielrennerij. Dat schijnt daar nog wel eens voor te komen. Ton Wagenmakers, met zijn kennis van stabiele isotopen en zijn kritische blik op manuscripten, Edgar van Mil, mijn bedaarde kamergenoot van het laatste jaar, maar ook Paul Schoffelen en Loek Wouters, voor als mijn Apple, die nog op steenkool loopt, weer kuren had. Wouter van Marken Lichtenbelt, met wie ik veel onderwijs heb gedaan. En verder het kleurrijke en enigszins geschifte gezelschap met wie ik op donderdagavond altijd een biertje drink, zoals Luc van Loon, mijn reisgenoot naar Rome, maar ook de immer beminnelijke Jos Stegen, Freddy Troost, Patrick Schrauwen, Chris Hukshorn, Erwin Meijer en Margriet Kruishoop.

Ik maak een mishaal en moet denken aan de voormalige Novartis Unit, waar ik de afgelopen jaren mijn werkplek had. Ik passeer de insteekhaven en zie dat er weer een brug is bijgebouwd. Nooit schijnt iets te blijven zoals het was en ik vraag me af of iedere verandering wel een verbetering is. Bijvoorbeeld voor mijn vroegere kamergenote Eva Kovacs, die gelukkig mijn paranimf is. Of voor mijn toenmalige collega's Peter Geurten, Eric van Breda, Dean Sewell, Martine Tiessen, Elke Trautwein, Bert Benthem, Rien Peeters, Margriet Westerterp en Gerard Hornstra.

Inmiddels beginnen mijn onderarmen te verzuren, waardoor ik weet dat ik technisch slecht vaar en bovendien te weinig train. Ik moet dus niet zeuren en ik zet nog eens aan. Er komt een groot vrachtschip voorbij en ik moet noodgedwongen wachten in de golfslag totdat ik verder kan. Ik ben niet ver meer van de Muntbrug vandaan, het eindpunt. Het laatste stuk loopt de skiff toch weer lekker door en tijdens tempo 22 dwalen mijn gedachten af naar de mensen van het AZM. Mijn nieuwe collega's van Gastroenterologie, die ik natuurlijk al ken, prettige mensen zoals Ardi Oberndorff, Ingrid van der Eijk, Martine Hesselink, Erik Schoon en Maurice Russel. Spijtig dat Bertine Geerling weg is, mijn reisgenote naar congressen in Parijs, Washington en Orlando. Zij was toch eigenlijk al die jaren mijn klankbord. Ik ben blij dat ze mijn paranimf wil 
zijn.

Terwijl ik nog een paar honderd meter te gaan heb, mijmer ik dat de afgelopen jaren eigenlijk nog wel meer mensen belangrijk voor mij zijn geweest. Zoals Mick Deutz en Hans van Eijk van Heelkunde. En Frank van der Vegt van het SIRC, die alle ademgasanalyses heeft gedaan. En Tiny Wouters, die dit proefschrift heeft gelayout. Vlak voor dat ik aan het eind van het kanaal ben, realiseer ik mij dat mijn hele promotieonderzoek onmogelijk zou zijn geweest als ik niet een onafzienbare rij proefpersonen bereid had gevonden om deel te nemen aan mijn experimenten. Sommigen bleven terugkomen, zoals Robert, Nico, Ruben, Marcel en Bob. Ik heb mij wel eens afgevraagd waarom mensen vrijwillig met slokdarmsondes, slikballonnetjes en infuusnaalden zich in het zweet fietsen. Ik weet het antwoord niet, maar ik ben blij dat ze er zijn, want ik ben ze veel dank verschuldigd. Ik zet aan voor de laatste paar harde halen, buk mijn hoofd, glij rustig onder de Muntbrug door en hijg even uit.

Ik maak de skiff rond en peddel op mijn gemak terug naar het botenhuis. Ik bedenk me dat het eigenlijk reuze meeviel. Na het douchen ga ik in de stad een hapje eten, samen met mijn oude vriend Gerben. Na afloop stap ik in mijn auto en in de duisternis rijd ik ontspannen op de jazzklanken van Rachelle Ferell terug naar Maastricht. Naar huis. Het is klaar. 


\section{Publications}

\section{Full papers}

1. Performance of the $\left[{ }^{13} \mathrm{C}\right.$-acetate gastric emptying breath test during physical exercise. MA van Nieuwenhoven, BJ Geerling, NEP Deutz, F Brouns, R-JM Brummer. Eur J Clin Invest 1999, in press.

2. The sensitivity of the lactulose/rhamnose gut permeability test. MA van Nieuwenhoven, BJ Geerling, NEP Deutz, F Brouns, R-JM Brummer. Eur J Clin Invest 1999: 29; 160-165.

3. The effect of physical exercise on parameters of gastrointestinal function. MA van Nieuwenhoven, $F$ Brouns, R-JM Brummer. Neurogastroenterology and Motility 1999, in press.

4. Gastrointestinal function during exercise; a comparison between water, a sports drink, and a sports drink with caffeine. MA van Nieuwenhoven, F Brouns, R-JM Brummer. Submitted.

5. Effects of the degree of dehydration and hyperthermia on gastrointestinal function at rest and during exercise. MA van Nieuwenhoven, B Vriens, F Brouns, R-JM Brummer. Submitted.

6. The effect of different dosages of guar gum on the rate of gastric emptying and intestinal transit of a consumed semisolid meal. MA van Nieuwenhoven, EMR Kovacs, AM Martin, R-JM Brummer, MS Westerterp-Plantenga, F Brouns. Submitted.

7. The effect of pre-and postabsorptive factors on the lactulose/rhamnose gut permeability test. MA van Nieuwenhoven, EAM de Swart, NEP Deutz, F Brouns, R-JM Brummer. Subrnitted.

8. The effect of physical exercise on gastrointestinal function in symptomatic subjects. MA van Nieuwenhoven, F Brouns, R-JM Brummer. Submitted.

9. Effect of dehydration on tympanic and rectal temperature, and perceived exhaustion in cyclists during intense exercise. WD van Marken Lichtenbelt, MA van Nieuwenhoven, submitted.

\section{Book Chapters}

1. Exercise and gastrointestinal function; a review: MA van Nieuwenhoven, F Brnuns, R-JM Brummer Chapter In: "Exercise: Basic and Applied Science". Volume No 1. William E. Garrett Jr. Philadelphia: Lippincott Williams \& Wilkins, 1999, in press

\section{Abstracts}

1. Consequences of ischemia or $\mathrm{Ca} 2+$-free perfusion for intracellular $[\mathrm{Na}+]$ as studied by ${ }^{23} \mathrm{Na}-\mathrm{NMR}$. CJA van Echteld, JH Kirkels, MHJ Eijgelshoven, MA van Nieuwenhoven, $\mathbf{P}$ van der Meer, TJC Ruigrok. J Mol Cell Cardiol 1990: 22 (Suppl 3); S59.

2. Effect of warm-up, stretching and massage on musle protein efflux due to eccentric exercise. JB Rodenburg, H Thomas, MA van Nieuwenhoven, P Schiereck, PR Bär. Med Sci Sports Exc 1993: 25 (No 3); S158.

3. Measurement of esophageal motility, LES pressure and gastroesophageal reflux during strenuous exercise with an advanced ambulatory system. MA van Nieuwenhoven, F Brouns, R-JM Brummer. Eur J Gastroenterol Hepatol 1996: 8(No 12); A30.

4. Ambulatory measurement of esophageal motility, LES pressure and gastroesophageal reflux during exercise. MA van Nieuwenhoven, F Brouns, R-JM Brummer. Gastroenterology 1996: 110; A704

5. Evaluation of a non-invasive ${ }^{13} \mathrm{C}$-acetate breath test measuring gastric emptying of liquids during exercise. MA van Nieuwenhoven, AJM Wagenmakers, J Senden, F Brouns, R-JM Brummer. Neurogastroenterol Motility 1996: 8; 195.

6. The use of a ${ }^{13} \mathrm{C}$-acetate breath test to determine differences in the gastric emptying rate of liquids during physical exercise. MA van Nieuwenhoven, AJM Wagenmakers, J Senden, F Brouns, R-JM Brummer. Eur J Gastroenterol Hepatol 1996: 8(No 12); A66.

7. The ${ }^{13} \mathrm{C}$-acetate breath test; dosage-dependent appearance of breath enrichment after intradundenal administration of ${ }^{13} \mathrm{C}$-acetate. MA van Nieuwenhoven, AJM Wagenmakers, F Brouns, R-JM Brummer. Eur J Gastroenterol Hepatol 1996: 8(No 12); A66.

8. Gut permeability test in subjects with and without exercise-induced gastrointestinal symptoms. MA van Nieuwenhoven, BJ Geerling, NEP Deutz, F Brouns, R-JM Brummer. Gut 1996: 39 (Suppl 3); A247.

9. Is intestinal permeability really increased in patients with inflammatory bowel disease? BJ Geerling. MA van Nieuwenhoven, RW Stockbrügger, R-JM Brummer. Gut 1996; 39 (Suppl 3), A 1433. 
10. Intestinal permeability is not increased in patients with inflammatory bowel disease. BJ Geerling, MA van Nieuwenhoven, RW Stockbrügger, R-JM Brummer. Eur J Gastroenterol Hepatol 1996: 8(No 12): A49.

11. The effect of strenuous exercise on gut permeability. MA van Nieuwenhoven, BJ Geerling, WH Aarnoudse, NEP Deutz, F Brouns, R-JM Brummer. Eur J Gastroenterol Hepatol 1996: 8(No 12 ); A46.

12. The effect of strenuous exercise on gut permeability. MA van Nieuwenhoven, BJ Geerling, WH Aarnoudse, NEP Deutz, F Brouns, R-JM Brummer. J Sports Sci 1998: 16 (No 5); 503-504

13. The assessment of gastric emptying of liquids during physical exercise using a ${ }^{13} \mathrm{C}$-acetate breath test. MA van Nieuwenhoven, AJM Wagenmakers, J Senden, F Brouns, R-JM Brummer. Eur J Physiol 1997: 434; R43 (A12).

14. The results of the ${ }^{13} \mathrm{C}$-acetate breath test are not only determined by the gastric emptying rate. MA van Nieuwenhoven, AJM Wagenmakers, F Brouns, R-JM Brummer. Eur J Gastroenterol Hepatol 1997: 9 (No 12); A33.

15. The assessment of gastric emptying of liquids during physical exercise using a ${ }^{13} \mathrm{C}$-acetate breath test. MA van Nieuwenhoven, AJM Wagenmakers, J Senden, F Brouns, R-JM Brummer. Gastroenterology 1997: 112 (4); A483.

16. Effect of mode of administration of ${ }^{13} \mathrm{C}$-acetate on ${ }^{13} \mathrm{C}$-appearance in breath: implications for the gastric emptying breath test. MA van Nieuwenhoven, AJM Wagenmakers, F Brouns, R-JM Brummer. Gastroenterology 1997: 112 14); A483.

17. The effect of exercise, carbohydrate and caffeine on the liquid orocecal transit time. MA van Nieuwenhoven, R-JM Brummer, F Brouns. Digestion 1998: 59 (Suppl 3): 664.

18. The sensitivity of the lactulose/rhamnose permeability test. MA van Nieuwenhoven, BJ Geerling, NEP Deutz, F Brouns, R-JM Brummer. Digestion 1998: 59 (Suppl 3); 665.

19. The sensitivity of the lactulose/rhamnose permeability test. MA van Nieuwenhoven, BJ Geerling, NEP Deutz, F Brouns, R-JM Brummer. Eur J Gastroenterol Hepatol 1998: 10 (No 12); A22.

20. The sensitivity of the lactulose/rhamnose gut permebility test is influenced by the dosage of lac/rham when the permeability is increased. MA van Nieuwenhoven. BJ Geerling, NEP Deut $z$, E Thys, F Brouns, R-JM Brummer. Gastroenterology 1998: 114; G1741.

21. Comparison of ${ }^{13} \mathrm{C}$-acetate and ${ }^{13} \mathrm{C}$-octanoate for determination of gastric emptying of semi-solids using the ${ }^{13} \mathrm{C}$-breath test. MA van Nieuwenhoven, EMR Kovacs, AM Martin, R-JM Brummer, F Brouns. Digestion 1998: 59 (Suppl 3); 246.

22. Caffeine does not change gastric $\mathrm{pH}$ and gastroesophageal reflux during strenuous exercise. MA van Nieuwenhoven, R-JM Brummer, F Brouns. Neurogastroenterol Motility 1998: 10 (No 5): A5.

23. Caffeine does not change gastric emptying and orocecal transit time during strenuous exercise. MA van Nieuwenhoven, R-JM Brummer, F Brouns. Neurogastroenterol Motility 1998: 10 (No 5); A97.

24. The effect of dehydration on gastrointestinal function during exercise. MA van Nieuwenhoven, BEPJ Vriens, F Brouns, R-JM Brummer. Gastroenterology 1999: 116(4); G4758.

25. The effect of dehydration on gastrointestinal function during exercise. MA van Nieuwenhoven, BEPJ Vriens, F Brouns, R-JM Brummer. Eur J Gastroenterol Hepatol 1999, in press.

26. Running increases liquid orocecal transit time in symptomatic athletes. TOC Kilkens, MA van Nieuwenhoven, F Brouns, R-JM Brummer. Eur J Gastroenterol Hepatol 1999, in press.

27. The effect of prolonged high-intensity cycling on liquid orocecal transit time and gastro-intestinal symptoms. MA van Nieuwenhoven, HPF Peters, R-JM Brummer, GP van Berge Henegouwen. Eur J Gastroenterol Hepatol 1999, in press.

28. Effect of dehydration on tympanic and rectal temperature during exercise. WD van Marken Lichtenbelt, MA van Nieuwenhoven. J Thermobiol 1999, in press. 


\section{Curriculum Vitae}

Michiel Adrianus van Nieuwenhoven werd geboren op 25 september 1965 te Amsterdam. In 1983 behaalde hij het HAVO diploma en in 1985 het VWO diploma aan het Christelijk Lyceum in Veenendaal. In 1985 startte hij met de studie Medische Biologie aan de Universiteit Utrecht, met als afstudeerrichtingen experimentele NMR-cardiologie en spierfysiologie. Het doctoraalexamen werd behaald in december 1992. Na een aantal tijdelijke functies begon hij in mei 1995 als toegevoegd onderzoeker bij de vakgroep Humane Biologie van de Universiteit Maastricht, onder begeleiding van Prof. dr. ir. WHM Saris, Dr. R-JM Brummer en Dr. F Brouns. In 1997 werd hij bij deze vakgroep assistent in opleiding (AIO). Tijdens de promotieperiode werd op het congres van het European College of Sport Science in Kopenhagen de tweede prijs behaald (U\$ 4000) in de Young Investigators Award voor de beste voordracht. Dit proefschrift beschrijft het onderzoek wat tijdens de promotieperiode is uitgevoerd. Sind 1 september 1999 is hij werkzaam als postdoc bij de vakgroep Interne Geneeskunde van het academisch ziekenhuis Maastricht en tevens studeert hij medicijnen. 


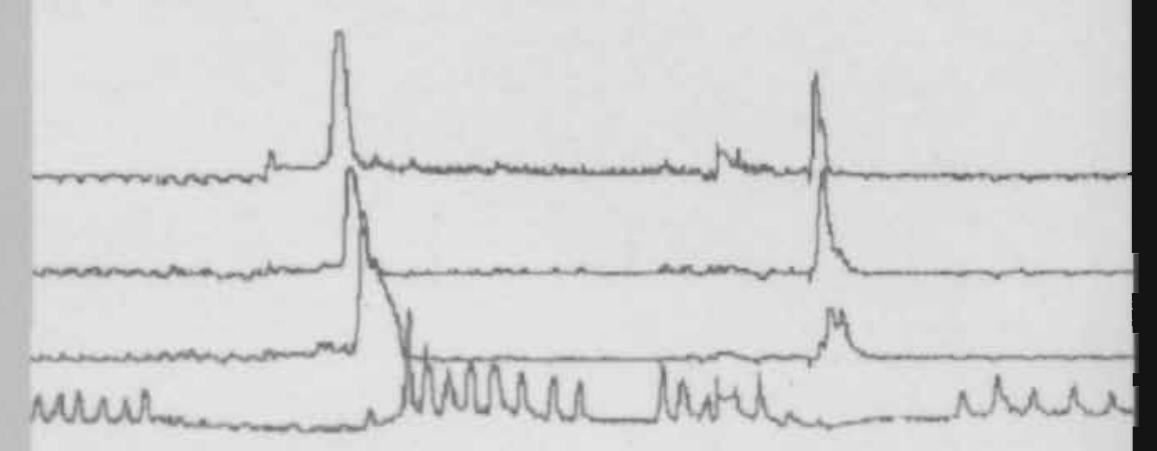

